


\section{Safety and Risk Assessment of Civil Aircraft during Operation Edited by Longbiao Li}



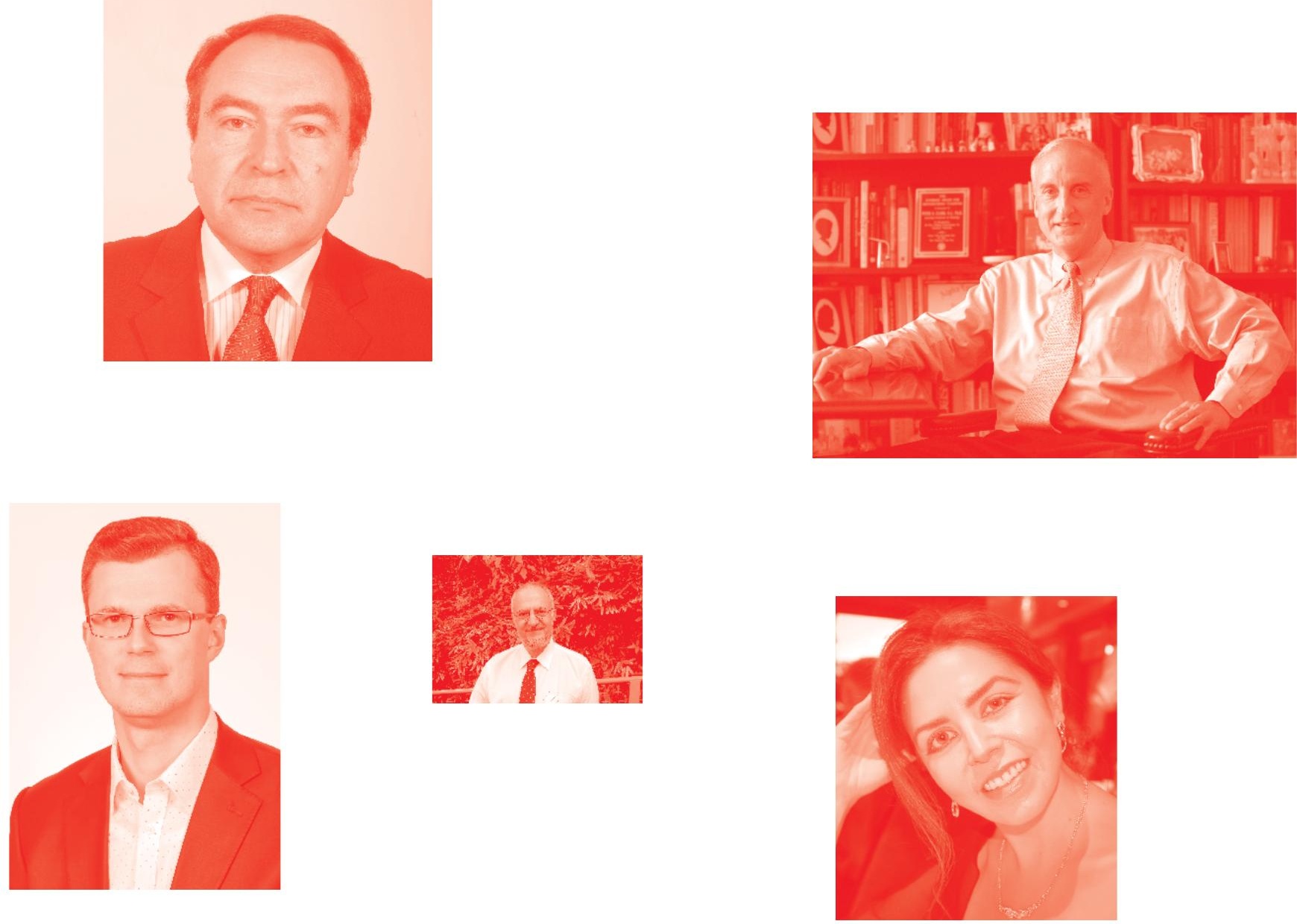

Supporting open minds since 2005
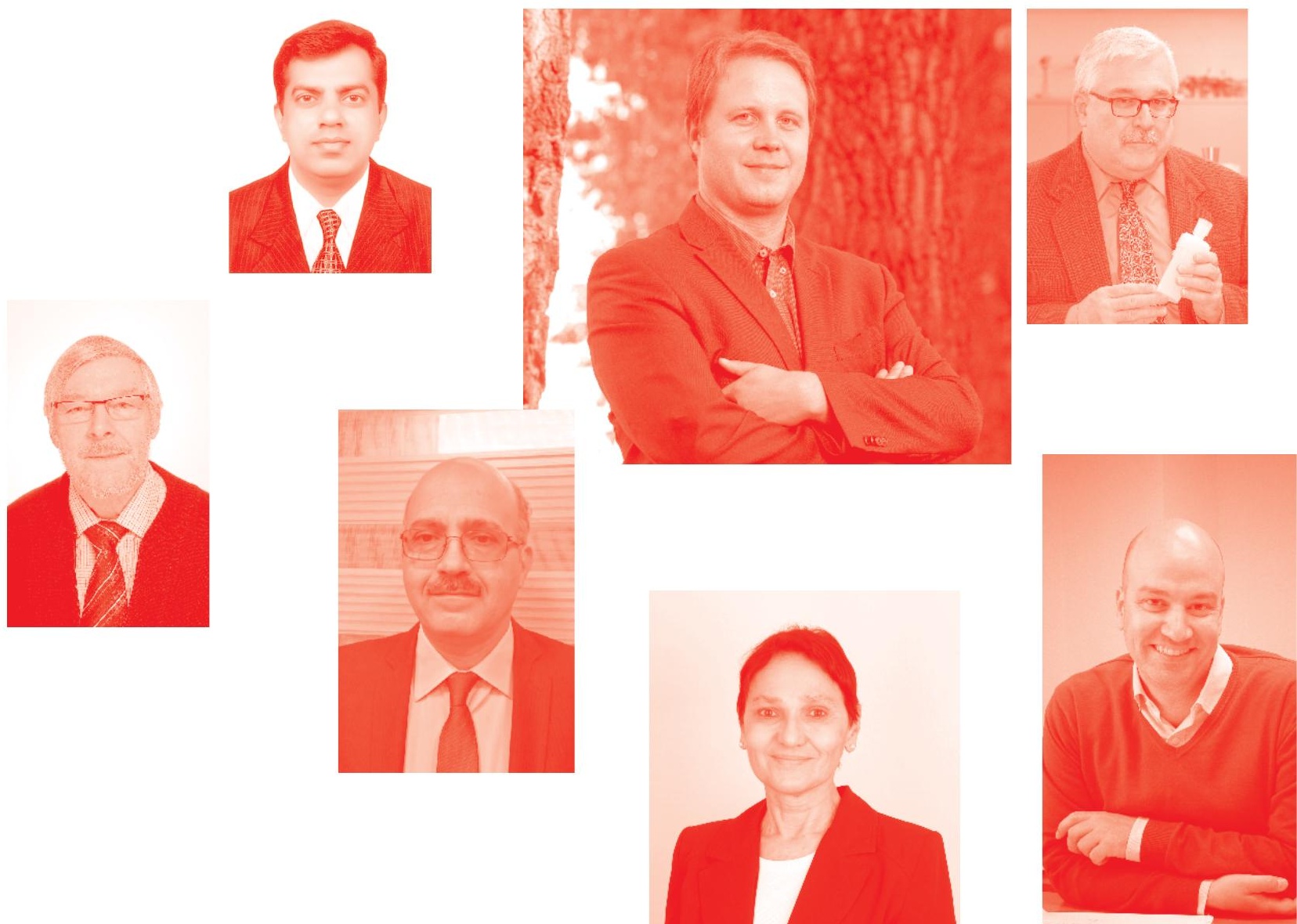
Safety and Risk Assessment of Civil Aircraft during Operation

http : //dx. doi. org/10.5772/intechopen. 90993

Edited by Longbiao Li

Contributors

Longbiao Li, Asif Mostafa, Chengzheng Zhu, Dmytro Tiniakov, Pryimak Andrii, Orlovskyi Mykhailo, Tretyakov Yevgeny, Serhii Pavlovych Borsuk, Oleksii Reva, Andrii Nevynitsyn, Valerii Shulgin, Volodymyr Kamyshyn, Huan Wang, En-Zhong Zhang, Sherkhan Aitugan, Muhammad Bilal Afzal, Wang Hong

(๑) The Editor(s) and the Author(s) 2021

The rights of the editor(s) and the author(s) have been asserted in accordance with the Copyright, Designs and Patents Act 1988. All rights to the book as a whole are reserved by INTECHOPEN LIMITED. The book as a whole (compilation) cannot be reproduced, distributed or used for commercial or non-commercial purposes without INTECHOPEN LIMITED's written permission. Enquiries concerning the use of the book should be directed to INTECHOPEN LIMITED rights and permissions department (permissions@intechopen.com).

Violations are liable to prosecution under the governing Copyright Law .

\section{(c)) BY-NC}

Individual chapters of this publication are distributed under the terms of the Creative Commons Attribution - NonCommercial 4.0 International which permits use, distribution and reproduction of the individual chapters for non-commercial purposes, provided the original author(s) and source publication are appropriately acknowledged. More details and guidelines concerning content reuse and adaptation can be found at http : //www . intechopen . com/copyright-policy. html.

Notice

Statements and opinions expressed in the chapters are these of the individual contributors and not necessarily those of the editors or publisher. No responsibility is accepted for the accuracy of information contained in the published chapters. The publisher assumes no responsibility for any damage or injury to persons or property arising out of the use of any materials, instructions, methods or ideas contained in the book.

First published in London, United Kingdom, 2021 by IntechOpen

IntechOpen is the global imprint of INTECHOPEN LIMITED, registered in England and Wales, registration number: 11086078,5 Princes Gate Court, London, SW7 2QJ, United Kingdom Printed in Croatia

British Library Cataloguing-in-Publication Data

A catalogue record for this book is available from the British Library

Additional hard and PDF copies can be obtained from orders@intechopen .com

Safety and Risk Assessment of Civil Aircraft during Operation

Edited by Longbiao Li

p. cm.

Print ISBN 978-1-78984-792-5

Online ISBN 978-1-78984-793-2

eBook (PDF) ISBN 978-1-78985-@55-๑

An electronic version of this book is freely available, thanks to the support of libraries working with Knowledge Unlatched. KU is a collaborative initiative designed to make high quality books Open Access for the public good. More information about the initiative and links to the Open Access version can be found at www. knowledgeunlatched. org 


\section{We are IntechOpen, \\ the world's leading publisher of Open Access books}

\section{Built by scientists, for scientists}

\section{$5,100+$}

Open access books available

156

Countries delivered to
$126,000+$

International authors and editors

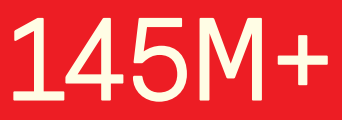

Downloads

Our authors are among the

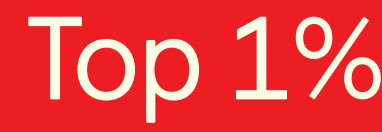

most cited scientists

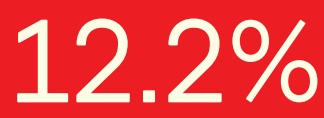

Contributors from top 500 universities

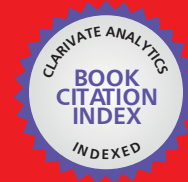

WEB OF SCIENCE ${ }^{\mathrm{TM}}$

Selection of our books indexed in the Book Citation Index in Web of Science ${ }^{\mathrm{TM}}$ Core Collection (BKCI)

Interested in publishing with us?

Contact book.department@intechopen.com

Numbers displayed above are based on latest data collected.

For more information visit www.intechopen.com

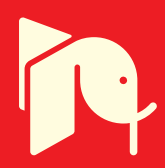





\section{Meet the editor}

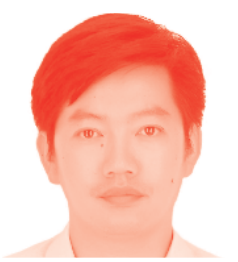

Dr. Longbiao Li is a lecturer in the College of Civil Aviation at Nanjing University of Aeronautics and Astronautics. Dr. Li's research focuses on the reliability and safety of aircraft. In this research area, he is the first author of 145 SCI journal publications, five monographs, two edited books, three textbooks, three book chapters, fifteen Chinese patents and one US patent, and more than twenty refereed conference proceedings. He has been involved in different projects related to structural damage, reliability, and airworthiness design for aircraft and aero-engines, supported by the Natural Science Foundation of China, Commercial Aircraft Corporation of China, Ltd. (COMAC), and Aero Engine Corporation of China (AECC). 



\section{Contents}

Preface

Section 1

Risk Analysis

Chapter 1

Risk Assessment of Civil Aircraft during Operation

by Longbiao $\mathrm{Li}$

Chapter 2

Risk and Economic Analysis Methods of Commercial Aero Engines by Sherkhan Aitugan and Longbiao Li

Chapter 3

Safety and Risk Assessment of Civil Aircraft during Operation

by Asif Mostafa

Section 2

Safety Analysis

Chapter 4

Design Approaches for Safety Increasing and Risk Decreasing for the Civil Aircraft's Operation

by Dmytro Tiniakov

Section 3

Human Errors

Chapter 5

Theories and Models of Human Errors Occurrence. Simulation of Aircraft Maintenance Processes

by Andrii Pryimak, Mykhailo Orlovskyi and Yevgeny Tretyakov

Chapter 6

Air Traffic Controllers' Attitude to the Mistakes Hazards during Their Professional Experience

by Oleksii Reva, Andrii Nevynitsyn, Serhii Borsuk, Valerii Shulgin

and Volodymyr Kamyshyn 
Section 4

Composites

Chapter 7

Non-Steady First Matrix Cracking of Fiber-Reinforced Ceramics

by Huan Wang

Chapter 8

The Effect of Random Load on Life Prediction of High-Temperature

Ceramic Matrix Composites

by En-Zhong Zhang

Chapter 9

Multiple Matrix Cracking of Fiber-Reinforced Ceramic-Matrix Composites during Operation

by Chengzheng Zhu

Chapter 10

Finite Element Analysis of Fiber Pull-Out of Ceramic Matrix Composites by Wang Hong

Chapter 11

Modeling of Damage Evolution of Fiber-Reinforced Composite Structure by Muhammad Bilal Afzal 


\section{Preface}

This book investigates safety and risk assessment methods for aircraft systems, structures, and engines.

The chapter "Risk Assessment of Civil Aircraft during Operation" categorizes probability levels for assessing aircraft system as "Probable," "Improbable," or "Extremely Improbable," while it categorizes hazard levels of the failure condition as "Minor," “Major," or "Catastrophic.” In this chapter, the risk level for aircraft systems is determined using Weibull analysis and Bayesian methods to analyze aircraft operation data. The chapter also assesses aircraft structure risk via the probability fracture mechanics approach based on material properties, environment, inspection, and so on. For assessing engine risk, the chapter gives methods for classification of failure risk level, determination of hazard ratio, and calculation of risk factor and risk per flight. The chapter also presents a risk assessment process for aero-engine multi-failure modes based on the Monte Carlo simulation to predict the occurrence of failure and assess failure risk.

The chapter "Risk and Economic Analysis Methods of Commercial Aero Engines" outlines the results of risk analysis and economic analysis of commercial aeroengines during aircraft operation. Risk analysis is the procedure for identifying risk factors and assessing their significance, that is, analysis of the likelihood that certain undesirable events may occur and, as such, adversely affect operation. Risk analysis includes risk assessment and methods to reduce risks or reduce adverse effects associated with it. Furthermore, economic analysis is a scientific way of understanding the essence of economic phenomena and processes, which in turn are based on dividing them into their constituent parts. In doing so, the variety of relationships and dependencies aimed at improving the associated work through the development and implementation of optimal solutions is studied. The purpose of the economic analysis is to give management of the actual state, and for persons who are not directly working with it but are interested in its financial condition, the information necessary for an impartial judgment.

The chapter "Safety and Risk Assessment of Civil Aircraft during Operation" provides a review of some methods and models for civil aviation risk and safety assessment. The key findings provide insight into the efforts already made to improve such methods and models, their inherent difficulty and lack of sufficient versatility, lack of available data for calibration and testing, and lack of sufficient predictive capabilities to encourage the implementation of new technical, procedural, and operational concentrations to assess risk and safety.

The chapter "Design Approaches for Safety Increasing and Risk Decreasing for the Civil Aircraft's Operation" presents reasons and approaches for "rational" aircraft structure. Design solutions are divided into groups by some common features and requirements. These groups include maintainability, serviceability, accessibility, labor effort, weather requirements, transportation, and so on. All these groups depend on engineers' structural solutions and, as such, they are interdependent and often contradictory. In other words, if one feature improves, another feature 
may worsen at the same time. It is important for aircraft designers to keep this in mind and try to find a compromise among the different requirements. A successful commercial aircraft is a set of rational design solutions for these specific tasks.

The chapter "Theories and Models of Human Errors Occurrence. Simulation of Aircraft Maintenance Processes" considers general issues of error occurrence by technical personnel. It presents classifications of errors based on an ergonomic understanding of their nature as well as on the results of an engineeringpsychological analysis of operators' activity. Much attention is paid to the methods used by the International Civil Aviation Organization (ICAO) to classify errors and violations. The chapter uses SHELL and James Reason models, and presents their adaptation for analyzing the impact of technical maintenance quality on the flight safety of aircraft. The chapter focuses on assessing the impact of technical personnel errors on flight safety. It also presents a wide range of existing methods and models that allow for obtaining a qualitative and quantitative assessment of this effect in order to prevent errors by technical personnel and mitigate their consequences.

The chapter "Air Traffic Controllers' Attitude to the Mistakes Hazards during Their Professional Experience" examines the work process of air traffic controllers as an uninterrupted set of decisions. These decisions occur and are implemented in both clear and stealth forms. Determined and stochastic risks are especially important in this process. Human factors that affect flight safety are considered through operators' attitudes towards unsafe acts and conditions. This seamlessly integrates into the ICAO safety paradigm. The chapter also discusses air traffic controllers' preferences systems in regard to typical professional mistakes set. Using paired comparison, the normative and differentiating parts of summary hazard determines the preferences systems of air traffic controllers. For the first time, mistakes pair summary hazard is determined on the unique qualimetric 100-point scale. Systems pair has a high correlation level according to the Spearman coefficient $(\mathrm{R}=0.9727)$. The proposed Kendall rank coefficient outweighs the traditional one by twice as much (Wtraditional $=0.2722$, Wproposed $=0.55237$ ). Significance level for all cases is equal to 1 percent. A multistep procedure of marginal opinions separation is implemented and results show that it increased the Kendall rank coefficient value up to Wproposed $=0.7$. A survey procedure influenced positively on the ability of mistakes memorization, recognition, and avoidance during simulation training.

Matrix cracking affects the reliability and safety of fiber-reinforced CMCs during operation. Cracking is divided into two types: steady-state cracking and nonsteady-state cracking. The chapter "Non-Steady First Matrix Cracking of FiberReinforced Ceramics" covers the non-steady stable cracking of fiber-reinforced CMCs. It analyzes the micro stress field of fiber, matrix, and interface shear stress along the fiber direction using the shear-lag model. It also derives the relationship between the crack opening displacement and the crack surface closure traction, as well as predicts the experimental first matrix cracking stress of different CMCs.

The chapter "The Effect of Random Load on Life Prediction of High-Temperature Ceramic Matrix Composites" investigates and predicts the fatigue life of fiberreinforced CMCs using micro-mechanical methods. It compares and analyzes the effect of random loading on fatigue life with constant peak stress fatigue life. The chapter also discusses the influence of composite constitutive properties on fatigue fracture. 
The chapter "Multiple Matrix Cracking of Fiber-Reinforced Ceramic-Matrix Composites during Operation" investigates the damage models for multiple matrix cracking of CMCs during operation. It considers the effects of materials properties on multiple matrix cracking of CMCs.

The chapter "Finite Element Analysis of Fiber Pull-Out of Ceramic Matrix Composites" based on the fiber pull-out experiment, using the cohesive zone model as the interface element model, establishes and simulates a two-dimensional axisymmetric fiber pull-out finite element model. The results show that within a certain range, greater interface bonding strength and interface fracture energy increase the maximum debonding load during fiber pull-out and enhance the material's bearing capacity.

The chapter "Modeling of Damage Evolution of Fiber-Reinforced Composite Structure" gives a comprehensive overview of existing approaches for modeling damage in composite structures. It pays particular attention to robust and reliable constitutive models that enable a uniform prediction of the fault triggering and the fault history in composite laminates.

I hope this book will improve engineering designers' knowledge of safety and risk assessment of civil aircraft during operation.

Dr. Longbiao Li
College of Civil Aviation,
Nanjing University of Aeronautics and Astronautics,
China



Section 1

Risk Analysis 



\title{
Risk Assessment of Civil Aircraft during Operation
}

\section{Longbiao Li}

\begin{abstract}
In this chapter, the risk assessment methods for aircraft system, structure, and aeroengine are investigated. For the aircraft system risk assessment, the probability level is divided into probable, improbable, and extremely improbable, and the hazard level of the failure condition is divided into minor, major, and catastrophic. Using Weibull analysis and Bayesian method to analyze the aircraft operation data, the risk level of aircraft system can be determined by combing methods provided in AC 25.1309-1A. For the aircraft structure risk assessment, the probability fracture mechanics approach can be used to determine the structure failure risk based on the data of material properties, environment, inspection, and so on. For the aeroengine risk assessment, the methods for classification of failure risk level, determination of hazard ratio, and calculation of the risk factor and risk per flight are given. The risk assessment process for aeroengine multi-failure modes based on the Monte Carlo simulation is presented to predict the occurrence of the failure and assess the failure risk.
\end{abstract}

Keywords: civil aircraft, risk assessment, aircraft system, aircraft structure, aeroengine, operation, fault tree analysis, Weibull analysis, Monte Carlo simulation

\section{Introduction}

Although the civil aircraft has obtained type certificate (TC), due to unknown changes in standard formulation or standard compliance, or unpredictable comprehensive failure caused by design defects and manufacturing defects, as well as unexpected operating conditions or environmental conditions and other factors, it will encounter various failures or failure conditions during operation. The aviation operator shall report various faults and failures to the aviation agency and the aircraft manufacturers. The aviation agency and the manufacturers will analyze the collected failure conditions to determine whether the aircraft or the fleet is unsafe. If it exists, corrective measures must be taken within the specified time limit, so that the aircraft or the fleet can return to the proper airworthiness safety level.

Boeing, Airbus, and other civil aircraft manufacturers can timely analyze and study the unsafe conditions of the aircraft they produce, formulate corrective measures, notify users to complete within the specified scientific and reasonable time limit, and ensure that the airworthiness safety level of the aircraft is maintained within an acceptable range. When an aircraft fails, it is necessary to assess the risk that may be caused. 
Risk assessment is to assess the expected loss of the system or subsystem and equipment and the effectiveness of measures from the possibility and consequences of the occurrence of a dangerous event. In the continuous airworthiness stage of civil aircraft, the failure, fault, or defect of aircraft or parts is actually observed in service before it becomes an event. Through risk assessment, one can determine the occurrence probability and consequence severity of the event, judge whether the impact of the event on the aircraft exceeds the specified airworthiness risk level, and provide decision support for risk mitigation measures and corrective measures. The higher the risk, the shorter the time needed to take corrective measures; the lower the risk, the longer the time allowed to take corrective measures.

Risk assessment is divided into three processes: risk identification, risk analysis, and risk assessment. The risk assessment method of events can be divided into qualitative risk assessment and quantitative risk assessment; the level of risk assessment can be divided into aircraft risk assessment and fleet risk assessment; and the category of events can be divided into aircraft system, aircraft structure, and aeroengine risk assessment. In this chapter, the risk assessment methods for aircraft system, aircraft structure, and aeroengine are given.

\section{Aircraft system risk assessment}

The airworthiness standard of transport aircraft, such as Article 1309 of Part 25 (FAR 25) of Federal Aviation Regulations of the United States [1] and Part 25 (CS 25) of European type certification specification, puts forward the top-level requirements for the safety of civil aircraft system. It is stipulated in 25.1309 (b) (1) and (2): the probability of any failure state impeding the continued safe flight and landing of the aircraft is extremely impossible; the probability of any other failure state reducing the ability of the aircraft or the crew to handle adverse operating conditions is impossible.

AC 25.1309-1A [2] is the Advisory Circular prepared by the Federal Aviation Administration (FAA) for FAR 25.1309. The Advisory Circular provides guidance and method description for airworthiness compliance verification and certification of FAR 25.1309.

The failure probability of an occurrence in AC 25.1309-1A is classified as probable, improbable, and extremely improbable, which are defined as:

1. Probable failure conditions are those having a probability greater than on the order of $1 \times 10^{-5}$.

2. Improbable failure conditions are those having a probability on the order of $1 \times 10^{-5}$ or less but greater than on the order of $1 \times 10^{-9}$.

3. Extremely improbable failure conditions are those having a probability on the order of $1 \times 10^{-9}$ or less.

The failure condition of an occurrence in AC 25.1309-1A is classified as minor, major, and catastrophic, which are defined as:

1. Minor: Failure condition which would not significantly reduce airplane safety and which involves crew actions that are well within their capabilities. Minor failure conditions may include, for example, a slight reduction in safety margins or functional capabilities, a slight increase in crew workload, such as routine flight plan changes, or some inconvenience to occupants. 


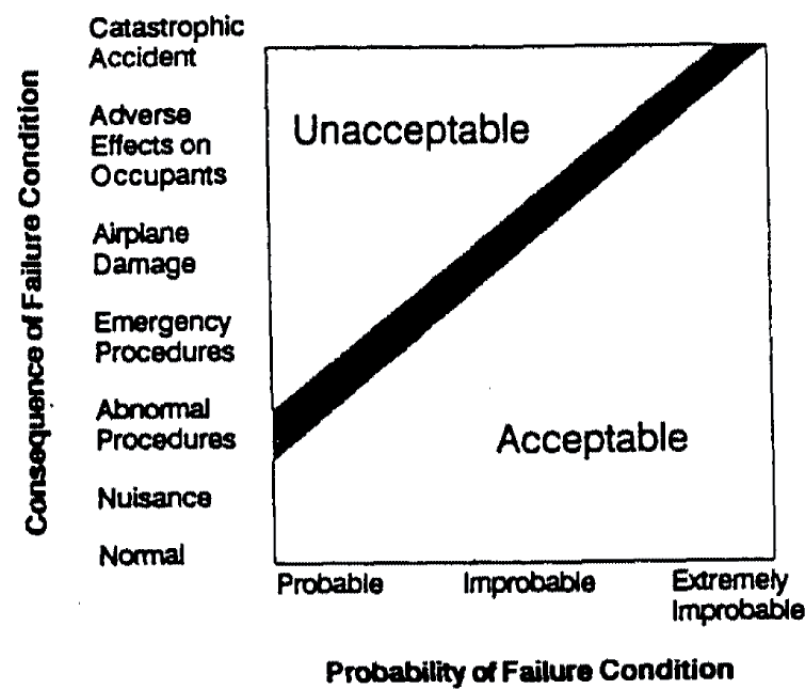

Figure 1.

The relationship between probability and failure condition.

2. Major: Failure conditions which would reduce the capability of the airplane or the ability of the crew to cope with adverse operating conditions to the extent that there would be. For example, a significant reduction in safety margins or functional capabilities, a significant increase in crew workload or conditions impairing crew efficiency, or some discomfort to occupants.

3. Catastrophic: Failure conditions which would prevent continued safe flight and landing.

Each failure state has a probability that is opposite to its severity. Figure 1 shows the relationship between probability and failure condition.

The qualitative and quantitative assessment methods are suggested in AC 25.1309-1A, including, failure modes and effects analysis, fault tree, or reliability block diagram analysis.

Using Weibull analysis and Bayesian method to analyze the aircraft operation event data, the failure probability of accidental event, hidden event, aging component failure event, and multiple factor failure event can be determined by combining the methods provided in AC 25.1309-1A, and the failure risk can be determined to provide input for the formulation of corrective/improvement measures and compliance time.

\section{Aircraft structure risk assessment}

Fatigue and corrosion are the main causes of aircraft structural failure during operation. The initial defect, crack size, residual strength, load spectrum, and maximum load of aircraft structure change with operation time, service environment, and service stage. In the risk assessment of aircraft structure, it is necessary to consider the above factors to calculate the risk of structural failure. Fatigue cracks may originate from defects in the material, such as holes or inclusions, or from damage during manufacturing and processing, or from environmental corrosion during aircraft operation. The risk of aircraft structure failure can be reduced by inspection and maintenance. However, the inspection interval and maintenance measures will affect the number and size of cracks and then affect the risk of aircraft structure 
failure. At present, during the operation of civil aircraft, aircraft structural risk assessment and analysis methods have been widely concerned in the field of aircraft structural integrity design and aircraft fleet management. When the aircraft enters into operation, the actual service life of the fleet will no longer depend on its design life at the time of certification but on factors such as maintenance cost, reliability, safety, and risk of fleet operation.

In the 1980s, the U.S. Air Force put forward a probabilistic fracture mechanics method (PROF) to calculate the risk of structural failure in the service of aircraft [3-5] (Figure 2). The input of this method includes: the distribution parameters of probability distribution (such as normal distribution, lognormal distribution, or Gumbel distribution) that the initial defect size or the defect size at a specific time obeys; the normal distribution parameters of fracture toughness; the distribution parameters that describe the inspection probability; the distribution parameters that the maximum stress obeys the probability distribution during the flight of the aircraft; and the data related to the aircraft, for example, the position and number of each aircraft, the number of hours per flight, the time interval, times of flight inspection, etc. The probability fracture mechanics method can be used to calculate the relationship curve between the aircraft instantaneous risk and flight time, and the cumulative probability distribution curve of aircraft structure crack size, which can determine the effectiveness of the inspection method and the distribution of defect size in each inspection interval.

FAA, together with aircraft manufacturers and aircraft operators, proposed a risk assessment method for wide-body aircraft, namely, SAIFE (Structure Area Inspection Frequency Evaluation, referred to as SAIFE) method [6], which is mainly to improve the structural integrity and inspection effectiveness of the operating aircraft. The SAIFE method considers the following factors: aircraft design analysis, aircraft full-scale fatigue test, manufacturing, service and corrosion defects, crack and corrosion inspection probability, aircraft modification economy, etc. Taking the above factors into account by Monte Carlo simulation method, SAIFE method obtains a safe and economic aircraft operation scheme. The main purpose of SAIFE method is to evaluate the inspection interval of aircraft. It is suitable for wide-body aircraft, such as Boeing 747 aircraft and aircraft components. It can analyze the number of defects caused by cracks, corrosion, manufacturing damage, and operation during the use of aircraft.

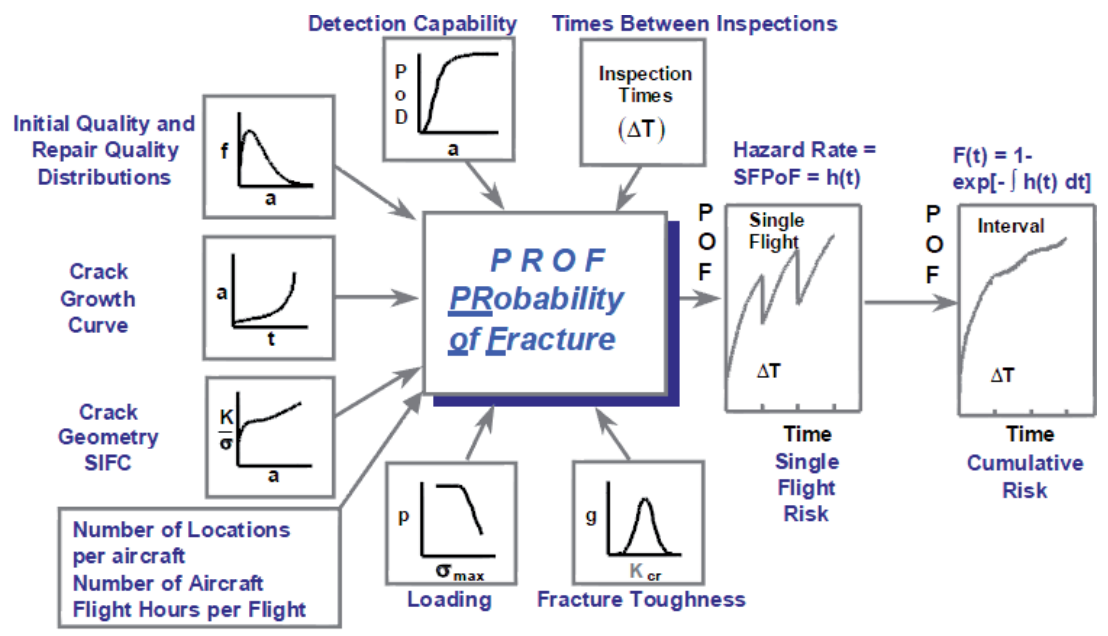

Figure 2.

The probability fracture mechanics approach. 
Southwest Research Institute of the United States proposed a Probabilistic Risk Assessment (PRA) method [7] for aircraft structure, which is used to assess the structural risk during the use of aircraft, determine the inspection and maintenance intervals, and establish a balance between aircraft safety and operating costs to provide opinions and suggestions for decision makers. Many analysis tools are used in this method, such as the Probability Fracture Mechanics (PROF) method of the U.S. Air Force, the aircraft engine probability risk assessment software DARWIN (Design Assessment of Reliability with Inspection, DARWIN), and Weibull analysis. The influence of load, material properties, fatigue and fracture, defect size, inspection interval and inspection method, as well as uncertainty on aircraft structure risk are analyzed. This method analyzes the risk assessment of T-38 aircraft wing surface crack damage tolerance, T-37 aircraft fatigue critical area risk assessment, A-10 aircraft risk assessment, etc. In addition to the above analysis methods and software, there are FEBREL software [8] of Boeing company, PROMISS software [9] of Martec company, PRISM software [10] of Bombardier company, etc., which are used for structural risk assessment of the aircraft operation stage.

\section{Aeroengine risk assessment}

The components whose primary failure can cause the harmful effect of aeroengine are defined as Engine Life Limited Part (ELLP). In the design of aeroengine, the main purpose is to improve the safety of the whole aeroengine by reducing the failure probability of ELLP. The U.S. aviation industry proposes to adopt the component life management method based on Probabilistic Risk Assessment (PRA) to further reduce the failure probability of ELLP [11, 12], and the Federal Aviation Administration (FAA) also puts forward relevant requirements in airworthiness regulations [13]; after the ELLP is determined through system safety analysis [14] in the joint definition stage of the engine, the risk assessment must be conducted to show that the failure probability risk of the ELLP within the expected service life is less than $10^{-8}$ /flight hour so that the engine can obtain the final type certificate. Therefore, it is one of the key technologies and implementation steps to evaluate the probability risk of the failure of ELLP in the service life.

In view of the great advantages of Probabilistic Risk Assessment in improving engine safety, the aviation industry departments have actively researched and developed a batch of highly integrated software, some of which have passed the certification of FAA; for example, the Southwest Research Institute (SwRI) in combination with Honeywell, Roll-Royce, P \& W (Pratt \& Whitney), and GE General Electric (GE) company developed the Darwin software [11, 12], which are mainly used to deal with the problem of low-cycle fatigue failure probability caused by hard $\alpha$ defect of titanium alloy turbine disk [11] and with the problem of fracture failure caused by other material defects and processing-induced defects [12]. Using DARWIN software to evaluate component design is not to replace the traditional safety life method but to provide a probabilistic risk prediction and management tool for aeroengine manufacturers. The risk assessment process and method adopted in DARWIN software basically integrate the main research contents of the above risk assessment method. The DARWIN software integrated the defect characteristics and material properties of components provided by four major engine companies and certified by FAA (Figure 3 ).

The working group of the Aerospace Industries Association (AIA) proposed a research achievement for the Federal Aviation Administration (FAA), aiming to develop more effective methods to identify and solve unsafe events on civil 


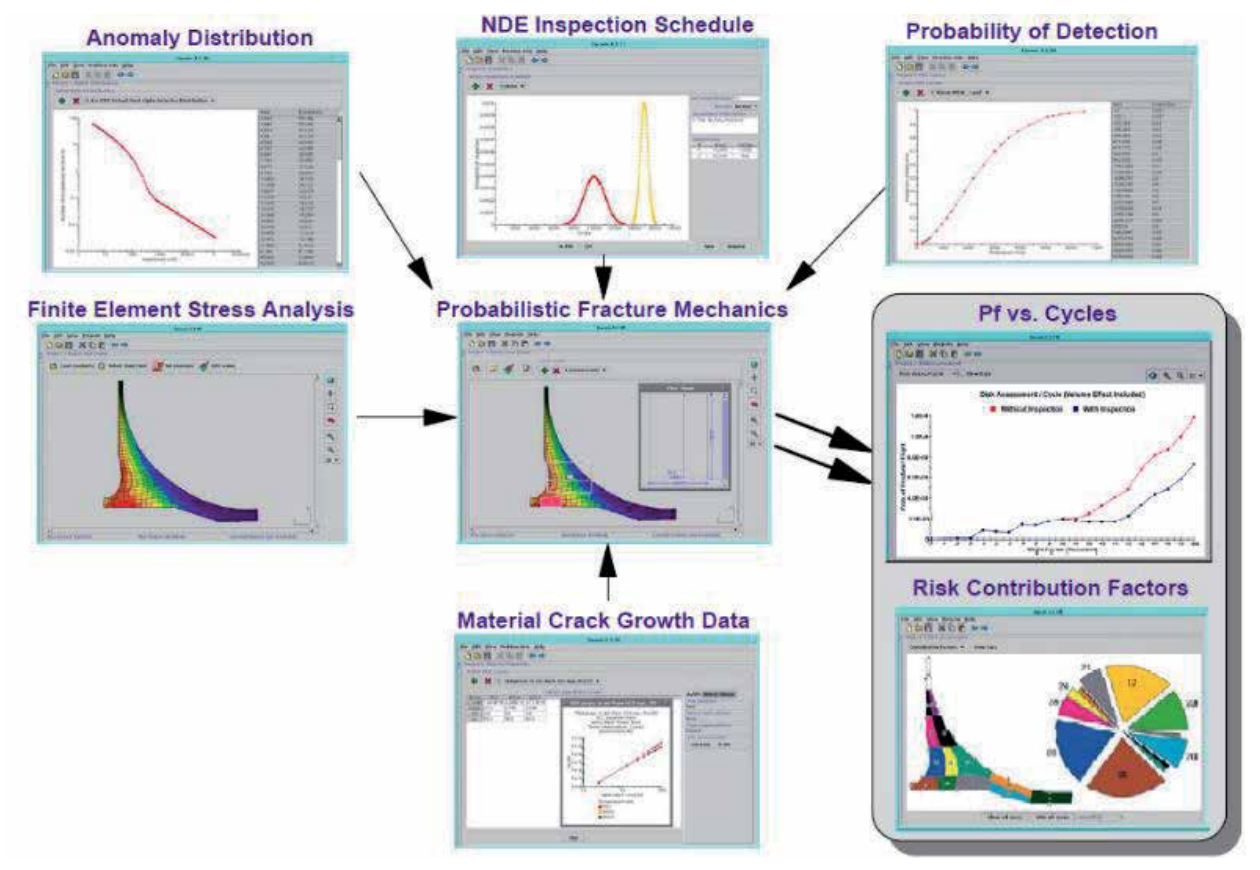

Figure 3.

The risk assessment flow chart in DARWIN software.

aircraft engines. The working group is the research committee of the Continuous Airworthiness Assessment Methodology (CAAM). Its members are mainly composed of GE, P \& W, Airbus, Boeing, Honeywell, Roll-Royce, and other companies. The study of Continuous Airworthiness Assessment Method covers all kinds of unsafe events related to the propulsion system and auxiliary power plant unit, gives the frequency and hazard level of aircraft level accidents caused by the above system faults in history, and establishes the risk level and risk criteria. The FAA engine propeller certification center uses this information to identify and prioritize the risk of failure for each engine, propeller, and APU. In September 2003, FAA issued Advisory Circular AC 39-8 [15] on the Continuous Airworthiness Assessment of power units and auxiliary power units of transport aircraft and gave the acceptable standard of flight risk level in the aviation industry. AC 39-8 points out that the risk analysis and evaluation of aeroengine failure is a management process of identifying, evaluating, controlling, or reducing risks and accepting risks. The potential damage of risks is measured by the probability of occurrence, exposure of risks, and the severity of consequences. At the same time, implementation decisions are made to minimize the negative effects and economic losses caused by risks. The basic steps are as follows:

1. Define the failure risk and find out the risk factors.

2. Identify the hazard level of the failure risk and obtain the risk coefficient to determine the priority of the failure risk.

3. Calculate the risk factor of each flight [when multiple failure risks exist at the same time, calculate the cumulative risk factors, that is, add the risk factors of risk events caused by various failure risk states; the risk of each flight of the flight crew is calculated by the failure risk factor and risk level coefficient obtained in (1) and (2)]. 


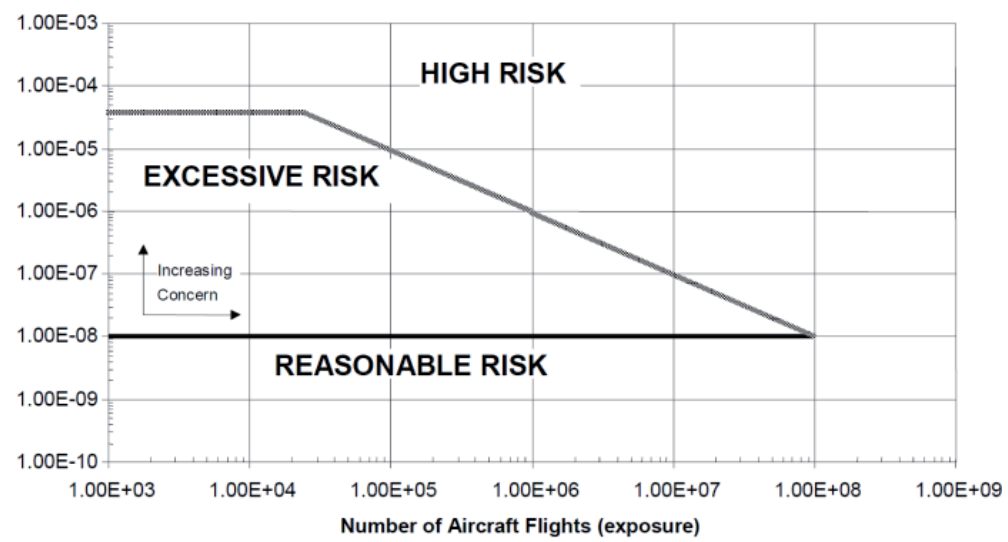

Figure 4 .

The division of flight risk area.

4. The risk of each flight is compared with the risk criteria to evaluate whether the risk of current aeroengine failure is acceptable. If the short-term risk exceeds the limit value of the risk criteria within 60 days, the risk reduction measures need to be taken immediately.

Figure 4 shows the division of flight risk area according to the risk standard. It can be found that the flight risk area is divided into high-risk area, multi-risk area, and acceptable risk area. When the flight risk is located in the high-risk area, measures need to be taken immediately to reduce the risk; when the flight risk is located in the multi-risk area, it is necessary to formulate and implement measures to reduce the risk within a certain period of time and make the residual risk after the implementation of the measures within the acceptable range; and when the flight risk is located in the acceptable risk area, it is not necessary to take measures.

\section{Conclusion}

In this chapter, the risk assessment methods for the aircraft system, structure, and aeroengine are investigated. For the aircraft system risk assessment, the probability level is divided into probable, improbable, and extremely improbable, and the hazard level of the failure condition is divided into minor, major, and catastrophic. Using Weibull analysis and Bayesian method to analyze the aircraft operation data, the risk level of aircraft system can be determined by combing methods provided in AC 25.1309-1A. For the aircraft structure risk assessment, the probability fracture mechanics approach can be used to determine the structure failure risk based on the data of material properties, environment, inspection, and so on.

For the aeroengine risk assessment, the methods for classification of failure risk level, determination of hazard ratio, and calculation of the risk factor and risk per flight are given. The risk assessment process for aeroengine multi-failure modes based on the Monte Carlo simulation is presented to predict the occurrence of the failure and assess the failure risk.

\section{Acknowledgements}

The work reported here is supported by the Fundamental Research Funds for the Central Universities (Grant No. NS2019038). 


\section{Conflict of interest}

The author declares that he has no known competing financial interests or personal relationships that could have appeared to influence the work reported in this chapter.

\section{Author details}

Longbiao Li

College of Civil Aviation, Nanjing University of Aeronautics and Astronautics, Nanjing, P.R. China

*Address all correspondence to: 1lb451@nuaa.edu.cn

\section{IntechOpen}

(c) 2020 The Author(s). Licensee IntechOpen. Distributed under the terms of the Creative Commons Attribution - NonCommercial 4.0 License (https://creativecommons.org/ licenses/by-nc/4.0/), which permits use, distribution and reproduction for non-commercial purposes, provided the original is properly cited. $\left(\right.$ (cc) $_{\text {BY-NC }}$ 


\section{References}

[1] Federal Aviation Administration. e-CFR 14 part 25: Airworthiness standards: Transport category airplanes. Washington DC; 2020

[2] Federal Aviation Administration. Advisory circular 25.1309-1B: System design and analysis. Washington DC; 1988

[3] Berens AP, Hovey PW, Skinn DA. Risk Analysis for Aging Aircraft Fleets Volume 1 - Analysis. Technical Report WL-TR-91-3066 OH 454336553, Flight Dynamic Directorate, Wright Laboratory, air Force Systems Command, Wright-Patterson air Force Base, October 1991

[4] Hovey PW, Berens AP, Loomis JS. Update of the Probability of Fracture (PROF) Computer Program for Aging Aircraft Risk Analysis. Technical Report AFRLVA-WP-TR-1999-3030, Air Force Research Laboratory, Wright-Patterson Air Force Base, November 1998

[5] Hovey PW, Berens AP, Loomis JS. Probabilistic risk assessment using an updated PROF. In: Aircraft Structural Integrity Program. USA: National Aeronautics and Space Administration; 1998

[6] Dinkeloo CJ, Moran MS. Structural Area Inspection Frequency Evaluation (SAIFE)-Vol I Executive Summary. Technical Report FAA-RD-78-29, U.S. Department of Transportation-Federal Aviation Administration, April 1978

[7] Southwest Research Institute. 2009. Available from: www.swri.org

[8] Torng TY, Edwards RM. Comparing B-1B wing carry through inspection requirements as defined by deterministic and probabilistic approaches. In: Proceedings of 1998 USAF Aircraft Structural Integrity Program Conference. Wright-Patterson
AFB OH, USA: Air Force Research Laboratory; 1998

[9] Orisamolu IR, Lou X, Lichodziejewski M. Development of Probabilistic Optimal Strategies for Inspection/Monitoring/Maintenance/ Repair and Life Extension, Martec, Ltd., Halifax, Canada, TR SRV-6-00251; 1999

[10] Forges SA. PRISM User's Guide, Rept. RAZ-DSD-101, Bombardier Aerospace, Montreal, Canada, Defence Services; 1997

[11] Leverant GR, Mcclung RC, Wu YT, et al. Turbine Rotor Material Design Phase I. Washington, DC: FAA Grant 92-G-041; 2000

[12] Mcclung RC, Leverant GR, Enright MP. Turbine Rotor Material Design Phase II. Washington, DC: FAA Grant 99-G-016; 2008

[13] U.S.Department of Transportation. Federal Aviation Administration. E-CFR 14 Part 33: Airworthiness Standards: Aircraft Engines. Washington, DC: FAA; 2009

[14] U.S. Department of Transportation FAA. Advisory Circular 33.75-1A: Guidance Material for 14 CFR 33.75, Safety Analysis. Washington, DC: FAA, AC33.75-1A; 2007

[15] US Department of Transportation Federal Aviation Administration, Advisory Circular 39-8, continued airworthiness assessments of power plant and auxiliary power unit installations of transport category airplanes, Initiated by AIR-100, 08 September, 2003 



\title{
Risk and Economic Analysis Methods of Commercial Aero Engines
}

\author{
Sherkhan Aitugan and Longbiao Li
}

\begin{abstract}
This chapter outlines the results of risk analysis and economic analysis of commercial aero engines during aircraft operation. Risk analysis is the procedure for identifying risk factors and assessing their significance, in essence, analysis of the likelihood that certain undesirable events may occur and as such adversely affect operation. Risk analysis includes risk assessment and methods to reduce risks or reduce adverse effects associated with it. Furthermore, economical analysis is a scientific way of understanding the essence of economic phenomena and processes, which in turn are based on dividing them into their constituent parts. In doing so, the variety of relationships and dependencies aimed at improving the associated work through the development and implementation of optimal solutions is studied. The purpose of the economic analysis is to give management of the actual state, and for persons who are not directly working with it, but are interested in its financial condition, the information necessary for an impartial judgment.
\end{abstract}

Keywords: aircraft, risk analysis, economic analysis

\section{Introduction}

Safety is one of the main characteristics of all human activities. In particular, safety issues are principally acute in activities and industries that are considered dangerous. Air transport may be regarded as falling within this category, as failures of aviation-related equipment, flight support services and human factors-specific errors increase the likelihood and the potential of a disaster, which in turn yields financial losses. At the same time, losses from catastrophes in civil aviation are significantly less than in many other hazardous industries [1]. It may be stated that this level is attained due to continuous investment in methods and techniques as well as maintaining high reliability levels, which cover the entire organization. Today, the available risks influencing activity of the developed economic conditions, it is necessary to have the effective tools for risk and economic analysis. This equally includes aviation industry as well as enterprises operating aircraft equipment. One of such tools is risk analysis and economic analysis [2-5].

As stated by Cruse et al. [6], the way in which organizations such as Pratt and Whitney and Rolls-Royce find that the safe life of an aircraft engine depends on the design. The safety factor is applied in order to improve various configurations so as to empower safety. In order for equipment manufacturers to increase the associated 
safety level of their products, the number of flight cycles is determined. Different problems have prompted investigating the manageability of an aircraft's engine life. Indeed, since 1984, resistance to damage has been a vital part of the ENgine Structural Integrity Program (ENSIP) contained in MIL-STD-1783. Currently, there is a program in the U.S. that uses probabilistic methods for gas turbine engines in ENSIP.

To reproduce the probability estimates important for hazard or failure assessment, various computing strategies are used, including Monte Carlo simulation. Monte Carlo simulation reproductions have been included in the probabilistic study, as they tend to be used in failure analysis and can give high accuracy. This strategy has been used in numerous aviation-specific electronics and hazard assessment schemes. The disadvantages of this methodology are the enormous estimated time and the dependence of the measured estimate on the size of the sample.

Economic analysis of aircraft and its components is one of the most important functions of airline management, the implementation of which is necessary to ensure its effective operation. As a matter of fact, economic analysis is known to represent numerous methods of economic theory. As such, economic analysis of aircraft and its components can be defined as an application of the theoretical foundations of the economy of the airline company and analytical sections of accounting to justify management-specific decisions.

This chapter will consider methods of risk analysis and economic analysis of one of the most important components of a commercial aircraft - the power plant or engine.

\section{Main risk analysis process}

To improve the efficiency and objectivity of risk analysis and to ensure comparability with other risk analysis outcomes, the following general rules should be observed. The risk analysis process should follow the following steps:

a. Defining the scope of application

b.Hazard identification and preliminary impact assessment

c. Evaluation of the risk value

d.Verification of the analysis results

e. Documentary substantiation;

f. Adjustment of the results of the analysis taking into account the latest data.

This process is shown in Figure 1. Risk assessment includes frequency analysis and consequence analysis. While Figure 1 shows the documentation as a separate unit, it is developed at each stage of the process. Depending on the application, only certain elements of the process presented are considered. For example, in some cases it may not be necessary to go beyond the original hazard and impact analysis.

A necessary requirement is a thorough knowledge of the system and the analysis methods used. If the results of a risk analysis for a similar system are available, they can be used as a reference. It is necessary to prove that the processes are similar and that the changes do not make significant differences in the results. Conclusions should be based on a systematic assessment of the changes and how they may affect the existing hazards. 


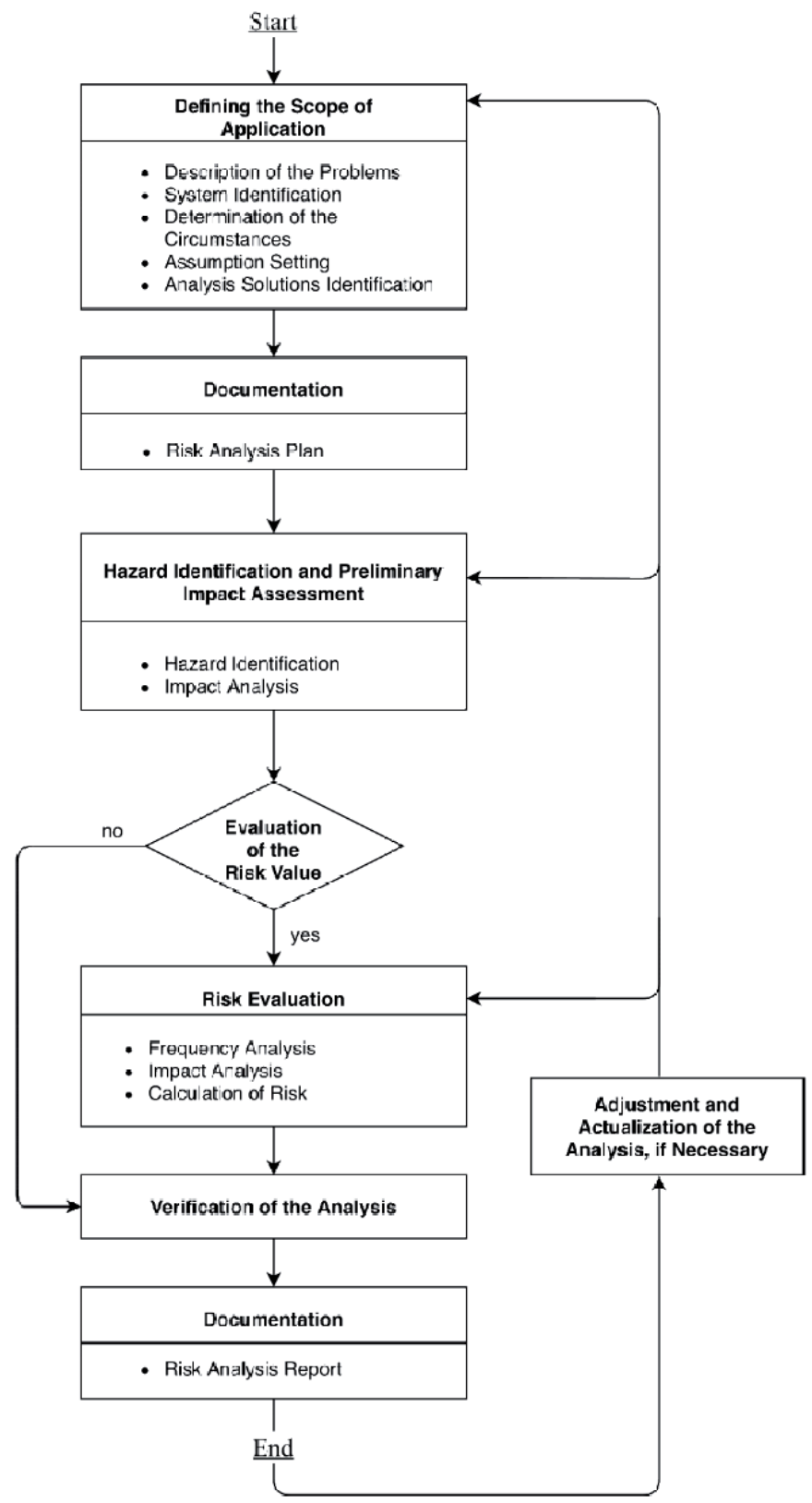

Figure 1.

Risk analysis process.

\subsection{Risk analysis methods}

A list of the most common methods is presented in Table 1. The list given in Table 1 is not exhaustive. The list of additional methods is presented in Table 2. Sometimes it may be necessary to use more than one analysis method.

\subsubsection{Analysis of a chart of possible consequences of an event (event tree analysis)} (ETA)

The Event Tree Analysis, ETA is a set of quantitative or qualitative techniques that are used to identify possible outcomes of an initiating event and, if required, 


\begin{tabular}{|c|c|c|}
\hline & Method & Description and application \\
\hline 1 & Event tree analysis & $\begin{array}{l}\text { A set of techniques for hazard identification and frequency analysis } \\
\text { that uses an inductive approach to translate various initiating events } \\
\text { into possible outcomes }\end{array}$ \\
\hline 2 & $\begin{array}{l}\text { Failure mode and } \\
\text { effect analysis, as well } \\
\text { as failure mode effects } \\
\text { and criticality analysis }\end{array}$ & $\begin{array}{l}\text { A set of methods for identifying the main sources of danger and } \\
\text { frequency analysis, with the help of which all the emergency conditions } \\
\text { of a given piece of equipment are analyzed for their influence on other } \\
\text { components and on the system as a whole }\end{array}$ \\
\hline 3 & Fault tree analysis & $\begin{array}{l}\text { A set of techniques for hazard identification and analysis of frequencies } \\
\text { of an undesirable event, with the help of which all ways of its } \\
\text { implementation are determined. A graphical image is used }\end{array}$ \\
\hline 4 & $\begin{array}{l}\text { Study of hazards and } \\
\text { related problems }\end{array}$ & $\begin{array}{l}\text { A set of fundamental hazard identification techniques by which each } \\
\text { part of the system is assessed to determine whether there may be } \\
\text { deviations from the design intent and what consequences this may have }\end{array}$ \\
\hline 5 & Human factor analysis & $\begin{array}{l}\text { The set of methods consider influence of errors of the person on } \\
\text { reliability }\end{array}$ \\
\hline 6 & $\begin{array}{l}\text { Preliminary hazard } \\
\text { analysis }\end{array}$ & $\begin{array}{l}\text { A set of techniques for hazard identification and frequency analysis } \\
\text { used at an early stage of design to identify hazards and assess their } \\
\text { criticality }\end{array}$ \\
\hline 7 & $\begin{array}{l}\text { Structural reliability } \\
\text { scheme }\end{array}$ & $\begin{array}{l}\text { A set of methods of frequency analysis, on the basis of which the } \\
\text { system model and its reserves are created to assess the system reliability }\end{array}$ \\
\hline
\end{tabular}

Table 1.

List of the most common methods used in risk analysis.

\begin{tabular}{|c|c|c|}
\hline & Method & Description and application \\
\hline 1 & $\begin{array}{l}\text { Classification of risk } \\
\text { groups by category }\end{array}$ & Classification of risk types by categories in order of priority of risk groups \\
\hline 2 & Inspection reports & $\begin{array}{l}\text { Inventory of generic hazardous substances and/or sources of potential } \\
\text { accidents that need to be addressed. These can be used to assess } \\
\text { compliance with laws and standards }\end{array}$ \\
\hline 3 & $\begin{array}{l}\text { General failure } \\
\text { analysis }\end{array}$ & $\begin{array}{l}\text { A method designed to determine whether an accidental failure (accident) } \\
\text { of a number of different parts or components within a system is possible } \\
\text { and to evaluate its likely cumulative effect }\end{array}$ \\
\hline 4 & $\begin{array}{l}\text { Impact description } \\
\text { models }\end{array}$ & $\begin{array}{l}\text { Assessment of the impact of an event on people, property or the } \\
\text { environment. Both simplified analytical approaches and complex } \\
\text { computer models are used }\end{array}$ \\
\hline 5 & Delphi's method & $\begin{array}{l}\text { The method presents expert assessments that can provide frequency } \\
\text { analysis, impact modeling and/or risk assessment }\end{array}$ \\
\hline 6 & Hazard indices & $\begin{array}{l}\text { A set of hazard identification/assessment techniques that can be used to } \\
\text { rank different system options and identify less hazardous options }\end{array}$ \\
\hline 7 & $\begin{array}{l}\text { Monte Carlo method } \\
\text { and other modeling } \\
\text { methods }\end{array}$ & $\begin{array}{l}\text { A set of methods for frequency analysis that uses the system model to } \\
\text { estimate variations in baseline conditions and assumptions }\end{array}$ \\
\hline 8 & Paired comparisons & $\begin{array}{l}\text { A way to assess and rank the universal risk by means of paired } \\
\text { comparison }\end{array}$ \\
\hline 9 & $\begin{array}{l}\text { Operation data } \\
\text { review }\end{array}$ & $\begin{array}{l}\text { A set of techniques that can be used to identify potentially problematic } \\
\text { areas and for frequency analysis based on accident data, reliability data, } \\
\text { etc. }\end{array}$ \\
\hline 10 & $\begin{array}{l}\text { Covert process } \\
\text { analysis }\end{array}$ & $\begin{array}{l}\text { A method for identifying hidden processes and paths that could lead to } \\
\text { unexpected events }\end{array}$ \\
\hline
\end{tabular}

Table 2.

List of additional methods used in risk analysis. 
their probabilities. ETA is widely used for project-specific facilities that contribute to the reduction of accidents and identify sequences of events that, in turn, lead to certain consequences of the initiating event. Each event in the sequence is assumed to be either a failure or a fault.

Note that the probabilities in the event tree are conditional probabilities. For example, the probability of the sprinkler functioning is not a probability derived from tests under normal conditions but is a probability of functioning under fire conditions caused by an explosion.

The ETA provides a relationship between the functioning (or failure) of a variety of systems and the hazardous event following the single initiating event. The ETA is very useful for identifying events that require further analysis using the FTA (i.e. the tip of the fault tree events). In order to be able to make a comprehensive risk assessment, all potential initiating events need to be identified. With this method, however, it is always possible to overlook some important initiating events. Moreover, in the case of event trees, we are only dealing with success and failure states. It is difficult to include delayed success or return events.

ETA can be used both for hazard identification and for probabilistic evaluation of the sequence of events leading to hazardous situations.

\subsubsection{Failure modes and effects analysis (FMEA)}

FMEA is a predominantly qualitative method, although it can be presented in a quantitative form that systematically identifies the consequences of each individual component of an emergency condition. An indispensable feature in any FMEA is to consider each major component/particle of the system as to how it achieves the emergency state and how this affects the emergency state of the system. The analysis is usually descriptive and is organized in the form of a table or worksheet intended for information. The FMEA certainly refers to the emergency conditions of a system component, the causal factors and the effects of this condition on the system as a whole and presents them in a "user-friendly" form.

FMEA is a bottom-up approach and addresses the consequences of component failures in a "one-at-a-time" manner. This method is capable of processing sufficient data. In addition, the results can be easily double-checked by another person familiar with the system.

The main disadvantages of the method are redundancy, the exclusion of recovery and repair activities and the focus on single component accidents.

FMEA can extend to performing what is called Failure Type, Function and Criticality Analysis (FMEA). In FMEA, each identified failure is ranked according to the likelihood of its occurrence and the severity of its consequences.

FMEA and FMESA provide input to analyses such as Fault Tree Analysis (a diagram analysis of all possible consequences of a failure or system crash). In addition to their application to system components, FMEA and FMECA can also be used in relation to human error; they can be used both for hazard identification and probability assessment (unless there is a limited level of redundancy in the system).

\subsubsection{Analysis of a diagram of all possible consequences of a failure or system crash (fault tree analysis (FTA))}

Fault Tree Analysis, FTA is a set of qualitative or quantitative methods which are built into a logical chain and graphically presented those conditions and factors that may contribute to a certain undesirable event (called the top of events). Malfunctions or accidents identified in the "tree" can be events associated with damage to a component's mechanical structure, personnel errors, or any other event 
that may cause an undesirable incident. Starting at the top of the events, possible causes or alarm states of the next, lower functional level of the system are identified. Subsequent step-by-step identification of undesired system operation in the direction of successively decreasing system levels leads to the desired system level, which is the alarm condition of the component. An example of a "fault tree" for an emergency generator is shown in Figure 2.

The FTA provides an approach that is highly systematic, but at the same time flexible enough to allow for the analysis of multiple factors, including human interactions and physical phenomena. The top-down approach, implicit in its methodology, focuses on those effects of a failure or accident that are directly related to the top of events. The FTA is particularly useful for analyzing systems with multiple areas of contact and interaction. Graphical representation makes it easy to understand the behavior of a system and the behavior of the factors included in it, but since the size of trees is often large, the processing of fault trees may require the use of computer systems. This feature also makes it difficult to check the trouble tree.

FTA can be used to identify hazards, although it is primarily used in risk assessment as a tool to assess the probability or frequency of faults and accidents.

\subsubsection{Hazard and operability analysis (HAZOP)}

HAZOP is a form of Failure Types and Consequences Analysis. HAZOP research was originally developed for the chemical industry. It is a procedure for detecting possible hazards across the entire facility. It is particularly useful for

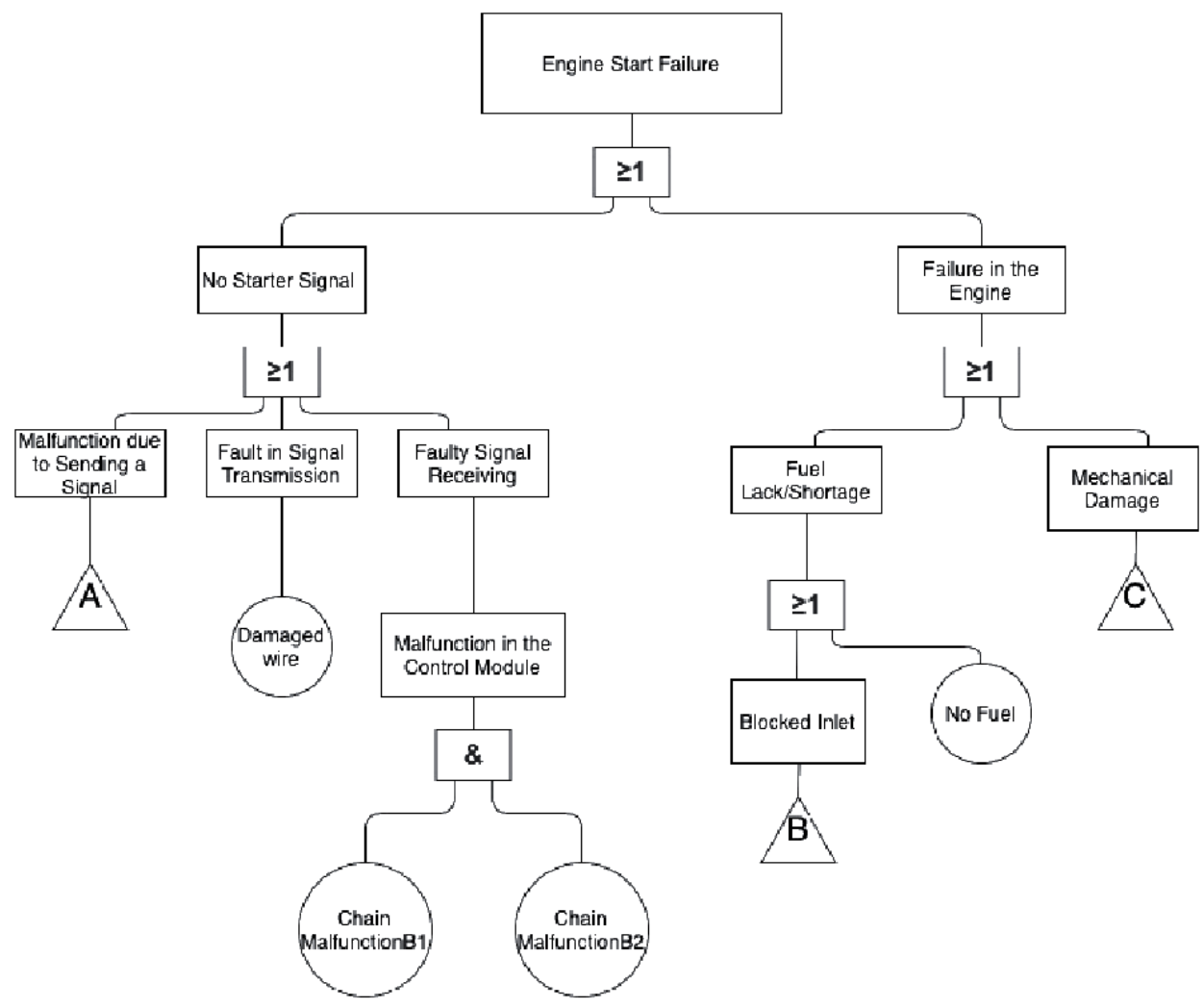

Figure 2.

Example of a "fault tree." 
identifying unforeseen hazards in a facility due to lack of development information, or hazards that manifest themselves in existing facilities due to irregularities in their operation.

The main tasks of the method are:

a. To compile a complete description of the object or process, including estimated design conditions;

b. To systematically check each part of the facility or process in order to identify ways in which deviations from the design intent may occur;

c. To decide whether hazards or problems associated with these deviations may occur.

The HAZOP research principles may be applied to technical facilities during their operation or at various design stages. HAZOP research performed during the initial design stage can be performed by the project manager.

The most common form of HAZOP research is during the working design stage and is called HAZOP II research.

The HAZOP II study has the following stages:

Stage 1 - identification of the goals, objectives and scope of the study, for example, the identification of hazards characterized only by non-local effects or only local effects, areas of the industrial facility to be considered, etc.;

Stage 2 - completing the HAZOP research team. This group should consist of designers and operators who have sufficient competence to assess the consequences of deviations from the conditions of the system operation;

Stage 3 - gathering the necessary documentation, drawings and descriptions of the technological process. This includes graphs of the sequence of technological operations; drawings of pipelines and measuring equipment; technical specifications for equipment, pipelines and measuring equipment; logical diagrams of process control related technology; design diagrams; operation and maintenance methods; emergency response methods, etc.;

Stage 4 - analysis of each main unit of equipment and all auxiliary equipment, pipelines and measuring equipment using documents collected at step 3. First of all, the purpose of the process design is determined; then, in relation to each line and unit of equipment with respect to such process variables as temperature, pressure, flow, level and chemical composition, the words-indicators are used (according to Table 3). (It is the author's view that these indicator words stimulate individual thinking and encourage collective discussion);

Stage 5 - document any deviation from the norm and the corresponding states. In addition, ways to detect and/or prevent deviations are identified. This documentation is usually indicated on HAZOP worksheets.

\subsubsection{Assessing the impact on human reliability factor (HRA)}

The assessment is related to the impact of human factor, namely operators and maintenance personnel, on system operation and can be used to assess the effect of personnel errors on safety and productivity.

Many processes contain potential for personnel errors, especially when the time available for the operator to make decisions is limited. The likelihood that problems will develop in a negative way is often low. Sometimes actions from outside personnel's jurisdiction are limited in their ability to prevent an initial fault progressing in the direction of an accident. 


\begin{tabular}{lllll}
\hline $\begin{array}{l}\text { Word } \\
\text { pointer }\end{array}$ & Rejection & Possible reasons & Consequences & Action required \\
\hline No, not & $\begin{array}{l}\text { No } \\
\text { expense }\end{array}$ & $\begin{array}{l}\text { 1. Absence of submitted } \\
\text { material }\end{array}$ & $\begin{array}{l}\text { The output of the } \\
\text { molded polymer } \\
\text { will be reduced }\end{array}$ & $\begin{array}{l}\text { a. Ensure good } \\
\text { communication with } \\
\text { the operator } \\
\text { b. Provide a low } \\
\text { level signal on the } \\
\text { installation tank }\end{array}$ \\
\cline { 2 - 4 } & & $\begin{array}{l}\text { 2. The pump is faulty } \\
\text { (many reasons) }\end{array}$ & $\begin{array}{l}\text { The output of the } \\
\text { molded polymer } \\
\text { will be reduced }\end{array}$ & $\begin{array}{l}\text { Provide for a low level } \\
\text { signal on the installation } \\
\text { tank }\end{array}$ \\
\cline { 2 - 4 } & $\begin{array}{l}\text { 3. A line is blocked or } \\
\text { a control valve is } \\
\text { erroneously closed or } \\
\text { not closed }\end{array}$ & $\begin{array}{l}\text { The pump will } \\
\text { overheat. }\end{array}$ & $\begin{array}{l}\text { Install a recirculation } \\
\text { line on each pump }\end{array}$ \\
& & & \\
\hline
\end{tabular}

Table 3.

HAZOP II indicator words.

The HRA identifies the various types of error actions that may occur, including the following:

a. Error by mistake, an oversight resulting in the failure to perform the required action;

b. An error of non-conformity, which may include:

1. A situation in which the action required is performed in a non-conforming manner;

2. An action performed with too much or too little force or without the required accuracy;

3. An action performed at a time not appropriate for it;

4. An action (or actions) performed in an incorrect order;

c. An extra action, an unnecessary action performed instead of or in addition to the required action.

The result of HRA identifies actions that can re-create previous errors.

The HRA methodology is a mixed discipline involving researchers and practitioners who are typically specialists in either the theory and practice of reliability or psychology and human factors.

The importance of HRA has been illustrated by various accidents in which critical human errors have contributed to a catastrophic sequence of events. Such accidents are a warning against risk assessments that focus exclusively on the mechanical design and software in the system. They illustrate the risk of ignoring human error. Moreover, HRAs are useful in considering errors that reduce productivity and in identifying the ways in which these errors and other faults (mechanical design and software) can be "replicated" by people, operators and maintenance personnel.

The HRA can include the following steps: (1) task analysis; (2) identification of personnel error; (3) quantitative determination of the impact of the human factor on reliability. 
The task analysis and personnel error detection should be started at the concept stage and the early stages of design and development. They should be updated at later stages of the system development.

The purpose of the task analysis in the HRA process is to describe and characterize the task to be analyzed in detail in order to identify human error and/or quantify the impact on human reliability. The task analysis can also be performed for other purposes, such as evaluating the person's interaction with the machine or planning a procedure.

At this stage, possible errors in the task are identified and described. The identification of personnel error may include:

- The detection of the possible consequences and causes of the erroneous actions

- The proposal of measures to reduce the probability of the error,

- The improvement regarding the prospects for correction and/or the reduction of the consequences of erroneous actions. Thus, HRA results provide a valuable contribution to risk management, even if no quantitative assessment is made.

The purpose of HRA is to assess the probability of correct execution of the task or the probability of erroneous actions. Some techniques may also include steps to assess the probability or frequency of certain sequences of unwanted events or undesirable outcomes.

\subsubsection{Preliminary hazard analysis (PHA)}

Preliminary Hazard Analysis, PHA is an inductive method of analysis whose purpose is to identify hazards, hazardous situations and events that may harm a given activity, facility or system. It is most often used at an early stage of project development when there is little information on design details and working procedures, and it can often be a precursor to subsequent research. In addition, it may be useful where existing systems or prioritize hazards where circumstances prevent the use of a wider range of techniques.

When conducting PHA, a list of hazards and general hazards is developed by considering such characteristics as:

a. The materials used or produced and their ability to react;

b. The equipment used;

c. Environmental conditions;

d.Location scheme;

e. Areas of contact and interaction between system components, etc.

The implementation of this method concludes with the determination of the potential for an accident, a qualitative assessment of the magnitude of the possible harm or health damage that may have been caused, and the identification of possible corrective measures. The PHA must be adjusted at the design, manufacturing, and testing stages to detect, correct, and improve new hazards. The results obtained can be presented in various ways, such as tables and "trees." 


\subsection{Hazard identification}

The detection of hazard assumes a systematic check of the investigated system with the purpose of identification of type of present unrecoverable dangers and ways of their display. Statistical records of accidents and experience of previous risk analyses can provide a useful contribution to hazard identification processes. It should be recognized that there is an element of subjectivism in hazard thinking and that identified hazards may not always be exhaustive hazards that could pose a threat to the system. It is necessary that identified hazards are reviewed when new data are available. Hazard identification methods are broadly divided into three categories:

a. Comparative methods, examples of which are inspection sheets, hazard indices and operational data review;

b. Fundamental methods, which are constructed in such a way as to encourage a group of researchers to use a prediction in combination with their knowledge of the hazard identification task by asking a series of questions such as "what if ...?”. Examples of this type of methodology are Hazard and Related Problem Research (HAZOP) and Failure Analysis (FMEA);

c. Methods of inductive approach, such as logic diagrams of possible consequences of a given event ("event tree" logic diagrams).

Other techniques can be used to improve hazard identification (and risk assessment capabilities) for certain problems. For example: hidden fault analysis, the Delphi method and human factor analysis.

Regardless of the techniques used, it is important that the overall hazard identification process pays due attention to the fact that human and organizational errors are significant factors in many accidents. It follows that accident scenarios involving human and organizational error should also be included in the hazard identification process, which should not focus exclusively on technical aspects.

\section{Economic analysis}

Economic analysis as a science is a system of specialized knowledge linked: with the study of economic processes in their interrelation, formed under the influence of objective economic laws and factors of subjective order;

- With scientific justification of business plans, and with objective assessment of their implementation;

- With identification of positive and negative factors and quantitative measurement of their action;

- With disclosure of trends and proportions of economic development, with recognition of unused intra-economic reserves;

- Generalization of the best practices,

- With the adoption of optimal management decisions. 
Economic analysis of aircraft and its components is one of the most important functions of airline management, the implementation of which is necessary to ensure its effective operation. As a matter of fact, economic analysis is known to represent numerous methods of economic theory.

Modern management theories determine the necessity of substantiation of all-important management decisions by means of analytical process called "rational problem solving". This process, the analytical part of which is identical to economic analysis, includes the following seven stages:

\subsection{Classification of analysis methods and techniques}

The method of analysis should mean the methods of investigation of the object of analysis, and the method of analysis acceptance - one or more mathematical or logical operations aimed at obtaining a specific result of analysis.

Mathematical methods are objective, as they yield the same results when applied by different analysts. In complex analysis, these methods are usually combined. Thus, the type of a mathematical model is often chosen intuitively, and the model parameters are determined by methods of mathematical statistics.

Mathematical models: mathematical economy models - theoretical and applied models - are widely used in the analysis. Theoretical models allow studying general properties of economy and its separate elements by deduction of conclusions from formal preconditions. They are important for understanding possible properties of the object of analysis. They are macroeconomic and microeconomic models, including models of firm theory and market theory. Applied models provide an opportunity to estimate parameters of functioning of a concrete economic object and to formulate specific recommendations for decision making. Applied models include, first of all, econometric models, which operate with numerical values of economic variables and allow statistically significant evaluation on the basis of available observations.

Mathematical models, besides, are subdivided into equilibrium models, which describe steady-state conditions and are therefore called descriptive, and optimization models, which allow establishing optimal, i.e. the best parameters of the system according to a certain criterion. Static models that describe the object state at a particular moment or period of time and dynamic models that include interrelationships of variables in time are distinguished.

Methods of applied mathematical statistics - econometrics, should be used as much as possible first of all in the analysis, since almost all data used in economic analysis contain a random component. Note that the results obtained by statistical processing of data may differ in the degree of accuracy and probabilistic validity. Estimates can be considered reasonable if their probability and accuracy are determined, otherwise they may not be credible.

Multidimensional methods: These methods provide objective quantitative tools to investigate data similarity, proximity, grouping or classification. Data can be presented as a set of indicators, variables that characterize objects or a single object at different points in time, e.g., an enterprise in different years. Most methods are designed to reduce the number of variables and highlight the most important characteristics. The following methods underline the most important ones:

The method of cluster analysis, which allows building a classification of several objects by combining them into groups or clusters, based on the criterion of minimum distance in space of certain indicators describing the objects, as well as the classification of objects by a given number of groups - clusters. Probabilistic justification of the clustering results can be obtained by discriminant analysis. 
Factor analysis: variables, whose values provide statistical or accounting data, are often quite conditional for the object or phenomenon under study. They can only indirectly reflect its internal structure, driving forces or factors. The analyst is limited to the set of indicators traditionally used in accounting and statistics. If an unknown factor manifests itself in changes of several variables, there is a correlation between these variables. The number of independent, initially hidden factors that can be detected by factor analysis is often significantly less than the number of traditional indicators.

In addition, there are two levels of use of expert judgments: quantitative, in which experts make estimates in the form of quantitative indicators, and qualitative, in which experts make comparative estimates, for example, "better and worse."

\subsection{Comparison method in economic analysis}

Comparison is a scientific method of knowledge, in the process of its unknown phenomenon; subjects are compared with already known, studied earlier cases, in order to determine common features or differences between them. By means of comparison the general and specific in the economic phenomena, changes of the objects under study, tendencies and lawfulness of their development are studied. Hence, the following evaluations in the area of economic analysis and comparisons are used for identifying observed problems and suggest a course of action(s):

1. Comparison of planned and actual indicators to assess the extent to which the plan has been implemented. This comparison allows the user to determine the extent to which the plan has been completed in a specific timeframe, such as a month, quarter, or year.

2. Comparing the actual indicators with the normative ones allows cost monitoring and promotes the implementation of resource saving technologies. The practice of analytical work also uses comparisons with approved norms (for example, consumption of materials, raw materials, energy, etc.). Such a comparison is necessary to identify savings or over-expenditure of resources for production, to assess the efficiency of their use during operation.

3. Comparison of actual indicators with those of previous years to determine trends in economic processes.

4. Comparison with the best results, i.e. with the best samples, best practices. New achievements of science and technology can be carried-out both within the framework of the enterprise under study and outside. Inside the enterprise the average level of indicators achieved in general is compared with indicators of advanced sites. This allows identifying best practices and new opportunities for production and operation.

5. Comparison of the indicators of the analyzed form with the average indicators of the zone/area to assess the results achieved and identified unused reserves.

6. Comparison of parallel and dynamic series to study the relationship of the studied indicators. This is used to identify and justify the form and direction of the relationship between different indicators. For this purpose the numbers, which characterize one of the indicators, should be placed in ascending or descending order and consider how in this connection other investigated indicators change: ascending or descending and to what extent. 
7. Comparison of different variants of managerial decisions in order to choose the most optimal of them.

8. Comparison of the results of activity before and after the change of any factor is applied in the calculation of the influence of factors and calculation of reserves.

The following types of comparative analysis are also distinguished in the economic analysis: horizontal, vertical, trend, as well as one-dimensional and multi-dimensional.

1. Horizontal comparative analysis is used to determine the absolute and relative deviations of the actual level of the studied indicators from the basic (planned, past period, average level, scientific achievements and best practices).

2. With the help of vertical comparative analysis the structure of economic phenomena and processes is studied by calculating the specific weight of parts in general, the ratio of parts of the whole among themselves, as well as the impact of factors on the level of performance indicators by comparing their values before and after changing the relevant factor.

3. Trend analysis is used to study relative growth rates and growth of indicators over a number of years to the level of a base year, i.e. to study the dynamics series.

4. In one-dimensional comparative analysis comparisons are made on one or several indicators of one object or several objects on one indicator.

5. By means of the multi-dimensional comparative analysis the results of activity of several operating enterprises (divisions) are compared on a wide spectrum of indicators.

\subsection{Factor analysis methodology}

The sequence of performing factor analysis includes the following stages:

1. Selection of factors that determine the performance indicators under study and their systematization in order to ensure the capabilities of the system approach;

2. The establishment of modeling and transformation of the factor systems

3. Calculation of the influence of factors and assessment of the role of each of them in changing the value of the resultant indicator;

An important methodological issue in factor analysis is the determination of the relationship between factors and performance indicators: functional or stochastic, forward or backward, straight or curved. Here, theoretical and practical experience as well as methods of comparison of parallel and dynamic series is used in conjunction with analytical groups of initial information, graphic and others.

The modeling of economic indicators (deterministic and stochastic) is also a complex methodological problem in factor analysis, the solution of which requires special knowledge and practical skills in this branch. 
The most important methodological aspect in economic analysis EA, is the calculation of the influence of factors on the value of effective indicators, for which the analysis uses a set of methods, the essence, name, scope of which and the procedure of calculation are considered in the following chapters.

Finally, the last stage of the factor analysis is the practical use of the factor model for calculation of reserves for the growth of the resultant index, for planning and forecasting its value in case of changes in the production situation.

\subsection{Economic optimization of the airline's lifecycle}

An increase in resource (durability), which is an integral part of reliability, accordingly, leads to an increase in the latter. Increasing reliability, as well as increasing resources (reliability component), requires a significant amount of work, significant cost and time. The past decades of aviation Gas Turbine Engines (GTEs) development have been marked by a continuous growth of resources: from several hundreds of hours to tens of thousands of hours.

When the engine resources did not exceed 1000 hours, there were no doubts about the economic expediency of their increase due to at least two circumstances: high expenses of the operating organizations and relatively small expenses for the works connected with the increase of resources (Figures 3 and 4).

A different situation occurs when justifying large resource values ( $>20,000$ hours). On the one hand, the operating costs are already significantly reduced (operating costs per hour of motor operation), and with small operating costs, further reduction of the operating costs brings ever less economic benefit.

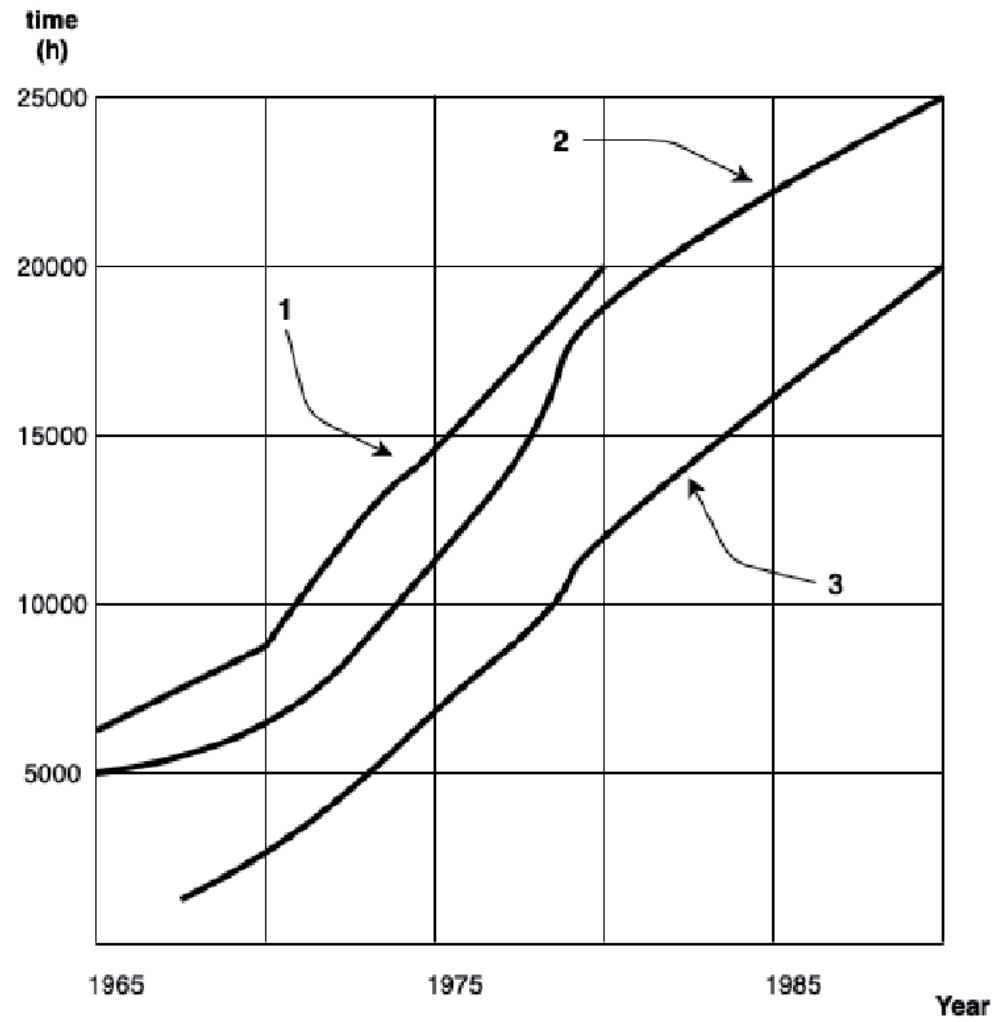

Figure 3 .

Growth of resources of engines AI-20 (1), AI-24 (2), AI-25 (3) on years of operation. 


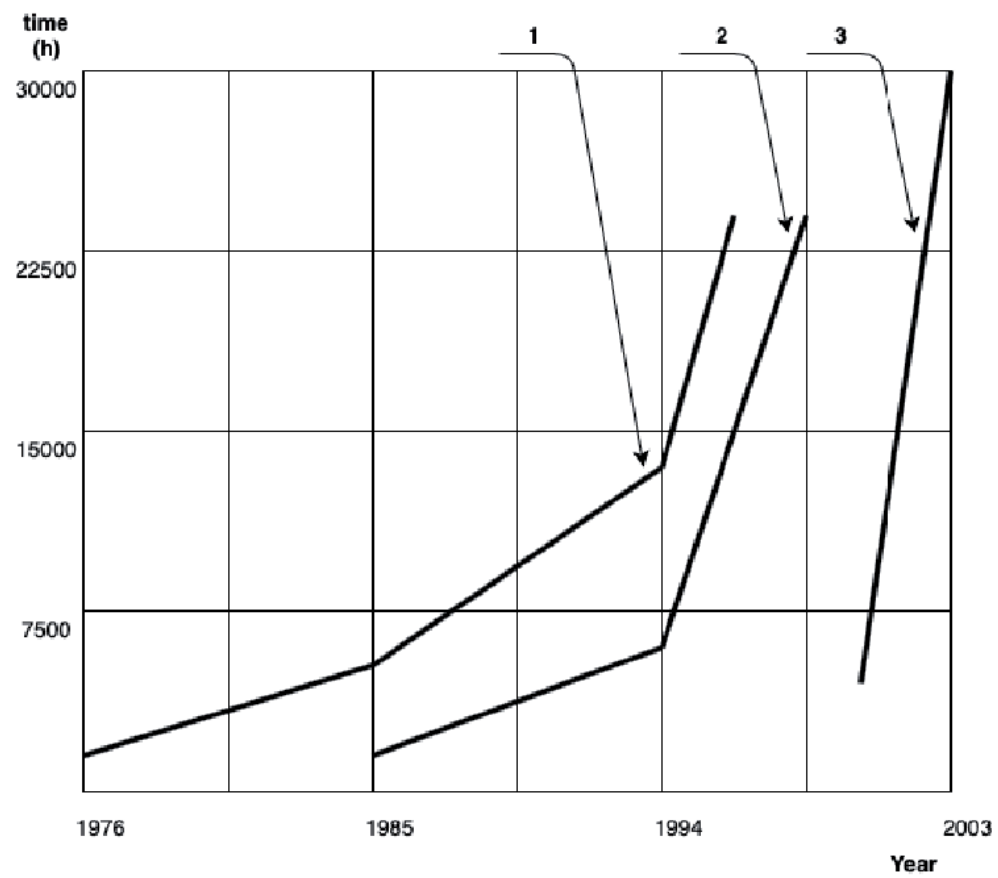

Figure 4.

Growth of resources of engines with a large degree of dual circuit D-36 (1), D-18T (2), D436T1 (3).

In addition, in accordance with the law of the dwindling limit value, the operating costs may increase starting from a certain service life.

On the other hand, an ever-increasing amount of effort is required to increase resources.

There is an economically optimal resource value, at which the total cost of increasing the resource is the lowest (TOP 1).

The introduction of electronic engine designers, the use of numerical methods and high-level models, application software packages (e.g. ANSYS), combined with the accumulated experience in the creation of aircraft GTEs and the high qualifications of engineering staff have allowed the development and successful application of calculation methods for resource determination.

It has given the chance to lower expenses essentially and to reduce calendar terms of an establishment of resources. At the same time, the importance of an economically optimal resource to the right has shifted significantly [7] (Figure 5).

For different engines, and even for the same engine installed on different aircraft, there will be different values of optimal service life, as operating costs may vary depending on the engine type, aircraft type, operating company, etc.

The engine resource can be very large; however, it will be far from economic optimum. The indicator of optimum resource can serve as total value of expenses for 1 hour of established resource.

Deviation of a resource of the engine from economic optimum can be connected with special requirements to the engine, overlapping at designing. In this case, the efficiency of the design solutions used may "prove to be as efficient as possible under imposed constraints."

The desire to establish an economically optimal resource was one of the reasons why the notion of resource design appeared. 


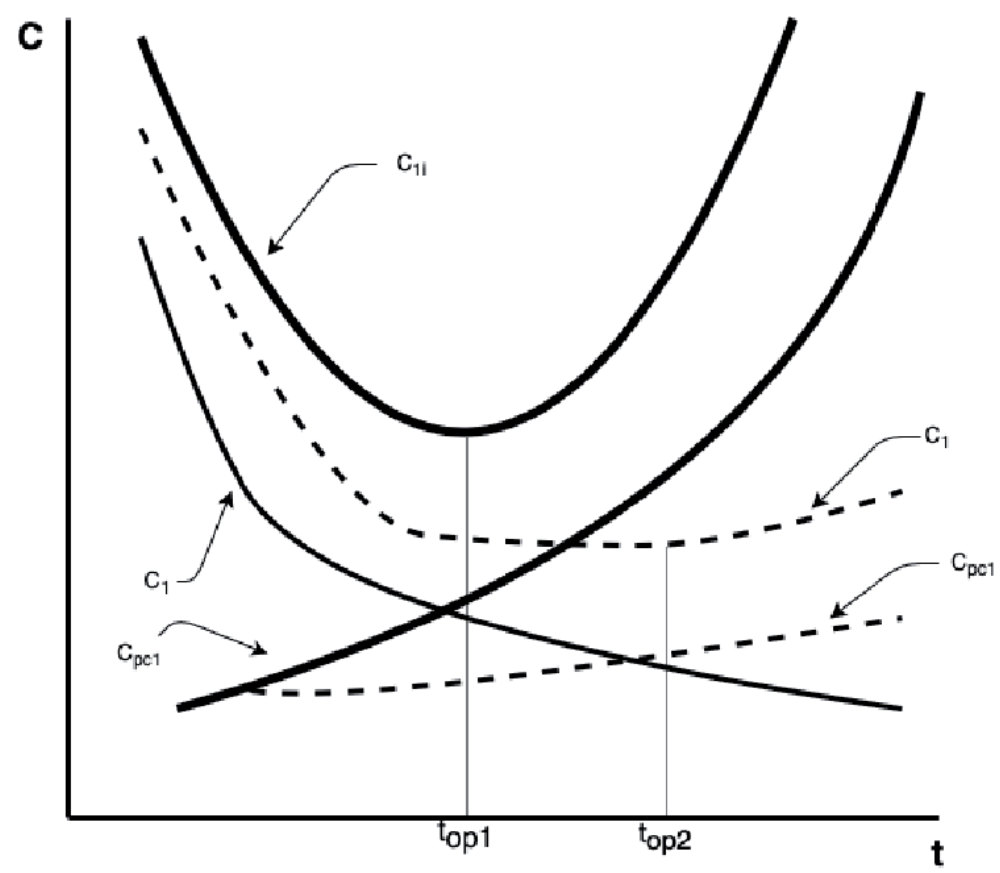

Figure 5.

Dependence of change in costs on the value of the engine resource.

Under resource designing of aviation GTEs, it is necessary to understand the durability details at a design stage of the engine. The full account of operating conditions is provided and optimization of a level of working parameters, indicators of effect and value of resource is made.

The development of technical (indiscriminate) diagnostics, modularity of design, content usability of engines and accumulated experience of operation allowed to carry-out the operation of aviation GTEs on technical condition. The economic effect from the exploitation according to the technical condition is very high:

- The number of spare parts is reduced by $20 \%$;

- The number of spare engines is reduced by half;

- The cost of maintenance and repairs is reduced by approx. $25 \%$.

The almost universal transition to maintenance-free operation, with the replacement of individual modules without removing the engines from the wing, has led to a review of the engine life as a whole.

For a complex, multi-component system, the concept of engine life becomes conditional. The economic purpose of engine reconditioning during repairs and the cost per hour of a life cycle are of paramount importance. The economic viability of engine reconditioning depends on the cost of repair and the cost of replacing parts that limit the life cycle (Table 4).

Using the data in Table 4, it is possible to determine repair costs per hour for a CFM56-3 engine with a thrust of 23,500 pounds $(10,657 \mathrm{kG})$ using Eq. (1):

$$
\mathrm{C}_{e p}=\frac{\mathrm{C}_{p}+\mathrm{C}_{d}}{N_{\Sigma} t_{z}}
$$


where $\mathrm{C}_{p}$ is the cost of repairs; $\mathrm{C}_{d}$ is the cost of replacing parts; $N_{\Sigma}-$ number of flight cycles worked out; $t_{z}$ - flight cycle time, hour.

Adding all the costs in columns 4 and 5 of Table 4, dividing by the number of flight cycles ( 28,000 cycles) and duration of flight (1.4 hours), yields $\$ 125.64$. Adding to cost of a new engine, attributed to 1 hour of operation, and the cost of fuel consumption for 1 hour of engine operation, results in the cost of 1 hour of the life cycle of the CFM56-3 engine (Eq. (2)).

$$
\mathrm{C}_{h o u r}=\frac{\mathrm{C}_{d v}+\mathrm{C}_{d}+\mathrm{C}_{p}}{t_{\mu} N_{\Sigma}}+\mathrm{C}_{u d} R \mathrm{C}_{m}
$$

where $\mathrm{C}_{d v}$ is the new engine price; $\mathrm{C}_{u d}$ is the specific fuel consumption, $\mathrm{C}_{m}$ - price of $1 \mathrm{~kg}$ of fuel; $\mathrm{R}$ is the engine thrust.

For each engine, there is an optimum operating time on the wing (before repair). For example, for the PW4000 engine, the optimum wing life is 3500-4500 flight cycles.

This is due to the ability to repair and rebuild the structure and properties of the fuel blades. Longer engine stay on the wing leads to a high degree of utilization of the blades. Therefore, it is very important to keep exact account of engine details operating time in hours and flight cycles. An error in the operating time can lead to a substantial increase in the cost of repairs.

Powder metallurgy, laser and micro-plasma welding methods are used in blade repairs. The limitations of the repair are related to cracks and thinning of the blade walls.

Modifying the structure and properties of the blade, allows the same blades to be used for a longer period of time in the engine. This results in significant cost savings. Based on performed research and the associated data, the recovery and repair of 30,000 work blades can bring savings of up to $\$ 80,000$.

Resource of details is expedient to provide at designing so that replacement of basic details in operation was possible less. It is necessary to plan replacement of details (not concerning the basic), limiting a resource, by a combination of replacement with repair of engines (visit of workshop).

In order to avoid forced removal of the engine from the wing due to the end of the service life of the main parts, most airlines operating GTE maintain a "service life balance" policy (minimum life of parts). The essence of the case is that the majority of parts that limit the life produce their life span in the range of 1500-3000 flight cycles from their limit life.

For example, the front rotor shaft of a CF6-50 engine has a limit of 11,500 flight cycles but is likely to be disposed of after $(9500-10,000)$ flight cycles (Table 5).

\begin{tabular}{lcccc}
\hline $\begin{array}{l}\text { Rental } \\
\text { no }\end{array}$ & $\begin{array}{c}\text { Working hours before } \\
\text { renting, hour }\end{array}$ & $\begin{array}{c}\text { Total } \\
\text { earnings, hour }\end{array}$ & $\begin{array}{c}\text { The cost of } \\
\text { repair, } \mathbf{~}\end{array}$ & $\begin{array}{c}\text { Cost of parts to be } \\
\text { replaced, } \mathbf{~}\end{array}$ \\
\hline 1 & 8500 & 8500 & 800.000 & - \\
\hline 2 & 6500 & 15.000 & 900.000 & 650.000 \\
\hline 3 & 6500 & 21.500 & 950.000 & 410.000 \\
\hline 4 & 6500 & 28.000 & 950.000 & 265.000 \\
\hline
\end{tabular}

Table 4.

Costs of scheduled maintenance of the CFM56-3 engine with 23,500 lb thrust. 


\begin{tabular}{cccc}
\hline & Engine & Cost of main parts, million \$ & Unused resource remnants, cycle \\
\hline 1 & JT9D & 2.1 & 2000 \\
\hline 2 & PW4000 & 2.44 & $2000-3300$ \\
\hline 3 & CF6-50 & 2.1 & $1400-2500$ \\
\hline 4 & CF6-80C2 & $2, .7$ & $2000-2500$ \\
\hline
\end{tabular}

Table 5 .

Costs and unused balances of resources of the main details of aero engines.

In this case, the cost of 1 hour of the engine's life cycle is reduced, which increases the competitiveness of the engine.

In addition to the planned reasons for removal (exhaustion of the reserve in terms of the temperature of exhaust gases, increase in the reserves of stability of the ATC, exhaustion of the service life of parts that limit the resource, etc.), a significant share is occupied by unplanned ones.

Unscheduled engine removals can make big corrections to the repair and replacement schemes of the parts that limit the service life. The number of unscheduled engine removals can be $50 \%$ of the total number of removals. For example, for the PW4000 family engines, unscheduled removals account for 35-45\% of all removals. For CF6-50 engines the reason for $25 \%$ of removals is exhaust gas temperature exhaustion, other $25 \%$ of removals are caused by the necessity to replace the main parts, which have reached their end-of-life, and another $50 \%$ of removals are unplanned removals [8]. In order to increase the economic efficiency of aviation GTEs operation it is necessary:

- To install the engine parts with minimum expenses;

- To ensure optimal stay of the engine on the wing of the aircraft in a single operation;

- Ensure the timely replacement of parts that limit the engine's life (avoid early removal of the engine due to lack of service life of the main parts or exhaustion of gas reserves);

- Accurately determine the current damageability of parts in hours and cycles depending on the operating conditions (automated hours and cycles);

- Quickly determine the scope of work and necessary parts replacement during unscheduled engine stripping;

- Taking into account unplanned surveys to correct the scope of work for subsequent engine reconditioning, and remain the engine on the wing, etc.

It is most convenient to perform the above-mentioned works using ground automated systems of engine operation monitoring. One of the essential elements of such systems is the algorithms of calculating the developed resource.

The conducted analysis of aviation GTE resources allows drawing the following conclusions:

1. There is an economically optimal engine resource for the given operation conditions. 
2. Economically optimal engine life can change significantly with changes in the cost of life.

3. To improve the economics of engine operation, ground-based automated engine performance monitoring systems should be used.

\section{Conclusions}

This chapter is the result of the study of a number of special disciplines, such as risk analysis and economic analysis of commercial aero engines during aircraft operation. Risk analysis includes risk assessment and methods to reduce risks or reduce adverse effects associated with it. The methods for risk analysis have been provided, including ETA, FMEA, FTA, HAZOP and PHA.

Furthermore, Economical analysis is a scientific way of understanding the essence of economic phenomena and processes, based on dividing them into its constituent parts and studying the variety of relationships and dependencies aimed at improving its work through the development and implementation of optimal solutions. The purpose of the economic analysis is to give management a picture of the actual state, and for persons who are not directly working with it, but are interested in its financial condition, the information necessary for an impartial judgment.

Aviation engineering as a commodity has its specificity. If one considers an aircraft as a whole, the aircraft operation efficiency is defined by perfection of the power plant. The engine may appear on the market as an independent product with a market price. But it must be taken into account that the aircraft engine is a subsystem of the aircraft, so its economic assessment should be carried out, if possible, taking into account the characteristics of the aircraft and its specifics of operation, which is a difficult task. Still, this is a necessary procedure, especially in the case of economic evaluation.

\section{Author details}

Sherkhan Aitugan* and Longbiao Li

Nanjing University of Aeronautics and Astronautics, Nanjing, China

*Address all correspondence to: sherkhan.aitugan@gmail.com

IntechOpen

(C) 2020 The Author(s). Licensee IntechOpen. Distributed under the terms of the Creative Commons Attribution - NonCommercial 4.0 License (https://creativecommons.org/ licenses/by-nc/4.0/), which permits use, distribution and reproduction for non-commercial purposes, provided the original is properly cited. (cc) BY-NC 


\section{References}

[1] Jardine AKS, Anderson PM, Mann DS. Application of the Weibull proportional hazards model to aircraft and marine engine failure data.

Quality and Reliability Engineering

International. 1987;3(2):77-82

[2] Berens AP, Hovey PW, Skinn DA.

Risk Analysis for Aging Aircraft Fleets.

U.S. Air Force Wright Laboratory

Report, WL-TR-91-3066, Vol. 1; 1991

[3] Cioclov DD. A model for fracture risk analysis. Revue Roumaine des Sciences Techniques. 1986;31(6):613-622

[4] Bigun ES. Risk analysis of catastrophens using experts' judgements: An empirical study on risk analysis of major civil aircraft accidents in Europe. European Journal of Operational Research. 1995;87(3):599-612

[5] Violette MG, Safarian P, Han N. Transport airplane risk analysis. Journal of Aircraft. 2015;52(2):395-402

[6] Cruse TA, Mahadevan S, Tryon RG. Fatigue reliability of gas turbine engine structures. NASA Report, No. NASA/ CR-97-206215

[7] Butushin SV, Nikonov VV, Fejgenbaum Yu M, Shapkin VS. Obespechenie letnoy godnosti vozdushnyh sudov grazhdanskoy aviacii po usloviyam prochnosti. Collection of scientific papers of the 4th International scientifictechnical conference "Modern scientifictechnical transport problems” M., MGTU GA; 2013. p. 772

[8] Itskovich AA, Fainburg IA.

Pokazateli effektivnosti processov podderzhaniya letnoy godnosti vozdushnyh sudov [indicators of the efficiency of process of maintenance of the aircraft air- worthiness] . Scientific Bulletin of the Moscow State Technical University of Civil Aviation. 2012;178:21-26 


\title{
Safety and Risk Assessment of Civil Aircraft during Operation
}

\author{
Asif Mostafa
}

\begin{abstract}
Risk and safety are always considered to be the most critical operational characteristics of civil aircraft. Typically, they relate to the possible occurrence of air traffic collisions that could result in loss of life, damage to infrastructure, and damage to property by third parties. Consequently, in addition to other adverse effects such as noise, air pollution, they were deemed externalities. Risk and protection became topics of continuous study, ranging from purely technical/technological aspects to explicitly administrative ones, due to their inherent very high importance. Such concerns require the establishment of appropriate regulations regarding designs and operations of device technology. In order assess the risk, there are several methods which include: identification of safety concerns, analysis of the risk factors likelihood, analysis of the risk factors severity, and assessment and the admissibility of risk factors. And finally, reducing of the risk should be performed by three general strategies which are: avoidance of the risk, reduction of risk, and isolation of the exposure. These strategies are implemented based on efficiency, technical measures, controlled measures, staffing measures, cost/benefit, practicality, acceptability of each party, durability, residual risk factor for flights safety, and new challenges. With the advancement of technology, new methods of risk deduction and safety concerns are being developed to ensure safe and risk-free flight operation.
\end{abstract}

Keywords: civil aircraft, risk assessment, safety assessment, risk and safety methods, operation

\section{Introduction}

The rapid worldwide growth in air traffic and aircraft technology requires a rapidly changing and adaptable aviation environment in which borders are hardly restricted single countries. Along with this ongoing change, safe aviation operations are crucial. Absolute safety does not exist. However, eliminating accidents and serious incidents is unachievable. Failures always occur, despite the most accomplished safety efforts, since all risks cannot be totally eliminated. No human-made system/innovation can be risk free. However, risk and error are acceptable in an inherently safe system. So, how to ensure that aircraft operations are safe if all risks cannot be eradicated? What is safety? What is risk? Safety is the condition in which the danger of harm to persons or property damage is minimized to and retained at or below an appropriate level by an ongoing process of hazard detection and risk management. In civil aviation, risk has been assessed as the probability of the 
occurrence of an air accident in terms of two aggregate indicators, the accident rate and the fatality rate. Thus, if new operations are to be undertaken, equipment is required to ensure that an acceptable level of safety is guaranteed and the upcoming risks are taken into consideration [1].

Safety and risk assessment are the two fundamental terms utilized in avionics to address the degree of safety of aircraft tasks [2]. The reason for this assessment is to distinguish the degree of safety related with a particular activity/activity by recognizing the normal risk(s) by giving direction in dynamic jobs to either acknowledge or not acknowledge the risk(s) to which the activity is required to be uncovered. Through this assessment, in light of a predecided adequate degree of risk, moderation procedures/remedial activities can and ought to be actualized dependent on explicit safety risks so as to decrease their potential impact(s). The phrasing of safety assessment and risk assessment has now converged into each other so that it has gotten hard to get whether they speak to two distinct techniques. In the event that it is unmistakable, in which circumstances we should utilize every one of them; or in the event that they supplement one another and the presentation of one command includes the accomplishment of the other. By the by, given these complexities, it is usually perceived that their definitive target is basic decide when and where estimates should be taken to guarantee the normal proper safety level.

\section{Safety and risk concept in civil aviation}

Aviation regulators and industry experts have continually developed and updated strategies and resources over the years for the evaluation of ongoing developments in the aviation industry in order to ensure appropriate standards of safety while enhancing flight operating capabilities, increasing the utilization of airspace, and reducing operational costs.

The concept of aviation safety and risk can have different perceptions: zero deaths or serious incidents, free from hazards, aviation employee attitudes toward unsafe acts and conditions, avoidance of error, and regulatory conformity.

Safety is defined as the "State where the potential for harm to persons or property damage is minimized to and preserved at or below an appropriate level by an ongoing process of hazard recognition and safety risk management. For technological systems, risk is related to the possibility of part failure or the whole system causing hazard exposure and related consequences. In economic structures, risk may be exposed to the threat of losing market prospects and/or resources due to unpredictable circumstances. In social systems, risk is the chance of being exposed to injury hazard and/or life loss. Therefore, risk could be viewed as a combination of the probability (or frequency of occurrence) and the magnitude (or severity) of a hazardous event."

When new equipment is developed, or for instance a new flight operational procedure is designed, the requirement for a safety assessment or risk assessment is very common in the aviation industry before the new technology or procedure is put into place. Very often, this is triggered by the operator/manufacturer through recommendations made by aviation associations/working groups or regulatory requirements.. An assessment usually includes an overall evaluation of something called a framework that may include a thorough review of particular subsystems. The assessment aims to identify the level of safety associated with a certain action/ operation by identifying the expected risk(s) through guidance on the decisionmaking roles to either accept or not accept the risk(s) to which the operation will be exposed. This assessment, based on a predetermined acceptable level of risk, can 
Safety and Risk Assessment of Civil Aircraft during Operation

DOI: http://dx.doi.org/10.5772/intechopen.93326

\begin{tabular}{|c|c|}
\hline Definitions term & Meaning \\
\hline Consequence & $\begin{array}{l}\text { An event's performance. A consequence may be definite or uncertain with } \\
\text { positive or negative effects on goals }\end{array}$ \\
\hline $\begin{array}{l}\text { Control (also can be } \\
\text { called mitigation) }\end{array}$ & Risk-modifying measure \\
\hline Establishing the context & $\begin{array}{l}\text { Defining external and internal requirements for risk management and } \\
\text { defining the scope and risk standards for risk management policy }\end{array}$ \\
\hline Event & $\begin{array}{l}\text { Defining the external and internal parameters to be taken into account } \\
\text { when managing risk and setting the scope and risk criteria for the risk } \\
\text { management policy }\end{array}$ \\
\hline Level of risk & $\begin{array}{l}\text { Risk magnitude or mixture of risks expressed in terms of balancing } \\
\text { consequences and probability }\end{array}$ \\
\hline Likelihood & Chance of something happening \\
\hline Monitoring & $\begin{array}{l}\text { Repetitive screening, tracking, vital observation, or status determination to } \\
\text { identify deviations from the necessary or planned output }\end{array}$ \\
\hline Residual risk & Remaining risk after therapy \\
\hline Risk & $\begin{array}{l}\text { The impact of uncertainty on events' potential goals and their } \\
\text { consequences, or a combination thereof }\end{array}$ \\
\hline Risk analysis & System to grasp risk nature and assess risk level \\
\hline Risk assessment & $\begin{array}{l}\text { In this context, the overall process of risk identification, risk analysis, risk } \\
\text { evaluation, and identification of controls (mitigation) }\end{array}$ \\
\hline Risk criteria & Reference terms against which risk significance was evaluated \\
\hline Risk identification & Process of finding, recognizing, and describing risks \\
\hline Risk management & Coordinated efforts to guide and monitor risk-related tasks \\
\hline Risk management plan & $\begin{array}{l}\text { The scheme within the department's risk management system defining the } \\
\text { strategy, management elements, and tools to contribute to risk } \\
\text { management }\end{array}$ \\
\hline Risk management process & $\begin{array}{l}\text { Systematic application of management policies, procedures, and practices } \\
\text { to communicating, consulting, and context-setting, identifying, analyzing, } \\
\text { evaluating, monitoring, and risk review activities }\end{array}$ \\
\hline Risk owner & Person or entity with the accountability and authority to manager risk \\
\hline Risk profile & Description of any set of risks. \\
\hline Risk source & $\begin{array}{l}\text { Element, which alone or in combination, has the intrinsic potential to give } \\
\text { rise to risk }\end{array}$ \\
\hline
\end{tabular}

Table 1.

Definition of aviation safety and risk terms.

and should implement mitigation strategies and corrective actions based on specific safety risks to reduce the potential effects of mitigation. Safety and risk assessments are the terms most commonly used for this assessment. Table 1 gives the definite of aviation safety and risk terms.

\subsection{Safety assessment}

A safety assessment mainly aims to identify which risks are expected to be exposed to a new operation/system or to be acceptable or not on the basis of the safety criteria normally established by aviation regulators. 


\subsubsection{Safety assessment process}

The ongoing safety assessment process continues the initiative that has begun during the design phase and ends with the launch of the new model of aircraft and continues until the aircraft is removed from service.

Three priorities are set in the ongoing safety assessment process: 1. Maintain airworthiness (certification) of the aircraft: in-service incidents are evaluated based on the safety standard of the certification process. 2. Maintain aircraft safety: inservice incidents are measured against the company's internal health objectives. 3 . Improve airplane safety: in-service incidents are analyzed to find potential for minimizing their number or exceeding the company's protection objectives. It is intended that the safety assessment process will be continuous, iterative, and closed. When an incident is identified, assessed, and actions are taken, the surveillance continues to validate the action's effectiveness. The safety of the aircraft depends on a variety of factors, including original design, development, aircraft crew and maintenance behavior, operational effects, parts quality, modifications, the atmosphere, and aging of the aircraft. The safety assessment consists of five steps: 1 . Establish Monitor Parameters, 2. Monitor for Events, 3. Assess Event and Risk, 4. Develop Action Plan, and 5. Disposition Action Plan. Figure 1 shows the steps involved.

"Establish Monitor Parameters" begins by identifying the company's basic safety framework, priorities, and objectives. This process also sets out the parameters for monitoring and their values.

"Monitor for Events" is a continuous process of searching for events of concern. This monitoring is based on the monitoring parameters set in the previous step.

"Assess Event and Risk" is a process that is initiated when an event is detected. This includes the assessment of an event that is sufficient to determine whether the event is of real concern. It also includes the preliminary determination of risk for use in prioritizing the initial extended evaluation and the development of the Action Plan. A more detailed and comprehensive risk assessment may be carried out on the basis of the seriousness of the event and the initial risk assessment.

"Develop Action Plan" is a process that provides for correction or improvement, such as a change in design or a change in operation, maintenance, or training procedures for the event identified. An action plan may not be needed if the event is determined to be sufficiently initiated.

"Disposition Action Plan" means the evaluation and/or implementation of the Action Plan. This may include determining whether or not the action will be taken and prioritizing, scheduling, and implementing the action. Once the action is completed or the determination is made not to implement the action, the process returns to the normal status of event monitoring. In some cases, revision or updating of the monitor parameters may occur as a result of an event or action taken.

Now let us begin an in depth research on the safety assessment process. Figure 2 shows an in detail the flowchart of the ongoing safety assessment process.

Establish Monitor Parameters: The "Establish Monitor Parameters" phase shown in Figure 1 is divided into "Establish Expectations" and "Establish Monitor Parameters" activities.

Establish Expectations: There are two simple "Establish Expectations" steps. The first is establishing organizational frameworks and principles before beginning this process. This will involve defining the organization's safety goals and guidelines. The second establishes operating requirements for each fleet. This activity involves determining what day-to-day operating expectations are and what types of operations and performance will or will not be accepted within the fleet. 


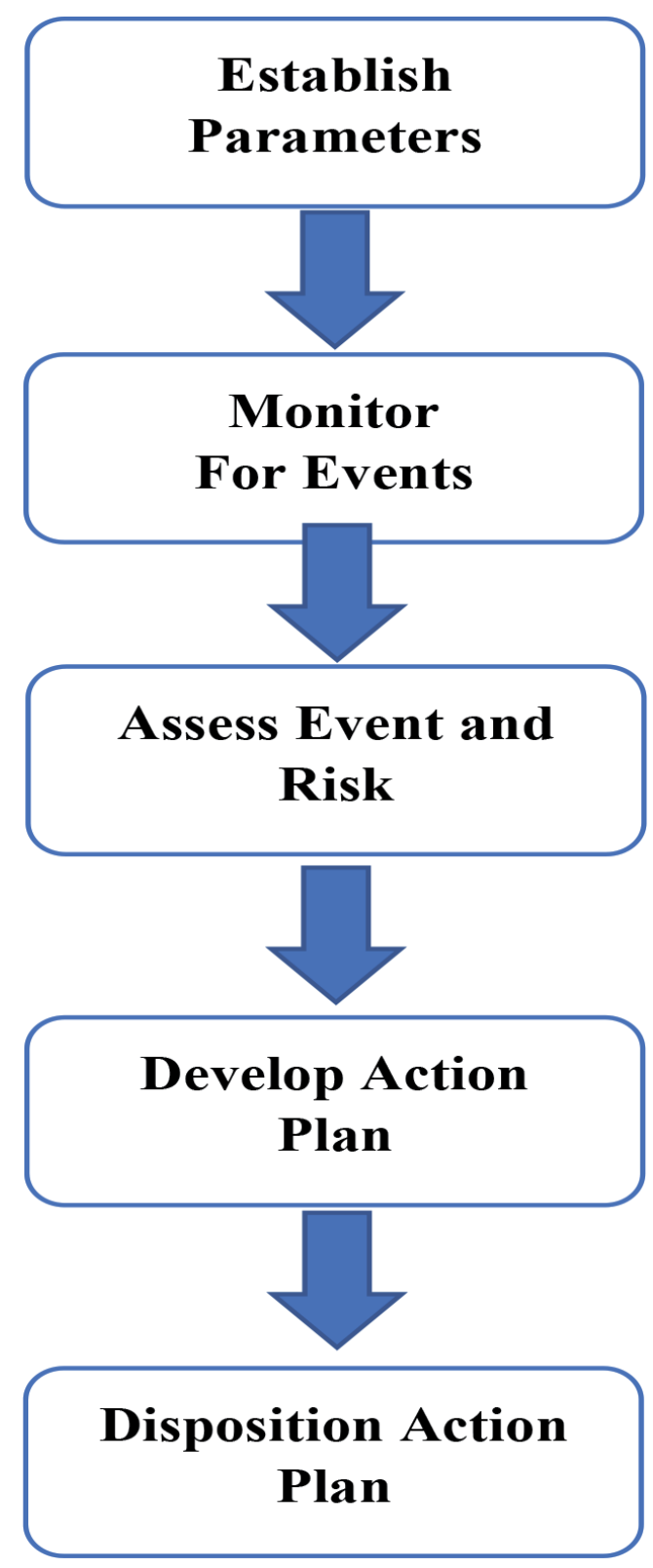

Figure 1.

Safety assessment steps.

"Establish Expectations" includes establishing the company's safety philosophy, assessing the role of safety within the company's structure, and defining acceptable levels of risk and performance. It may vary from a structured formal security organization to an informal structure. The safety organization must be adequately autonomous to ensure it can affect the safety philosophy.

There are at least two expectations levels. The first is standards levied by regulatory body, aimed at establishing minimum operational health. The second is the user's own standards, which can surpass regulatory agency requirements. These expectations imposed internally may include parameters or requirements not covered by regulations or lower-than-required risk levels. Requirements and expectations can be dependent on many factors, including the following: 
1. Basic aircraft requirements

2. Safety analysis

3. Requirements for regulatory reporting

4. Operational features (e.g., cargo vs. passenger carriers)

5. Aircraft maintenance programs

6. Operating environment conditions (e.g., operations, tropical vs. arctic operations)

7. Experiences identified by earlier process use (i.e., continuous improvement)

8. Industry-related accidents and incidents (where available)

\section{Lessons learned}

Fleet-specific expectations are passed on to the phase of the process "Establish Monitor Parameters."

Establish Monitor Parameters: Phase "Establish Monitor Parameters" builds on previously set expectations. This step develops the information or data to be collected, how it will be collected, and how it will be compared to expectations. This can range from minor reportable compliance issues to comprehensive data collection and review programs. The actual parameters to be chosen are the company's option depending on the level of ongoing safety assessment process that management wants. Selecting different parameters will be affected, among others, by data availability. Communication between organizations is helpful in setting correct parameters.

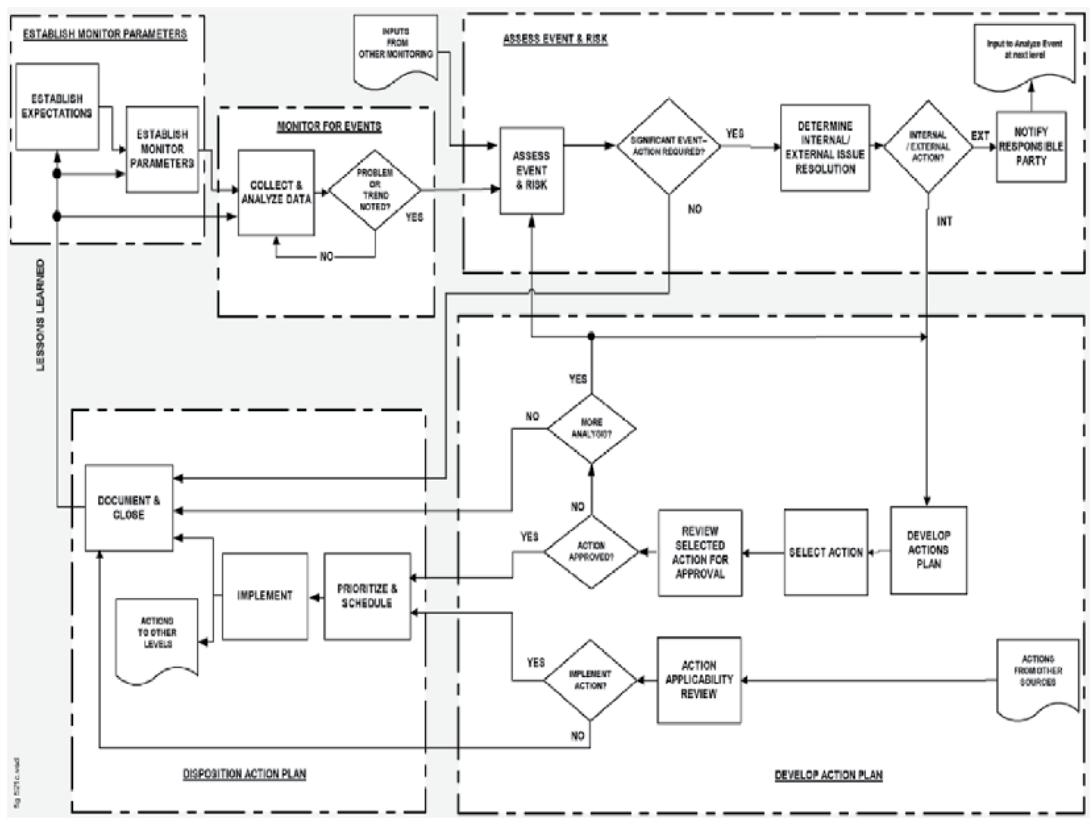

Figure 2.

Safety assessment process. 
Monitoring Effectiveness of Previous Actions: After developing the initial maintenance plan for a given aircraft, the operator continues to monitor the program's effectiveness for the desired reason of keeping the aircraft secure. The following are one of several ways to achieve this.

Once actions are undertaken to address a problem, a follow-up testing process should be developed to track implementation and assess action effectiveness. This follow-up method can be achieved by comparing pre- and post-conditions of correction-affected systems. Comparison frequency should be based on probability and severity factors. During this post-implementation review, initial findings (e.g., teardown reports) may be reexamined. This verifies the action implemented eliminates the problem, and the assumptions used in the analysis are valid.

After the expectations and monitoring parameters are defined, they are then used during the "Monitor for Events" phase.

Monitor for Events: This phase consists primarily of the "Collect and Analyze Data” process. An event may be of interest by itself, for example, engine shutdown, or it may only be of interest in conjunction with other events that may or may not have occurred concurrently, for example, one navigation receiver failure. An event may be an operation or maintenance error. An event may or may not be relevant to aircraft safety. (An event may be a single incident or set or compilation of separate and distinct occurrences considered as a single event for discussion and analysis convenience).

Event monitoring includes two related but distinct elements. Collect and analyze data concerned with "new" events of concern and monitoring the effectiveness of previous actions that monitor events already evaluated through the process.

Collect and Analyze Data: The aim of the "Collect and Analyze Data" phase is to provide continuous monitoring of actual operations to determine expectations. In this step, data available for monitoring any parameters specified in the step "Establish Monitor Parameters" should be obtained and analyzed. While collecting and analyzing this data, possible problems and patterns will be established. Compared to the potential cost of lost assets and equipment, data collection and analysis is relatively low.

Where no issue or pattern is identified, the process continues in the phase "Collect and Analyze Data." Whenever the analysis identifies a possible issue or trend, the data will be summarized for process phase "Asses and Event Risk."

Assess Event and Risk: Once a potential problem or trend has been identified, internal data collection and analysis or the "Assess Event and Risk" is initiated from an external source. This process develops a sufficient level of understanding of the event and its cause(s) to assess the possible consequences and the associated risk. If these are known, it can be determined if the incident needs further action. If the incident is determined not to warrant further action, the process shifts to "Register and Close." If an event warrants further action, the appropriate organization(s) should be determined. If the problem requires external action, the party responsible should be informed of such action in a reasonable time. If internal action is established, proceed to "Develop Action Plan."

The "Assess Event and Risk" phase shown in Figure 2 is divided in to "Assess Event and Risk, "Determine Internal or External Issue Resolution" and "Notify Responsible Party."

Assess Event and Risk Task: Event assessment and subsequent risk offers information identifying the severity of a particular safety concern. It also offers risk reduction and optimization of inspection and alteration services for in-service security-related issues. This assessment is conducted to determine whether an issue is a safety problem or to provide awareness of major risks. Risk assessments may be qualitative or quantitative and should involve assessing magnitude and likelihood of occurrence. 
Determine Internal/External Issue Resolution: If the company reporting the incident has the capacity and ability to take the action, it must follow the "Develop Action Plan" process. If not, exterior organization is determined.

Notify Responsible Party: Once the responsible organization is identified, they are contacted and start evaluation with the "Assess Event and Risk" step in their process. The investigation often continues, involving more than one organization. Consider an incident in the field, for example. Operator must assess the event and danger and can contact OEM. It is necessary to note that the processes between the originator and the organizations are now intertwined. The originator will want to organize and monitor the progress of the company toward timely action resolution. Communication skills involved between all organizations. Through the "Action Applicability Review" step, actions formulated by the external organization will reenter the originators safety assessment process.

Develop Action Plan: The phase proceeds with the responsible organization addressing the event in their respective "Develop Actions Plan," "Select Action," and "Review Selected Action for Approval" processes.

The "Develop Action Plan" phase involves more analysis on event triggers and the creation of one or even more potential actions. This will include future behavior of risk assessment. Developing actions for all problems simultaneously due to limited resources may not be practical. Hence, the company must assign priorities based on its internal issue tolerance and potential regulatory oversight. Both priorities require resource allocation first to concentrate on safety-critical items and later to identify and monitor operator-sensitive issues. When developing an action, understanding the root cause is important.

Select Action: "Select Action" consists of evaluating options and identifying those with acceptable safety levels. This stage typically includes providing organizational approval action(s). Typically, technical expert(s) presentations to a review board or management position should include a statement of the issue or concern, historical background, results and assumptions of risk analysis, actions already taken, and recommended future actions.

Review Selected Action for Approval: Based on technical expert reports, management or review board accepts or refuses the planned action. As a practical matter, the management of the organization would also consider the economic impacts of certain acts approved by the review board or management, and the implementation approach depends on the form of organization.

If the decision is to approve the proposed action(s), the process proceeds into the "Disposition Action Plan" phase and begins the "Prioritize and Schedule" and "Implement" steps. If the company does not accept the suggested action, they must decide how to proceed. If more research is necessary, then either the "Assess Event and Risk" step to reevaluate the significance of the recommended action or the "Develop Actions Plan" step to refine potential action may be returned. If the recommended action is not accepted and no further review is deemed appropriate, the process moves to "Register and Close" stage. The decision is then reported and sent for future reference.

Action Applicability Review: “Action Applicability Review” is conducted by the potentially affected entity to decide how an externally generated action impacts any aircraft in their fleet. Once external action has been produced to fix a problem found earlier by the reviewing entity, it will be closely reviewed by relevant technical experts to ensure that it is resolved. Any dissatisfaction with the proposed action should be expressed as soon as possible.

When it is the decision is to implement, the "Disposition Action Plan" phase and the "Prioritize and Schedule" and "Implement" steps begin. When the decision is not to enforce the action, the process shifts to "Document and Close." The decision is then documented and stored for future reference. 
Prioritize and Schedule: "Schedule" is unique to each organization, showing its specific processes and approval cycles. The combined effect of danger, likelihood of occurrence, risk exposure, and availability of parts and other tools help to assess priorities for action. During normal process execution, multiple possible issues can be assessed simultaneously. This usually results in prioritizing the order in which problems will be corrected.

The process includes determining relative priorities (e.g., risk reduction, cost, and implementation ease) of this and other actions and scheduling implementation. And once an implementing plan is developed and approved organizationally, implementation process is initiated.

Implementation: After identifying and checking the action plan to better address the issue or concern, it can be enforced in the fleet or organization. Issue remedies should be tracked to ensure success in reducing or removing the issue. The monitor performance requirements and data collection and assessment method should be established in the "Disposition Action Plan" phase and forwarded to the "Monitor for Events" part of the process. If this monitoring concludes the intervention is unsuccessful, the issue reenters the ongoing safety assessment process where further data collection and root cause analysis may be needed. The question is then readdressed via the usual safety evaluation process, leading to updated action plans and implementation.

Actions to Other Level: Where service bulletins, ADs or activities that may affect other organizations have been made, they should be forwarded for implementation consideration. Many manufacturers' contractual agreements with operators include monitoring for SB implementation, while others do not provide a closed-loop operation.

Document and Close: Usually, issues can be solved by releasing an official technical document from the company implementing the transition. Examples of documents that can be modified include the following:

\section{a. Flight Operations Manual}

b. Engineering Orders

c. Maintenance Alerts

d. Maintenance Manuals

e. Flight Operations Bulletins

For a manufacturer, the document issued may:

i. be focused toward the operator in the form of a Service Bulletin, Service Letter, All Operator Telex, Maintenance Tips, etc.

ii. be directed toward its own organization which may include new process instructions, production guidelines, new drawings, etc.

If the sequence of documents, procedures, and changes have been completed and monitoring indicates that the problem has been successfully solved, the company will then go back to a mode of tracking criteria and perhaps assess lessons learned from the resolution process.

If no action has been taken, the decision and the reasoning are maintained here. 
Lessons Learned: A Lessons Learned process seeks to use in-service experience to enhance all aspects of aircraft operations and design. Introducing a Lessons Learned process allows the systematic reuse of factual information in an efficient manner to improve performance characteristics, such as the following:

a. Safety, reliability, quality, and cost-effectiveness.

b. Product quality and business processes efficiency.

c. Amount and cost of product modifications.

d. Human/machine-interface compatibility.

e. User satisfaction needs.

The steps mentioned above are the detail explanation of what happens in a safety assessment process during civil aircraft operation. Now a detail explanation of what happens in risk assessment process will be mentioned below.

\subsection{Risk assessment}

Before assessing a risk, different procedures are to be performed to identify an event. Aircraft safety depends on various factors including the original design, flight crew, manufacturing and maintenance activities, operational results, parts quality, modifications, surroundings, and aircraft being old. Departmental aviation risk assessments will follow a standard model. The model identifies the task and context, risks and possibility, present and future mitigation approaches, and the resulting amount of risk. The evaluator considers all possible realistic risk controls, determines those that already exist, assesses the current level of risk, and then selects additional risk measures to reduce the level of risk to one that would usually be appropriate to the organization.

\subsubsection{Preliminary risk assessment}

Safety and risk assessment have merged into one another in such a way that it is impossible to explain both of them distinctively. There, in order to perform a preliminary risk assessment, we need the help of ongoing safety assessment. In this assessment, the primary focus is risk and the steps that are defined will be similar to safety assessment.

Figure 3 describes a suggested high-level method for ongoing safety assessment, part of the initial risk assessment phase. This standardized method involves five high-level steps:

A. Establishing Parameter: Defines the control criteria of a company's organizational structure, priorities, and goals.

B. Monitor for Events: Continuous process of searching for events of concern. In other words, it is the process of tracking events and failures.

C. Assess Event and Risk: The cycle begins when an event is detected. This method decides whether the incident is troubling or a minor failure. This involves initial risk-to-use determination in prioritizing initial extended assessment and implementation of action plan. However, it depends on the 


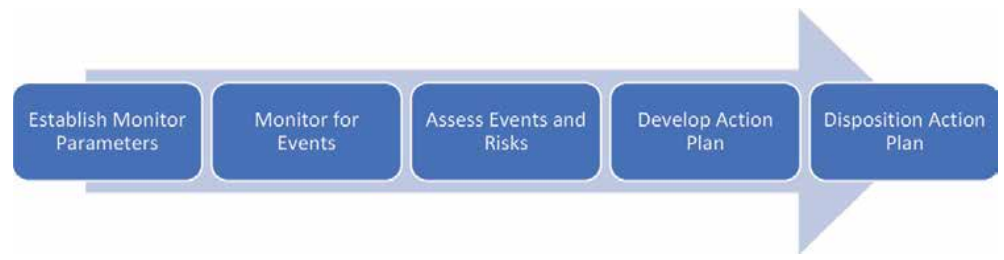

Figure 3.

Preliminary safety assessment.

situation's priority, and a more thorough and full risk assessment can be done in case of major issue.

D.Develop Action Plan: It is a process that sets out corrections or improvements, such as design changes or changes to operations, maintenance, or training procedures for identifying events. The action plan may not be needed if the event is defined not to be a threat.

E. Disposition Action Plan: Evaluating and/or implementing the action plan. This process decides whether to consider, select, and implement the action. Depending on the urgency of the situation, it means deciding whether or not the event will qualify as a threat and require further investigation. If the action is done or decided not to execute the action, the mechanism returns to the usual tracking status for incidents. In some cases, the monitor parameters may be revised or updated as a result of the event or action implemented.

Now let us begin an in depth research on the risk assessment process. Figure 4 shows an in-detail flowchart of the risk assessment process.

When its extent, triggers, and magnitude are identified and the event is detected, risk assessment will begin. As investigation progresses, the next phase is generally to determine the problem's likelihood. Risk assessment is conducted to identify the risk scale and determine if steps are required to manage it within separate boundaries. Risk assessment is not an end in itself but could control risks to a reasonable or bearable level. It is also the way of evaluating potential losses from a hazard using a combination of known circumstance information, knowledge of the primary process, and judgment of unknown or well-understood information. For understanding the risk management process, the definition used in the aviation

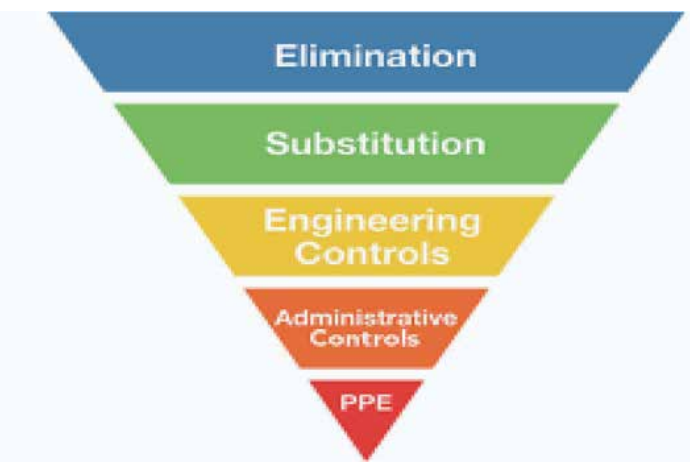

Figure 4 .

Risk management hierarchy. 
industry must be clearly understood. Table $\mathbf{1}$ describes such terminology used in aircraft industries.

A work profile and risk assessment is included in every aviation activity. Where a task can relate to a defined task profile and risk assessment, the task preparer will refer to the profile of the task and follow it. If a task profile and risk assessment is covered and no deviations are reported, the task may proceed without further permission, although the pilot and any crew member should provide continuous operational risk assessments during a flight. The corresponding risk evaluation must be reviewed if any job profile changes. Where the planning and task personnel determine that the proposed activity does not fit within a current task profile, a new task profile is created in coordination with the correct designated individual. Danger and regulation awareness is essential to departmental aviation management. Risk management does not end with a risk assessment but is a continuous process for all people who are interested in air use and security. Aviation operators will provide risk evaluation and reduction services. The aviation risk management system of the department follows a qualitative rather than quantitative approach, while historical data are suitable for determining the probability of an incident and provide some indication of the potential effects. The risk assessment process involves looking for hazards, assessing their implications, probability, and identifying risk mitigation plans. This technique is used to assist in developing aviation risk assessments.

Risk assessment is an important part of the processes for concentrating and profiling tasks. We are tightly related and should be twice reviewed to ensure that there are no irregularities or contradictions. Suitable aspects of a job profile can be used to determine the risk management context, and the creation of a role profile can be used for further consideration. Current or expected risk controls may be part of the history, but these must also be assessed in the risk assessment. Both people engaged in aviation services planning and administration must use this aviation risk assessment process during the training and organization. Models of accidents and accidents show the importance of managing risks at all rates. The risk evaluation and judgment development shall include individuals within organizations and the individual aircraft operator responsible for flight and mission actions. Danger is calculated in order to assess the total risk ranking. The Local Control Center can establish evaluated levels of low risk negligence as a general policy, low to high, for acceptance by the Policy Coordinating Center or government. Only the Director General or delegate and aircraft operator can approve extreme risks, therefore, controls must be implemented to reduce risk or the task is not performed.

The consequence is a loss or disadvantage incident demonstrated in qualitative instead of quantitative terms. As a result, the possible adverse effects of task-related incidents are evaluated in the sense of security, economic, organizational and public opinion is shown to the subcontractor and the agency. Selection of magnitude depends on risk parameters and design of risk. Subcontractor, aircraft, or equipment expert advice or background information can be used to determine an event's implications, including information on actual accidents, incidents, or events. For opportunity, probability or possibility the agency uses conceptual concepts. That is the measurement of the likelihood of an incident with a certain outcome, along with a total of the exposure to the incident during the mission. The exposure can be defined as the frequency of the event and the time of the incidence during the behavior.

Factors like crashworthy seats and PPE such as helmets and fire resistant clothes can handle the consequences. Likelihood may be classified according to planning, architecture, expectations or functions. The system of controls will also be considered when determining on controls for determining efficacy. The least efficient risk 
management tool (PPE) is at the bottom of the map displaying more controls available to reduce risk, preferably using a number of controls to make the risk mitigation more efficient. The findings should be checked in an evaluation and debate process to ensure that no additional risks and hazards have been identified or properly managed. Section 4 shows the hierarchy of risk control.

Figure 5 represents the process risk assessment cycle. This helps visualize the process although, while the process may seem complex, the actual way should be relatively simple. Using standard format should support the risk process. Standard format reproduces typical aviation considerations. These are included to center the total aviation task picture. Without normal aviation operations, no activity can be considered. The process shows how to treat risk assessment step by step and how to arrange it so that errors can be understood clearly but more importantly.

\subsubsection{Risk assessment process}

Figure 6 explains how the risk assessment process works and how interventions and activities are considered. The method requires skillful expertise and a detailed analysis to avoid making mistakes and prevent further risks.

a. Establish the context and gather data: To focus the analysis, avoid overdesign, and define roles and tasks, general idea of the security limit is required. Some initial components of a risk analysis should be security, scope of analysis, functional perimeter, operational use cases, perimeter of architecture, initial security countermeasures, edges environmental, and user-related assumptions, external needs and agreements. Use a graphical representation to gather border information, highlight functional interfaces, and communicate.

Establishing the task context allows consideration of risk reduction. For example, if the task is to be performed in summer, icing is unlikely to be a significant risk in low-level operations. However, if the task under

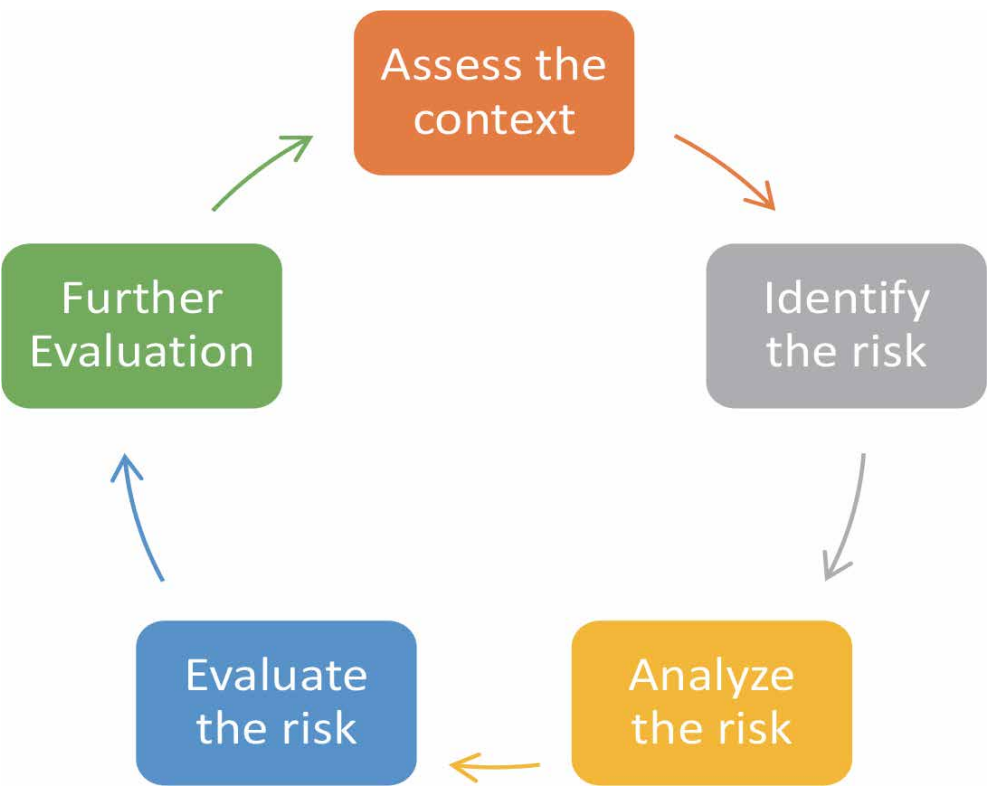

Figure 5.

Risk assessment cycle. 


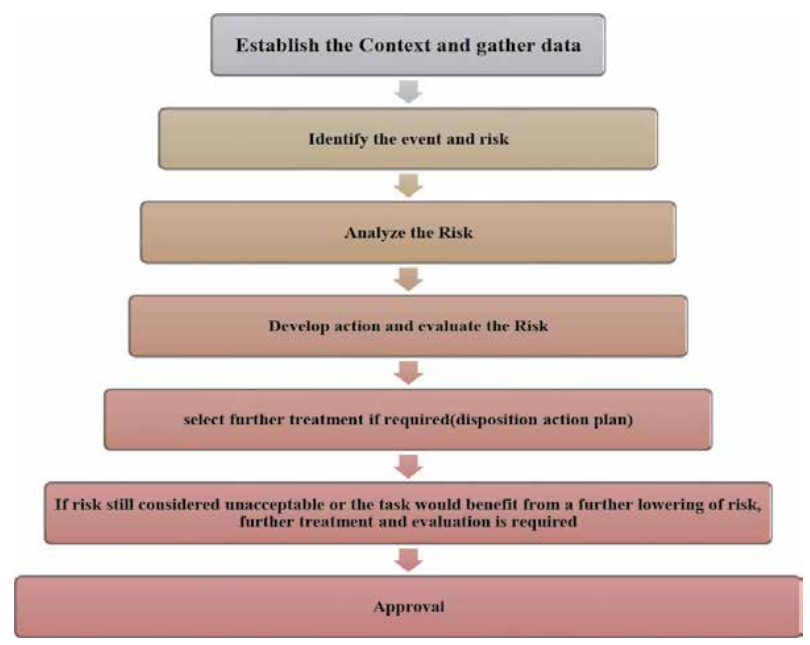

Figure 6.

Risk assessment process.

\begin{tabular}{lll}
\hline Level & Event assessment priority criteria \\
\hline Hazard level & Severity & How bad is the situation? \\
\hline Risk level & Severity + probability & $\begin{array}{l}\text { How bad are the situation and the possibility for it to } \\
\text { happen? }\end{array}$ \\
\hline Fleet risk level & $\begin{array}{l}\text { Severity + probability } \\
\text { + exposure }\end{array}$ & $\begin{array}{l}\text { How bad is the situation, the possibility for it to happen, and } \\
\text { what is the size and utilization of the affected fleet }\end{array}$ \\
\hline
\end{tabular}

Table 2.

Event assessment criteria.

consideration is performed throughout the year, icing becomes consideration in certain areas of the state. The assessor should establish both external and internal perspectives. The external background can be political, social, environmental, financial, and human. Internal context considerations may contain specific project objectives and their importance to the department that is the department's internal policies, standards, and guidelines. Department must identify risk factors including impact and probability measures.

b. Identify the event and risk: Table 2 shows how to assess an event risk. These are the three main classes demonstrating how to assess an incident when addressing crucial issues.

Risk sources, their impact zones, causes, and possible impacts need to be identified. The traditional format or template provides certain criteria, but in a particular way, the evaluator must look past the obvious while considering a new task or common task. For starters, spray operations typically occur far away from built-up or blocked areas. The spray area may be situated in a lowjet route from which military aircraft fly at a very low altitude. The risks of a mid-air crash can be high if the pilot does not search (Airmen Notice) to warn may routes and where are involved. Significant causes and effects should be taken into consideration. It should also be pointed out that the "race" in aviation starts at the scheduling and planning stage, so issues of fatigue and adequate access to information should be addressed, as well as the calculation 
of power margins and the availability of landing areas. Risk assessment factors may include modalities for failure, failure classification, distribution of probability and conditional probability, probability for inspection detection, operational/maintenance restrictions, and candidate actions.

c. Analyze the Risk: When a potential problem is detected, either as a result of an internal data collection and analysis or from an external source study, it is difficult to address all known situations. It is important to quantify their likelihood and safety impact, determine whether or not risks are acceptable, and measure the effort to prevent most likely and dangerous threats. For example, the qualitative possibility that an attack being successful provided the Typical ED-202 model with five probability levels: "highly improbable," "extremely remote," "very distant," "probable," and "frequent," and "risk analysis" involves developing comprehension that danger. The work covers risks and factors, positive and detrimental outcomes, as well as the possibility of consequences. In aviation, regulatory requirements require certain degrees or procedures to reduce risk, such as the registration of aircraft, but different levels of regulation concern various parts of the industry. Chapter 3 offers a number of methods for risk and safety assessment. The initial use of a risk assessment helps to understand the extent of a particular problem. The risk assessment should however be reviewed later on to help determine whether potential action plans are adequate. Considerations of both impact and likelihood may be based on historical data, but use of historic data should be reinforced by ensuring that they are relevant to the mission in question. Historical analysis will also involve consideration of existing NSW DPI controls in conjunction with controls present or probably existed in historical details. It is a call for judgment, but retrospective research is useful when searching for a realistic picture of the probability of the case. Ideally, consideration should be given without substantially reducing the circumstances. NSW DPI Aviation has a standard category definition. The Table 3 below shows the categories of consequences.

d. Develop Action and Evaluate the Risk: This is also part of the "risk analysis" which is understandable, defined and evaluated for likely performance. No calculation is commonly considered to be accurate. It is important to provide several safety therapies. If there is only one therapy at a specific risk, without reduction of risk, the therapy must be improperly handled. When assessing or implementing therapy to reduce a specific risk, it must be guaranteed that treatments themselves do not undermine or actually introduce a new risk to other therapies. For example, if a suspected therapy was performed only in the winter to minimize heat-related exhaustion, a new risk could be added for freezing or icing exposure.

Understanding the idea of implementing an action plan is important, because it helps explain the root cause of an issue. It can help identify frequently occurring failures, and with time these problems have led to more serious causes. When the resolution is recognized, it should be developed in detail, tested to verify and validate the action. Records should include the rationale and benefits of recommended actions.

e. Disposition Action Plan and Further Treatment: Disposition Action Plan is divided into various aspects such as prioritization and scheduling, implementation, actions at other levels, document, and close. 


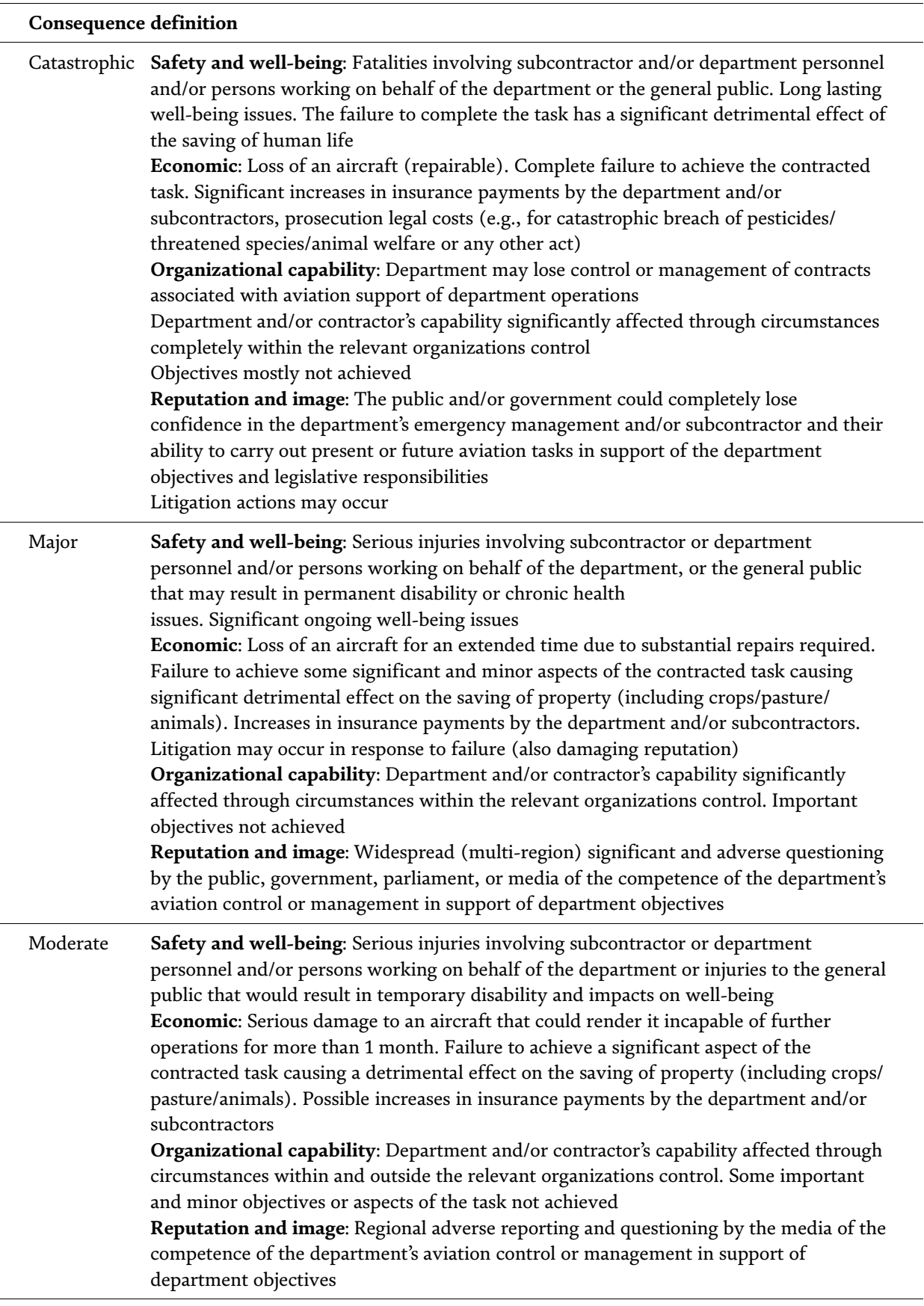

Table 3.

NSW DPI aviation risk assessment and management consequences definition [3, 4].

Prioritize, Schedule: Schedule is unique to every company that has its own way of managing the schedule. The process determines qualified emergencies, for example, risk reduction, cost, and implementation ease. This process involves setting up tasks and resources to create and issue a service bulletin to organize the system.

Implementation: When identifying and evaluating the action plan to correctly address the issue or concern, it can be extended to the fleet or organization. Problem 
management should be tracked to ensure the efficacy of the action in lowering or removing the issue.

Actions to Other Levels: When service bulletins, ADs, or actions that may impact other organizations have been created, they should be sent for execution consideration. Some manufacturer's contractual arrangements with operators provide tracking for SB implementation, while others do not have a closed-loop process.

Document and Close: The problems are usually solved by issuing an official technical document from the change-making organization.

If the current checks found do not reduce the risk to appropriate standards or where there is consensus that further checks are needed in order to accomplish the job safely, further checks should then be incorporated into the evaluation. Additional checks cannot be applied without the mission priorities being taken into account. This will also be a delicate balancing act, so returning to the project can often help to keep risk management in mind.

Reevaluate the Risk: Once therapy is necessary, it is important to reassess the risk in order not to add any additional risks. For example, if a decision were taken to fly a different form of door aircraft, there will have been a new chance of items falling out of the plane. This should be considered as a new vulnerability and an appropriate diagnosis or solution if there is a potential door issue. The above example shows the criticality of continuous risk analysis.

Further steps and evaluation are required where risk is already deemed intolerable or whether the function will benefit from further risk management.

Ultimately, the appraisal and analysis process continues until one of the two consequences is reached, the task risk remains too high and then the assignment is denied or input from senior departmental management is required, the assignment risk is lowered to the acceptable level, and the work profile and risk assessment is accepted.

Submitting for Approval: The planner/worker individual shall send the final job profile and risk assessment to the Director of Operations for approval. The document is then forwarded to the Emergency Management Unit to be placed on the Internet to be easily available to aircraft planning and operations personnel.

This chapter describes step by step, or in detail, how risk assessment and safety assessment is initiated and processed in aviation. The initial assessment and major assessment are divided into two different aspects. It describes how to detect and process an event. If an event is not too serious, use basic process to eliminate the threat. But if the event is complicated, a major risk and safety assessment is considered and implemented. In the next chapter, we will discuss about the methods or tools required to carry out these assessment.

\section{Methods/tools that are used in the safety and risk assessment process}

Any analysis is as valid as its conclusions, data, and analytical techniques. Therefore, the underlying assumptions, data, and analytical techniques should be identified and justified to ensure validity of analysis conclusions. Variability can be inherent in elements such as failure modes, failure results, failure levels, failure probability distribution functions, failure exposure times, failure detection techniques, failure independence, human interfaces (e.g., crew behavior and procedures), and limitation of analytical approaches, processes, and assumptions. The rationale of the conclusions on the above things should be an important part of the analysis.

Assumptions can be checked using experience with identical or similar systems or components with due allowance for design, duty cycle, and climate variations. 
Where the adequacy of the analysis cannot be entirely explained and where evidence or conclusions are crucial to the conclusion's acceptability, extra conservatism should be incorporated into either the research or intervention. Additionally, all data and conclusions ambiguity should be analyzed to the degree required to show that the research results are indifferent to this ambiguity. Any assumptions and other uncertainties related to a safety analysis must be identified and documented in order to judge their effect on the conclusions of such an analysis and to conduct sensitivity analysis. Ongoing field experience should be tracked to continue validating conclusions and reducing risks, or to collect the data required to minimize the effects of the extra conservatism built into the initial study. Finding any flaws in the assumptions requires reviewing the safety analysis.

However, the need to calibrate the safety analysis with past experience helps ensure that the future forecast is realistic, ensuring that operational parameters (deadlines, etc.) remain constant. If the analysis does not calibrate, further evaluation is required to determine which safety analysis assumptions may be in error. The safety analysis will not predict accurately unless it can calibrate to actual experience.

\subsection{Hazard identification methods}

In the airline industry, understanding and defining what a hazard is has changed over the years and continues to be the subject of discussion and discussion in the world of aviation. Throughout the early 1950s, safety enhancements were attributed to resolution of technical issues, with an event/accident often defined as human error in the late $1960 \mathrm{~s}$ as the underlying causal factor(s). Organizational factors started to be identified as possible threats in the 80 s, adding to or triggering a safety standard in an activity. It is widely recognized that their natural root is a combination of various areas when determining threats or contributing factors.

Hazard can be any factor within the following four main aspects:

a. Technical

b. Human

\section{c. Organizationa}

\section{d. Environmental}

Other definitions can be found in the aviation industry (Table 4).

Risk detection is historically a subjective task and therefore its effectiveness relies on individual or team knowledge to determine it. In the industry, various analytical tools and information sources are available for the risk detection process, such as organizational observations or process analysis.

Interviews with organizational experts and key informants: This method is very selective and limited because it is based exclusively on individual information and restrictions.

Brainstorming hazard sessions: Specialists in all operating fields found it to be helpful and successful in recognizing as many hazards as possible. This approach is largely based on knowledge and experience. Guidance on how these sessions and techniques can be used easily in the public domain on the Internet.

Hazard and operability tool (HAZOP): brainstorming technique used to identify hazards and operability problems when the process design or scheduled changes are completed during brainstorming sessions. This strategy depends on the expertise and experience of the team and must be as interdisciplinary as possible to identify 


\begin{tabular}{ll}
\hline Source & Hazard definition \\
\hline $\begin{array}{l}\text { CAA UK, and } \\
\text { Euro control }\end{array}$ & Any condition, occasion, or situation which could incite a mishap \\
\hline CAA UK & $\begin{array}{l}\text { A physical circumstance, frequently following from some starting occasion that can } \\
\text { prompt a mishap }\end{array}$ \\
\hline FAA & $\begin{array}{l}\text { Any current or potential condition that can prompt injury, disease, or passing to } \\
\text { individuals; harm to or loss of a framework, hardware or property; or harm to the } \\
\text { earth. A peril is a condition that is an essential to a mishap or occurrence }\end{array}$ \\
\hline CAA Canada & $\begin{array}{l}\text { A wellspring of possible mischief, or a circumstance with a potential for causing hurt as } \\
\text { far as human injury; harm to wellbeing, property, nature, and different things of } \\
\text { significant worth; or a mix of these } \\
\text { Condition, article, or movement with the capability of making injury work force, harm } \\
\text { to gear or structures, loss of material, or decrease of capacity to play out an endorsed } \\
\text { work }\end{array}$ \\
\hline
\end{tabular}

Table 4 .

The definition of hazard.

any deviations from the planned process, plan, or activity. It is considered very useful in new operations, when other approaches that focus on experienced personnel are less effective, as the team uses a range of standard questions to construct a list of possible deviations by integrating word (Table 5) with a variable parameter or process terms.

Fault hazard analysis (FHA): This is a standardized and detailed approach used for the analysis of roles to identify and describe the potential nature of failures. If desired, it can only be used as a qualitative or quantitative analysis. A comprehensive top-down configuration analysis is required in order to evaluate computer danger modes, danger causes and potential system/operational performance. I would like to respond to the following questions:

- What's wrong with this?

- How is it possible to fail?

\begin{tabular}{ll}
\hline No & $\begin{array}{l}\text { This is the complete negotiation of the design intention. No part of the intention is achieved } \\
\text { and nothing else happens }\end{array}$ \\
\hline More & This is a quantitative increase \\
\hline Less & This is a quantitative decrease \\
\hline As well as & All the design intention is achieved together with additions \\
\hline Part of & Only some of the design intention is achieved \\
\hline Reverses & The logical opposite of the intention is achieved \\
\hline $\begin{array}{l}\text { Other } \\
\text { than }\end{array}$ & $\begin{array}{l}\text { Complete substitution, where no part of the original intention is achieved but something } \\
\text { quite different happens }\end{array}$ \\
\hline Early & Something happens earlier than expected relative to clock time \\
\hline Late & Something happens later than expected relative to clock time \\
\hline Before & Something happens before it is expected, relating to order of sequence \\
\hline After & Something happens after it is expected, relating to order of sequence \\
\hline
\end{tabular}

Table 5 .

HAZOP guide words. 
- How many times is it going to fail?

- What will happen if it fails?

- How important are the safety effects?

External intelligence sources of the company: Efficient to track and review current activities in order to recognize potential threats, analyze identified risks and recognize patterns. Examples are the following: dispatch logs, maintenance reports, manufacturing reports, and security reporting database of aircraft flight data (flight data extracted from equipment such as FDR or QAR).

External public information sources: Useful for showing operators temporarily or permanently recognized dangerous conditions. NOTAMs, AIPs, and rules for aviation.

FACS: Method of detecting human fault in accidents, major injuries, injuries, and other safety-related activities (based on the concept of Professor James Reason) and their inquiry and study. It also helps to determine where corrective measures and mitigation measures are required to eliminate the risk.

\subsection{Risk assessment methods}

Methods/tools for risk analysis provide means for the analysis of formal or informal risk information as a result of a proposed action or the risk involved in failure to take a certain action. Support in determining the severity of risks posed by incidents which are or may be subjected to an aircraft operator; they help also to determine what events are most susceptible to a serious incident or accident.

Risk assessment techniques were originally designed for the nuclear sector and a range of uses, from chemistry to aeronautical, have undergone many approaches and tools over the years.

There are currently a wide range of different risk assessment models in all types of business industries and the methodology used around the world is inconsistent.

Quantitative and qualitative evaluations coexist and organizational risk mitigation approaches must all be considered. Much effective risk management never perform systematic risk analyses and continue their use only for certain risks that need analytical reasoning or the acceptance of a contingency strategy. A qualitative risk analysis (designation of high, medium, or low probability or impacts) is deemed sufficient for the selection of the most important risks.

Regardless of the specific description, regulatory inclination is to break the risks down in two components of the hazard, but discrepancies are again noted on the designation of the two components: probability (or probability) of occurrence if the risk is caused by a risk, intensity (or magnitude) of the hazard-caused adverse effect. Likelihood is based on exposure to quantify the possibilities in stages, periods, men, etc. Thus, exposure may or may not be integrated depending on how the probability is calculated. Raised risk of adverse effects is raised by exposure to unhealthy conditions. Therefore, danger is described as follows:

$$
\text { Risk }=\text { Likelihood } \mathrm{x} \text { Severity }
$$

Equation 1 - ICAO Risk equation.

The ARMS working presents risk as a breakdown of each one of the four components:

$$
\begin{aligned}
\text { Risk }= & (\text { Likelihood } \mathrm{x} \text { Frequency of Avoidance }) \\
& \mathrm{x} \text { (Frequency of Recoverability } \mathrm{x} \text { Severity })
\end{aligned}
$$


Equation 2 - ARMS Risk Equation.

The stability of an action without taking into account risk exposures, the effectiveness of barriers to the materialization of the risk, and the efficacy of barriers to recovery and without enabling the accomplishment of a worse-case situation, as seen in the ARMS bow-tie diagram, cannot be adequately assessed. However, as such factors require a high degree of subjectivity; they do not necessarily need to be included in the risk formula.

The protection of an action cannot be adequately measured without taking into account hazard detection, the productivity of the barriers preventing the danger of materializing, or the efficacy of the barriers to recovery and inability to accomplish the worst case scenario (the worst scenario), as seen in the diagram, Weapons

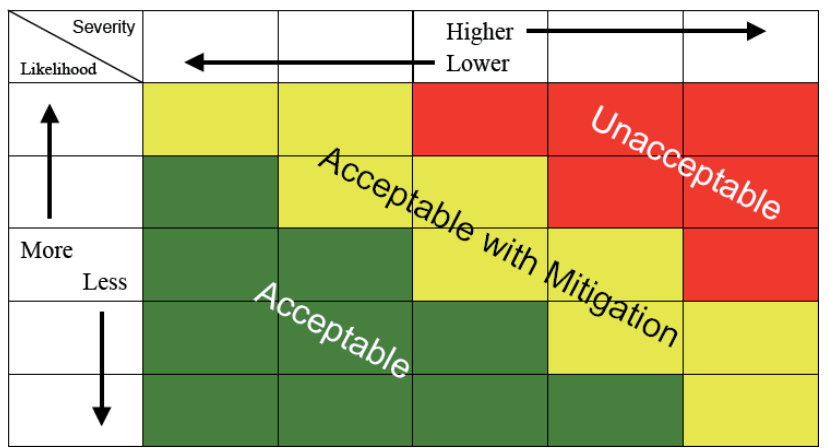

Figure 7.

Risk assessment sample matrix.

\begin{tabular}{|c|c|c|c|c|c|}
\hline \multicolumn{3}{|c|}{ Severity of consequences } & \multicolumn{3}{|c|}{ Likelihood of occurrence } \\
\hline $\begin{array}{l}\text { Severity } \\
\text { Level }\end{array}$ & Definition & Value & $\begin{array}{l}\text { Likelihood } \\
\text { level }\end{array}$ & Definition & Value \\
\hline Catastrophic & $\begin{array}{c}\text { Hardware annihilated; different } \\
\text { passings }\end{array}$ & 5 & Frequent & $\begin{array}{l}\text { Likely to occur } \\
\text { many times }\end{array}$ & 5 \\
\hline Hazardous & $\begin{array}{l}\text { Enormous decrease in safety edges, } \\
\text { physical trouble or a remaining burden } \\
\text { to such an extent that administrators } \\
\text { cannot be depended upon to play out } \\
\text { their undertakings precisely or totally. } \\
\text { Genuine injury or demise to various } \\
\text { individuals. Significant gear harm }\end{array}$ & 4 & Occasional & $\begin{array}{l}\text { Likely to occur } \\
\text { sometimes }\end{array}$ & 4 \\
\hline Major & $\begin{array}{l}\text { Huge decrease in safety edge, decrease } \\
\text { in the capacity of administrators to } \\
\text { adapt to unfriendly working conditions } \\
\text { hindering their effectiveness. Genuine } \\
\text { occurrence. Injury to people }\end{array}$ & 3 & Remote & $\begin{array}{l}\text { Unlikely but } \\
\text { possible to } \\
\text { occur }\end{array}$ & 3 \\
\hline Minor & $\begin{array}{l}\text { Nuisance. Operating limitations. } \\
\text { Use of emergency procedures. Minor } \\
\text { incident }\end{array}$ & 2 & Improbable & $\begin{array}{l}\text { Very unlikely to } \\
\text { occur }\end{array}$ & 2 \\
\hline Negligible & Little consequence & 1 & $\begin{array}{l}\text { Extremely } \\
\text { improbable }\end{array}$ & $\begin{array}{l}\text { Almost } \\
\text { inconceivable } \\
\text { that the event } \\
\text { will occur }\end{array}$ & 1 \\
\hline
\end{tabular}

Table 6.

Sample of severity and likelihood criteria [4]. 


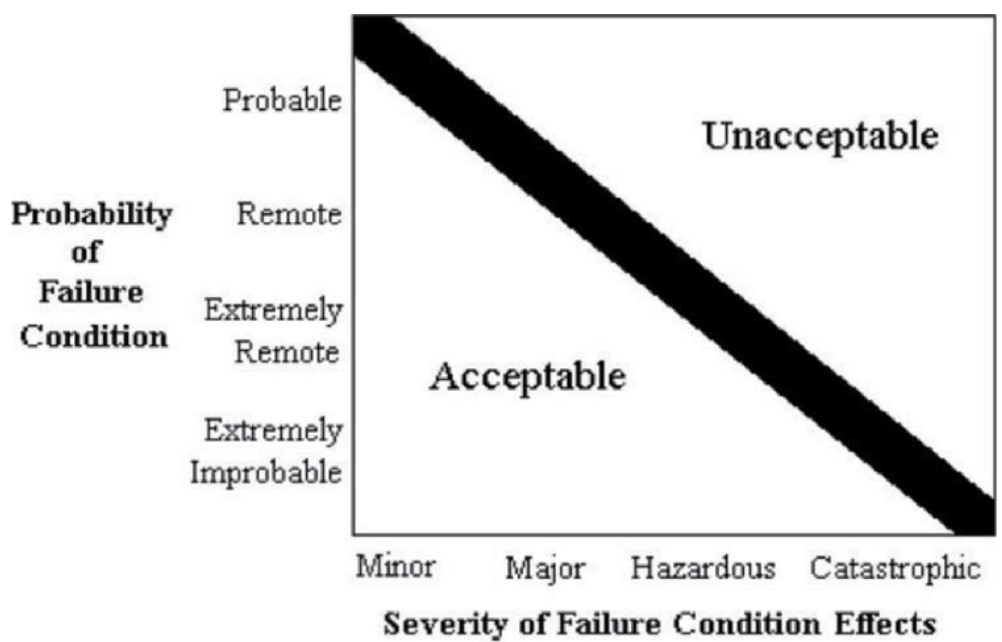

Figure 8.

Probability and severity relationship for failure condition effects.

\begin{tabular}{|c|c|c|c|}
\hline $\begin{array}{l}\text { Failure } \\
\text { condition }\end{array}$ & Definition & $\begin{array}{l}\text { Qualitative } \\
\text { probability }\end{array}$ & $\begin{array}{l}\text { Quantitative } \\
\text { probability } \\
\text {-Average } \\
\text { probability } \\
\text { per flight } \\
\text { hour }\end{array}$ \\
\hline $\begin{array}{l}\text { No safety } \\
\text { effect }\end{array}$ & $\begin{array}{l}\text { Failure conditions that would have no effect } \\
\text { on safety; that would not affect the } \\
\text { operational capability of the airplane or } \\
\text { increased workload }\end{array}$ & $\begin{array}{l}\text { No probability } \\
\text { requirement }\end{array}$ & $\begin{array}{l}\text { No } \\
\text { probability } \\
\text { requirement }\end{array}$ \\
\hline Minor & $\begin{array}{l}\text { Failure conditions which would not } \\
\text { significantly reduce airplane safety, and which } \\
\text { involve crew actions that is well within their } \\
\text { capabilities. May include, for example, a slight } \\
\text { reduction in safety margins or functional } \\
\text { capabilities, a slight increase in crew } \\
\text { workload, such as routine flight plan changes, } \\
\text { or some physical discomfort to passengers or } \\
\text { cabin crew }\end{array}$ & $\begin{array}{l}\text { Probable-that can be } \\
\text { anticipated to occur } \\
\text { one or more times } \\
\text { during the entire } \\
\text { operational life of each } \\
\text { airplane }\end{array}$ & $\begin{array}{l}\text { Probability } \\
>1 \times 10^{-5}\end{array}$ \\
\hline Major & $\begin{array}{l}\text { Disappointment conditions which would } \\
\text { lessen the capacity of the plane or the capacity } \\
\text { of the group to adapt to antagonistic working } \\
\text { conditions to the degree that there would be, } \\
\text { for instance, a critical decrease in safety edges } \\
\text { or useful abilities, a huge increment in team } \\
\text { outstanding task at hand or in conditions } \\
\text { debilitating group effectiveness, or } \\
\text { inconvenience to the flight team, of physical } \\
\text { trouble to travelers or lodge group, } \\
\text { conceivably including wounds }\end{array}$ & $\begin{array}{l}\text { Remote-unlikely to } \\
\text { occur to each airplane } \\
\text { during its total life, but } \\
\text { which may occur } \\
\text { several times when } \\
\text { considering the total } \\
\text { operational life of a } \\
\text { number of airplanes of } \\
\text { the type }\end{array}$ & $\begin{array}{l}1 \times 10^{-7} \\
<\text { Prob } \\
<1 \times 10^{-5}\end{array}$ \\
\hline Hazardous & $\begin{array}{l}\text { Disappointment conditions, which would } \\
\text { decrease the capacity of the plane or the capacity } \\
\text { of the group to adapt to unfriendly working, } \\
\text { conditions to the degree that would be: } \\
\text { i. A huge decrease in safety edge or } \\
\text { practical capacities }\end{array}$ & $\begin{array}{l}\text { Extremely remote-not } \\
\text { anticipated to occur to } \\
\text { each airplane during its } \\
\text { total life but which may } \\
\text { occur a few times when } \\
\text { considering the total }\end{array}$ & $\begin{array}{l}1 \times 10^{-9} \\
<\text { Prob. } \\
<1 \times 10^{-7}\end{array}$ \\
\hline
\end{tabular}




\begin{tabular}{|c|c|c|c|}
\hline $\begin{array}{l}\text { Failure } \\
\text { condition }\end{array}$ & Definition & $\begin{array}{l}\text { Qualitative } \\
\text { probability }\end{array}$ & $\begin{array}{l}\text { Quantitative } \\
\text { probability } \\
\text {-Average } \\
\text { probability } \\
\text { per flight } \\
\text { hour }\end{array}$ \\
\hline & $\begin{array}{l}\text { ii. Physical trouble or over the top } \\
\text { outstanding burden with the end goal } \\
\text { that the flight group cannot be the } \\
\text { depended upon to play out their } \\
\text { errands precisely or totally } \\
\text { iii. Serious or deadly injury to a generally } \\
\text { modest number of the inhabitants } \\
\text { other than flight group }\end{array}$ & $\begin{array}{l}\text { operational life of all } \\
\text { airplanes of the type }\end{array}$ & \\
\hline Catastrophic & $\begin{array}{l}\text { Failure conditions which would result in } \\
\text { multiple fatalities, usually with the loss of the } \\
\text { airplane }\end{array}$ & $\begin{array}{l}\text { Extremely improbable } \\
\text { —unlikely that they are } \\
\text { not anticipated } \\
\text { occurring during the } \\
\text { entire operational life } \\
\text { of all airplanes of one } \\
\text { type }\end{array}$ & $\begin{array}{l}\text { Probability } \\
<1 \times 10^{-9}\end{array}$ \\
\hline
\end{tabular}

Table 7.

Failure condition definition and relationship with probability [5].

bow-tie. But as these factors require a high degree of subjectivity, they do not necessarily have to be included in the dangerous formula.

Similar methodologies are described in a risk matrix for both elements, each of which has different acceptance rates (Figure 7). Authorities recommend that each operator develop its own matrix and criteria that best reflect its operating environment.

If both the severity of the consequences and their likelihood of occurrence are expressed qualitatively (e.g., by words like high, medium, or low), the risk assessment is called a qualitative risk assessment. Table 6 provides an example of an aircraft operator's qualitative criteria.

Follow-ups are numerically described in a quantitative risk assessment or probabilistic risk assessment (e.g., number of persons who may have been hurt or killed) and are expressed as probabilities or frequencies (e.g., number of occurrences, probability of occurrence per unit time), as shown in Figure 8 and Table 7.

Quantitative criteria are determined by the historical architecture and assessment of systems engineering. Aircraft regulators have long established quantitatively acceptable levels of quality for all aircraft construction equipment or systems in the certification specifications. Failure to comply with these criteria does not authorize unique certification of equipment.

Risk evaluation and risk control for each hazard or category are standardized, comprehensive hazard detection and risk assessment. The acceptability of risk is assessed by matching the measured risk level with defined requirements or safety objectives.

\section{Conclusion}

This chapter includes the concept of safety and risks in civil aviation during operation and focuses only on the actual safety and risk assessment process that is carried out by different organizations in order to maximize the safety while trying 
to avoid possible risks. The steps and analysis that are carried out are actually based on facts and data. It is hard to determine whether these results are actually "safe and risk free" to be carried out. Lack of real-time data and real environment factfindings make it difficult for this section of civil aviation to prosper. But day by day, results are getting better with the inclusion of new technologies and methods. This study shows that these assessments might not have too much impact on civil aviation but serve as a probability to avoid minimum risks and increase the safety concerns.

The chapter also provided a review of some methods/models for civil aviation risk and safety assessment. The key findings provided insight into the efforts already made to improve such methods/models; their inherent difficulty and lack of sufficient versatility; lack of available data for calibration and testing; and lack of sufficient predictive capabilities to encourage the implementation of new technical, procedural, and operational concentrations to assess risk and safety. On the one hand, they aimed at increasing the system capacity and, on the other hand, at reducing the acceptable risk and safety thresholds. The need to develop "specialized" or "dedicated" methods/models for particular system parts has been discovered in many cases. Moreover, difficulties such as lack of real-life data were overcome by including expert judgment despite awareness of its uncertainty and biases. Also noted was the systematic need for balance and compromise between sophistication of methods/models, development time and expense, and consistency of performance. Prospective research needs to be considered to further improve the existing models in line with recommendations that generally implied risk and safety assessment capabilities during development and after implementation of new technologies, with generality on the one hand and dedication on the other hand, predictive capabilities, flexibility and easier understanding, and handling of modular system structures.

\section{Author details}

Asif Mostafa

Nanjing University of Aeronautics and Astronautics, Nanjing, China

*Address all correspondence to: asifmostofa91@yahoo.com

\section{IntechOpen}

(C) 2020 The Author(s). Licensee IntechOpen. Distributed under the terms of the Creative Commons Attribution - NonCommercial 4.0 License (https://creativecommons.org/ licenses/by-nc/4.0/), which permits use, distribution and reproduction for non-commercial purposes, provided the original is properly cited. (cc) BY-NC 
Safety and Risk Assessment of Civil Aircraft during Operation

DOI: http://dx.doi.org/10.5772/intechopen.93326

\section{References}

[1] Federal Aviation Administration

[FAA]. Introduction to Safety

Management Systems for Air Operators

(AC 120-92), June 22th, USA; 2006

[2] International Civil Aviation

Organization [ICAO]. Safety

Management System (Doc 9859).

2nd ed. Montreal, Canada: International

Civil Aviation Organization, ICAO;

2009

[3] NSW Department of Primary Industries Reference: TRIM INT11/ 73583

[4] Boeing, Air Traffic Alliance. Air Traffic Alliance - Boeing Required Navigation; 2005

[5] European Aviation Certification Specification [EASA]. Certification Specifications for Large Airplanes CS-25 (Annex to ED Decision 2009/017/R), Amendment 8, December 18th; 2009 

Section 2

Safety Analysis 



\title{
Design Approaches for Safety Increasing and Risk Decreasing for the Civil Aircraft's Operation
}

\author{
Dmytro Tiniakov
}

\begin{abstract}
The safety and risks of civil aircraft operation depend on a lot of factors. One of them is the structural features of an aircraft. In aviation history, there are examples when "non-rational" design solution was the reason for crashes, but there are examples about successful civil aircraft that have "rational" structure and long operational time without critical incidents. So, how can a designer provide high safety of level and decrease incidents' risks in time of a regular aircraft operation? This chapter partly can help to understand some reasons and approaches for providing "rational" aircraft structure. Design solutions can be divided into some groups by some common features and requirements. They are maintainability, serviceability, accessibility, labor effort decreasing, weather requirements, transportation, etc. All these groups depend on engineers' structural solutions. They are interdependent and often contradictory. In other words, if one of the features will be better, another will be worse at the same time. And, a designer must remember all the time about this and try to find compromise between different requirements. The successful commercial aircraft is composed of a set of rational design solutions for these specific tasks.
\end{abstract}

Keywords: aircraft, design solutions, maintainability, serviceability, safety, risk

\section{Introduction}

In the processes of civil aircraft operation, there is a need to solve the problems of ensuring safety and reducing risks, taking into account environmental factors, human factors, etc. [1]. Two ways to solve such problems are by decreasing number of risks and increasing reliability on the basis of the deep risk analysis [2-4]. In both cases, risk analysis must be.

The problem of risk control is prevalent nowadays. Risk is a complex issue.

A continuous improvement in safety is due to several factors, and aircraft have become more reliable.

Safety systems have been developed significantly. A number of design solutions had a significant impact on decreasing accident rate, including improving the aerodynamic characteristics and design of the liner, improving the criteria for fault tolerance of the structure, improving the cockpit instruments, and increasing the number of aircraft with automatic control flight.

Scientific advances have also enabled the aviation industry to understand better how the human factor affects flight safety. At the same time, significant 


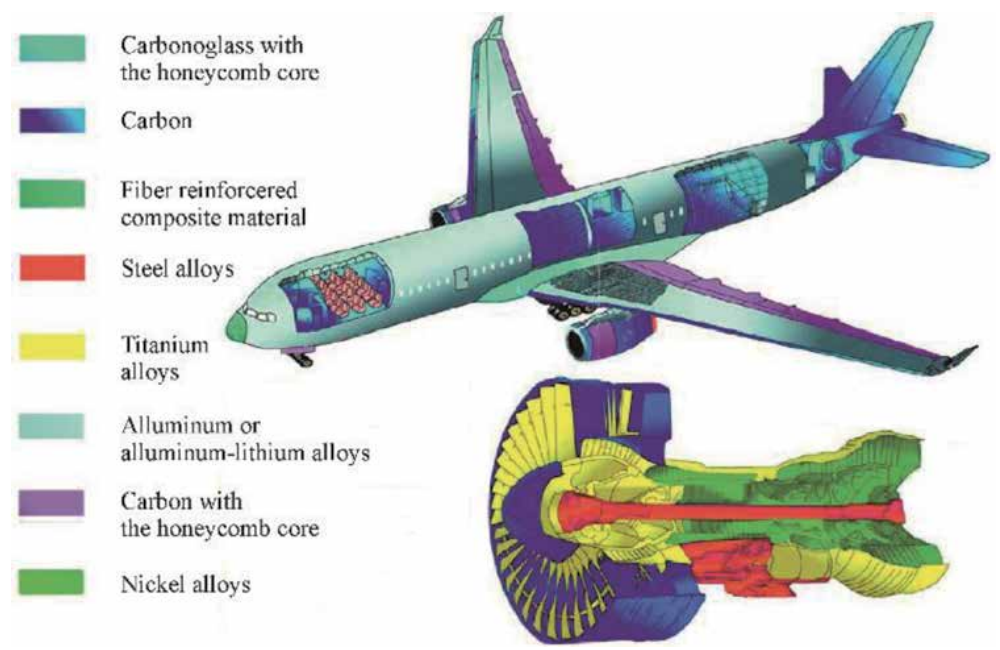

Figure 1.

Structural material application in airframe and engine.

improvements were also achieved in manufacturing processes, aircraft operations, and regulations.

All of these factors, synonymously, have effect on the safety level. But, they also have an opposite effect on the risk number. For example, in modern engines there are composite material structural members (Figure 1), as carbon fiber fan blades, or newest structural solution, composite ceramic turbine blades, etc. [5, 6]. This solution provides higher aviation engine efficiency. But, in case of damage, they require more complex, expensive, and longer repair procedures. At this time, the probability of mistake will be higher, and as a result, risks will be higher too than for traditional metallic structure. Another example of electrical systems is high automation of the flight control. It is possible only by applying computer-controlled electrical system and units, although it is complex. Boeing 787 Dreamliner in 2013 had some problems with the electrical system [7]. Solving these problems, the Boeing Company stopped their servicing for about half a year. The Boeing 737 Max had serious problems also with automation computer control system. We see that more complex solution also creates additional risks.

Environmental effect of the aircraft operation is very high. According to the FAA, in 2018, there were about 14,600 collisions between aircraft and animals [8].

Considering risks in aircraft maintenance is an important factor. Modern airline companies have a great number of different airplane types, which require different maintenance approaches, including refueling, recharging, servicing, etc. Mistakes by the ground staff create real conditions for the expansive damage or crash.

Although the incidents in flights become more seldom, a number of incidents in airports are high, and in the nearest future, they can increase [9]. Airport equipment is expensive, and making changes in aircraft structure features, their numbers, and safety requirement needs is not easy.

So, deep risk analysis allows us to find rational solution for aircraft structure, maintenance approaches, logistic ways, etc. that can provide a decrease in risks and an increase in safety level.

\section{Safety and risks as functions of structural features}

Safety and risk have deep interconnection [4]. Increasing the safety level directly relates with aspects of risk analysis and risk control. Risk control is a set of 
systematic procedures for achieving a risk value within specified limits. Procedures of the risk control involve activities related to overcoming uncertainty in a situation of inevitable choice, in the process of which it is possible to quantitatively and qualitatively assess the probability of achieving the intended result, failure, and deviation from the goal. Risk control depends on two factors: the air transport system and its main tool-aircraft.

The air transport system has the following features [10]:

1. Extreme complexity of the system itself and its main components (aircraft, etc.), due to the diversity of its subsystems and elements, the multiplicity of their relationships, and interdependencies

2. A high level of uncertainty of the impact of external hazardous factors, both natural and artificial

3. The special and diverse role of man at different stages of the designing, manufacturing, organization, preparation, and implementation of air transportation

Artificial hazard factors also depend on the complexity of structural components of air transport system and aircraft.

Human factors directly depend on human specifics, but rational or non-rational structural features can influence on their effect.

Structural aircraft features depend on a lot of factors (Figure 2):

1. Market requirements such us passenger capacity, flying speed, fuel consumption, etc.

2. Design process specifics such us traditions, structural materials, equipment contents, etc.

3. Manufacturing process limits such us aircraft number production per year, structural materials, labor conditions, etc.

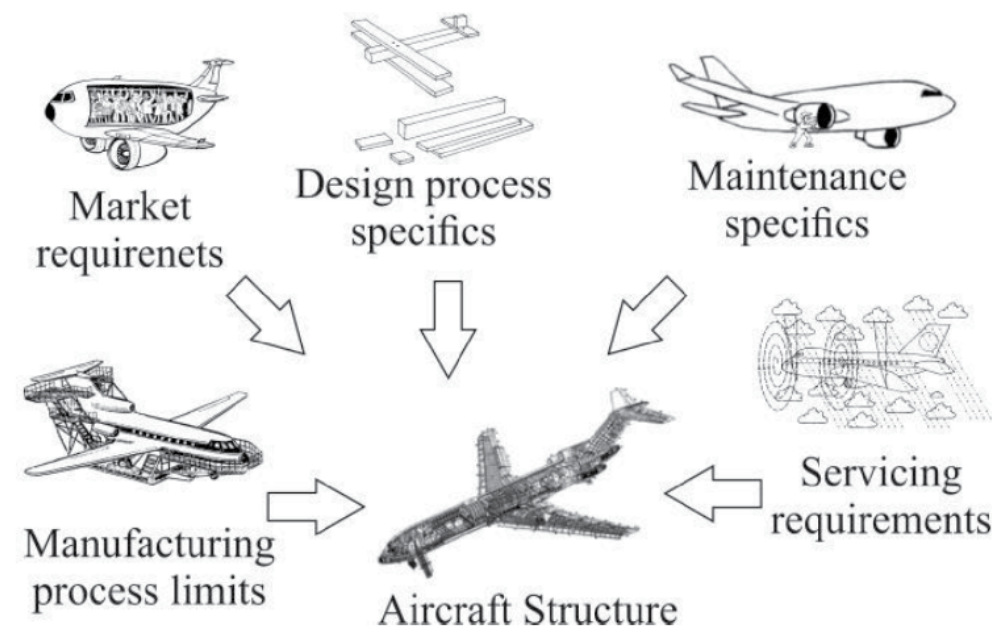

Figure 2.

Structural aircraft specifics and their dependencies. 
4. Servicing requirements like the weather and environment conditions, traffic intensity, pilot training, etc.

5. Maintenance specifics like maintenance time limit, environmental conditions, staff training, ground equipment, etc.

All of these features have direct relation to the structural specifics of related aircraft.

So, as we see, structural specifics are important to all factors that influence risk and safety. Researchers make an analysis of these dependencies.

\section{Civil aircraft maintainability specifics}

Aircraft maintainability is one of the important factors that influence safety. The more complex the maintenance process is, the higher the possibility of ground staff making mistakes and it poses higher risk.

Aircraft maintenance consists of operation, servicing, repair, etc. (Figure 3). It takes into account the following specifics:

1. Safety requirements

2. Structural materials' specific properties that are applied in an airframe (corrosion resistance, combustibility, ability to absorb moisture, ability to destruction, etc.)

3. Ergonomic requirements for the servicing simplification

4. Accessibility of aircraft systems and units for their checking and servicing

5. Application in an aircraft structure of the systems and units that are unattended or not demanding frequent servicing

6. High labor-out ratio and time limits of servicing and repairing

7. Fatigue and service life requirements

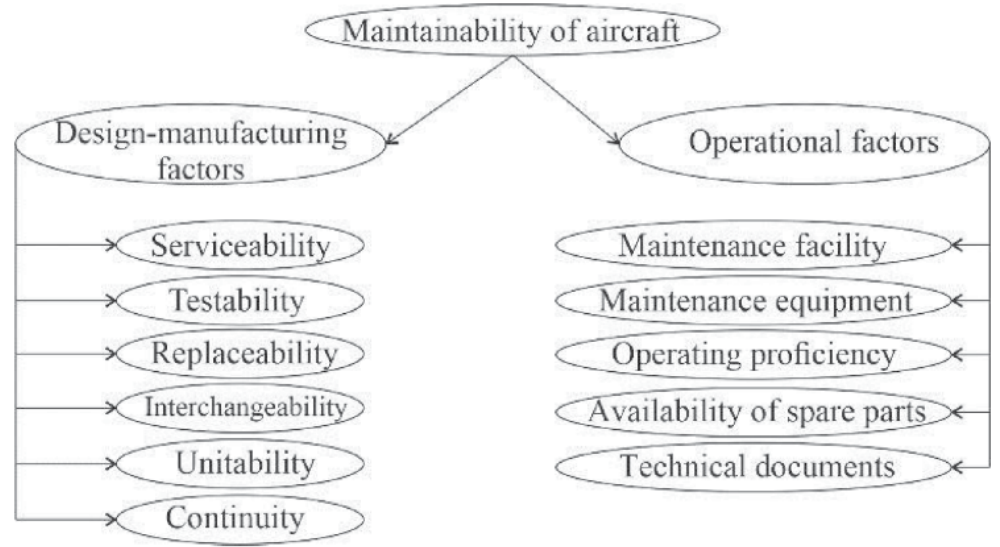

Figure 3.

Maintainability contents. 
A designer can take into account all of these specific features at the time of the designing process and can improve them by applying rational structural solution. Moreover, it can decrease the risks in servicing process.

\section{Aircraft structure adjustment for the progressive servicing and repair methods}

Aircraft structure has developed for more than 100 years (Figure 4). One of the factors that influence on this process is the servicing way. With technic development, the processes of servicing and repairs undergo changes. New ideas and approaches provide a decrease in process time and increased efficiency. But, to provide new servicing approaches, the aircraft structure must have changes too.

\subsection{Aircraft structural features}

For the required safety level, providing aircraft structure must have the following properties:

1. Repair modular method.

2. Aircraft technical condition is the main factor for replacement and repair of units and systems.

3. Units and systems' periodic check without access removal.

4. Possibility for these specialized equipment (Figures 5-12).

Specialized equipment really decreases the risk level. It has the main function of simplifying servicing procedures and decreasing maintenance time.

These structural properties can be provided by the following ways:

1. Applying the "fail-safe" principle in the structure. It means that a single element or a subsystem failure does not lead to emergency. It can be provided by redundancy.

2. Applying easily dismountable joints and panels.

3. Applying built-in indicators and equipment access connectors (Figure 13).

4. Applying interchangeable systems, unit's structural members, etc.

The specialized ground equipment from the one side adjusts maintenance safety, and from the other side special knowledge can be required from the staff. So, the ground staff must have required level of knowledge and skills.
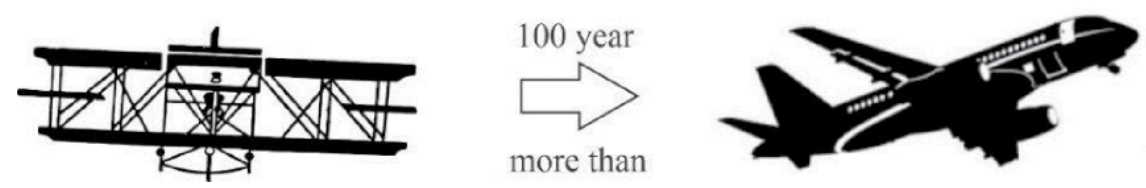

Figure 4.

More than 100 years from Wright brother's aircraft to modern airliner. 


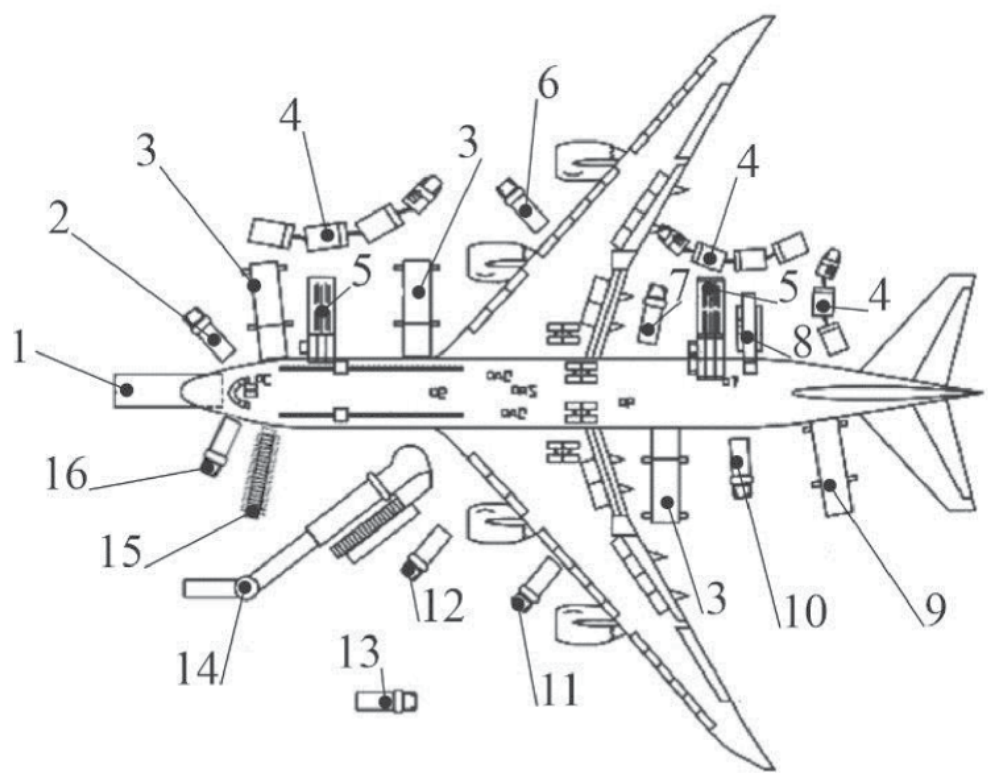

Figure 5.

Arrangement of the special equipment for airport passenger aircraft B747 servicing [11]: 1, tow tag; 2, electrical power; 3, galley truck; 4, baggage train; 5, lower lobe loader (Figure 6); 6, hydrant fuel truck

(Figures 9 and 10); 7, potable water truck; 8, belt loader (Figure 7); 9, cabin cleaning truck; 10, lavatory truck; 11, hydraulic power (Figure 8); 12, conditioned air truck (Figures 11 and 12); 13, air start truck; 14, passenger boarding bridge; 15, passenger stairs; 16, waste servicing truck.

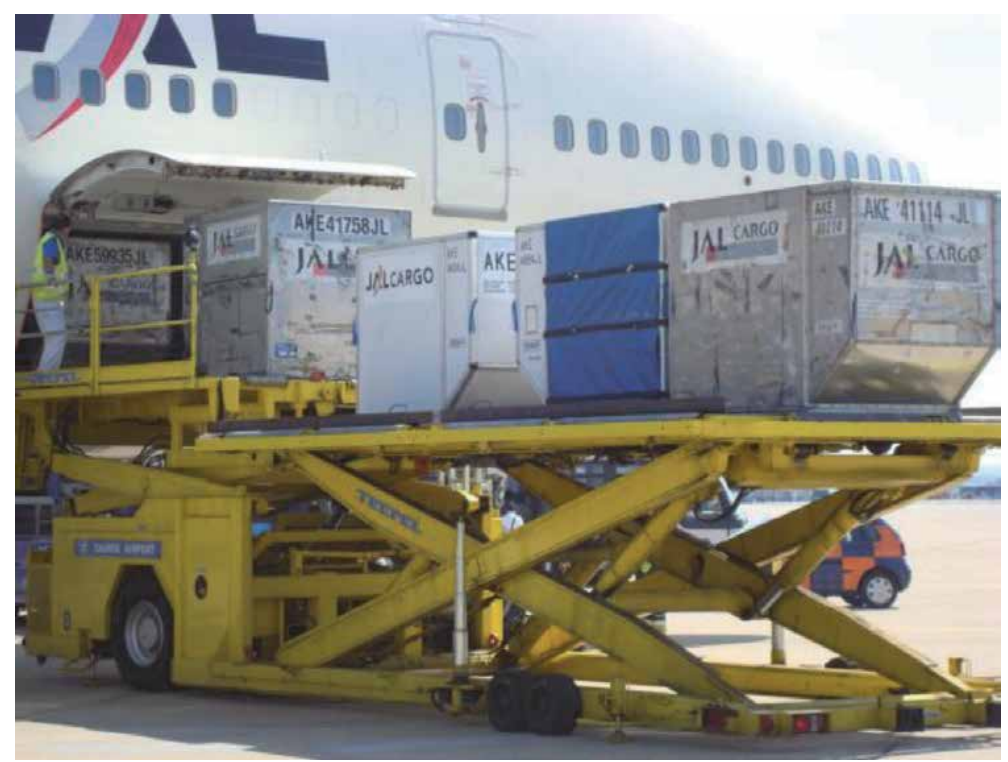

Figure 6.

Special luggage elevator.

Sometimes aircraft fuel valves have special control handle for correct identifying the position (Figure 13).

\subsection{Aircraft servicing specifics}

For service availability, the following are the recommendations: 
1. Access to subsystems and units (especially of a power plant), their built-in indicators, and connectors by cowls and covers for their free checking and servicing (Figure 14, Example 3 and Figure 17) should be provided.

2. The systems and units should be grouped in easily mounting panels. Deep analysis of the checking and servicing procedures can show what kinds of structural members required check and access more frequently (Example 1 and Figure 15).

3. Separate units dismounting for access and servicing of others (Example 2 and Figure 16) should be excluded.

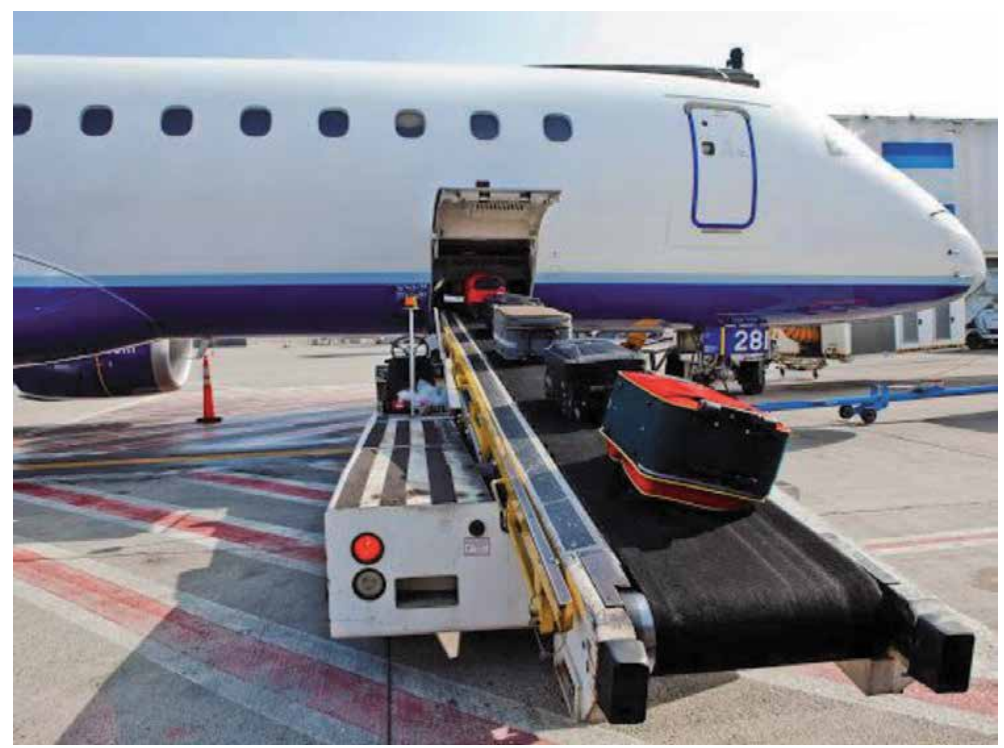

Figure 7.

Belt luggage loader.

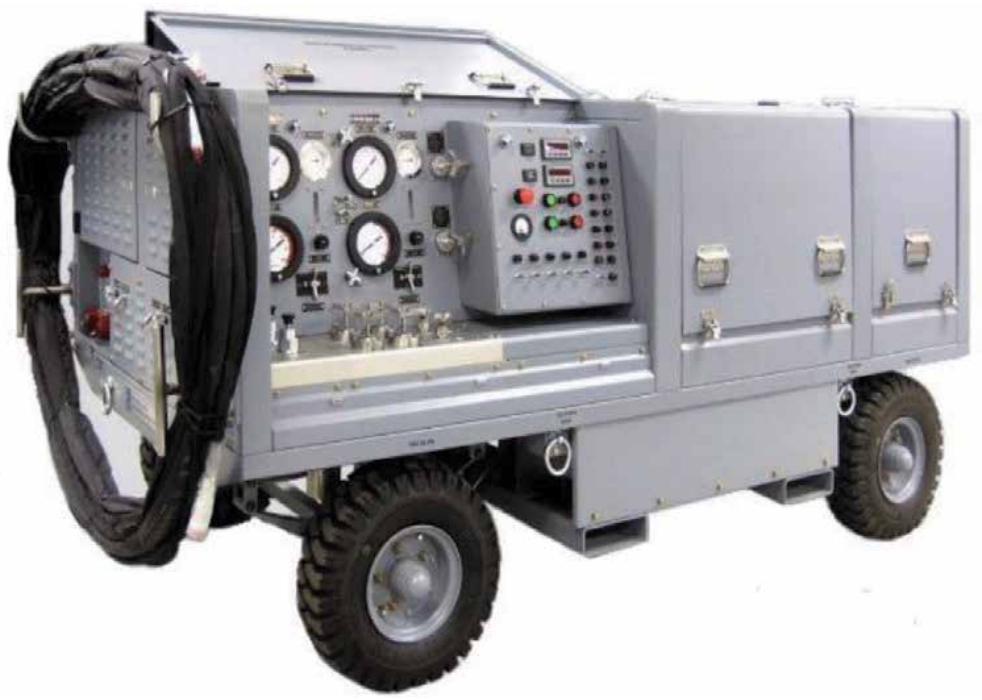

Figure 8.

Special equipment for hydraulic system checking. 


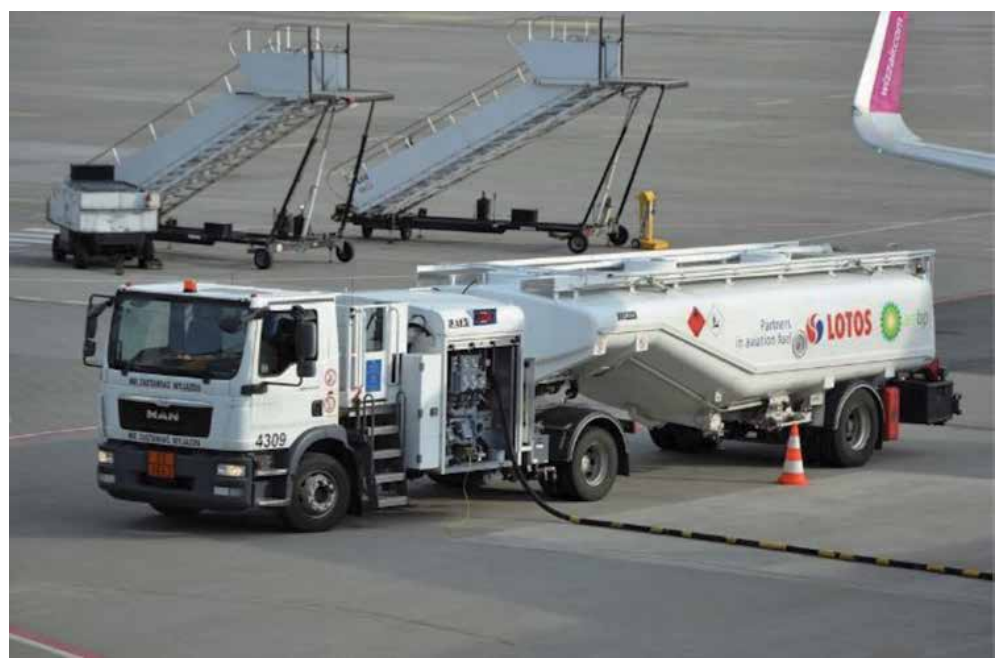

Figure 9.

Fuel tank truck.

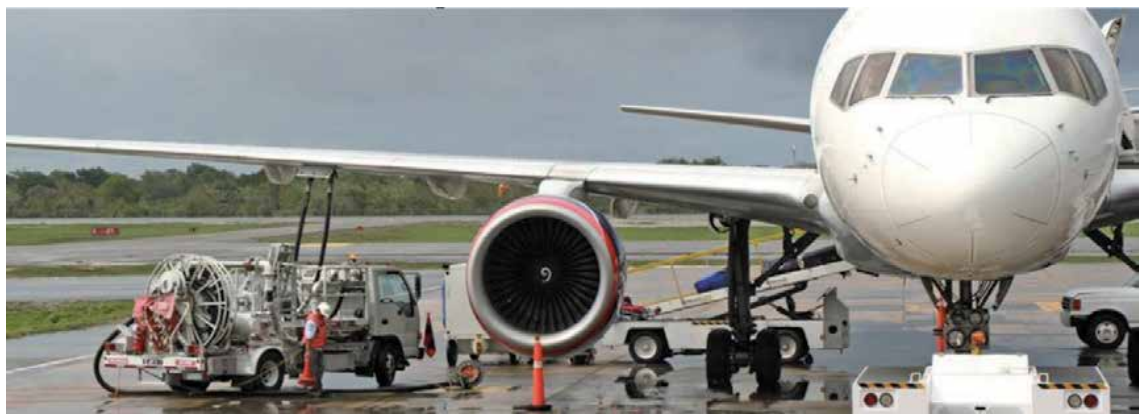

Figure 10.

Centralized underground fuel system and hydrant fuel truck.

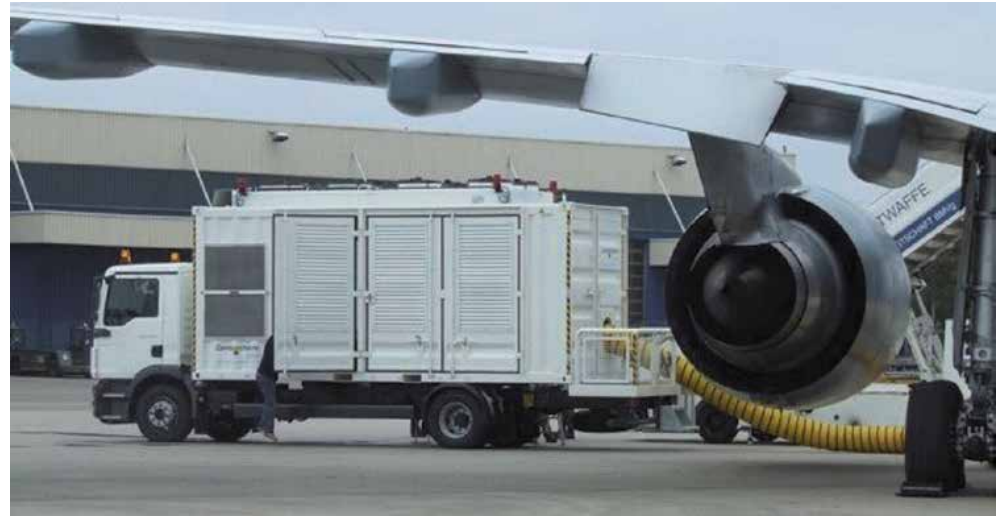

Figure 11.

Conditioned air truck.

4. Removable hatches without the need for breaking the main structure integrity for access bolt joints should be provided.

5. Joint elements at non-pressurized part should be located in case pressurized compartments are present. 


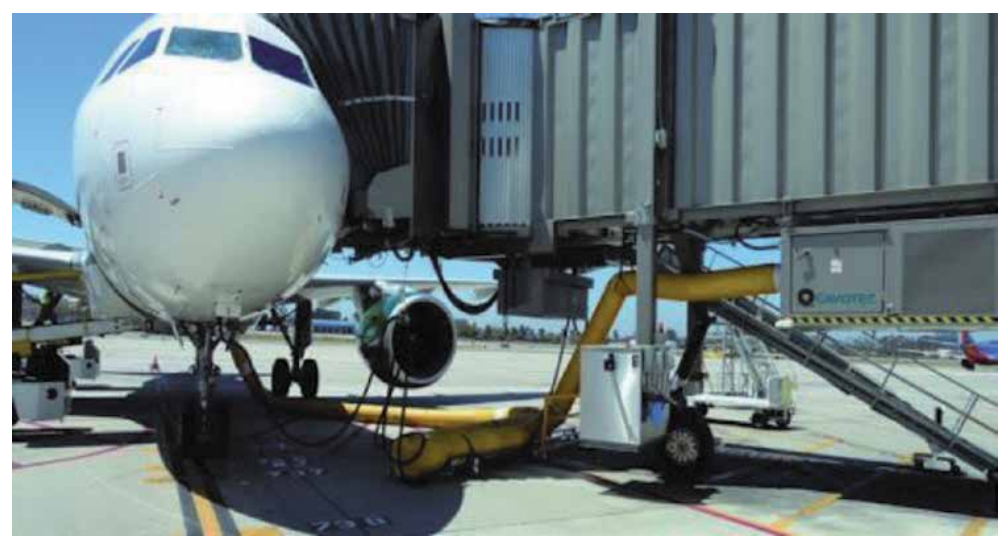

Figure 12.

Some airports have passenger boarding bridges that supply air-conditioning, ground power, potable water, etc.

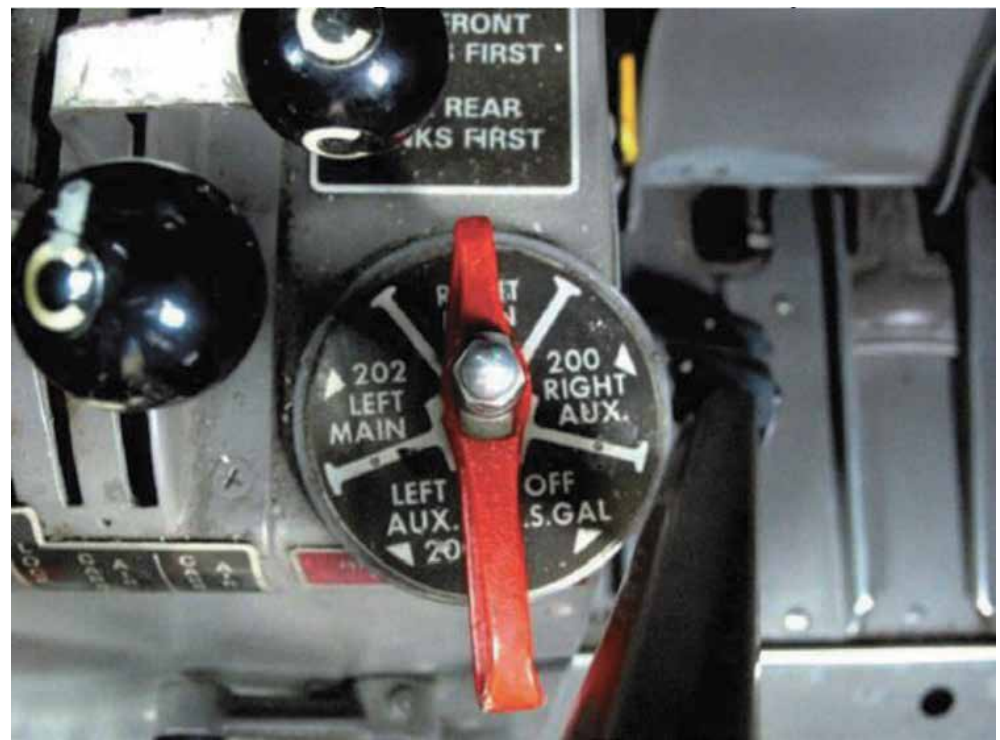

Figure 13.

Fuel valve with detents and the indicating handle for each position.

6. Access to hatches or easily removable panels for periodic checking and servicing of the units' attachment fitting and their load-carry elements should be provided.

7. Access to control system of structural members (rods, bell cranks, brackets, rollers, cables, actuators, etc.) for their checking and servicing should be provided.

8. Bearing servicing (control surfaces, high-lift devices, etc.) without dismounting them should be provided.

9. All movable attachments by lubrication, especially for a landing gear parts for extension configuration, should be provided.

10. Availability of special equipment at an airport (Figures 6-12) should be taken into account. 


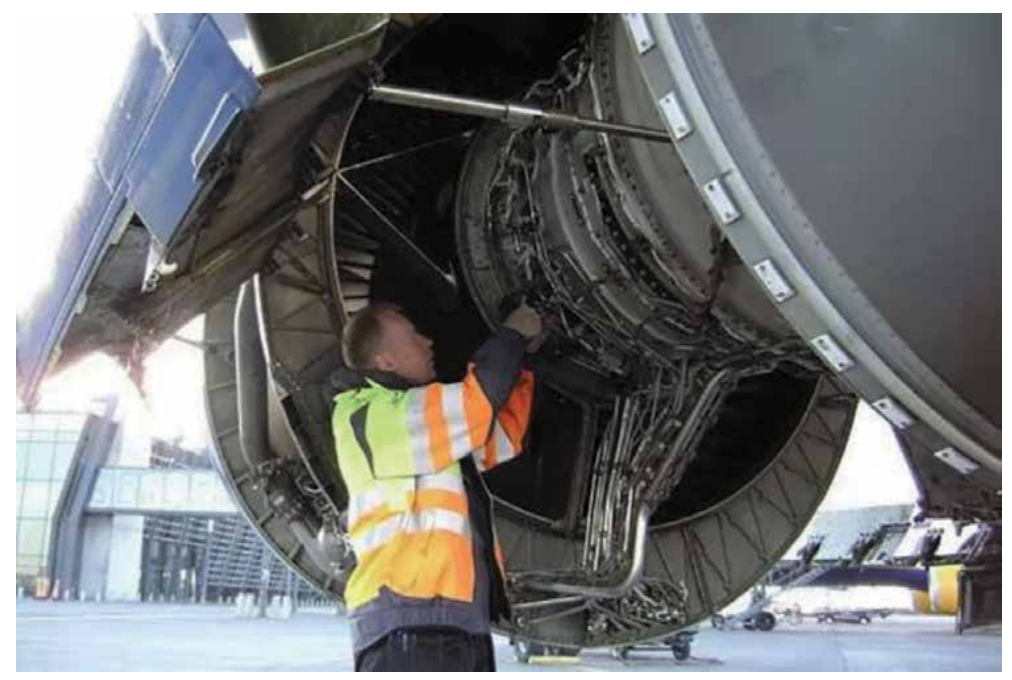

Figure 14.

Providing free access to power plant systems.

\subsubsection{Example 1}

Different kinds of servicing structural members' location are shown in Figure 15.

All of these structural elements have one aim-to provide good access for different systems and units' check points.

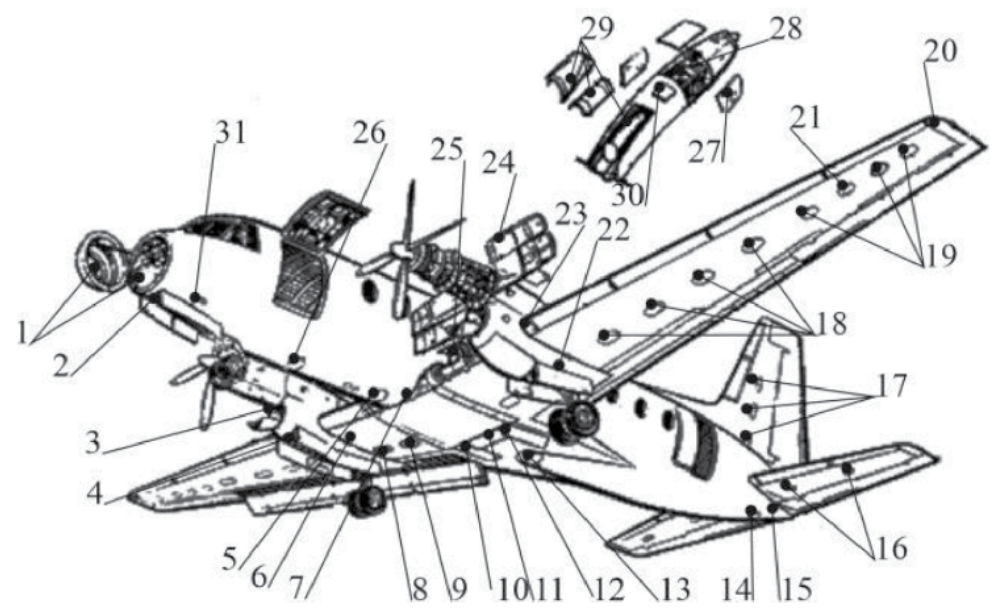

Figure 15.

The example of location of hatches, covers, and doors for service, check and repair of units, and systems and elements of the airplane: 1, battery; 2, members of hydraulic system; 3 , socket of hydraulic system check; 4, hydro tank and filter; 5, electrical equipment and equipment of the air-conditioning system; 6, access to center wing section; 7, electric connectors; 8, fuel precipitation tank; 9, access to wing root; 10, actuator and gear of flap; 11, transmission and shaft of flap system; 12, cable tension adjuster of aileron control system; 13 , gyroscopic sensors of autopilot; 14, servo actuators of elevators; 15, tail cone; 16, access for stabilizer servicing; 17, access for fin servicing; 18, access for fuel tank servicing; 19, access for wing servicing; 20, removable wing tip; 21, landing light; 22, doors of the main landing gear leg; 23, filter of anti-icing system; 24, the cowls; 25, access to engine control system; 26, electrical equipment and air-conditioning members; 27, filter of the air pressure blower; 28 , accessory gearbox drive; 29, exhaust pipe; 30, valve and balloon of fire protection system; 31, members of attachment flaps; 32, the socket of fueling. 


\subsubsection{Example 2}

In Figure 16, the variants of joint structure of two elements are given: not checkable and checkable from the point of view of visual detection of fatigue cracks and bolt joints.

\subsubsection{Example 3}

The variants of placement of detachable section of wing attachment to center section and fairing. In the first variant, attachment is closed by fairing (Figure 17a). Speaking about the requirements of aerodynamic perfection, such option is rational, but as for checkable variants, it is not convenient. Fatigue damages of attachment in operation are possible. But, it is not possible to determine the external visual servicing because the attachment is closed by fairing.

The second variant of structure (Figure 17b) is more checkable because of the visual servicing.

\subsection{Interchangeability properties}

Interchangeability at servicing and repair is the way of simplifying the maintenance and decreasing risk ability.
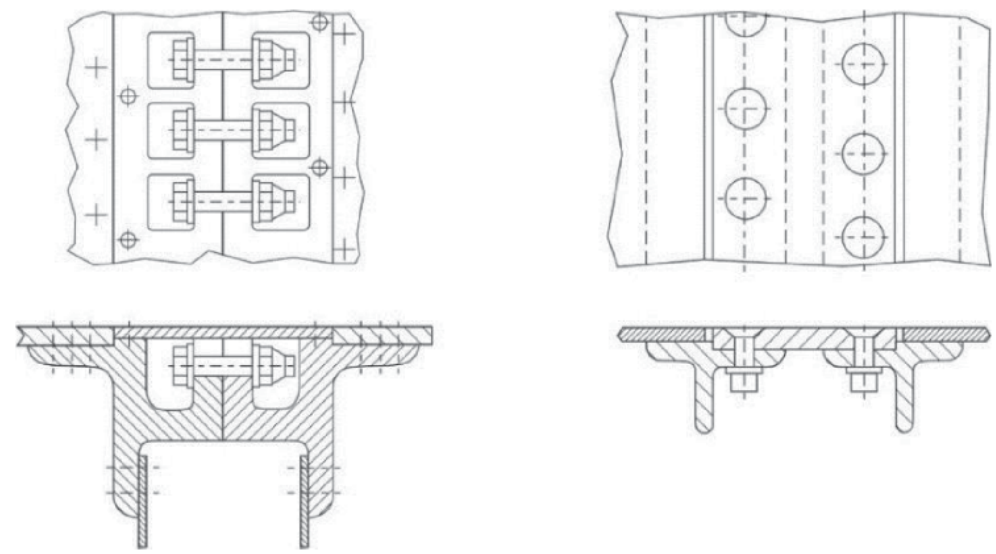

a

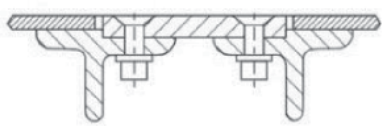

$\mathrm{b}$

Figure 16.

Variants of a joint structure: (a) good check ability; (b) bad check ability.

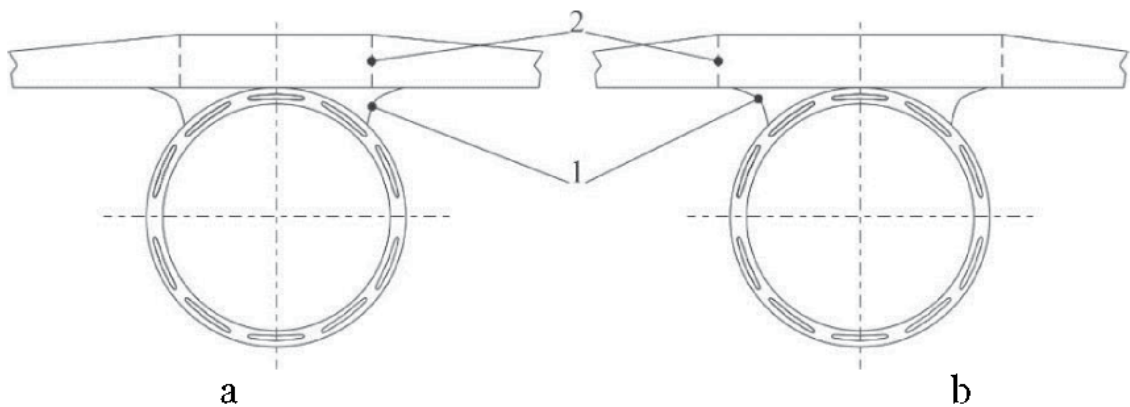

Figure 17.

Variants of a structure: (a) bad check ability; (b) good check ability (1, fairing; 2, joint). 
1. The units, systems, and elements are removed and replaced by new (or repaired) at servicing and repair. It will have the functional and geometrical interchangeability. It especially belongs to such units, systems, and elements which most often are required for replacement or repair. Examples of such are the following:

a. Moveable units—control surfaces (ailerons, elevators, rudders), flaps, slats, interceptors, spoilers, trimmer-tabs, and also their members of attachment

b. Removable panels, covers, hatches, and fairings

c. Cowls of engines and engine attachment elements

d. Entrance and cargo doors, cargo compartment shutters and gates, and their locks

e. Landing gear legs, their locks, and doors of landing gear compartment

f. Control system components (rods, bell cranks, rollers, cables, actuators) and sealed lead-outs

g. Nose section of wing and tail, air intakes, and nose and rear fairing of fuselage

h. Glasses of windows of passenger compartment and cockpit.

2. Units, members, and elements of systems and the equipment also will have to complete functional and geometrical interchangeability (see Example 4 and Figure 18).

3. The modified units, members, and elements will have opportunity to replace older variants of members at all aircraft types where they are installed.

\subsubsection{Example 4}

Bolt joints are important structural solutions applied at the high-loaded structural members. However, there can be some differences in aviation bolts and general engineering bolts (Figure 18).

One of the differences is as follows: aviation bolt body consists of two partsgrip has length $t_{\mathrm{ag}}$ and thread has length $\mathrm{t}_{\mathrm{bt}}$. In the general engineering bolt structure, there is only one-part thread that has length $t_{b t}$. So, the thickness of the jointed elements for the aviation bolt must be equal to the length of the thread:

$$
t_{\mathrm{e} 1}+\mathrm{t}_{\mathrm{e} 2}=\mathrm{t}_{\mathrm{bt}}
$$

For the general engineering bolt, it may be equal or smaller than the thread:

$$
t_{\mathrm{e} 1}+\mathrm{t}_{\mathrm{e} 2}=\mathrm{t}_{\mathrm{bt}}-\mathrm{t}_{\mathrm{wnf}},
$$

where the $t_{w n f}$ is the total thickness of washer, nut, and bolt free tip that is usually equal to $2-3$ screw pitch.

As we can see, the general engineering bolt has more universal applications than aviation bolt, because the aviation bolt, we can apply only at one place or at place 

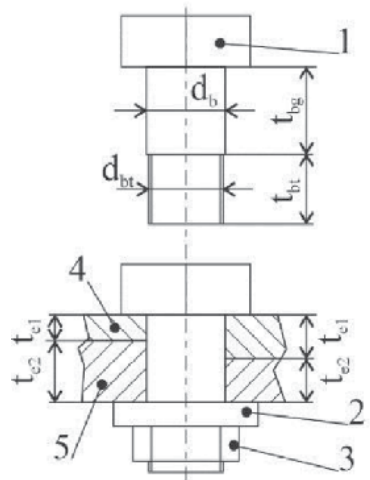

(a)

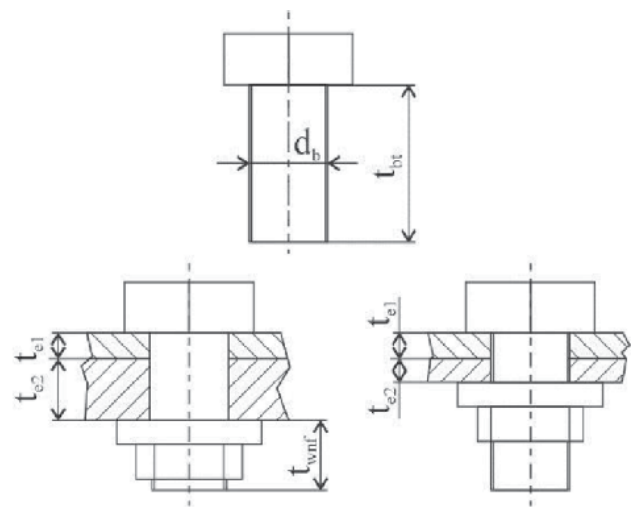

(b)

Figure 18.

Aviation bolt joint (a) and general engineering bolt joints (b): 1, bolt; 2, washer; 3, nut; 4, 1st jointed element; 5, 2nd jointed element.

with the similar thickness of the jointed elements. For the general engineering bolt, this strict is softer.

Usually, joints in an aircraft structure have low interchangeability features, and designers should try to adjust to this feature.

\subsection{Aircraft repair specifics}

Repairing the units depends on the following:

1. Interchangeability of parts, members, and units.

2. Capability of replacing parts without disassembling members located nearby.

3. Development of block (modular) structures (Figure 19).

4. With failure, the inoperative module (block) is replaced by a serviceable one and forwarded for repair to the specialized site.

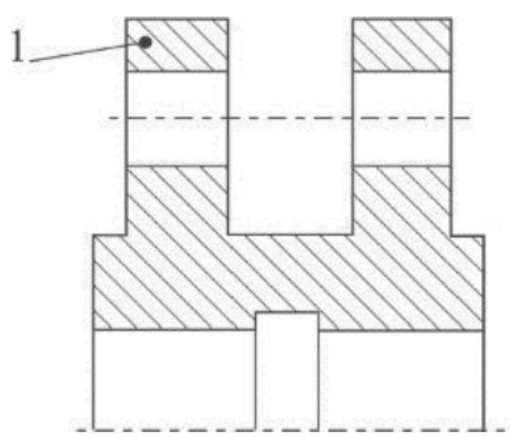

a

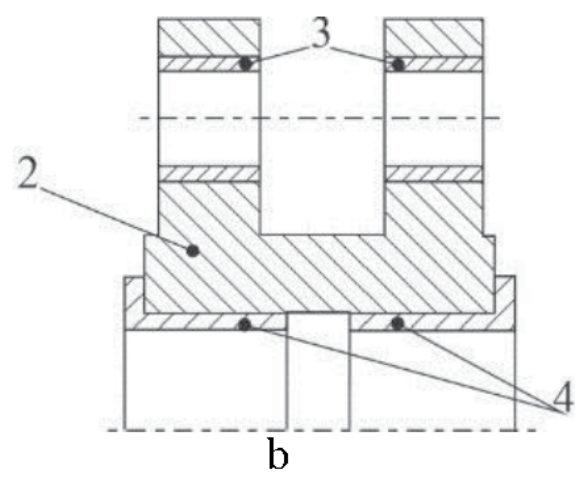

Figure 19.

Variants of structures: (a) is discouraged; (b) is recommended. 
5. Removing the necessity of developing all units, searching for the inoperative member under field conditions.

6. Utilization of widely standardized and unified parts and units.

It is necessary to develop a structure that allows for its simple and quick removal and replacement. For example, the replacement of the engine on AH-56A helicopter is made for $30 \mathrm{~min}$ [12].

\subsubsection{Example 5}

Complex and hard-load element must have modular structure. In Figure 19a, there is monolithic flange. In Figure 19b, there is an assembler flange with the same functions. Elements 3 and 4 are presented at hard-load zones that transfer the main loads. So, they have a short service life compared with body 2 . Fast changes of elements 3 and 4 provide simpler repair and cheaper reserve elements.

It is a rational way to apply such structures that could be removed with the help of ground equipment and strength of the maintenance personnel.

\section{Requirements of simplicity of performance of fueling, oil servicing, and adjusting works}

Refueling, recharging, oil servicing, etc. are important and dangerous operations for the aircraft maintenance. They create many risks.

For this purpose, an aircraft structure must have the following properties:

1. Minimization of quantity and unification of fuel and oil types, fueling, and oil servicing devices.

2. Easy access to threaded joints which demand in using periodic check of tightening torque.

3. Decreased standard sizes of the used fasteners.

4. Unification of the turnkey sizes for bolts and nut heads.

5. Unification of connectors for measuring checking equipment.

6. Unification of connectors for filling operations.

7. The structure of fillers should exclude getting fuel (or oil) in the airplane during spillage passage. That is why it is better to apply the system of filling having jointers in the bottom parts of the airplane (Figures 20-23).

Figures 20-22 show the regular refueling procedures at the airport. It may be directly from the ground (Figure 20), and this way requires minimum possible time. It may be completed by the special stairs, and in this case, it will be more complex and longer.

In Figure 23, there are situations when the airfield has not specialized on refueling equipment and ground staff is done by manual mode. On the one hand, 
Design Approaches for Safety Increasing and Risk Decreasing for the Civil Aircraft's Operation DOI: http://dx.doi.org/10.5772/intechopen.92560

it is good, when an airplane can be refueled without specialized equipment. On the other hand, the risk of the emergency situation in time of procedure or after that is very high.

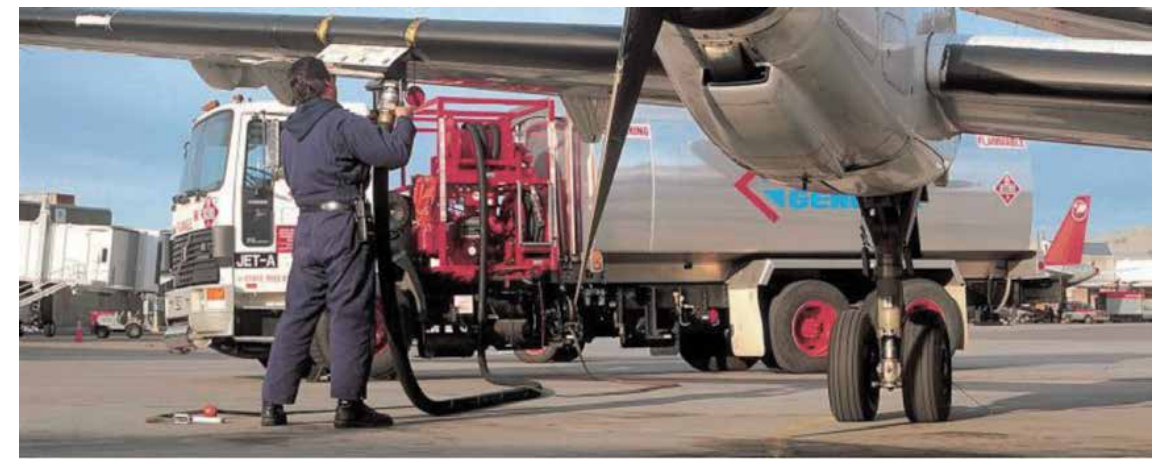

Figure 20.

Arrangement of the fueling connectors at the bottom wing surface.

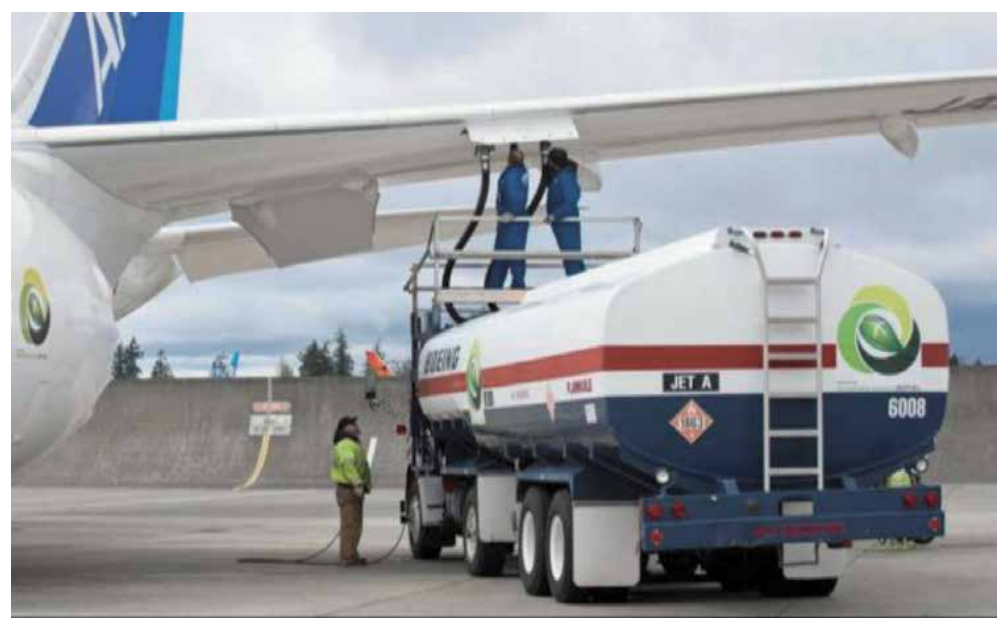

Figure 21.

Airplane fueling from the service car-non-rational.

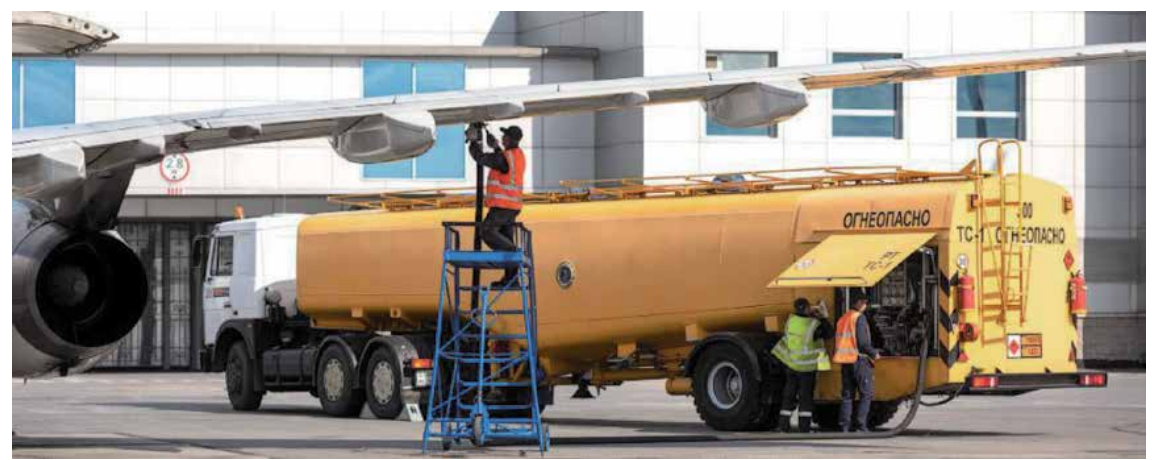

Figure 22.

Airplane fueling from the ground stairs. 


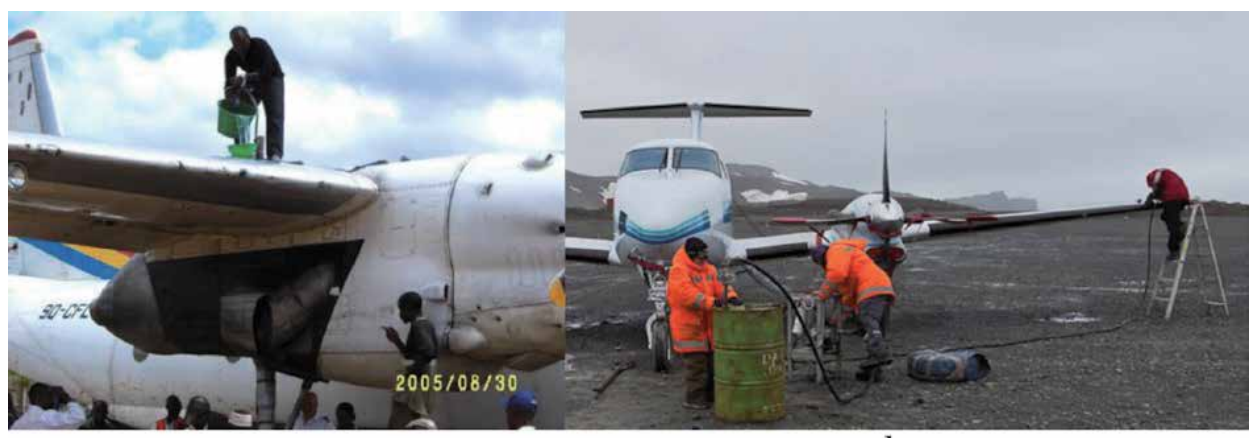

a

$\mathrm{b}$

Figure 23.

Handle refueling aircraft: (a) Antonov An-26 in Africa; (b) Beechcraft 300 at the Antarctic Air Base Pot. E. Frei $M$.

\section{Requirements ensuring reduction of labor input of carrying out loading and discharging}

There are risks for the aircraft during the loading-unloading procedures. To provide this requirement, we use the following design solutions:

1. Cargo compartments must have the equipment for loading-unloading (door stairs, cat crane, lift), the device for cargo fastening (Figures 24 and 25).

2. Cargo compartments will have to be located as possible near to the runway. It simplifies loading-unloading process. For example, the landing gear with the possibility of squatting the nose and main legs are used for airplanes (Figures 26-32).

In Figures 25-27, there is Antonov An-124 supercargo airplane that has nose and rear cargo door, special lift equipment that is built in its cargo compartment, light system for the night conditions, etc. All of these features provide successful airplane applications.

Figures 28 and 29 show cargo airplanes Boeing Company Dreamlifter and Airbus Company Beluga. Both of them require specialized loading-unloading equipment, and they cannot be applied at the airports without these tools.

Cargo door side location (Figure 30) has more easy structural solution, but the dimensions of a cargo must be smaller than the previous examples.
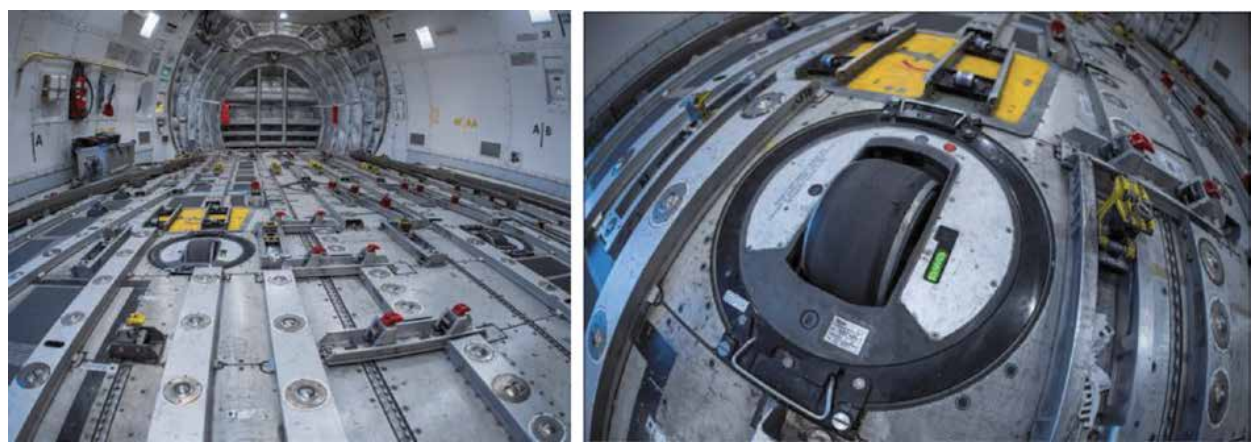

Figure 24 .

Floor of the airplane B747 cargo compartment with the devices for moving and fastening of cargo. 
Design Approaches for Safety Increasing and Risk Decreasing for the Civil Aircraft's Operation DOI: http://dx.doi.org/10.5772/intechopen.92560

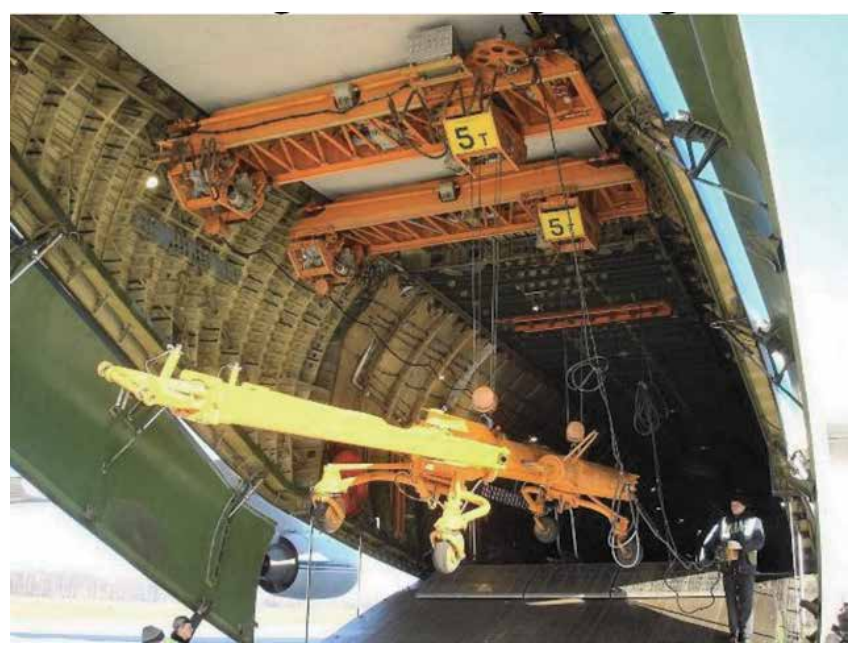

Figure 25.

Cargo compartment with the built-in hoist of the cargo aircraft Antonov An-124.

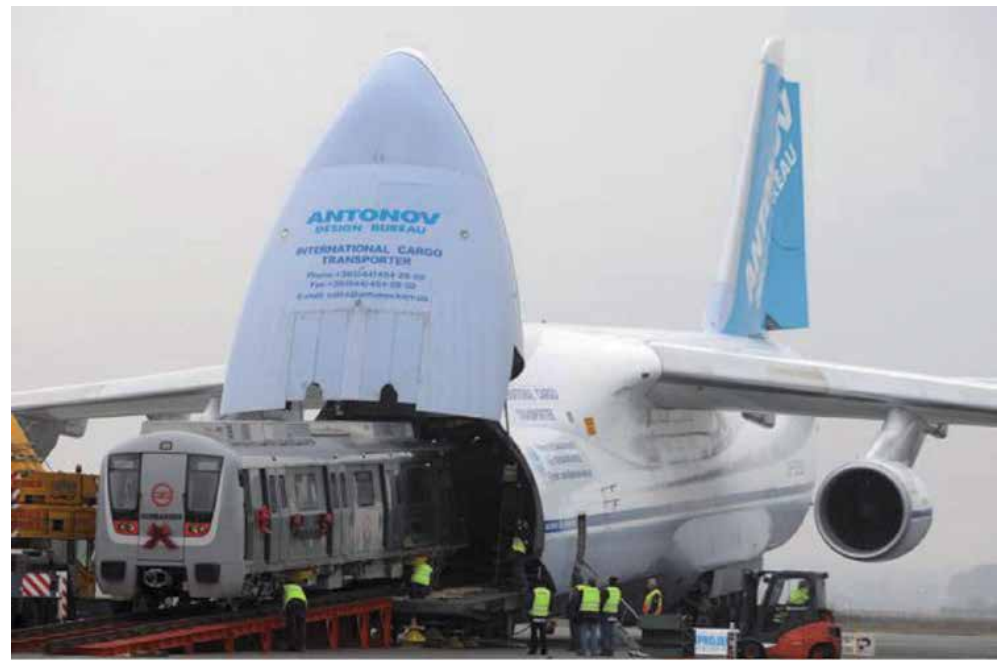

Figure 26.

Nose cargo door of the heavy cargo airplane Antonov An-124.

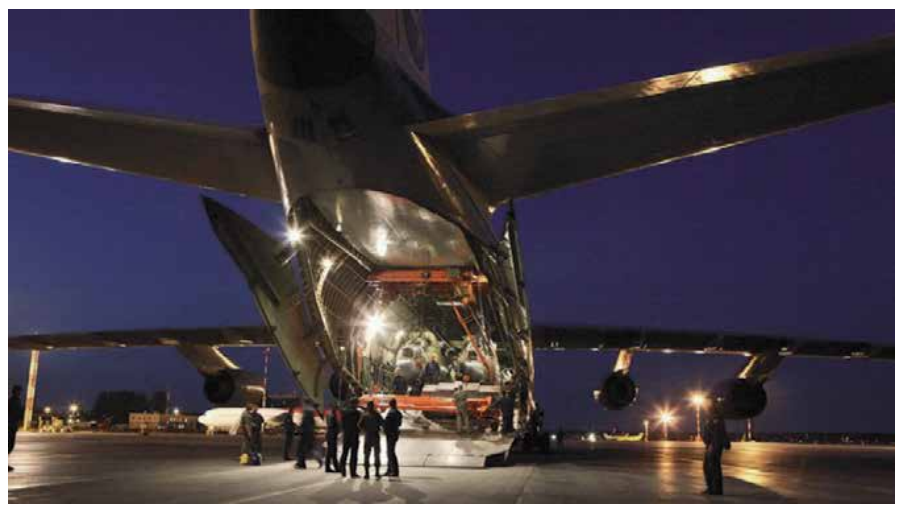

Figure 27.

The rear cargo door of the heavy cargo airplane Antonov An-124, night loading procedure. 


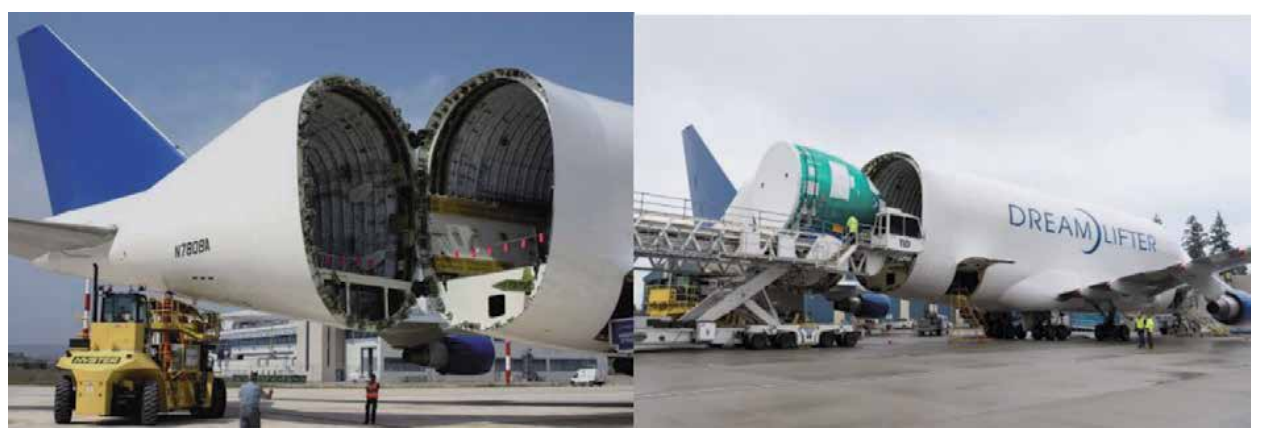

Figure 28.

Rear cargo door of "Dreamlifter" B747.

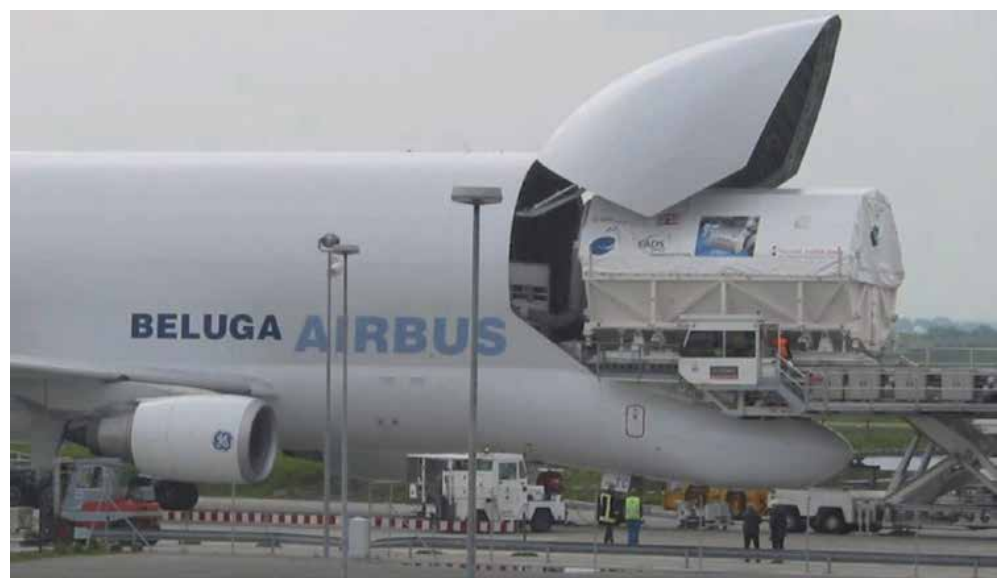

Figure 29.

Loading cargo into Airbus beluga cargo plane from nose cargo door.

For the passenger aircraft there is a task of passenger stairs location selection. In bigger airplanes, usually car drive stairs (Figure 31) or passenger boarding bridges (Figure 12) are used. For small airplanes (Figure 32a) or regional airplanes (Figure 32b) that can land on the unpaved runways at airports without special stairs tools and the built-in passenger stairs (Figure 32), there is rational solution.

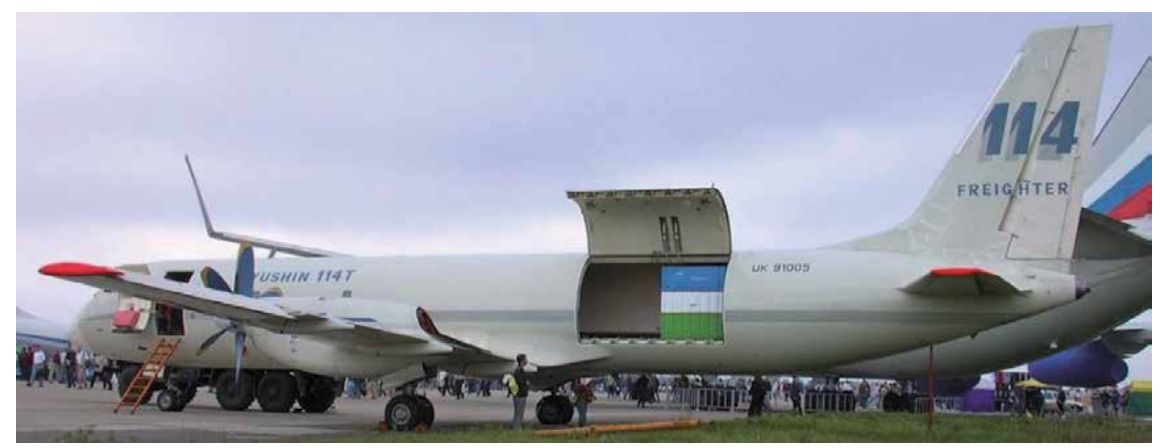

Figure 30.

The side location of cargo door in the Ilyushin-114T cargo airplane. 


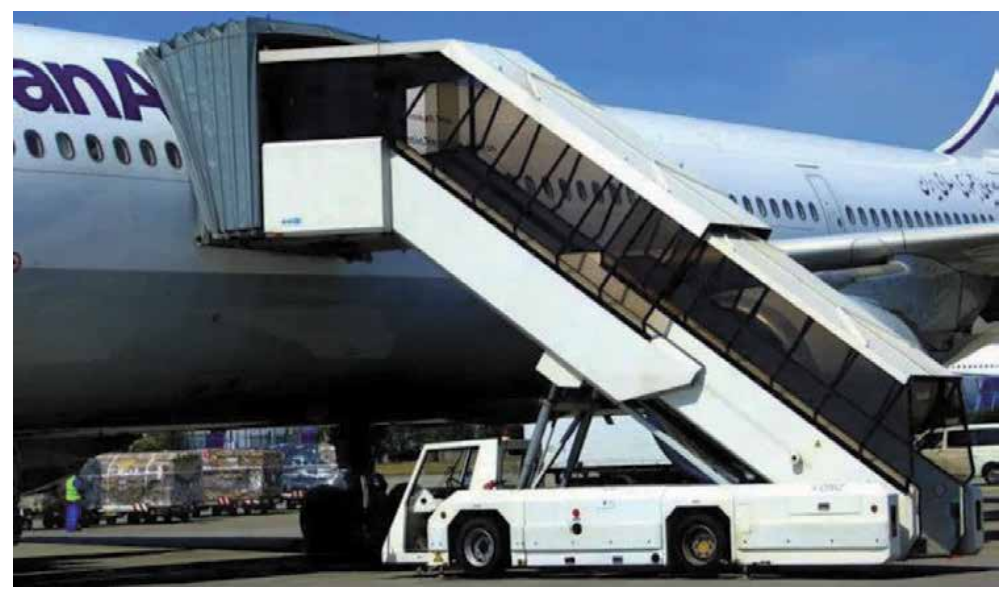

Figure 31.

Passenger stairs.

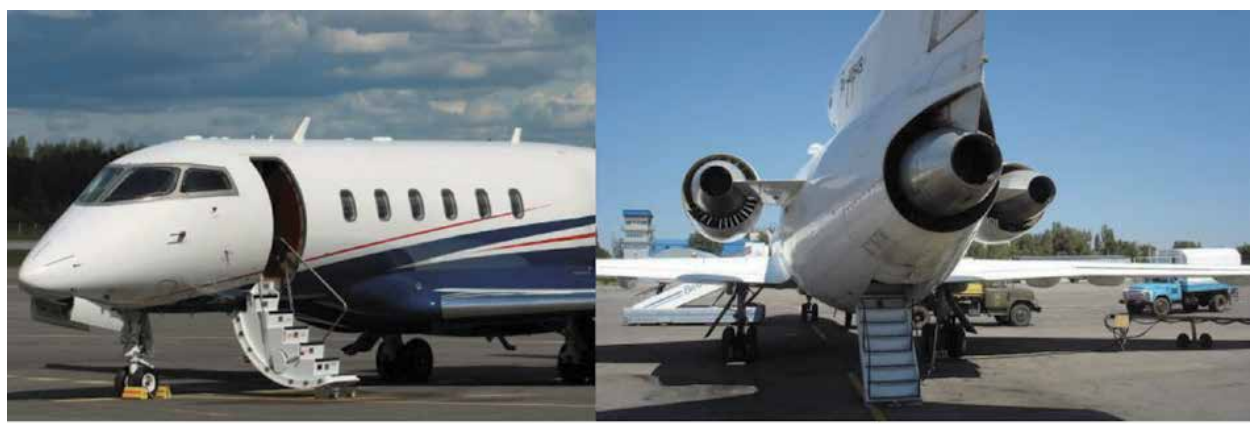

a

b

Figure 32.

The door stairs at passenger airplanes: (a) side location for Bombardier Challenger 300; $(b)$ rear location for Yakovlev Yak-42.

\section{Requirements for operating capability in various weather conditions and storages out of doors}

External factors, like the weather conditions, have negative effects on the aircraft maintenance, related to risks and its safety. Hot and cold temperatures both have a negative influence on the staff activity, aircraft's structural member, tools, etc. Not only temperature has this feature, extreme humidity, strong wind, solar radiation, etc. also have the same effect.

\subsection{Design solutions}

A designer on the base of the deep analysis of operational conditions, a customer requirement, engineering solution database, etc. can influence on the risk factors.

\subsubsection{Example 6}

There is a retractable nose leg of landing gear and its compartment. If an airplane can be used on unpaved runways, then it is necessary to minimize the possibility of 
getting in landing gear compartment of different dangerous foreign objects, especially dirt and snow.

Some baseline arrangement solutions are possible:

1. After retraction of the landing gear leg, the landing gear compartment must be closed again (Figure 33); however, it complicates the structure of the gear in opening and closing of the landing gear compartment door.

2. Rational using the direction of a leg ejection: a, front ejection (Figure 34a), full values of dirt, snow, and stones get in the landing gear compartment; $b$, backward ejection (Figure 34b), all dirt put on the bottom (closed) section of fuselage; c, non-retractable landing gear (extreme variant).

Front ejection has other advantages compared with backward ejection. One of them is as follows: wheel is more easy to locate at the variant because in this case it will be arranged at the bigger fuselage cross section.

So, collisions between some of the operational requirements are a possibility, and the designer-engineer must find a compromise between all of these requirements taking into account aircraft's operational limits, required safety level, etc.

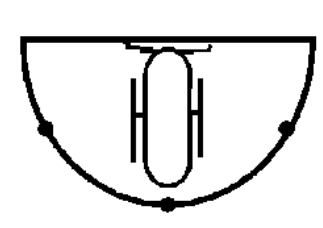

a

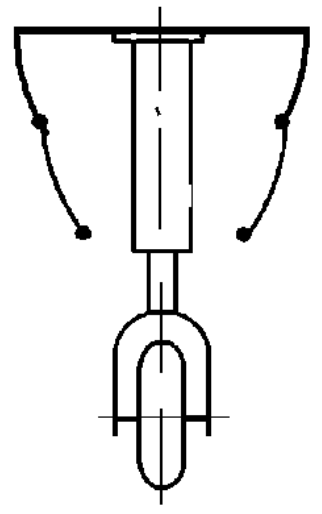

b

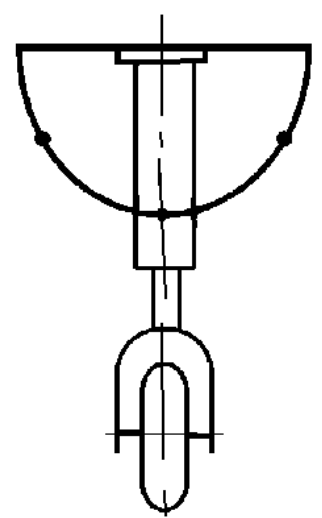

c

Figure 33.

The arrangement variant of landing gear for an airplane with the take-off and landing at soft surface runway: (a) base position (retract); (b) eject of the landing gear leg; (c) final eject position.

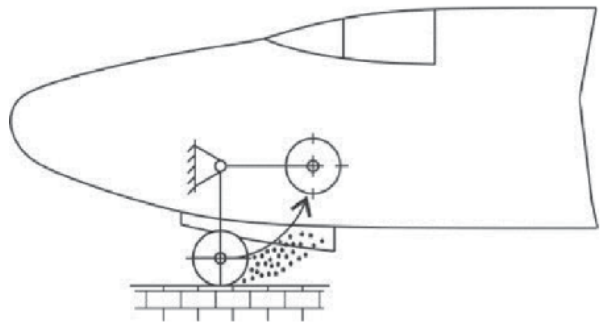

a

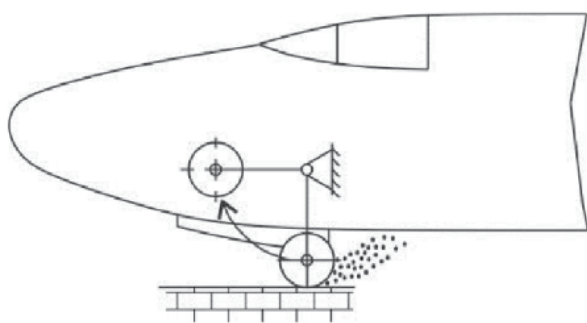

b

Figure 34.

Diagrams of retraction-ejection of nose landing gear leg of regional airplane which operates at soft surface runway: (a) non-rational; (b) rational. 
Design Approaches for Safety Increasing and Risk Decreasing for the Civil Aircraft's Operation DOI: http://dx.doi.org/10.5772/intechopen.92560

\subsection{Manufacturing solutions}

1. To apply materials, proof to environment.

2. To use open but not closed-loop sections in which moisture can be collected (in places of probable accumulation of moisture on the lower surfaces, the drain holes must be provided) (Figure 35).

3. To carry out anticorrosive procedures.

Structural materials that are widely applied in modern aircraft are as follows:

1. Artificial thickening of protective oxide coating with the help of anodic treatment (Figure 36) and chemical oxidizing for metallic structural materials like aluminum alloys, steel, etc.

2. Metal coatings (plating, metal spraying) (Figure 37)

3. Protection with protectors (for aluminum alloys, zinc is more often applied)

\section{Paint coatings (Figure 38)}

\subsubsection{Example 7}

Metals and alloys with more positive potential, when contacting with aluminum alloys, increase their corrosion. They are copper, and its alloys, nickel, tin, alloys of

a
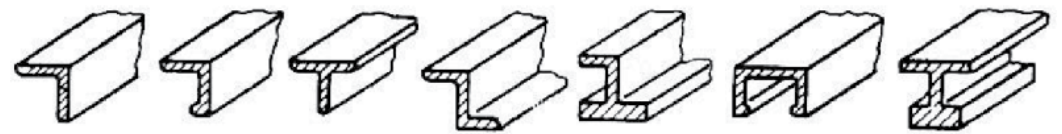

b
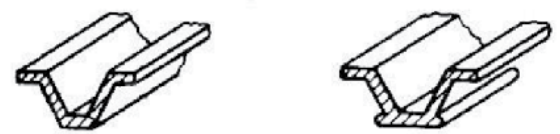

Figure 35.

Open (a) and closed-loop (b) structural elements for stringers.

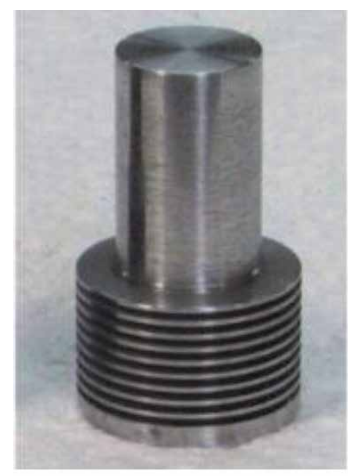

a

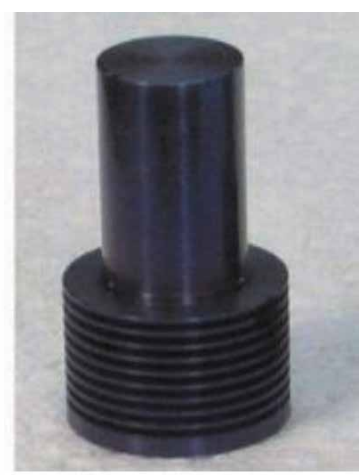

b

Figure 36.

Steel element: (a) before anodizing; (b) after anodizing. 


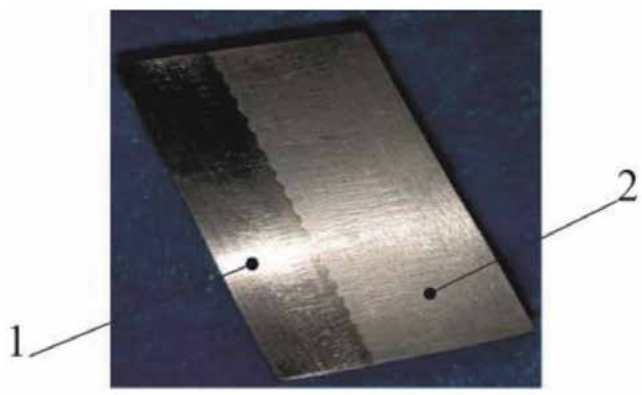

Figure 37.

Cladding for the aluminum alloys by steel: 1, steel layer; 2, aluminum layer.

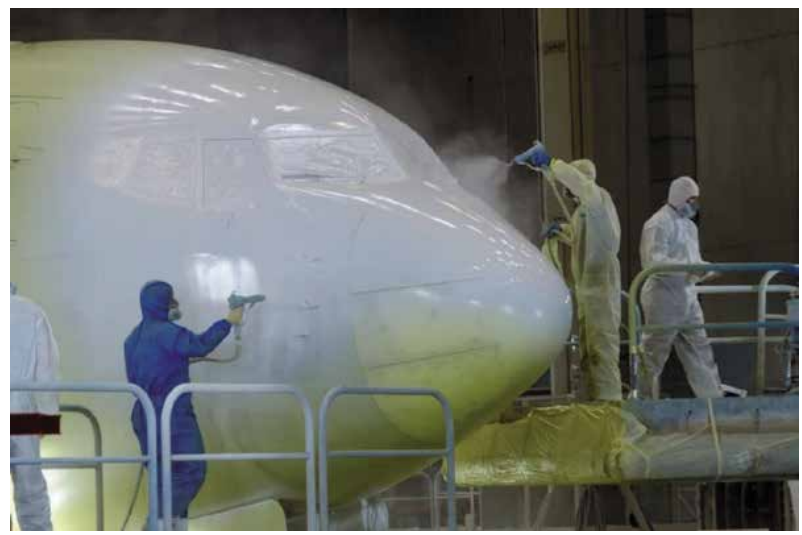

Figure 38.

Aircraft painting.

nickel, steel, and lead, are considered as noble metals. Without special protection, contact of these metals with aluminum alloys is not allowed. For example, riveting is impossible by copper rivets. If contact is necessary, then special gaskets should be applied (Figure 39).

If the materials have the same potential, contact can be allowed. These are alloys on a basis of zinc and cadmium: any materials covered with zinc, cadmium, and aluminum.

\subsection{Servicing solutions}

The weather factor can be solved by the solutions for airports. Applying special building for the aircraft is necessary to keep its high efficiency (Figure 40).
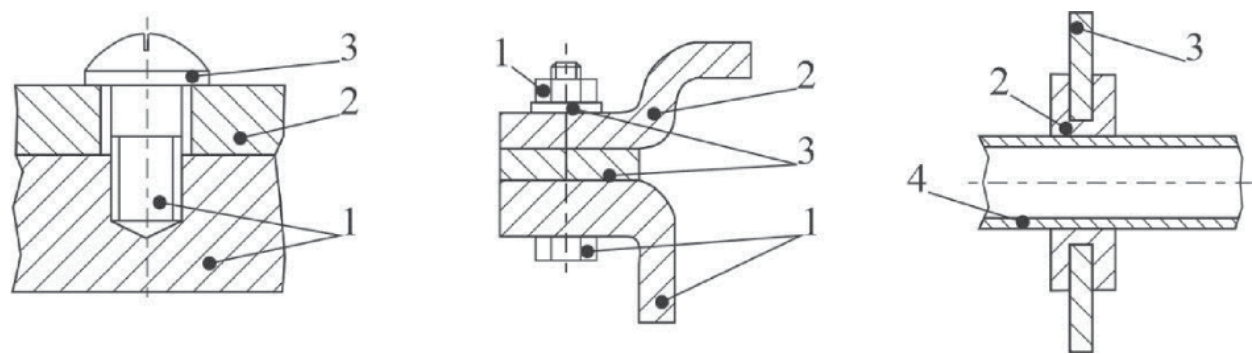

Figure 39.

Protection of metals at contact: 1, steel; 2, aluminum alloy; 3, cadmium; 4, copper alloy. 


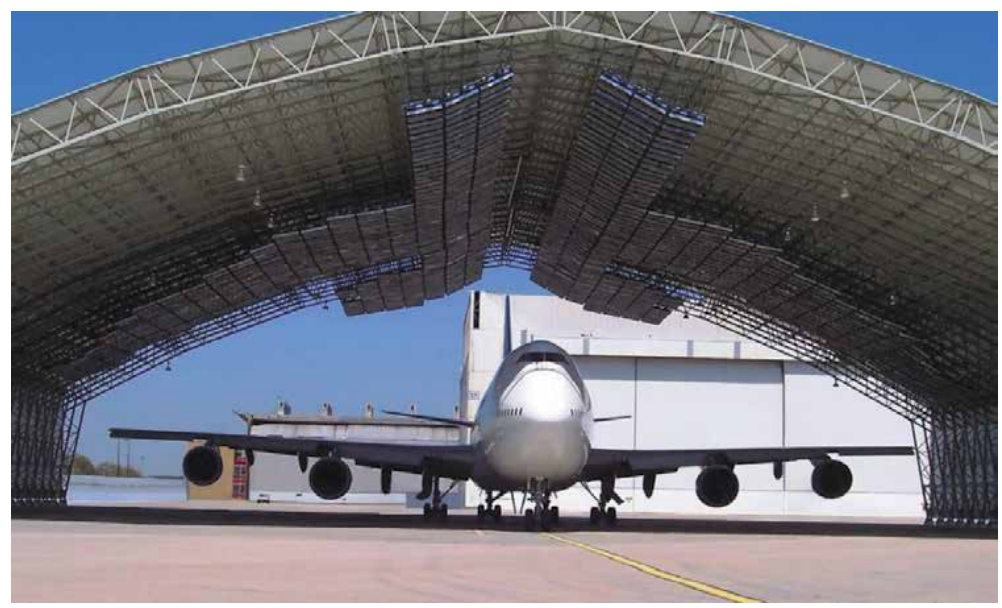

Figure 40.

Boeing 747 in the special aircraft shed.

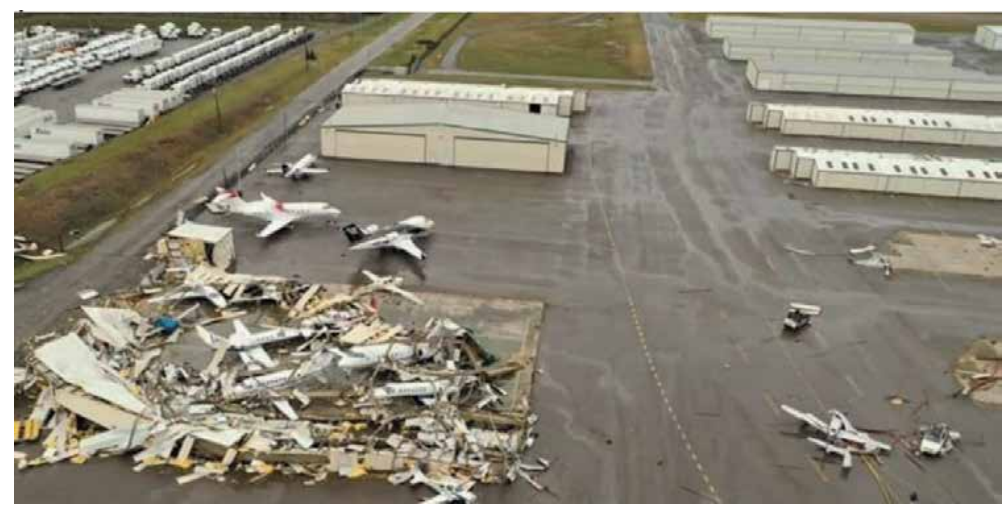

Figure 41.

The impact of tornado in the West Nashville John C Tune Airport on March 03, 2020.

Some of their advantages are as follows:

1. It keeps an airplane from long parking caused by weather.

2. It provides good conditions for the ground staff in time maintenance or repair: temperature, light, etc.

The results of the environment negative affect are shown in Figure 41. There you can surely see that airport buildings are good, but some airplanes were destroyed after tornado.

\section{The requirements for transportation}

It implies that the units of the airplane are to be no more than certain established sizes and also have attachment capability.

The possibility of an airplane or its separate units transportation depends on specifics of rail-way, ships, highways and soft-roads (Figure 42 [13]). 


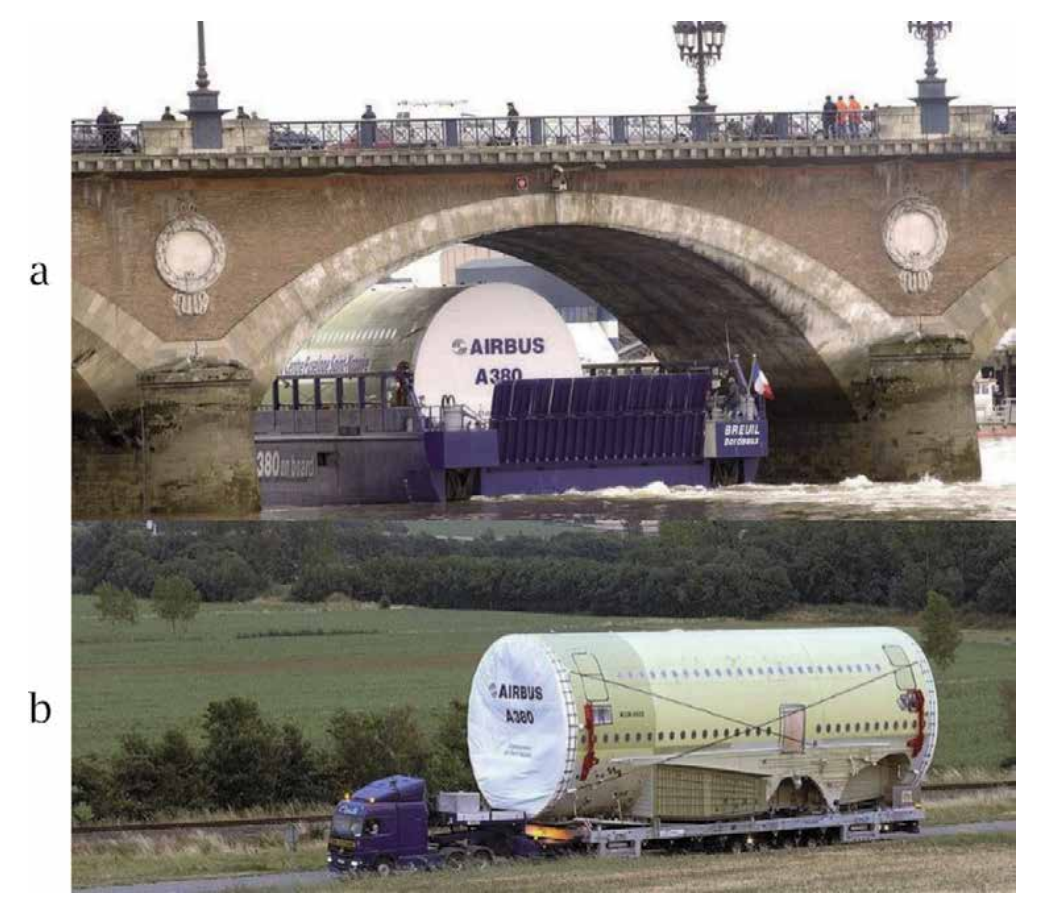

Figure 42.

Transportation of Airbus A380 section: (a) fuselage by river ship; (b) fuselage by road.

One of the reasons for the high cost of the aircraft A380 project is the complex logistics of its units to the final assembly place. During transportation, it is necessary to provide the required safety level at all stages. It is a complex and expensive task.

\section{Afterword}

As it is shown in this chapter, the different stages of maintenance, servicing, etc. are important and mission-critical for decreasing risk and providing safety. Rational structural solution that can provide convenient maintenance procedures, simpler repair, which can compensate environmental effect, etc. can be developed (implement at the designing stage).

However, they require from designer-engineers deep and wide knowledge in the engineering sciences. Also, often, they are facing challenges in economic requirements for manufacturing or minimal weight requirements, etc., and a designer together with a customer should take a balanced decision that can provide the highest possible economic efficiency with the required safety level. 


\section{Author details}

Dmytro Tiniakov

Nanjing University of Aeronautics and Astronautics, Nanjing, China

*Address all correspondence to: tiniakov_d@nuaa.edu.cn

\section{IntechOpen}

(C) 2020 The Author(s). Licensee IntechOpen. Distributed under the terms of the Creative Commons Attribution - NonCommercial 4.0 License (https://creativecommons.org/ licenses/by-nc/4.0/), which permits use, distribution and reproduction for non-commercial purposes, provided the original is properly cited. (cc) BY-NC 


\section{References}

[1] Krause S. Aircraft Safety. 2nd ed. New York, US: The McGraw-Hill Companies Inc.; 2003. p. 498

[2] Kritzinger D. Aircraft System Safety. Cambridge, England: Woodhead Publishing Limited; 2006. p. 367

[3] Zubkov V, Minaev E. Flight Safety Base. Moscow: Transport; 1987. p. 144

[4] Risk Management Handbook. U.S. Department of Transportation, FAA, Flight Standards Service, Change 1; 2009. p. 112. Available from: www. Militarybookshop.Co.UK

[5] Baker A, Dutton S, Kelly D. Composite Materials for Aircraft Structures. 2nd ed. Reston, Virginia: American Institute of Aeronautics and Astronautics, Inc.; 2004. p. 602

[6] Pourhashemi A. Engineering Materials. Toronto, New Jersey: Apple Academic Press; 2015. p. 286

[7] Boeing 787 Dreamliner battery problems [Internet]. Wikipedia. 2013. Available from: https://en.wikipedia. org/wiki/Boeing_787_Dreamliner_ battery_problems

[8] Wildlife Strikes to Civil Aircraft in the USA 1990-2018. Serial Report Number 25. U.S. Department of Transportation FAA [Internet]. 2019. p. 123. Available from: https://www.faa. gov/airports/airport_safety/wildlife/ media/Wildlife-Strike-Report1990-2018.pdf

[9] Statistical Summary of Commercial Jet Airplane Accidents Worldwide Operations|1959-2018. 50th ed. Boeing Company; 2018. p. 28. Available from: https://www.boeing.com/resources/ boeingdotcom/company/about_bca/ pdf/statsum.pdf
[10] Mahitko VP, Dmitrienko GV, Gavrilova EA. Estimation of risks and factors of danger in the system of safety of flights of airships. Bulletin of the Samara Scientific Center of the Russian Academy of Sciences. 2017;4(19): 192-197

[11] Eggink R, Bateman P. 747-8 offers operational improvements and crossmodel commonality. AeroMagazine, Boeing Company. 2010;03(39):5-15

[12] Velichko I. Mi-28 vs AH-64 Apache. Catching up always lagging behind? Nauka and Technika Journal. International Space Station; 2015;9 (112):52-62. Available from: https:// naukatehnika.com/mi-28-protiv-ah-64apach-dogonyayushhij-vsegda-otstaetchast-1.html

[13] Newton J. The amazing story of the A380 told through incredible pictures. MailOnline. 2019. Available from: https://www.dailymail.co.uk/travel/ travel_news/article-6700789/Theamazing-story-A380-told-incrediblepictures.html?ico=embedded 
Section 3

\section{Human Errors}





\title{
Theories and Models of Human Errors Occurrence. Simulation of Aircraft Maintenance Processes
}

\author{
Andrii Pryimak, Mykhailo Orlovskyi and Yevgeny Tretyakov
}

\begin{abstract}
General issues of the errors occurrence by technical personnel were considered, their causes and consequences. Classifications of errors based on an ergonomic understanding of their nature, as well as on the results of an engineering-psychological analysis of operators' activity are given. Much attention is paid to the methods used by ICAO to classify errors and violations. Details considered models SHELL and J. Reason. Their adaptation is presented for analysis cases of the impact of the technical maintenance quality on the flight safety of aircraft. A special place is occupied by the disclosure of assessing issues impact of technical personnel errors on flight safety. A wide range of existing methods and models is presented, allowing obtaining qualitative and quantitative assessment of this effect in order for the prevention of errors by technical personnel and mitigating their consequences.
\end{abstract}

Keywords: maintenance, technical staff, particular qualities of professional activities of technical staff, errors, classifications, causes, consequences, ICAO models, general research methods, expert methods, mathematical modeling

\section{Introduction}

The problem of human error is by no means new. World literature is replete with reports of accidents and disasters, where people are recognized as the main cause. However, the actualization of this problem, its isolation into a separate science, "the human factor," occurred not so long ago, only 30-40 years ago.

In the aviation industry, the term "human factor" began to be widely used in the second half of the 80s of the XIX century, due to the recognition of this problem by the ICAO Assembly, which adopted resolution A26-9 in 1986 in which, in particular, the importance of recognizing the role of human factor in aircraft operations, as well as the need to develop for them practical material and activities related to the human factor. It was the awareness of the breadth of the problem and its consequences for flight safety that made it possible to move from studying the influence of individual errors on the safety of the aviation system to studying the causes of their occurrence, which is the essence and subject of the study of the "human factor."

Considering the issues of the "human factor" and its impact on flight safety, the main emphasis is made by the majority of experts on the analysis of its manifestation in the practice of the flight crews and personnel performing maintenance and air traffic control. At the same time, in our opinion, little attention is paid to the problem of the manifestation of the human factor during maintenance and inspection 
of aircraft. Nevertheless, this problem becomes more and more significant every year, which is confirmed, for example, by the materials of [1-3] and a number of other official sources, including official documents adopted by FAA, EASA, ICAO in recent years $[4,5]$, materials of relevant seminars on the human factor, etc.

The rapid development of the global aviation market in the future will only aggravate the human factor problem. Thus, according to forecasts of the leaders of the global aviation market, the companies Airbus and the Boeing [6, 7], world park of commercial aircraft by 2038 will amount to more than 48,000 aircraft, which will require putting into operation according to various forecasts from 39,200 to 42,700 units of new aircraft with a capacity of 100 seats. In this case, the maximum growth rate of the park, according to the agency "Oliver Wyman" [8], will be observed in the first decade from 2020 to 2029 . These will be fundamentally new aircraft, which will require about 620-640 thousand of well-trained technical personnel for their service. Therefore, the contradiction between the needs of the market and the readiness of the aviation personnel training system to provide the market with so many technical specialists without loss of training quality seems to be tidy. In addition, it should be taken into account that even with the most optimistic forecasts, a significant market share is about 8.5 thousand according to [7] will still consist of aircraft of outdated structures with operating lives exceeding 25 years. The level of reliability of such equipment and safety, as shown in [9], is significantly lower than that of the entire park, which imposes additional requirements on the level of training of technical specialists.

Of course, it is only predictions, the validity of which we will be able to evaluate only after some time. However, regardless of the results forecasts, now become quite clear that the role of human factors in maintenance will only increase, providing more and more critical impact on the safety of civil aviation. Therefore, it is extremely important to develop analytical tools to identify problematic issues arising from aircraft maintenance and inspection, to predict possible consequences and to develop mechanisms to avoid, reduce or isolate manifestations of the human factor during the work of technical personnel.

\section{Maintenance errors, statistics, causes, and consequences for the flights safety}

\subsection{Maintenance error statistics}

The key concept in the study of the human factor and the subject of research in studying the problem are human errors, conditions and mechanisms of their occurrence, features of manifestation, and, of course, the consequences for the functioning of the system (technical, environmental, social, etc.).

It should be noted that according to the official statistics of the ICAO and other influential organizations that study the problem of flight safety, human errors in aviation account for $60-80 \%$ of all aviation accidents. Of course, the main carrier of these errors is flight crews. According to various sources, they account for between 40 and $75 \%$ of all accidents and incidents that occur. Clear generalized data on technical personnel are not available. However, quite complete, although somewhat contradictory information about the magnitude of the problem has been published and is contained in documents [10-12].

So, in [10], the results of several studies are presented at once concerning the effect of human errors during maintenance and inspection of aircraft on the accident state in civil aviation. The most voluminous of them is the study conducted by Sears R.L. It contains the results of an analysis of 93 major aircraft accidents that occurred between 1959 and 1983. In accordance with it, the problem of maintenance and 
inspection takes the fourth place among the factors directly affecting the accident rate in civil aviation, and is the main reason for about $12 \%$ of the incidents studied. At the same time, the results of the National Transportation Safety Board (NTSB) studies published in 2000 at (for updated results see [11]) indicate that out of 14 accidents that were investigated by the Council, 7 had the main reason is maintenance, which is $50 \%$ of all incidents. This allowed NTSB experts to conclude that service problems are growing as the design of the aircraft improves, as flight crews, personnel and air traffic control equipment are trained. A proportion of incidents related to these factors will decline, and the impact, technical service on the contrary will increase. Partially their predictions confirmed by data presented in [12], as well as by the annual safety reports of the International Air Transport Association (IATA).

In particular, in [12] states that the activities of an aircraft maintenance averaged $10 \%$ of the threats that led to the 432 aircraft's accidents in the period from 2009 to 2013 year. Maintenance operations, including standard operating procedures and training systems, were recognized by latent conditions for $8 \%$ of the 338 non-fatal accidents that occurred during the same time period in world aviation.

A subsequent analysis of the statistical material available to us indicates a positive trend in the number of accidents, fatal accidents and non-fatal accidents. During the period from 2013 to 2018 the average number of accidents, for which the technical service, including standard operating procedures and training were considered latent conditions ranged from $3.2 \%$ for fatal accidents, to $16.2 \%$ for the non-fatal accidents. Maintenance Events are recognized as threats on average for $6 \%$ of registered fatal accidents and $12 \%$ of non-fatal accidents. The highest values of these indicators registered for period 2014-2018, and amounted to respectively (latent conditions/Threats):

a. for accidents $-19 / 13 \%$;

b. for fatal accidents $-8 / 7 \%$;

c. for non-fatal accidents - 20/14\%.

\subsection{Causes of technical maintenance errors}

The data presented above characterize the problem as a whole, without specifying the reasons for its generation. However, it is not surprising, because speaking of the reasons we are faced with a conceptual and purely technical problem.

The concept of "cause" is part of a broader concept - "factor," which, being the driving force of any process, phenomenon, contains individual causes and their combinations, which, in turn, determine its influence on these processes and phenomena. In this regard, we have a technical problem, which, speaking about errors in the maintenance and inspection of aircraft, does not allow us to clearly identify all the specific causes of their occurrence, since there are usually a lot of them, and many of them are latent in nature. Therefore, researchers often prefer to study the problem either by focusing on the consequences of the manifestation of causes, or by grouping them for separate study, or for other purposes [13,14]. Only a few studies attempt to analyze the entire path "from cause to effect." An example of such a study is to survey more 1300 licensed Engineers held in 1998 by Australian Transport Safety Bureau [10, 15]. An analysis of the results made it possible to identify the nine most common direct causes of errors of technical personnel (Table 1) for cases related to and not related to airlines.

Below is the ranked information about typical errors made by technical personnel in the process of aircraft maintenance (Table 2), as well as the results of studies 
of the frequency of occurrence of these errors [10, 13]. For completeness, the results of several studies are immediately demonstrated (Tables 3 and 4).

\begin{tabular}{lcc}
\hline Occurrence causes and contributory factors & Airline & Non-airline \\
\hline Pressure & $21 \%$ & $23 \%$ \\
\hline Fatigue & $13 \%$ & $14 \%$ \\
\hline Coordination & $10 \%$ & $11 \%$ \\
\hline Training & $10 \%$ & $16 \%$ \\
\hline Supervision & $9 \%$ & $10 \%$ \\
\hline Lack of equipment & $8 \%$ & $3 \%$ \\
\hline Environment & $5 \%$ & $1 \%$ \\
\hline Poor documentation & $5 \%$ & $4 \%$ \\
\hline Poor procedure & $4 \%$ & $4 \%$ \\
\hline
\end{tabular}

Table 1.

Causes of technical personnel errors [15].

1. Incorrect installation of components

2. Fitting of wrong parts

3. Electrical wiring discrepancies (including cross-connections)

4. Loose objects (tools, etc.) left in aircraft

5. Inadequate lubrication

6. Cowling, access panels and fairings not secured

7. Landing gear ground lock pins not removed before departure

Table 2.

Errors in frequency [13].

\begin{tabular}{lc}
\hline Errors & Frequency of occurrence \\
\hline Omissions & $56 \%$ \\
\hline Incorrect installation & $30 \%$ \\
\hline Wrong parts & $8 \%$ \\
\hline Other & $8 \%$ \\
\hline
\end{tabular}

Table 3

The results of the analysis of 122 cases of engineering errors in the period 1989-1991 [16].

\begin{tabular}{lc}
\hline Errors & Frequency of occurrence \\
\hline Fastenings undone/incomplete & $22 \%$ \\
\hline Items left locked/pins not removed & $13 \%$ \\
\hline Caps loose or missing & $11 \%$ \\
\hline Other items left loose or disconnected & $10 \%$ \\
\hline Items missing & $10 \%$ \\
\hline Tools/spare fastenings not removed & $10 \%$ \\
\hline Lack of lubrication & $7 \%$ \\
\hline Panels left off & $3 \%$ \\
\hline
\end{tabular}

Table 4.

Research results by professor James Reason [17]. 


\subsection{Consequences of errors}

Technical maintenance and inspection of air vessels are important components of the system to ensure the safety of flights of civil aviation. Moreover, when we talk about maintenance, we should not understand this term too narrowly and focus only on the mistakes made during its implementation. After all, mistakes can be made directly in the project, and in technical documentation, and in the organization of work, etc. Speaking about maintenance errors, you should understand them as errors that are related to maintenance personnel.

In the Cir. ICAO 253-AN/151, technical maintenance personnel (hereinafter referred to as technical personnel) are defined as personnel who are at the forefront of resolving technical problems that arise during daily flights. Its activities are carried out under the influence of various conditions, which, aggregating into larger factors, directly affect the quality of work and operations. As a result of these influences, there are additional opportunities for errors of technical personnel, which, as a result, cause breaks in the safety chain of the aviation system. This is how the consequences are determined in a number of documents of ICAO and other authoritative organizations.

Speaking about the consequences that are possible as a result of errors made by the technical personnel of airlines and other organizations providing technical maintenance of modern aircraft, we should refer to the experience of research in this area, which has been brought up in a number of educational publications and practical experience on flight safety.

In accordance with the theory of safety, there are two large groups of consequences of errors of technical personnel:

a. failures of aviation engineering in flight. Here, by aviation engineering, we mean the aircraft, its engines, as well as removable and permanently installed equipment on board the aircraft.

b.events, leading to the immediate threat of flights safety. This division has a number of drawbacks, but plays an important role in the selection of methods for assessing the impact of the reliability of technical personnel on the state of flight safety and will be rather fully discussed below. However, there is another idea of the consequences of errors, which is more understandable and consists in dividing all the events associated with them by:

- active failures - associated with errors or irregularities that immediately cause an adverse effect They are usually considered (retroactively) hazardous activities. The operator of the "front line", performing direct maintenance and inspection of aircraft, usually makes such errors.

- hidden faults - are the result of decisions or actions that were committed long before the event and the consequences of which may not occur for a long time. Such failures are usually generated at the decision-making and rule-setting levels or at the level of linear leadership, that is, people far removed from what happened, both in time and location. Hidden failures resulting from dubious decisions or incorrect actions, although they do not cause harm if they are detected in isolation, can interact with each other, creating a "window of opportunity" for them to develop into active failures, which are destructive in essence to all types of system protection.

Here are a few examples, which demonstrate entered above classification of the consequences, and give brief explanations to them. 


\subsubsection{Active failures}

\subsubsection{Example 1}

The crash of the aircraft Embraer EMB-120RT 11.09.1991 year near Eagle Lake (Texas, USA) [18].

Fatal accident circumstances: Continental Express's Embraer EMB-120RT Brasilia airliner (operated by Britt Airwaysruen) operated a scheduled BTA 2574 flight on the Laredo - Houston route, but lost control while approaching Houston Airport and crashed to the ground near Eagle Lake, Texas, killing all 14 people on board - 11 passengers and 3 crew members.

Information about the aircraft: Embraer the EMB-120RT Brasilia - released in 1987 year (the first flight 17 November 1987 year). April 15, 1988 was acquired by Continental Express airline. On the day of the disaster has made 10,009 cycles "takeoff-landing" and flown 7229 hours. On the eve of the flight, work was done to replace the anti-icing pads on the horizontal tail of the aircraft.

Reasons leading to fatal accident: This case is a vivid example of the occurrence of an active failure due to erroneous actions, violations of the company's technical personnel when performing dismantling and installation work on the elements of the horizontal tail of the aircraft, immediately before the flight.

The incident was investigated by the NTSB.

According to its results, the following was indicated: "The failure of Continental Express maintenance and inspection personnel to adhere to proper maintenance and quality assurance procedures for the airplane's horizontal stabilizer deice boots that led to the sudden in-flight loss of the partially secured left horizontal stabilizer leading edge and the immediate severe nose-down pitchover and breakup of the airplane. Contributing to the cause of the accident was the failure of the Continental Express management to ensure compliance with the approved maintenance procedures, and the failure of FAA surveillance to detect and verify compliance with approved procedures."

NTSB board member John K. Lauber filed a dissenting statement on the investigation report, believing the probable cause should read as follows:

1. The failure of Continental Express management to establish a corporate culture which encouraged and enforced adherence to approved maintenance and quality assurance procedures, and

2.the consequent string of failures by Continental Express maintenance and inspection personnel to follow approved procedures for the replacement of the horizontal stabilizer deice boots. Contributing to the accident was the inadequate surveillance by the FAA of the Continental Express maintenance and quality assurance programs.

\subsubsection{Example 2}

The crash of the Boeing 727-264 on March 31, 1986, near Maravatio (Mexico).

Fatal accident circumstances: The Mexicana Boeing 727-264 Advanced airliner made a MX940 flight on the route Mexico City - Puerto Vallarta - Mazatlan - Los Angeles, but 15 minutes after departure from Mexico City it caught fire, fell into two parts and crashed into Mount El Carbon, resulting in killing 167 people.

Information about the aircraft: Boeing 727-264 Advanced was manufactured by Boeing Corporation in 1981 (first flight May 4, 1981). In May and June of the same year was sold to airline Mexicana, which awarded him the name of Veracruz. 
Reasons leading to fatal accident: According to the "Aviation Safety Network" resource, the accident with the Boeing 727-264 Advanced was the result of a number of errors and violations that were made in preparing the aircraft for flight by technical personnel directly to the Mexico City airport. The main reasons are indicated:

a. brake failure of the left main landing gear;

b. violation of the technology of charging pneumatics of wheels, as a result of which air was inside them instead of neutral gas;

The low level of inspection for this important element of security did not allow us to identify these shortcomings in time and, therefore, did not allow us to prevent subsequent adverse events.

Due to these errors and violations, events developed as follows: "The left main gear brake was overheated during the takeoff run. When the aircraft had reached FL310 the heat caused a tire on the left hand main gear to explode. Fuel and hydraulic lines were ruptured and electrical cables severed resulting in a cabin decompression. An emergency was declared, but spilt fuel ignited and caused a massive fire on board. Control was lost and the aircraft crashed into a mountain in the Sierra Madre, at an elevation of 9000 feet. It was found that the tire had been serviced with air rather than nitrogen. The air, under high temperature and pressure, resulted in a chemical reaction with the tire itself. This led to a chemical explosion of the tire" (Aviation Safety Network).

This is another example of active failures of aviation equipment in consequence of the action of human error during maintenance and inspection of aircraft. Their distinctive feature is the absence of long time intervals between the error and its consequence. Speaking about the hidden failures, we have a somewhat different picture. They are also caused by errors of technical personnel, but the consequences here are removed in time directly from the moment of the error. Let us illustrate this with examples.

\subsubsection{Hidden failures}

Examples of hidden failures are a series of incidents that have occurred over the past 50 years of civil aviation. Probably the most resonant of them are (events are given in chronological order):

1. The crash of the aircraft McDonnell Douglas DC-10-10 of American Airlines in O'Hare International Airport Chicago (Illinois, USA) 05/25/1979.

2. The crash of a Boeing 737-222 aircraft of Far Eastern Air Transport airline $151 \mathrm{~km}$ south of Taipei (CHINA) on 08/22/1981.

3. The crash of a Boeing 747SR-100 aircraft airline Japan Air Lines 08/12/1985, which was one of the most massive in the number of dead passengers.

4. The crash of a Boeing 737-200 aircraft by Aloha Airlines over Kahului (HAWAII, USA) on April 28, 1988.

5. The crash of a McDonnell Douglas McDonnell Douglas DC-10-10 plane of United Airlines airline at the airport of Sioux City (Iowa, USA) on 07/19/1989. 
6. The crash of a Boeing 747-200 aircraft of China Airlines over the Gulf of Taiwan on May 25, 2002.

There are many other examples where poor maintenance and manufacturing errors have caused the most recent military accidents in military aircraft.

Examples here are:

1. The accident of the F-15C aircraft, 110 aviation squadron, 131 fighter wings, Missouri National Guard during a training flight at the Lambert Field Air Base (St. Louis) 11/7/2007.

2. The crash of the Mi-24 helicopter $18 \mathrm{~km}$ from the airfield of Pugachev, Saratov Region, 10/03/2009.

3. The crash of the aircraft KS-130 over Liflor 07/10/2017.

However, the undisputed leader here is China Airlines Boeing 747-200 crash that occurred on May 25, 2002 over the Gulf of Taiwan [19].

Fatal accident circumstances: The China Airlines Boeing 747-200 airliner made a scheduled flight on the Taipei-Hong Kong route, but 25 minutes after take-off it suddenly fell apart in the air and crashed into Taiwan, killing all 225 people on board -206 passengers and 19 crew members.

Information about the aircraft: Boeing 747-209B was produced in 1979 (the first flight on July 16, 1979). On July 31 of the same year, it was transferred to China Airlines with tail number B-1866; on January 1, 1999 it was re-registered and received tail number B-18255.

At the time of the crash, the aircraft had 64,810 flight hours (21,398 take-off cycles).

Reasons leading to fatal accident: The Aviation Safety Council (ASC) Investigation Report (China) notes that on February 7, 1980, 22 years before the crash, while landing at a Hong Kong

airport, the aircraft touched the runway with its tail. Subsequently, the tail was repaired, and the aircraft continued to fly. It was at this moment, according to ASC experts, that the conditions of the 2002 incident were laid.

During the investigation, a number of organizational and technical flaws were identified, but the immediate causes that led to the disaster were:

a. poor-quality repair;

b.low efficiency of quality control during repair;

c. deficiencies in performing an aircraft inspection by a structural inspector;

d.flaws in the documentation defining the technology for the repair, maintenance and inspection of the aircraft, and others.

By the way, this is not the only disaster of this kind. A very similar accident occurred on 08/12/1985 with the Boeing 747SR-100 of Japan Air Lines [20].

Fatal accident circumstances:

The Japan Air Lines (JAL) airliner Boeing 747SR-46 made an internal flight JAL 123 on the Tokyo - Osaka route, but 12 minutes after takeoff, the elements of the aircraft critical for control were destroyed (the vertical tail and the hydraulic pipelines of the aircraft were destroyed). Despite the selfless struggle of the crew for the 
survivability of the aircraft, an almost uncontrolled aircraft collided with Otsutaka Mountain $112 \mathrm{~km}$ from Tokyo 32 minutes after takeoff. Of the 524 people on board (509 passengers and 15 crew members) only 4 survived.

Aircraft Information: The Boeing 747SR-46 was released by “Boeing” in 1974 (first flight on 28 January 1974 ode) on request for use on domestic flights in Japan. On February 19 of the same year, it was transferred to Japan Air Lines (JAL). On the day of the disaster, he made 18,835 takeoff and landing cycles and flew 25,030 hours.

Reasons leading to fatal accident: In the course of the fatal accident investigation, Aircraft Accidents Investigation Commission specialists found that on June 2, 1978, the JA8119, completing the JAL 115 flight on the Tokyo-Osaka route, hit its tail on the runway of Osaka Airport. As a result, the pressure bulkhead was damaged, separating the tail passenger compartment of the liner, which maintains approximately constant air pressure, from the leaky tail section of the aircraft.

During the repair process, the technical conditions stipulated by the Boeing company were not fulfilled, according to which it was prescribed to strengthen the damaged parts of the bulkhead using an integral amplifier plate fixed by three rows of rivets. Instead of installing a single amplifier with three rows of rivets, the repairing technicians used two separate reinforcing elements, one of which was fixed with a double row of rivets, and the second with only one row of rivets. Under the influence of variable loads during takeoff and landing cycles 7 hours after the impact, the bulkhead at the place of repair was destroyed.

Analyzing these two incidents, it should be noted once again the importance of ensuring high technological discipline in the maintenance, repair and inspection of aircraft. It should become an element of corporate culture of airlines. Very often, this is the only effective tool (protective mechanism) for preventing aircraft accidents.

\section{Classifications of technical personnel errors}

Having examined the issues of causes and consequences, we intentionally did not address issues relating to directly dangerous actions. They are characterized as personnel errors, when performing maintenance and inspection of aircraft, and which are identified by modern regulatory documents as actions or inaction, leading to deviations from the intentions or expectations of the organization or specific individuals (Doc.9859, 2018 edition). This was partly because the fact of error alone does not carry the necessary useful information to effectively prevent their occurrence in the future. At the same time, a clear understanding of the causes of personnel errors allows the development of various preventive strategies to prevent their occurrence in the future. On the other hand, understanding the consequences allows us to assess the risks from the corresponding errors and to rank them according to the degree of criticality for flight safety or in terms of financial and material losses for the airline. The result of this approach is a tool that allows you to set clear s sequence and implementation of preventive measures for the prevention of technical staff errors and optimizing, thus, possible losses of companies.

The presence of relationships such as "cause - dangerous action," "dangerous action - consequence," "cause - consequence" allows to classify errors of technical personnel, thereby reducing the degree of uncertainty that the relevant managers almost always encounter in the decision-making process.

There are a large number of different classifications of human errors, if we consider this issue from the point of view of the human factor, as a global problem. However, we will focus only on some of them, which, in our opinion, are of practical interest from the point of view of their applicability in the field under study. 
One of the main systems of descriptions of human error, which is already more than 50 years and is used by various researchers in the field of analysis of human reliability is a diagram referred to in A. D. Swain [21], according to which, human errors occur:

a. when a man fails to perform a task or a part of a task;

b. when he performs the task or step incorrectly;

c. when he introduces some task or step which should not have been performed;

d.when he not performs some task or step out of sequence, or

e. when he fails to perform the task or step within the allotted time period.

A somewhat different way of human operator error classification proposed D.A. Norman in [22], which is based on a psychological approach to the problem. He links groups of "working breakdowns" with alleged sources, which are modeled and analyzed using the activation-trigger-schema system (ATS) model.

Model ATS is composed of a set and schemes representing a sensorimotor cognitive structure. Each subsequent task in the model is considered as a hierarchy of schemes, changing the characteristics and activation modes of which it becomes possible to simulate the action of various sources that cause operator errors. Assuming the presence of these sources, Norman identified the following three main types of disruptions [22]:

a. errors in the formation of the intention (which includes the subcategories of mode and description errors);

b.faulty activation of schemas (which includes the subcategories of capture errors, data-driven and associative activations, loss of intention, and misordering of action components); and

c. faulty triggering (which includes the subcategories of spoonerisms, blends, intrusions of thoughts, and premature triggering).

As indicated in [23], the classification according to Norman is perfectly suitable for the theoretical analysis of the causes of human operator errors, but this classification is not suitable for analyzing its reliability. The reasons are as follows:

a. the use of the Norman classification is based on activation-trigger schemes, without which it and the analysis method itself lose its meaning;

b.the practical use of the ATS model is problematic:

- due to the contradictory views of psychologists on human behavior;

- due to excessively high requirements for the level of professional training of performers (experience in cognitive psychology);

c. individual errors operator can be interpreted in various ways, which entails the destruction of the whole system is empirically obtained data. 
Classifications and models presented by Swain and Guttmann [24] are of great practical importance. They are a further development of the classification given in the work [21] and the most adapted for solving a task analysis of human reliability.

The scientific work clarifies the concept of external and internal factors affecting productivity, gives a clear interpretation of intentional and not intentional errors, corrected (errors without consequences) and not corrected errors.

In the framework of the developed model for solving problems associated with the analysis of the reliability of the human operator, the wrong actions of the latter are considered by them in the framework of the following classification:

1. Errors of omission:

a. omits entire task;

b.omits a step in a task.

2. Errors of commission:

a. selection error:

- selects wrong control

- mispositions control (includes reversal errors, loose connections, etc.);

- issues wrong command or information (via voice or writing);

b.error of sequence;

c. time error:

- too early;

- too late;

d.qualitative error:

- too little;

- too much.

This classification partly echoes the classification of operator errors, which was developed, in particular, by Professor B. F. Lomov. The work of M. A. Kotik ("The Course of Engineering Psychologists”, 1978) provides a fairly extensive classification of errors by the authors G. M. Zarakovsky and V. I. Medvedev, developed and presented by them in the work "Classification of Operator Errors" in 1971. It is proposed to analyze human errors using the following criteria:

a. places of error in the structure of the functioning of the "man-machine" system;

b.the outward manifestation of the error; 
c. the consequences of the error;

d.the nature of the error display in the operator's consciousness;

e. causes of error.

An interesting approach is the authors to analyze errors for the reasons for their occurrence. The following categories of error causes are highlighted here:

1. Immediate causes - differ from two points of view:

a. by place in the structure of activities:

- errors of perception (visual, auditory, kinesthetic, etc.);

- memory errors (storage, reproduction, short-term, long-term);

- decision-making errors (when acting according to the rules, in logical operations, when calculating, when thinking creatively);

- errors in the response (movement, speech response, memorization), etc.;

b.the following error types are distinguished by the form of violated laws:

- mismatch of the information processing process (excessive flow of information, lack of information, lack of input data, etc.);

- mismatch of the skill (transfer of the skill to the conditions where it is unacceptable, error switching skills, lack of skill, etc.);

- lack of attention (improper distribution of attention or switching attention, lack of concentration, excessive concentration).

2. The main causes of operator error are associated with the following factors:

a. operator's workplace;

b.organization of work and rest;

c. preparing the operator and the system for a specific operation;

d.the physical and mental state of the operator;

e. motivation of the operator to perform the operation.

\section{Causes contributing to the error.}

Flow from the more fundamental properties of the operator. They are associated with the general attitudes of the operator's personality, his general state of health, his training system, life organization, relationships in the team and in the family, etc.

Despite a fairly detailed study, the classification of G.M.Zarakovsky and V.I. Medvedev for objective reasons described in the work of M.A. Kotik, did not 
receive wide recognition in solving psychological and ergonomic problems operator error analysis. However, the idea of dividing the causes into main, immediate and contributing, is actively used now in the analysis of errors of aviation personnel, as well as in the investigation of the causes of incidents and aircraft accidents.

Thus, all the above classifications are intended exclusively for solving ergonomic problems and performing engineering and psychological analysis of operators in the human-machine system and are practically not used for solving practical problems of assessing the reliability of aviation personnel of airlines. Nevertheless, their ideas, in particular the ideas laid down in [24], were continued when developing the classification of errors of aviation personnel into personal errors and human errors. In this classification:

1. Personal error (personal factor) - is errors that occur due to mismatch conditions of work with individual properties of experts: level of professional training, physical and psychophysiological state, level of personal discipline and others. This often includes the reaction of technical personnel to changing external working conditions.

2. Human errors (human factor) - these are errors that arise in connection with the occurrence of conditions exceeding the capabilities of the personnel according to the boundary standards of their psychophysiological capabilities, which are inherent in all people with the training necessary for professional activity, manifested in the interaction of specialists and technology.

The above classification is useful in that it establishes clear markers that allow, according to the results of the analysis of errors of technical personnel, to relate them to a particular group and, subsequently, apply corrective actions specific to a particular group of reasons.

On the other hand, the above classifications do not solve the problem of establishing the depth of responsibility of technical personnel for making mistakes, which is crucial when deciding on the development of preventive and corrective actions aimed at reducing the human factor influence on the flight safety state of airlines. At the same time, the effective implementation of proactive flight safety management systems for suppliers of products or services and the effective supervision of their functioning by the state require a clear understanding of the differences between the concepts of error and violation. This difference is the basis of the classification recommended for implementation in the practice of airlines of the ICAO member countries by document Doc.9859 "Safety Management Manual" (2013 edition).

In accordance with the ICAO classification, all dangerous actions associated with the human factor, including during maintenance and inspection of aircraft, are divided into two types: errors and violations.

An error is defined as an action or inaction by an operational person that leads to deviations from organizational or the operational person's intentions or expectations.

A violation is defined as a deliberate act of willful misconduct or omission resulting in a deviation from established regulations, procedures, norms or practices.

As you can see, the difference between errors and violations is the intention of the performer. And if mistakes are an unintentional act, then the violation is a deliberate act or inaction in order to move away from established procedures, protocols, norms and practices. This is where the focus of Doc. 9859 is.

Errors of aviation personnel are divided into the following types: 
1. Slips and lapses are failures in the execution of the intended action.

a. slips are actions that do not go as planned;

b.lapses are memory failures.

\section{Mistakes are failures in the plan of action}

Unfortunately, the mechanisms of these errors regarding the activities of technical personnel are poorly understood today. As for the flight crew, the error data of the pilots and their mechanisms are well disclosed in the works of N. A. Nosov, the founder of a fundamentally new scientific approach to the study of "virtual realities" of a person, his followers Pronin, Yuryev and others [25, 26].

ICAO is not categorical in matters of maliciousness of violations, which allows a balanced and fair approach to the issue of impact on personnel, allowing them out of the belief that this will simplify the tasks and will not lead to negative consequences. ICAO proposes to identify such violations as judgments, and classifies them into types:

1. Situational violations are committed in response to factors experienced in a specific context, such as time pressure or high workload.

\section{Routine violations become the normal way of doing business within a work} group.

This type of violation arises as a response to difficulties with the implementation of the established rules of work, shortcomings in the organization of the manmachine interface, etc. As a result, the performers, maintenance teams establish their own, as it seems to them, "best" rules, which eventually become mundane. As a result, we are dealing with a practical shift, the consequences of which may be most serious over time. Sometimes these personnel actions are justified and can be taken as an official's procedures after carrying out the necessary examination and evaluation of safety risks.

3. Organizationally induced violations may be considered as an extension of routine violations.

This type of violation occurs when security requirements are sacrificed for immediate financial gain. Thus, as a rule, is disturbed balance between the desired level of productivity/profitability airlines and necessary layer eat protection (Doc.9859, 2018).

The value of the ICAO approach to the classification of human errors and violations consists, firstly, in its universality and adaptability. It can be applied with equal success both to the analysis of errors of flight crews and to the analysis of errors of technical personnel made by them during the flight operation, as well as in the process of maintenance and inspection of aircraft. Secondly, a clear division of the dangerous actions related to the human factor into errors, non-malicious violations (judgment errors) and intentional violations allows us to develop clear triggers that are used in the algorithms for analyzing errors/violations of airline personnel. An example of such an algorithm is presented in Figure 1.

Such algorithms are essential elements of the Safety Management Manual. They are developed by each individual airline as part of documentary support 


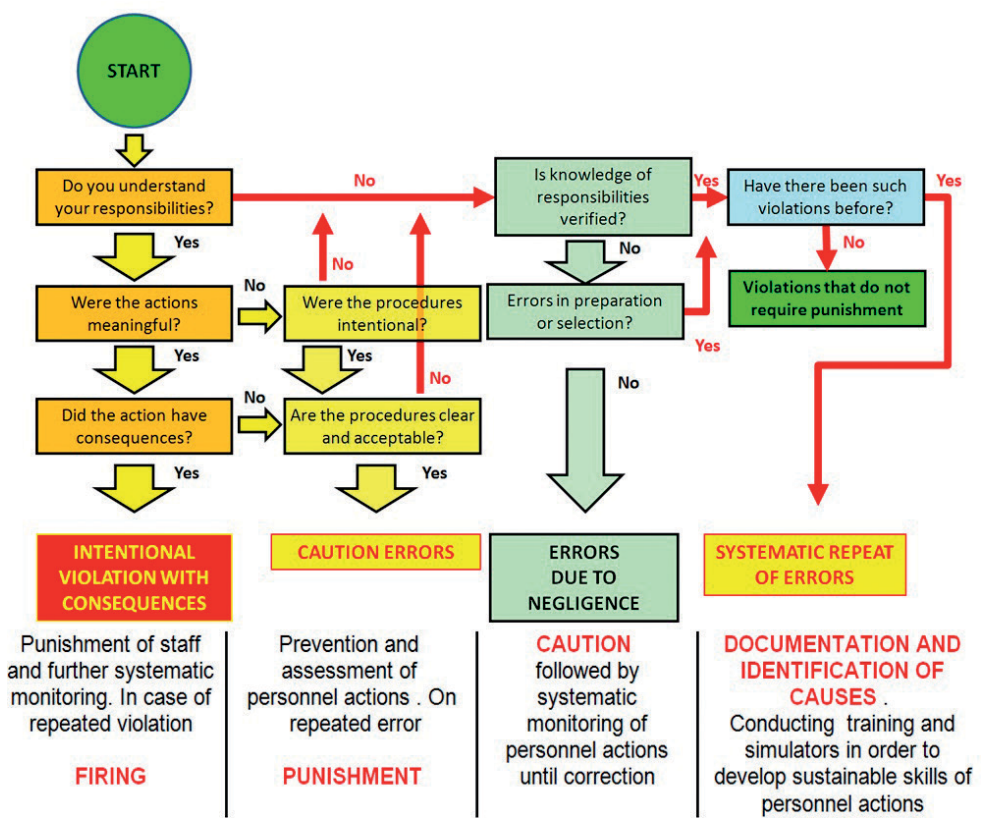

Figure 1.

Airline personnel error/violation analysis algorithm.

for the creation of safety management systems for organizations. In addition, the presence of such algorithms with a well-defined and clear triggers (action rules) stimulates the creation within the fair airline safety culture, and their integration in the adopters a airline models and operation allows to identify the causes of errors in a timely manner they eliminate or reduce the severity of consequences.

\section{Models and theories of human factor. Modeling the aircraft maintenance process}

The usefulness of error classifications is obvious and has been shown above. However, using only the classifications previously developed to study human errors, we significantly limit our ability to study their influence on the efficiency of the aviation system, which is largely determined by its flight safety status. Indeed, using only the information that is supplied to us by the existing classification of human errors, only one "static" state of the problem becomes available to us. At the same time, for a full study of the problem of the human factor, in particular, during maintenance and inspection of aircraft, consideration of the problem should be carried out taking into account its "dynamics". Only in this case we can count on the maximum result in solving problems:

a. minimizing the risk of accidents due to human factors;

b.obtaining the most adequate assessment of the effectiveness of protective mechanisms even before their practical implementation;

c. the formation of a common vision of the problem by all participants in the aviation community. 
Today, various approaches and models of the human factor are used in aviation. Their synthesis was possible due to many years of work such eminent scientists like J. Rasmussen, G. Heinrich, E. Adams, S. Shappell, J. Reason, D. Wiegmann and many others. Under their leadership and with their active participation, several directions and approaches to the study of the human factor, including in aviation, have been developed. These include [27]: cognitive, systemic, behavioral, psychosocial, medical (psychophysiological) and organizational approaches. There are many publications on each of them, and each publication deserves close attention and analysis. However, due to objective reasons, we confine ourselves to a brief consideration of some of them in terms of applicability in practice of aircraft maintenance. Probably one of the most famous models, which represent a modern systematic approach to the consideration of the human factor, is the SHELL model. Proposed by Professor E. Edwards 1972 year, this model has received wide popularity and in 1993 was recommended by ICAO as the basis for the analysis of human factors in accident investigation (Doc. ICAO 9859).

The model describes the four main components necessary for the successful integration of a person and his functioning as part of man-machine systems, the first letters of the name of which make up its name. These components include:

1. Software (S) - procedures (procedures, training, tools, and software, etc.).

2. Hardware $(\mathrm{H})$ - object (machines, systems and equipment).

3. Liveware (L) - subject (people in the workplace).

4. Environment (E) - environment (operating conditions in which all other components of the L-H-S system must function).

The SHELL model is based on the model of a person who, as a central element, interacts with its other elements. According to E. Edwards, it is precisely at the borders of these elements that problems arise that lead to erroneous human actions. Although this model is designed primarily to take into account all possible contextual and task-related factors that affect the performance of the pilot, including the design of cockpit equipment, etc., it can also be adapted to the working conditions of technical personnel, which in principle and confirmed in Cir. ICAO 253-AN/151.

The model allows, when studying the features of the work of aircraft maintenance specialists, to take them precisely as the central link, since they also operate in a specific environment specific to them (possibly even more complex than that of the flight crew), they use complex equipment $\mathrm{H}$, and numerous instructions and apply the software S. In this case, the lower block L displays both the flight crew and other specialists (for example, line management), with whom maintenance specialists come into contact with the production necessity. However, most often under the central unit still understand aircrew.

Since the global goal of the work of all aviation personnel is to ensure flight safety, it is therefore of interest to specify the initial SHELL model in relation to ensuring flight safety of aircraft. It is precisely this concretization that is presented in Figure 2.

In the figure, in addition to the notation already known to us, there are new ones:

Lf - flight (in the original diagram, the central block $\mathrm{L}$ is a subject, a person).

The lower block $\mathrm{L}$ of the circuit can be rationally represented as a "stack" of four blocks: Lm - maintainer, service, operator personnel; Lt - air traveler; Lp - producer, manufacturer; Ld - designer. 


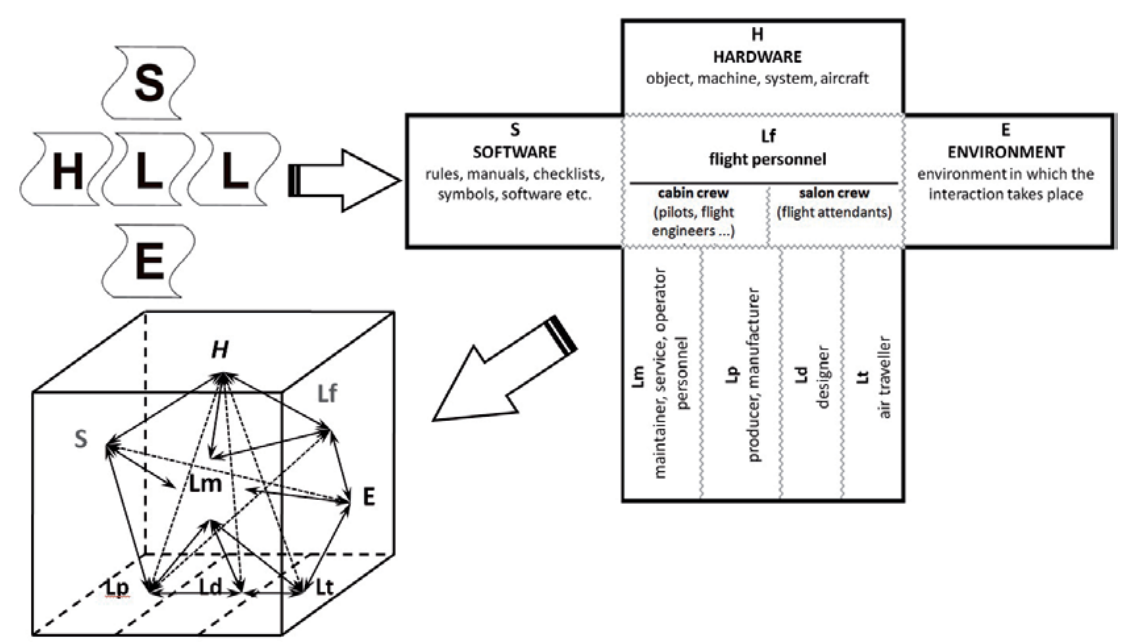

Figure 2.

Specification of the SHELL model.

Specification of the model allows us to more clearly understand the complexity of the relationship between the elements of the aviation system. In the future, by performing a spatial convolution of this model, it is possible to obtain a certain hypercube where the faces will be the corresponding new and known elements, and the edges will be the relationships between them. In addition, the logic suggests that depending on the situation (flight mode, stage of technical operation, etc.), the subordination of the model elements will be different.

So, when performing aircraft maintenance, the central place of the model should be given to technical personnel. At the same time, cabin and cabin crews will take a subordinate position, providing technical personnel with the necessary information about the state of the aircraft, problems noticed during the flight, etc. The nature of the relationship between the elements will change accordingly.

The described transformation is useful in the analysis of incidents and aircraft accidents caused by faults in maintenance and allow you to take into account many contextual and analysis-related factors, including equipment design. Moreover, avoids the need to focus on technical staff. However, it should also be remembered that the complete exclusion of a person from analysis, which is resorted to by many experts using this model, can cause incorrect conclusions, which is unacceptable when it comes to flight safety. An interesting and quite informative is the D. Peterson behavioral model [27] (Figure 3), which describes personnel performance as a characteristic that depends on innate abilities and motivation, which, in turn, depends on a number of other factors. For example, staff selection and training play an important role. At the same time, the decisive role in this model is assigned to motivation, regardless of where this motivation comes from - from work, colleagues, unions, or from the person himself.

This model has wide practical application in the aviation industry. It and other similar models underlie the formation of the aviation personnel's collective responsibility for ensuring flight safety in airlines: voluntary safety data reporting systems; incentives for safe and high-quality maintenance operations, etc.

Based on the principles of the modern approach, modern Maintenance Resource Management (MRM) systems are built [28]. The essence of the approach is to focus on the psychological and social interaction of personnel within, in particular, maintenance teams, as well as between specialists belonging to different professional 


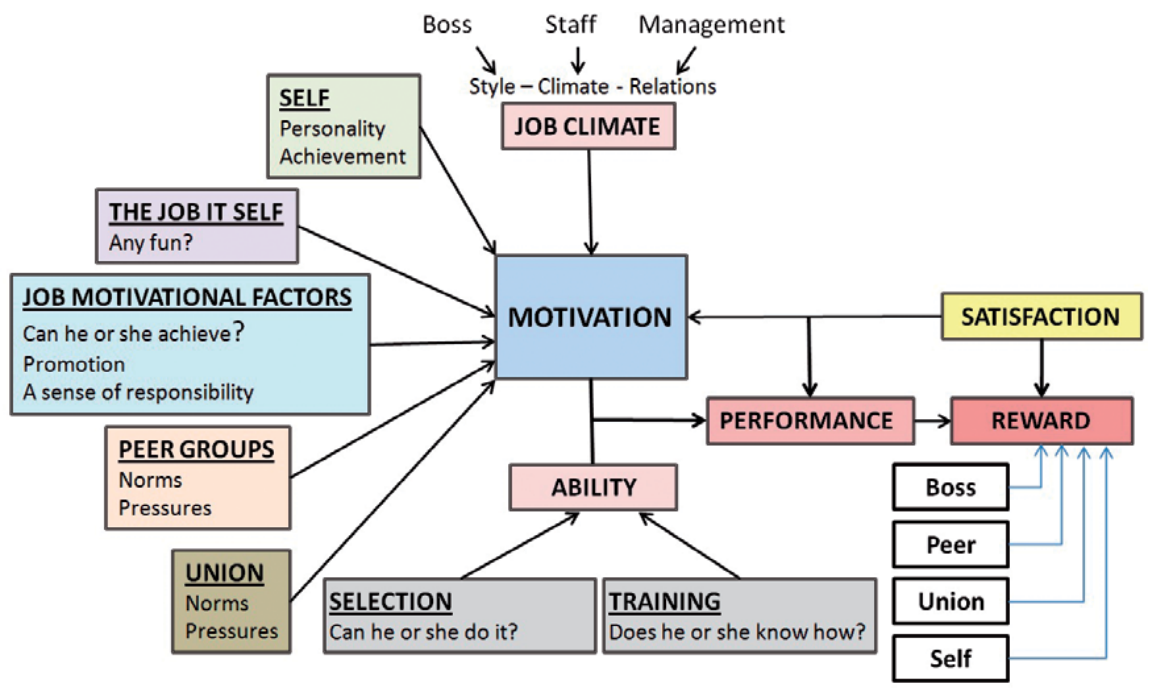

Figure 3.

Peterson's motivation, reward, and satisfaction model.

groups. These thin, but the complex interactions found in the heart model, a bid R.L. Helmreich and H. C. Foushee in [29].

Interesting and very useful, in particular, for understanding the functioning and spread of hazardous factors within an aviation organization, is the J. Reason model [30].

The model uses an analogy with the physiological concept of the human immune system. According to the model, all organizational systems carry within themselves the "embryos of their own demise" in the form of some analogues of "pathogens" that violate the normal functions of the systems. Such organizational "pathogens" give rise to latent errors or, in other words, latent malfunctions in the functioning of the system. Latent errors can accumulate over time and interact with each other. Finally, this leads to the appearance of qualitatively new errors - no longer hidden, but obvious failures (active errors) in the system.

Investigating the paths of error, J. Reason made an important conclusion that the most important "pathogens" arise at high levels of leadership, since strategic decisions are made there. Strategic decisions are designed to provide maximum performance and at the same time - the greatest security of the system as a whole. This thesis by J. Reason was welcomed by safety experts and international organizations.

The following model deserves to be examined in more detail - this is the J. Reason accident causality model $[17,31]$, which can be found in various manuals and circulars, both international and regional civil aviation organizations, as well as in various departmental documents.

This model, known as the Swiss Cheese model (Figure 4), explains how people cause dysfunctions of complex, interacting and well-protected systems (such as a commercial transportation system), resulting in an accident. If a strategic, conceptual decision is made incorrectly, and this is not compensated by the common sense of linear management ("getting into" the second "window"), and preconditions (organization of labor, availability of equipment) do not allow revealing a potentially dangerous defect and, moreover, when in the event of an emergency there is no means to prevent its transition into a catastrophic one - the windows in all the barriers coincided and the accident leads to dire consequences.

One can imagine that these obstacles (like in a good shooting range) swing under the influence of specific conditions (personal experiences of the leader, 


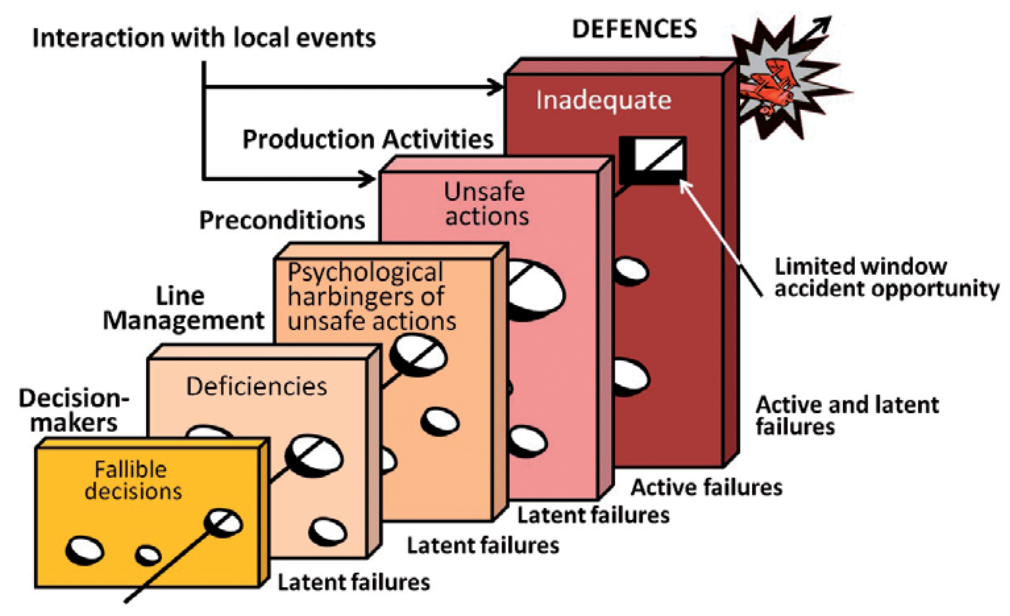

Figure 4.

Model causation accident J. Reason.

delayed maintenance of the aircraft and reduced time for maintenance, equipment breakdown, fatigue, illness of technical personnel), as a result of which "through lumbago" remains possible and even more difficult to predict.

Strictly speaking, all the components of the human factor discussed above must be included in the J. Reason model, preconditions, and also (zero barrier) environmental conditions. In fact, this model has incorporated all the best of the theories and models considered above.

The model interprets the incident as a coincidence in time during the flight of imperfection at the same time in several levels of protection against an accident. In addition, for the implementation of an accident during a flight, conditions must arise that are critical when there is a coincidence of the "windows" in the protection levels.

For the efficient and productive work of the maintenance technical staff, certain preconditions must be met: the equipment must be available and reliable; employees - qualified and interested; working conditions - safe, contributing to high quality; various precautions, usually designed to prevent foreseeable bodily harm, damage or costly interruptions.

If one or more of these conditions is not met, the work of the maintenance personnel does not guarantee the prevention of an accident (for example, the specialist will not be able to detect a hidden defect if the necessary equipment is not available). Let us turn to an example that may give a clearer understanding of all of the above.

\subsection{Example}

The crash of DC-10-10 of American Airlines on May 25, 1979 [32].

The crash occurred from- for failure flight control system after termination of the left engine at the end of the takeoff roll (node had 19,871 hour operating time) killed 271 people on board and 2 people on the ground. The root cause of the disaster was not enough quality securing the left engine pylon after his regular replacement. After replacing the engine, maintenance specialists improperly tightened the pylon mount bolts, which caused bending stresses in the nodes and, ultimately, their fatigue failure. The immediate cause of the disaster was the spontaneous cleaning of six sections of the slats of the outer part of the left console and the failure of two alarm systems in the cockpit caused by damage to the hydraulic 


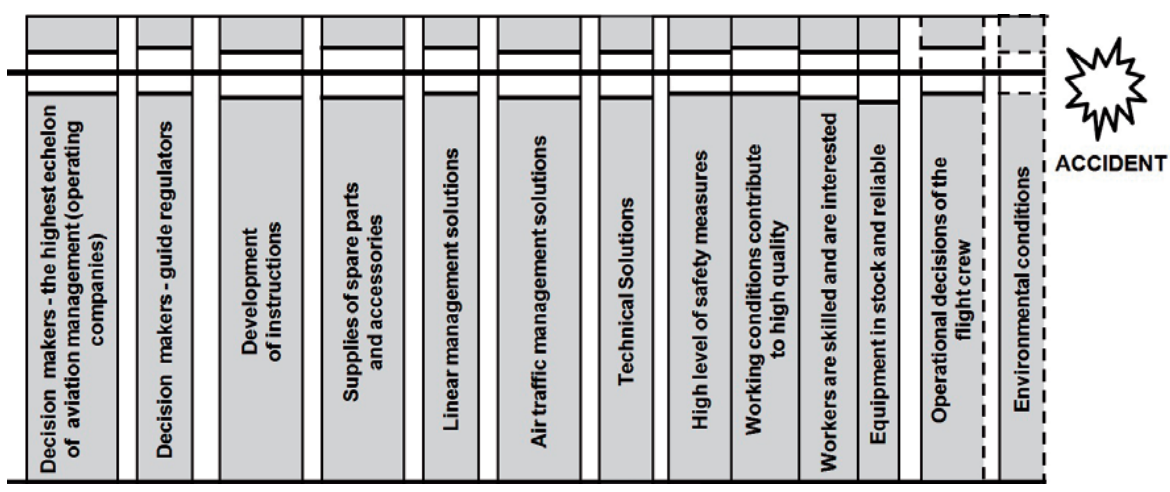

Figure 5 .

A model of causation of an accident built on the basis of the model of Professor J. Reason.

systems and control system when the engine with the pylon was separated from the wing. From - for a fault in the alarm system of the discrepancy between the position of the slats and their control knobs, as well as failure in the device control column pilots were unable to correctly identify the arisen emergency situation and prevent its transition to a catastrophic, although in principle it was possible. The low altitude and, as a result, the small time available for decision-making played a role. To confirm the validity of the approach, we analyze this incident from the point of view of the J. Reason model, a variant of which is shown in Figure 5.

In the diagram, the first condition from the incident is a flight situation, environmental conditions. The aircraft was at a low altitude and had not yet gained cruising speed, as a result of which there was a short available time for the crew to evaluate the situation and make a decision, as well as low efficiency of the controls and fast dumping of the aircraft in a tailspin. Further, qualified and conscientious specialists usually carry out the replacement of the engine. It is hard to imagine that there was a "criminal negligence." Most likely, they did not have a calibrated key for tightening the bolt with the necessary effort. Although it is possible that the mounting bolts were counterfeit (the problem was noticed after the crash of the Partvair Convair 580 aircraft on September 8, 1989). But someone decided to purchase such "cheap" bolts. It was unlikely that this was a personal initiative of someone from the line management. Most likely, the "strategy" of using such components was given the leadership of the company, which constantly has to resolve the contradiction between the cost of operating the aircraft price (competitiveness) on the ticket s and profit. Although it cannot be that the line management did not know about such a policy, they did not oppose this and did not conduct sufficient explanatory work with service specialists. Thus, the incident considered is quite consistent with the J. Reason model.

\section{Conclusion}

Unfortunately, the material presented above is only an excerpt from the accumulated over more than 30 years of activity in the field of safety research and the human factor. Nevertheless, we hope that we were able to state the very essence of the problem and clearly define the relationship between the causes of dangerous actions of personnel, the dangerous actions themselves and their consequences in the key to solving the human factor problems in aircraft maintenance.

In considering the issues of modeling were considered only the most commonly used in aircraft conceptual model of human. They do not imply a mathematical formalization of the problem, however, as shown by the authors' studies in the field 
of military aviation, some of them, for example, the J. Reason model (Figure 4), can be successfully formalized to obtain quantitative characteristics of personnel reliability. Naturally, there are other approaches to modeling staff activities. In particular, probability-theoretical analysis models are known. They are widely used in engineering research on safety issues and have their own characteristics.

In conclusion, I would like to focus on the fact that absolute models do not exist, especially when it comes to studying human errors. The researcher himself has to answer, how useful it a particular model. In any case, we hope that the material presented in this chapter will be useful from the point of view of expanding and structuring information about this most relevant area of research.

\section{Author details}

Andrii Pryimak, Mykhailo Orlovskyi* and Yevgeny Tretyakov

Kharkiv Aviation Institute, National Aerospace University, Kharkiv, Ukraine

*Address all correspondence to: orl104@ukr.net; matrix_1971@ukr.net

\section{IntechOpen}

(C) 2020 The Author(s). Licensee IntechOpen. Distributed under the terms of the Creative Commons Attribution - NonCommercial 4.0 License (https://creativecommons.org/ licenses/by-nc/4.0/), which permits use, distribution and reproduction for non-commercial purposes, provided the original is properly cited. (cc) BY-NC 


\section{References}

[1] Shanmugam A, Paul RT. Human factors in training for aircraft maintenance technicians. In: Proceedings 19th Triennial Congress of the IEA; 9-14 August 2015. Melbourne: IEA; 2015. pp. 1-7

[2] Virovac D, Domitrović A, Bazijanac $\mathrm{E}$. The influence of human factor in aircraft maintenance. Journal of Traffic and Transportation Engineering. 2017;29(3):257-266. DOI: 10.7307/ptt.v29i3.2068

[3] Demetris Y, Charalampos S. Human Factors in Aircraft Maintenance. 1st ed. Boca Raton: CRC Press; 2019. p. 120. DOI: $10.1201 / 9780429280887$

[4] FAA, Office of Aerospace Medicine Washington, DC 20591. Operator's Manual for Human Factors in Aviation Maintenance [Internet]. January 2015. Available from: https:// www.faa.gov/data_research/research/ med_humanfacs/oamtechreports/2010s/ media/201502.pdf [Accessed: 12 March 2020]

[5] CAA. Safety Regulation Group. CAP 718. Human Factors in Aircraft Maintenance and Inspection (previously ICAO Digest No. 12) [Internet]. 24 January 2002. Available from: https:// publicapps.caa.co.uk/docs/33/CAP718. PDF [Accessed: 10 March 2020]

[6] Boeing World Air Cargo Forecast Team. World Air Cargo Forecast 20182037 [Internet]. 2018. Available from: https://www.boeing.com/resources/ boeingdotcom/commercial/about-ourmarket/cargo-market-detail-wacf/ download-report/assets/pdfs/2018_ WACF.pdf [Accessed: 23 January 2020]

[7] Airbus' Global Market Forecast. Cities, Airports \& Aircraft 2019-2038 [Internet]. 2019. Available from: https:// www.airbus.com/aircraft/market/ global-market-forecast.html [Accessed: 23 January 2020]
[8] Global Fleet \& MRO Market Forecast Commentary 2019-2029 [Internet]. 2019. Available from: https://www. oliverwyman.com/content/dam/oliverwyman/v2/publications/2019/January/ global-fleet-mro-market-forecastcommentary-2019-2029.pdf [Accessed: 23 January 2020]

[9] Orlovskyi M, Pryimak A, Yl V, Halchinsky K. Investigation of the airworthiness conditions and perspectives development of the civil aviation park of Ukraine. Open Information and Computer Integrated Technologies. 2019;83:42-58. DOI: 10.32620/oikit.2019.83.03

[10] CAP 716. Aviation Maintenance Human Factors (EASA/JAR145 Approved Organisations) [Internet]. 2003. Available from: https:// publicapps.caa.co.uk/docs/33/CAP716. PDF [Accessed: 25 January 2020]

[11] Schmidt JK, Lawson D, Figlock R. Human Factors Analysis \& Classification System - Maintenance Extension (HFACS-ME) Review of Select NTSB Maintenance Mishaps: An update [Internet]. Available from: https://www.faa.gov/about/initiatives/ maintenance_hf/library/documents/ media/hfacs/ntsb_hfacs-me_updated_ study_report.pdf [Accessed: 25 January 2020]

[12] The Operator's Manual for Human Factors in Maintenance and Ground Operations. Federal Aviation Administration (FAA) [Internet]. 2014. Available from: https:// www.faa.gov/about/initiatives/ maintenance_hf/library/documents/ media/human_factors_maintenance/ hf_ops_manual_2014.pdf [Accessed: 14 January 2020]

[13] Latorella KA, Prabhu PV. A review of human error in aviation maintenance and inspection. International 
Journal of Industrial Ergonomics. 1997;26(2):133-161. DOI: 10.1016/ s0169-8141(99) 00063-3

[14] William BJ, Watson J. Reducing Installation Error in Airline

Maintenance [Internet]. 2000. Available from: https://www.faa.gov/about/ initiatives/maintenance_hf/library/ documents/media/human_factors_ maintenance/reducing_installation_ error_in_airline_maintenance.pdf [Accessed: 10 March 2020]

[15] Adrian J. Xavier Managing Human Factors in Aircraft Maintenance through a Performance Excellence Framework [Internet]. 2005. Available from: https:// www.system-safety.com/articles/ xavier\%20thesis.pdf [Accessed: 28 April 2020]

[16] Graeber RC, Marx DA. Reducing human error in aircraft maintenance operations. In: Proceedings of the 46th Annual International Air Safety Seminar; November 1993; Kuala Lumpur. Malaysia: 46th Annual International Air Safety Seminar. 1993. pp. $147-160$

[17] Reason J. Managing the Risks of Organizational Accidents. Abingdonon-Thames: Routledge; 2016. p. 252. DOI: $10.4324 / 9781315543543$

[18] NTSB/AAR-92/04. Aircraft Accident Report: Britt Airways, Inc., d/b/a Continental Express Flight 2574 In-Flight Structural Breakup EMB12ORT, N3370 1 Eagle Lake, TEXAS [Internet]. September 11, 1991. Available from: https://ntsb. gov/investigations/AccidentReports/ Reports/AAR9204.pdf [Accessed: 15 March 2020]

[19] ASC-AOR-05-02-001. Aviation Occurrence Report Volume I: In-Flight Breakup Over the Taiwan Strait Northeast of Makung, Penghu Island China Airlines flight CI611 Boeing 747200, B-18255 [Internet]. 25 May 2002.
Available from: http://www.asc.gov.tw/ upload/acd_att/5542a63a-c165-49cdb9b5-2fb41ad852da.pdf [Accessed: 16 March 2020]

[20] Aircraft Accident Investigation Report: Japan Air Lines Co. Ltd. Boeing 747 SR-100. JA8119 Gunma Prefecture. Japan, August 12. 1985. Aircraft Accident Investigation Commission Ministry of Transport [Internet]. June 19, 1987. Available from: http://www. mlit.go.jp/jtsb/eng-air_report/JA8119. pdf [Accessed: 15 March 2020]

[21] Swain AD. A Method for Performing a Human Factors Reliability Analysis.

Sandia National Laboratories: Albuquerque; 1963. p. 62. DOI: $10.2172 / 4265332$

[22] Norman DA. Categorization of action slips. Psychological Review. 1981;88(1):1-15. DOI: 10.1037//0033-295X.88.1.1

[23] Salvendy G. Handbook of Human Factors, Hoboken, New Jersey: John Wiley \& Sons; 1987, p. 1898. Translated and Published in Russian by Mir Publishers [Internet]. 1991. Available from: https://eknigi.org/ psihologija/92046-chelovecheskijfaktor-v-6-t-toma-1-6.html [Accessed: 23 February 2020]

[24] Swain AD, Guttmann HE. Handook of Human Reliability Analysis with Emphasis on Nuclear Power Plant Application. Albuquerque: Sandia National Laboratories; 1983. p. 711. DOI: $10.2172 / 5752058$

[25] Pronin MA, Yuryev GP. Ontology of an error: Non-Virtualistics and the Virtual Approach (In Russian) [Internet]. 2009. Available from: http:// www.intelros.ru/pdf/Etik_misl/3/13.pdf [Accessed: 15 April 2020]

[26] Pronin MA. Virtualistics in the Institute of Human Studies RAS (In Russian). Russian Academy of Sciences 
Institute of Philosophy: Moscow; 2015.

p. 179. ISBN 978-5-9540-0291-1

[27] Wiegmann DA, Shappell SA. A Human Error Approach to Aviation Accident Analysis. The Human Factor Analysis and Classification System. Bodmin, Cornwall (Great Britain): MPG Books Ltd; 2003. p. 165. DOI: 10.4324/9781315263878

[28] Sian B, Robertson M, Watson J. Maintenance Resource Management Handbook [Internet]. 1998. Available from: https://docplayer.net/ storage/27/10168788/1588098948/ p2R0u7IjABhJLfVfUdWttw/10168788. pdf [Accessed: 21 April 2020]

[29] Helmreich RL, Foushee HC. Why CRM? Empirical and theoretical bases of human factors training. In: Kanki BG, Helmreich RL, Anca J, editors. Crew Resource Management. 2nd ed. St. Paul: Academic Press; 2010. pp. 3-57. DOI: $10.1016 /$ b978-0-12-374946-8.10001-9

[30] Reason J. Human Error. New York: Cambridge University Press; 1990. p. 302. DOI: 10.1017/ CBO9781139062367

[31] Reason J. Human error: Models and management. BMJ. 2000;320(7237):768-770. DOI: $10.1136 /$ bmj.320.7237.768

[32] NTSB/AAR-79-17. Aircraft Accident Report: American Airlines, Inc., DC-10-10, N110AA. ChicagoO'Hare International Airport Chicago, ILLINOIS [Internet]. 25 May 1979. Available from: https://www.ntsb. gov/investigations/AccidentReports/ Reports/AAR7917.pdf [Accessed: 15 March 2020] 


\title{
Air Traffic Controllers' Attitude to the Mistakes Hazards during Their Professional Experience
}

\author{
Oleksii Reva, Andrii Nevynitsyn, Serhii Borsuk, \\ Valerii Shulgin and Volodymyr Kamyshyn
}

\begin{abstract}
Air traffic controllers' (ATCs) work process can be presented as uninterrupted set of decisions. These decisions occur and are implemented in both clear and stealth forms being influenced a lot. Determined and stochastic risks are especially important in this process. Human factor (HF) effect on flight safety is proven to be better considered through operators' attitudes toward unsafe acts and conditions. This seamlessly integrates in ICAO safety paradigm. Air traffic controllers' preferences system (PS) is discussed in regard to typical professional mistakes set. Using paired comparison, normative part of summary hazard and differentiating part of summary hazard, the preferences system of air traffic controllers is received. For the first time, mistakes pair summary hazard is determined on the unique qualimetric 100-point scale. Systems pair has high correlation level according to Spearman coefficient $(R=0.9727)$. Proposed Kendall rank coefficient outweighs the traditional one twice $\left(\mathrm{W}_{\text {traditional }}=0.2722, \mathrm{~W}_{\text {proposed }}=0.55237\right)$. The significance level for all cases is equal to $1 \%$. Multistep procedure of marginal opinions separation is implemented. It increased Kendall rank coefficient value up to $\mathrm{W}_{\text {proposed }}=0.7$. Survey procedure influenced positively on the ability of mistakes memorization, recognition, and avoidance during simulation training.
\end{abstract}

Keywords: flight safety, human factors, decision-making, air traffic controllers, typical mistakes, preferences system

\section{Introduction}

As for today human factor (HF) has approved dual influence on flight safety (FS). Unfortunately the statistics of dangerous air events and serious accidents shows that negative component of this influence has advantage. This stimulated ICAO to publish multiple circulars, annexes, and manuals with generalized world experience on the topic. They are based on the reports and proceedings of air companies and regional administrations dedicated to negative HF influence prevention [1-4]. It is natural that all kinds of such generalization should be scientifically based.

Frontline air operators (in this chapter we talk only about air traffic controllers (ATCs)) work process can be presented as uninterrupted set of decisions. They are 
generated and implemented in clear and stealth forms under the influence of various factors. These factors could be classified as external/internal, biased/unbiased, stochastic and deterministic, etc. [5]. Thus it seems possible to present actual ICAO FS paradigm [4] with leading role of HF influence on decision-making (DM). Figure 1 proposed by authors and cited in various proceedings proves this thesis [6-9].

It is important that blocks (a)-(e) designation in Figure $\mathbf{1}$ is used according to the ICAO safety concept introduction. Components (h)-(l) inserted in block (e) correspond to the authors' vision of HF influence on the DM process. They draw "attitudes toward unsafe acts and conditions" which also belongs to the mentioned concept. Blocks ( $h, i, j$ ) are already researched both for ATC students and professionals. Research results are summarized and published [10]. Less attention is paid to (k) and (l) components.

Taking into account all mentioned above, this chapter is dedicated to the preferences system (PS) research. The system is referred as HF to DM influence component, thus playing its role in "attitudes toward unsafe acts and conditions." Such attitudes are reasonable to be determined via ATC PS across typical errors set in professional activity process.

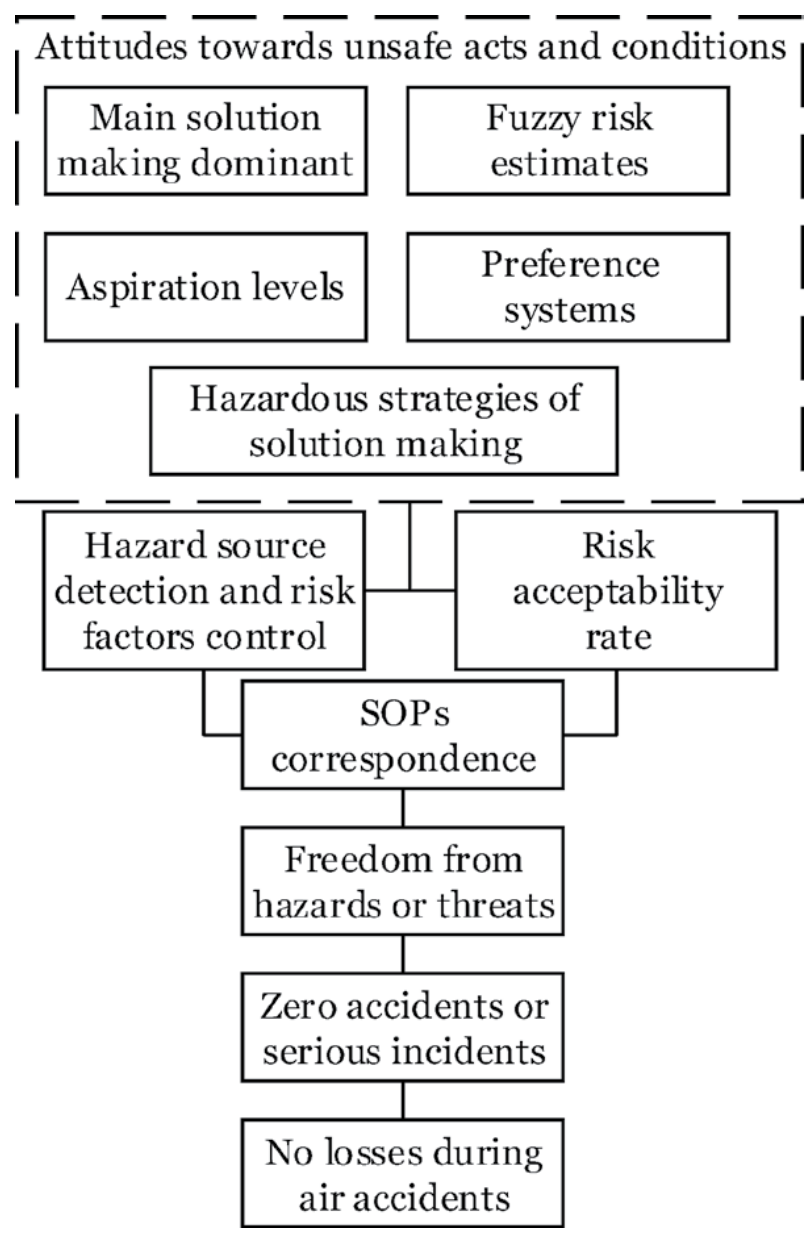

Figure 1.

Influence scheme of HF in regard to decision-making and ICAO flight safety concept components interaction. 


\section{Theoretical fundamentals of preferences system determination technology}

On the basis of such sources like ICAO recommendations, air accidents statistic, specific ATC experience, and ATC personnel education experience, the following list of typical errors for ATC during their professional activity was composed $[9,11,12]$ :

- Er.1-Radiotelephony phraseology violation.

- Er.2-Inconsistent aircraft entry into the adjacent ATC zone.

- Er.3-Longitudinal course time interval violation.

- Er.4-Counter course time interval violation.

- Er.5-Cross-aircraft separation violation at crossing courses.

- Er.6-No address in ATC messaging.

- Er.7-Error in aircraft call sign determination.

- Er.8-Error in aircraft identification.

- Er.9-Misuse of ATC schedule.

- Er.10-Absence of the note of control transfer to the adjacent air traffic control center in the ATC strip.

- Er.11-Absence of the coordination mark for aircraft entrance into adjacent ATC in the ATC strip.

- Er.12-Violation of coordinated geographic control transfer boundary by ATC.

- Er.13-Violation of coordinated time control transfer boundary by ATC.

- Er.14-Non-efficient/saving ATC.

- Er.15-Negligence while applying of the letter-digital information (potential multiple interpretations) to the strip.

- Er.16-Violation of shift transition procedures.

- Er.17-Issued commands to change the altitude or direction of flight are not reflected on the strip.

- Er.18-Attempt to control the aircraft under condition of TCAS system operation in the "resolution advice" mode.

- Er.19-Errors at aircraft concerning information input into the automated system.

- Er.20-Emergency procedures violation.

- Er.21-Airspace use violations. 
Different errors obviously possess different hazard levels. This requires ATC attitude to be found and arranged in preferences system for those errors. Referring to proceedings $[9,11-13]$ and current research context, this PS is considered as ATC hazard levels experience. This includes the most hazardous error, the least hazardous error, and all other error types arranged in hazard descending order.

Finalized PS is important for ATC correct person-targeted professional training arrangement. Also it can be used in preventive maintenance of HF negative influence on FS. Really all information of FS allows experienced instructors to determine peculiarities of ATC individual experience, including air accidents and catastrophic experience. On the other hand, such knowledge might contribute revealing of flaws in professional training and conceptual safety model. The latter two grow during professional activity process.

There are several most common ways to determine PS. They could be used for ATC attitude identification toward hazards of typical errors and mistakes with ranking method $[9,13]$ :

1. Sorting is used in case of previous clustering of huge number of alternate options. For example, the ICAO states that ATC mistakes and errors clustering should be performed with regard to such types and sources [3]: mistakes caused by incorrect equipment utilization, procedural mistakes, and communication mistakes. At that point the proposed list of typical mistakes was also partially based on the ICAO recommendations.

This set of mistakes significantly exceeds operative capabilities of human memory expressed with "magic Miller's number" ( $7 \pm 2$ units at the same time) [14] and reaches the so-called Parkinson's inefficiency coefficient [15]. However participants encouraged to pass the survey are highly experienced ATC. Each of them has significant real occupational experience including nonstandard situation solving. These situations include potential conflicts, urgent conflicts, catastrophic, high work pressure, and psychological overload. They also had teaching experience. Thus in their case, clustering procedure with secondary ranking step was unnecessary.

2. Direct ranking is a simple process, although its application has certain limits. They are operating memory capacity and cognitive functions limitations mentioned above.

3. Pair comparison and relative input calculation.

4. Determination of weighted hazard coefficients (importance, significance, etc.).

5. Determination of biased hazardous mistakes probabilities.

6. Application of fuzzy variables in order to find mistakes rate.

For the current research, the pair comparison method was chosen with further relative contribution calculation for both components. It was applied for every mistakes pair. Such approach could be presented $[9,13,16]$ as following:

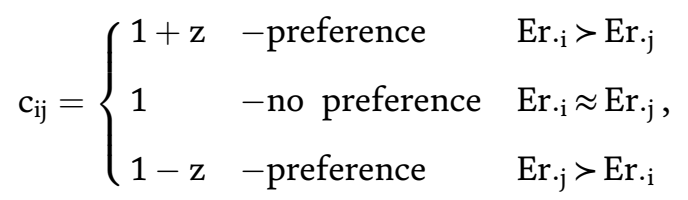


where $c_{i j}$ is the quantitative index of preferences of mistake Er. ${ }_{. i}$ over mistake Er. ${ }_{. j}$ in regard to hazard level and $\mathrm{z}$ is the index that describes summary hazard level of mistakes $\mathrm{Er}_{\text {. }}$ and $\mathrm{Er}_{\text {.j. }}$.

Proposed method of PS calculation is quite simple since researched mistakes are compared in pairs. This pushes expert's attitude to other mistakes out of the single comparison scope. All presented is a part of wide class of experts' opinions explication methods where expert opinion is taken as basic undividable statement.

Preferences $c_{i j}$ value sequence determination as quantitative characteristics of mistakes comparison is the following:

1. Experts express their statements via pair comparisons of mistakes hazards. They use their own professional experience and statistics of accidents and incidents. Initially it's just a prevalence or equality of hazard level that is determined for each pair without quantitative estimation.

2. Using information analysis or ATC experts support, the range in hazard values is determined for mistakes being compared. These estimations are saved as ranked set boundary components ratio.

$$
\frac{\mathrm{C}\left(\mathrm{Er}_{\cdot \mathrm{i}}{ }_{\mathrm{max}}\right)}{\mathrm{C}\left(\mathrm{Er} \cdot{ }_{\mathrm{j}}^{\min }\right)}=\mathrm{K}_{\mathrm{p}},
$$

where $\mathrm{Er}_{{ }_{\mathrm{i}}}^{\max }, \mathrm{Er}_{\cdot \mathrm{j}}{ }_{\mathrm{j}}^{\max }$ are mistakes with maximal $\mathrm{C}\left(\mathrm{Er}_{{ }_{\mathrm{i}}}{ }^{\mathrm{max}}\right)$ and minimal $\mathrm{C}\left(\mathrm{Er}_{{ }_{\mathrm{j}}}^{\mathrm{min}}\right)$ hazard values and $\mathrm{K}_{\mathrm{p}}$ is the compared mistakes hazard ratio coefficient.

3. Desired values of integral mistakes hazard coefficients $\mathrm{z}$ are found with coefficient $K_{\mathrm{p}}$.

$$
\mathrm{z}=\left(\frac{\mathrm{K}_{\mathrm{p}}-1}{\mathrm{~K}_{\mathrm{p}}+1}+\sqrt{\frac{0.05}{\mathrm{n}}}\right),
$$

where $\mathrm{n}=21$ is the number of mistakes being arranged.

4. On the basis of paired mistakes hazard level comparison systems and with the help of $c_{i j}$ coefficients, squared matrix $C=\left\|c_{i j}\right\|$ is created:

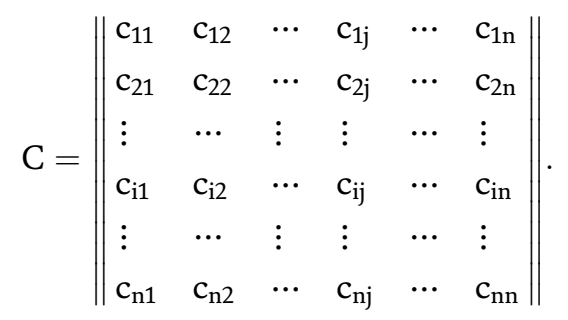

5. With iterative priority arrangement method (PAM) [16], the values of mistakes hazards priorities $\mathrm{C}_{\mathrm{i}}(\mathrm{k})$ are found.

6. Actual coefficient of mistakes hazard level ratio $\mathrm{K}_{\mathrm{A}}$ is calculated. It is compared to the empiric coefficient of the same kind $\mathrm{K}_{\mathrm{p}}$. If they match, then the task of $\mathrm{z}$ index determination is successfully solved. Otherwise coefficient correction is performed. 
The proposed method has several major advantages:

1. Simplification of the statements of expression procedure (no quantitative estimation of compared mistakes is required).

2. The method of $\mathrm{c}_{\mathrm{ij}}$ selection coefficients matches quantitative empiric estimations with their real quantitative hazard ratios.

3. Non-transitive input data is allowed along with non-transitive output preferences.

There is one most important and valuable step in this method application. It is the estimation of boundary mistakes hazard ratio empiric coefficient $\mathrm{K}_{\mathrm{p}}$. If it is possible to estimate mistakes ratio, then they should be arranged to define boundary elements of their whole set. PAM with $\mathrm{z}$ coefficients can be used for that purpose. In whole task this is the only part with quantitative estimation. Thus it should be paid more attention. If pair comparison systems are non-transitive or possess equality (indifference), the $\mathrm{z}$ values procedure calculation should be changed in a proper way [16]. This happens when certain mistakes make no difference in ATC expert opinions, thus receiving "average" ranks.

For this reason formula (1) is commonly transformed into two formulas. They have summary quantitative estimations of compared alternatives (mistakes) equal to 1 or 2:

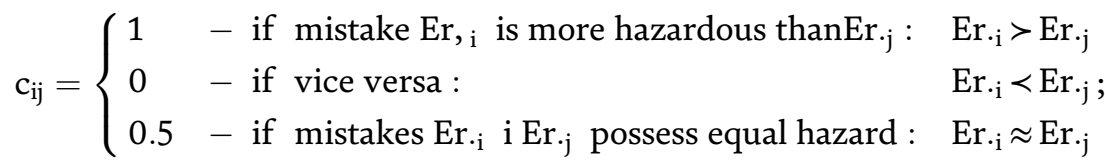

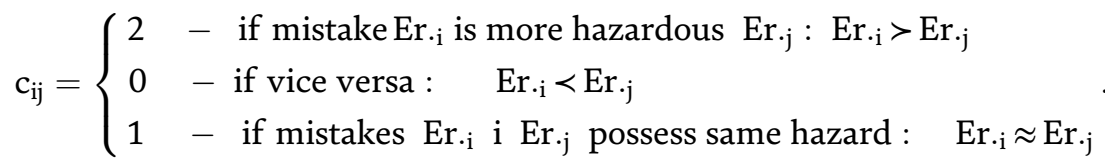

Formulas (5) and (6) show that part of summary mistakes hazard is normalized. It supposed to simplify their pair comparison and PS determination. Indeed human thinking deals better with qualitative comparative tasks rather than quantitative. However normalizing makes results rough and brings methodology error in final conclusion about real hazards (actual mistakes place in the ranked sequence).

\section{Normative approach application to find ATC preferences system on the set of typical mistakes}

So formula (5) is used to find individual PS (IPS) of National Aviation University and DP "Ukraeroruh" employees $\mathrm{m}=37$. All of them have significant work experience and methodical (training) practice. IPS found with the help of group decision method was ere aggregated in generalized group PS (GrPS) via averaging and summation:

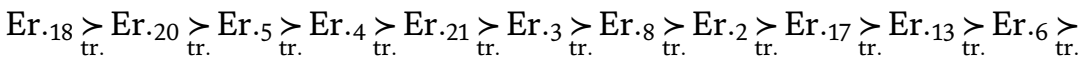

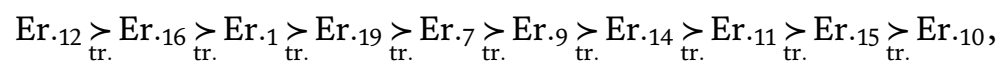


where $\succ$ tr. - defines the preference of one mistake comparing to the other one in GrPS. All IPSs used for this purpose are received with traditional method using formula (5).

Hence GrPS of type (7) is received via "traditional" method of the distribution of normative mistakes hazard sum which is equal to 1 . It clearly shows their ordered set starting with the most hazardous (Er.18-Attempt to control the aircraft under condition of TCAS system operation in the "resolution advice" mode) down to the least hazardous one (Er.10-Absence of the note of control transfer to the adjacent air traffic control center in the ATC strip). Although before the conclusion about GrPS of type (7) acceptability could be made, the consistency verification of ATC experts engaged in the process should be performed.

The indicator for such consistency is Kendall multiple rank correlation coefficient (RCC) $\mathrm{W}_{\mathrm{tr} .}=0.2728$. The low value of this indicator can be explained by several reasons: firstly, the big variety of mistakes and big variety of ATC experts engaged to the research inevitably influenced the diversity of opinions and thus influenced RCC, and secondly, no efforts to find and remove marginal opinions were made (by marginal here, we understand certain extremely specific experience rather than roughly wrong).

Taking into account that low absolute value of RCC could be statistically acceptable, let us use Pearson $\chi^{2}$ criterion to test the corresponding hypothesis. It is found that $\chi_{\text {calc. }}^{2}=201,412>>\chi_{\alpha=1 \%, \mathrm{k}=36}^{2}=58,619$ which allows to state that RCC indicator value is statistically acceptable. Thus opinions of ATC experts engaged to the research are consistent for (7). It means that GrPS of the type (7) can be used in flight safety management processes or during ATC training procedures.

However it should be stated that the absolute value of RCC criterion $\mathrm{W}_{\text {tr. }}=0.2728$ does not satisfy criterion [17]:

$$
\mathrm{W} \geq 0.7,
$$

thus type (7) GrPS is not absolutely acceptable as well.

\section{Differential approach application to the preferences system determination within the set of typical mistakes}

Let us consider all mentioned above taking into account proceeding [9] . It allows to dedicate current section to the development of enhanced method of mistakes hazard levels sum distribution. Its efficiency and application are also discussed.

Once again let us underline that formulas (5) and (6) hold mistakes hazard levels sum equal to 1 or 2 . It is normatively distributed by the expert among mistakes being compared. In other words each mistake's contribution in aggregate hazard value is limited. It does not operate with $[0,1]$ or $[1,2]$ ranges but uses simple decision about " $>$ " or " $<$ " preference (or their equality indifference " $\approx$ "). This simplifies IPS construction but makes final estimations result rough. Such roughness is transferred further to the generalized results of mistakes hazards set arrangement.

To get rid of this flaw, the partial and overall mistakes hazard is proposed to be calculated. Special absolute qualimetric scale with 100 points [13] is proposed for this purpose. Expression (1) evolution in this case is the following: 


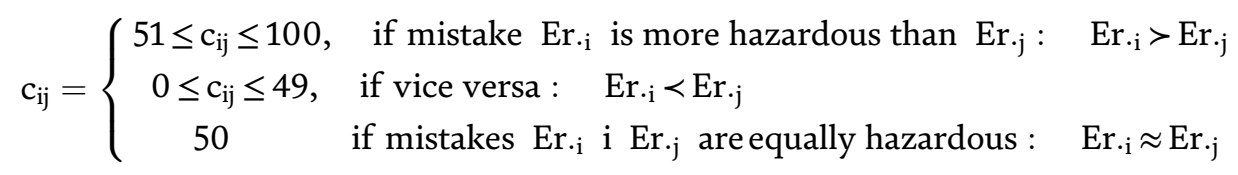

Same $\mathrm{m}=37$ professional ATCs were engaged in the second round of the survey. They fulfilled 210 paired comparisons one more time with the help of expression (9) and constructed new IPSs. IPS to GrPS generalization is once again performed with ranks averaging and summation strategy for group decisions. The formal overview of new empiric GrPS is the following:

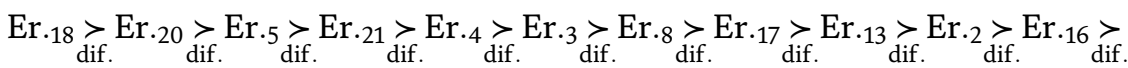

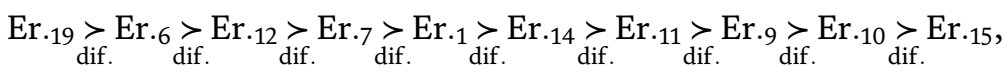

where $\underset{\text { dif. }}{\succ}-$ determines the preference of one mistake to the other.

The absence of tied mistakes ranks is noticeable while comparing GrPS (7) and (10). It means that the ranking of researched mistakes is strict. The rate of two GrPS coincidences is checked with Spearman rank correlation coefficient. Its value is equal to $\mathrm{R}_{\mathrm{S}}^{\text {tr.-dif. }}=0.9727$. This witnesses about overwhelming match of ATC experts' opinions about mistakes hazards in compared GrPS (7) and (10).

Finding opinions consistency in (10) with the help of RCC gives $\mathrm{W}_{\text {dif. }}=0.5237$, that is, 1.92 times more than the initial one. It shows the efficiency of newly proposed method in general (partial mistakes inclusion).

The coefficient value is statistically acceptable which is proven by hypothesis testing with Pearson $\chi^{2}$ criterion. For newly calculated value, it is equal to $\chi_{\text {dif. }}^{2}=$ $387,508>>\chi_{\alpha=1 \%, \mathrm{k}=36}^{2}=58,619$. This means that GsPS of type (10) can be considered as generally consistent.

Yet again there are a big number of ATC respondents and a big number of mistakes proposed for arrangement. It influences in adverse way on the RCC absolute value. Requirement (8) is not satisfied again.

With the given significance level, both of GrPS are statistically acceptable. However even in brief comparison of GrPS indexes $\left(\mathrm{W}_{\text {tr. }}=0.2728\right.$ and $\mathrm{W}_{\text {dif. }}=$ 0.5237 ), it is clear that current research points on the second result to be used. It includes a negative HF influence prevention on the FS as flight safety management measures and ATC professional training.

Proposed differentiating method disadvantage lies in the quantitative requirement. It forces experts to express their opinions about mistakes hazards levels in numerical values. But it is well known that people tend to operate with qualitative information. Altogether this requires only high-quality ATC experts to be engaged in the survey.

\section{Multistep method of determination and losing marginal ATC opinions concerning mistakes hazards}

As it was mentioned before, the marginal opinions of ATC engaged in the survey are not examples of their bad training or experience. In current research context, it's rather a certain particular experience. Such rarity greatly influences their personal 
IPS, making a difference with others' opinions. Because of that, it is very important to pay attention to their opinions separation and analysis. This is what briefly explained in proceeding [18].

Let us measure single ATC influence on group estimate as

$$
\mathrm{C}=\frac{\overline{\mathrm{a}}_{\mathrm{m}+1}}{\overline{\mathrm{a}}_{\mathrm{m}}},
$$

where $\overline{\mathrm{a}}_{\mathrm{m}}$ is the average estimation of experts group with members and $\overline{\mathrm{a}}_{\mathrm{m}+1}$ is the average group estimation with $m+1$ members.

Let us specify acceptable influence level for single opinion $b$ of $(m+1)$ th ATC expert. Basing on the proceedings $[18,19]$, it can be limited with $5-10 \%$ change:

$$
\begin{cases}1.05 \leq C \leq 1.10, & \text { if } b>\bar{a}_{m} \\ 0.90 \leq C \leq 0.95, & \text { if } b<\bar{a}_{m}\end{cases}
$$

This is valid for ATC opinions analysis. It can be applied both for particular mistakes and already given integral indexes of mistakes hazards set. Once again the nature of these estimates is numerical and quantitative, while people better operate with qualitative and comparative ranking meanings. Thus it is important to develop corresponding procedures and methods of ATC experts' competence determination based on the mistakes hazards they work with.

Let us apply research results and methods of image detection theory [20-22] to find experts' competence. Risk recognition term is introduced. It is a mathematical expectation of information losses due to recognition mistakes for qualified and unqualified ATCs.

$$
r(\delta)=\int_{X} \sum_{i=1}^{I} L[i, k=\delta(x) P(i) p(x / i) d x],
$$

where $\mathrm{X}$ is the space for $\mathrm{x}$ signals (these are hazards scoring characteristics, assigned by the ATC experts to the mistakes), $i=\overline{1, I}$ estimation classes numbers, $\mathrm{k}=\overline{1, K}$ recognition alternatives numbers $\delta(\mathrm{x}), \mathrm{L}(\mathrm{i}, \mathrm{k})$ information losses during class assignment of estimate from class $\mathrm{i}$ to the class $k, \mathrm{P}(\mathrm{i})$ classes probabilities known in advance, and $\mathrm{p}(\mathrm{x} / \mathrm{i})$ classes probability densities known in advance.

So it is all about distance calculation between points in the image space. Herewith the particular point belongs to certain class if it is determined with the distance to the reference point. Members that belong to the same class should form a compact cluster in the system parameters space.

In observed case the following distance is used as a generalizing value:

$$
\mathrm{L}_{j}=\sum_{\mathrm{i}=1}^{\mathrm{n}=21}\left|\mathrm{r}_{\mathrm{ij}}-\mathrm{r}_{\mathrm{ig}}\right|,
$$

where $L_{j}$ is the generalized distance of IPS of jth ATC expert toward GrPS and $r_{i g}$ is the rank of ith mistake in GrPS.

It is important to underline that GrPS consistency here is taken as an assumption. For further convenience, normalized $L_{j}$ index value is introduced:

$$
\mathrm{L}_{\mathrm{j}}^{*}=\frac{\mathrm{L}_{\mathrm{j}}}{\mathrm{L}_{\mathrm{j}}^{\max }}
$$


The next step is to calculate average group mistake value:

$$
\overline{\mathrm{L}}_{\mathrm{g}}=\frac{1}{\mathrm{~m}} \sum_{\mathrm{j}=1}^{\mathrm{m}} \mathrm{L}_{\mathrm{j}}^{*}
$$

and corresponding to formula (12), the criterion for marginal IPS of ATC experts is determined.

$$
\mathrm{L}_{\mathrm{j} \text { marg. }}^{*} \geq 1.1 \cdot \overline{\mathrm{L}}_{\mathrm{g}}
$$

Applying formulas (14)-(17) to IPSs that are found with proposed differentiated method (which uses mistakes hazards sum distribution), it is possible to find the following opinions marginality criterion:

$$
\mathrm{L}_{\mathrm{j} \text { marg. }}^{*} \geq 0.57 \text {, }
$$

It is calculated that marginal thoughts are expressed by 10 ATC experts, which is shown in Figure 2. Removing their IPS allows to receive subgroup A with $\mathrm{m}_{\mathrm{A}}=$ $\mathrm{m}-\mathrm{m}_{\mathrm{marg}}=27$ ATC members with such GrPS:

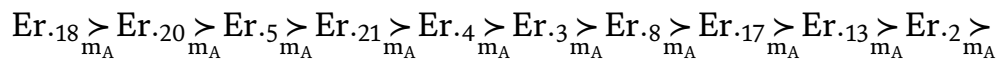

$$
\begin{aligned}
& \operatorname{Er} \cdot 16 \underset{m_{A}}{\succ} \operatorname{Er} \cdot 19 \underset{m_{A}}{\succ} \operatorname{Er} \cdot 6 \underset{m_{A}}{\succ} \operatorname{Er} \cdot 12 \underset{m_{A}}{\succ} \operatorname{Er} \cdot 7 \underset{m_{A}}{\operatorname{Er}} \cdot 1 \underset{m_{A}}{\succ} \operatorname{Er} \cdot 14 \underset{m_{A}}{\succ} \operatorname{Er} \cdot 11 \underset{m_{A}}{\succ} \operatorname{Er} \cdot 9 \underset{m_{A}}{\succ} \operatorname{Er} \cdot 10 \underset{m_{A}}{\succ} \operatorname{Er} \cdot 15,
\end{aligned}
$$

where $\underset{\mathrm{m}_{\mathrm{A}}}{\succ}-$ shows the prevalence of one mistake hazard level over another mistake in GrPS combined with $\mathrm{m}_{\mathrm{A}}$ ATC expert opinions.

It is found that correspondent correlation coefficient value is equal to $\mathrm{W}_{\mathrm{A}}=0.7$ for $\mathrm{m}_{\mathrm{A}}$ subgroup. It satisfies the requirements of criterion (13) and is statistically acceptable because $\chi_{\mathrm{A}}^{2}=377,743>>\chi_{26, \alpha=1 \%}^{2}=45,642$. Thus GrPS found for $\mathrm{m}_{\mathrm{A}}=27$ subgroup actually can be used for flight safety management measures and ATC professional training.

Further filtering and analysis could be performed with the same proposed method for $m_{B}=m-m_{A}=10$ ATC subgroup as is shown in Table 1. Figure 3 clearly shows the main steps of presented multistep algorithm.

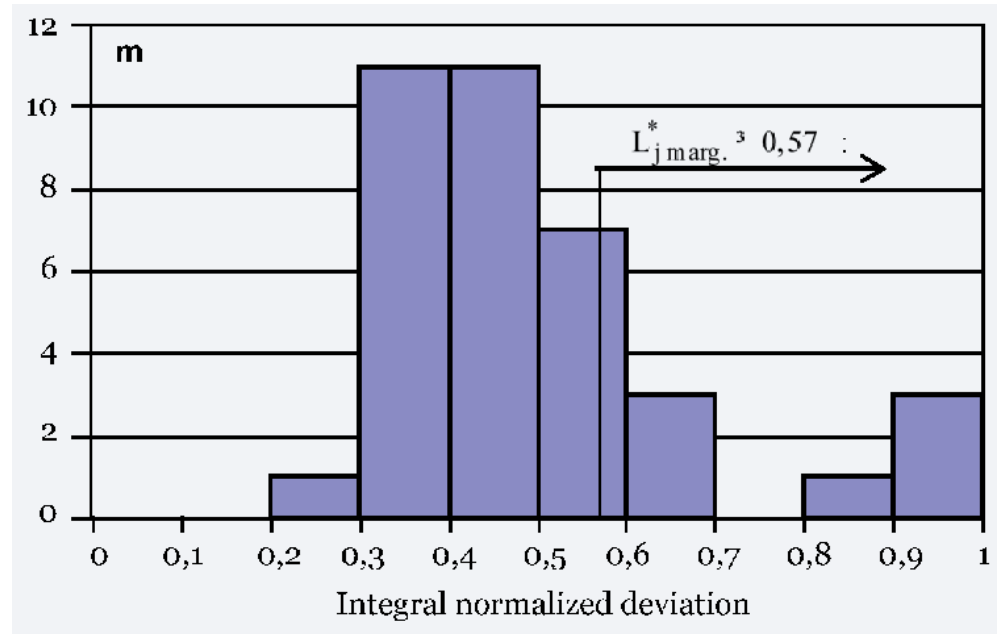

Figure 2.

Finding ATC marginal opinions about mistakes hazards in their professional experience. 
Air Traffic Controllers' Attitude to the Mistakes Hazards during Their Professional Experience DOI: http://dx.doi.org/10.5772/intechopen.91937

\begin{tabular}{lccc}
\hline Experts groups & $\mathrm{W}$ & $\chi_{A}^{2}$ & $\chi_{k=m-1, \alpha=1 \%}^{2}$ \\
\hline 1 & 2 & 3 & 4 \\
\hline $\mathrm{m}=37$ & 0.5237 & 387,508 & $\chi_{36, \alpha=1 \%}^{2}=58,619$ \\
\hline $\mathrm{m}_{\mathrm{A}}=27$ & 0.700 & 377,743 & $\chi_{26, \alpha=1 \%}^{2}=45,642$ \\
\hline $\mathrm{m}_{\mathrm{B}}=10$ & 0.2727 & 55,305 & $\chi_{9 ; \alpha=1 \%}^{2}=21,666$ \\
\hline $\mathrm{m}_{\mathrm{C}}=6$ & 0.4934 & 59,211 & $\chi_{5 ; \alpha=1 \%}^{2}=15,086$ \\
\hline $\mathrm{m}_{\mathrm{D}}=5$ & 0.5629 & 56,292 & $\chi_{4 ; \alpha=1 \%}^{2}=13,277$ \\
\hline
\end{tabular}

Table 1.

Multistep method of determination and losing marginal opinions of ATC experts about mistakes hazard levels.

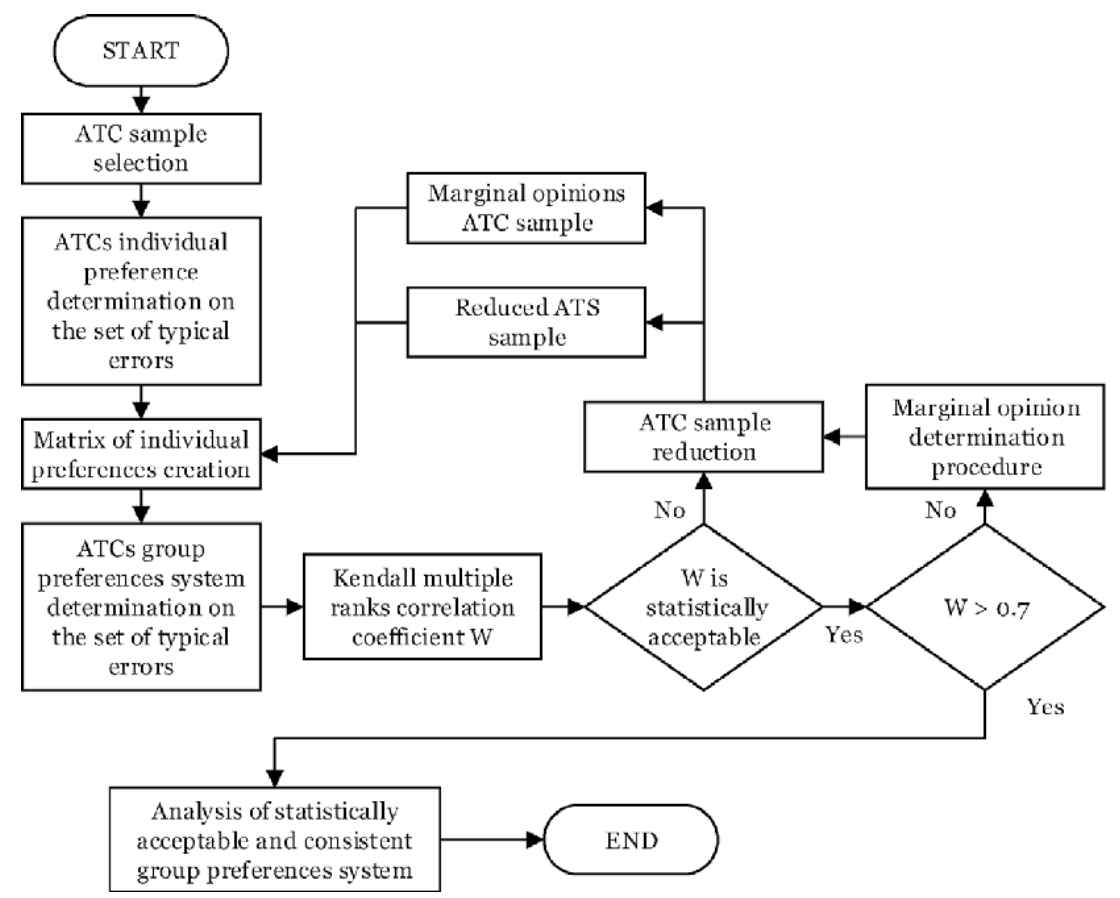

Figure 3 .

Multistep algorithm of ATCs' group preferences determination on the set of typical mistakes.

It is clear that after $m_{A}$ subgroup separation, it was impossible to find any other subgroups with internal opinions consistency. That is the reason for these 10 ATCs to be under increased attention during prevention of negative HF influence upon FS.

Finally it is worth mentioning the positive influence of the procedure on the ATC experts' personal traits. Since during the survey, they had to imagine and compare 210 pairs of mistakes with an attempt to determine their hazard levels.

\section{Conclusions}

Scientific results received and presented in this chapter explain proactive attitudes of ATCs to the mistakes hazards. Summarizing them allows to state the following: 
1. The most comprehensive list of $\mathrm{n}=21$ typical mistakes for ATC allows to fully analyze their mistakes.

2. There are 37 IPSs received with the help of normative and proposed mistakes hazard analysis methods. They are generalized in GrPS afterward. Proposed method efficiency is defined by Kendall rank correlation coefficient which is 1.92 times greater than the normative method.

3. Multistep method of determination and losing marginal opinions of ATC experts which allows to separate subgroups with increased internal opinions consistency.

4. Taking initial group of $\mathrm{m}=37$ participants, there was $\mathrm{m}_{\mathrm{A}}=27$ subgroup separated. Their internal opinions consistency was higher. Other 10 people should be paid increased attention during prevention of negative HF influence upon FS.

5. Positive influence of the procedure on the ATC experts' personal traits is determined.

Further researches of PS determination for ATCs' typical mistakes set should be performed in the following areas:

- Classic decision-making criteria application to determine ATCs' group preferences systems and their risk level analysis.

- Kemeny median determination as optimum indicator for group opinions in regard to mistakes risk levels.

- Frames and neural networks application for ATC incorrect actions analysis and modeling. 


\section{Author details}

Oleksii Reva $^{1}$, Andrii Nevynitsyn ${ }^{2}$, Serhii Borsuk ${ }^{3 *}$, Valerii Shulgin ${ }^{2}$ and Volodymyr Kamyshyn ${ }^{1}$

1 Ukrainian Institute of Scientific and Technical Expertise and Information, Kyiv, Ukraine

2 Flight Academy of the National Aviation University, Kropyvnytskyi, Ukraine

3 Wenzhou University, Wenzhou, People's Republic of China

*Address all correspondence to: grey1s@yandex.ua

\section{IntechOpen}

(C) 2020 The Author(s). Licensee IntechOpen. Distributed under the terms of the Creative Commons Attribution - NonCommercial 4.0 License (https://creativecommons.org/ licenses/by-nc/4.0/), which permits use, distribution and reproduction for non-commercial purposes, provided the original is properly cited. (cc) BY-NC 


\section{References}

[1] Fundamental Human Factors Concept. Human Factors Digest N0. 1. Circular. ICAO 216 AN/131. Montreal, Canada. 1989. p. 36

[2] Investigation of Human Factors in Accidents and Incidents. Human Factors Digest No. 7. ICAO Circular 240-AN/ 144. Montréal, Quebec, Canada. 1993. p. 66

[3] ICAO Circular 314. Threat and Error Management in Air Traffic Control. ICAO. 2008. p. 34

[4] Safety Management Manual (SMM). Doc ICAO 9859 AN/460. 4th ed. (Advance Unedited). Montreal, Canada. 2018. p. 182

[5] Reva AN, Tumyshev KM, Bekmuhambetov AA. Human Factor and Flight Safety (Proactive Influence Research); Almaty. 2006. p. 242

[6] Reva OM, Borsuk SP, Shulgin VA, et al. "Front line" aviation operators attitude to the hazardous actions or conditions of professional activity as main actor of flight safety provision. In: MINTT-2016; 24-26 May 2016;

Kherson. 2016. pp. 90-97

[7] Reva OM, Borsuk SP, Bala MM, Peyman MS. New approach to determination of main solution taking dominant of air traffic controller during flight level norms violation. In: Advances in Human Aspects of Transportation. Proceedings of the AHFE 2016 International Conference on Human Factors in Transportation; July 2016. Florida, USA: Walt Disney World; 2016. pp. 137-147

[8] Reva OM, Borsuk SP, Shulgin VA, Nedbay SV. Ergonomic assessment of instructors' capability to conduct personality-oriented training for air traffic control (ATC) personnel. In: Advances in Human Factors of
Transportation. Proceedings of the AHFE 2019 International Conference on Human Factors in Transportation, Washington, DC, USA; July 24-28, 2019. pp. 783-793

[9] Reva AN, Kamyshin VV, Nevynytsyn AM, Shulhyn VA. Differential method for establishing a comparative danger of air traffic controllers' errors in professional activity. Science, Technology, Innovations: Scientific Magazine. 2019; 3(11):70-82

[10] Reva OM, Borsuk SP, Kamyshin VV, Shulhyn VA, Parhomenko VD,

Lypchansky VO. Systematic informational methodology of proactive qualimetry of human factor influence on the decision making in aeronautical systems. In: Reva OV, editor. Monograph. Kyiv: UkrINTEI; 2019. pp. 166

[11] Reva OM, Kamyshin VV, Nevynitsyn AM, Nasirov SS. Decisionmaking: system of preferences of air traffic controllers on indicators of frequency and danger of characteristic errors. In: Intellectual Systems for Decision Making and Problems of Computational Intelligence (ISDMCI'2019). Zalizny Port, 21-25 May 2019, Kherson: FOP Vyshemirsky V.S.; 2019. pp. 159-161

[12] Reva OM, Nevynitsyn AM, Nasirov SS, Lypchansky VO. Improving the procedure for identifying prevention systems of air traffic controllers on the spectrum of specific errors. In: XXIV International Propulsion Engineering Congress, 2-7 September 2019, Kharkiv. 2019. pp. $89-90$

[13] Reliability and Efficiency in Technique Handbook. Efficiency of Technical Systems. Moscow: Mashinostroenie Publisher; 1988. p. 328

[14] Herasimov BM, Kamyshin VV. Organizational ergonomics: Methods 
and algorithms of research and design. In: Monograph. Kyiv: Information Systems; 2009. pp. 212

[15] Parkinson CN. Parkinson's Law and Other Studies in Administration.

Cutchogue: Buccaneer Books; 1957. pp. 117

[16] Blumberg VA, Glushchenko VF. What is the best solution? In: Method of Arrangement of Priorities. Leningrad: Lenizdat Publ.; 1982. pp. 160

[17] Tarasov VA, Herasymov BM, Levyn YA, Korneichuk VA. Intelligent Decision Support Systems: Theory, Synthesis, Efficiency. Kyiv; 2007. pp. 336

[18] Reva OM, Kamyshin VV, Nevynitsyn AM, Radetska SV. Multistep procedure of decision making in regard to group preferences system for air traffic controllers. In: Technical Regulations, Metrology, Information and Transport Technologies: 14-15 October 2019, Odessa. 2019. pp. 147-152

[19] Beshelev SD, Hurvich FG. Mathematic-Statistical Methods of Experts Estimate. Moscow: Statistics; 1980. pp. 263

[20] Babak VP, Kharchenko VP, Maksimov VO, et al. In: Babak VP, editor. Flight Safety. Kyiv: Techniques; 2004. p. 504

[21] Vasyiev VI. Recognizing Systems: Reference Book. Kyiv: Naukova Dumka; 1983. p. 423

[22] Reva OM, Suvorova IM. Methods of images recognition within instructors' proficiency estimation of their work motivation indicators priorities. In: Projects Management, System Analysis and Logistics: Scientific Magazine. Vol. 6. Kyiv: NTU; 2009. pp. 208-216 

Section 4

Composites 



\title{
Non-Steady First Matrix Cracking of Fiber-Reinforced Ceramics
}

\author{
Huan Wang
}

\begin{abstract}
Matrix cracking affects the reliability and safety of fiber-reinforced ceramic-matrix composites during operation. The matrix cracking can be divided into two types, that is, steady state crack and non-steady state cracking. This chapter is about the non-steady stable cracking of fiber-reinforced CMCs. The micro stress field of fiber, matrix, and interface shear stress along the fiber direction is analyzed using the shear-lag model. The relationship between the crack opening displacement and the crack surface closure traction is derived. The experimental first matrix cracking stress of different CMCs are predicted.
\end{abstract}

Keywords: ceramic-matrix composites (CMCs), first matrix cracking stress, brittle matrix, non-steady state, pre-existing defect

\section{Introduction}

Fiber-reinforced ceramic-matrix composites (CMCs) have greater specific strength and specific stiffness. It will decrease the weight of the aircraft structure when it is applied to the aircraft. However, there are some disadvantages like complex processing and preparation, expansive, and so on. Now, there are some models for first matrix cracking. The MCE model [1] is one of the most famous models which established the relation between A.C.K and crack theory.

McCartney model [2] gives a detailed process about the numerical solution. Chiang et al. $[3,4]$ used a modified shear-lag model considering the matrix deformation and the fiber failure is also considered. This chapter is about the non-steady matrix cracking of fiber reinforced CMCs. We assume that the fiber is strong enough to keep intact when matrix cracking occurs, and the composites with interface debonding are susceptible to weak frictional resistance. The growth characteristics of short cracks are evaluated using the stress intensity method. We will do some analysis about the fiber-matrix stress and solve equations to get the closing traction distribution. Then, the matrix cracking condition is combined to obtain the critical matrix cracking stress. The final results will show how the cracking stress is related to the size of a pre-existing defect and prediction of the threshold stress. Differences between the MCE model and McCartney model are also analyzed.

\section{Fiber-matrix stress analysis}

All analyses come from McCarteny model [2]. By performing stress analysis, the influence of the fiber can be equivalent to applying a distribution of closing pressure 
$\mathrm{p}\left(\mathrm{x}_{1}\right)$ on the crack surface, and the influence of the applied stress can be evaluated by regarding the stress as a uniform opening pressure $\sigma_{\infty}$ acting along the matrix crack surface. Therefore, we can obtain the net pressure on the crack surface, $\left[\sigma_{\infty}-\mathrm{p}(\mathrm{x})\right]$. And the relation can be assumed for the continuum model [1]:

$$
\mathrm{p}\left(\mathrm{x}_{1}\right)=\lambda \sqrt{\mathrm{u}\left(\mathrm{x}_{1}\right)}=\mathrm{p}\left(-\mathrm{x}_{1}\right)
$$

where $\mathrm{x}_{1}$ represents the location on the crack surface. According to the Sneddon and Lowengrub [5] and the force analysis, we can get the relation between the effective traction $\mathrm{p}\left(\mathrm{x}_{1}\right)$ and displacement distributions $\mathrm{u}\left(\mathrm{x}_{1}\right)$ as follows:

$$
\mathrm{u}\left(\mathrm{x}_{1}\right)=\frac{2}{\pi^{2}} \int_{\mathrm{x}_{1}}^{\mathrm{a}} \frac{\mathrm{t}}{\sqrt{\left(\mathrm{t}^{2}-\mathrm{x}_{1}^{2}\right)}}\left\{\int_{0}^{\mathrm{t}} \frac{\sigma_{\infty}-\mathrm{p}(\xi)}{\sqrt{\left(\mathrm{t}^{2}-\xi^{2}\right)}} \mathrm{d} \xi\right\} \text { dt } 0 \ll \mathrm{x}_{1}<a
$$

And we can also get the corresponding stress intensity factor [6]:

$$
\mathrm{K}=2 \sqrt{\frac{\mathrm{a}}{\pi}} \int_{0}^{\mathrm{a}} \frac{\sigma_{\infty}-\mathrm{p}(\xi)}{\sqrt{\left(\mathrm{a}^{2}-\mathrm{x}^{2}\right)}} \mathrm{dx}
$$

To make the formula more simplified, we can get the following simpler formula [2]:

$$
\mathrm{u}\left(\mathrm{x}_{1}\right)=\frac{1}{\pi^{2}} \int_{0}^{\mathrm{a}}\left\{\sigma_{\infty}-\mathrm{p}(\xi)\right\} \ln \left|\frac{\sqrt{\left(\mathrm{a}^{2}-\xi^{2}\right)}+\sqrt{\mathrm{a}^{2}-\mathrm{x}_{1}^{2}}}{\sqrt{\left(\mathrm{a}^{2}-\xi^{2}\right)}-\sqrt{\mathrm{a}^{2}-\mathrm{x}_{1}^{2}}}\right| \mathrm{d} \xi 0 \ll \mathrm{x}_{1}<a
$$

After making some substitutions, we can obtain the following equation [2]:

$$
\mathrm{P}^{2}(\mathrm{X})=\mu\left\{\sqrt{1-\mathrm{X}^{2}}-\frac{1}{\pi} \int_{0}^{1} \mathrm{P}(\mathrm{t}) \ln \left|\frac{\sqrt{1-\mathrm{t}^{2}}+\sqrt{1-\mathrm{X}^{2}}}{\sqrt{1-\mathrm{t}^{2}}-\sqrt{1-\mathrm{X}^{2}}}\right| \mathrm{dt}\right\} 0 \ll \mathrm{X}<1
$$

here

$$
\begin{gathered}
\mu=\lambda^{2} \mathrm{a} / \pi \sigma_{\infty} \\
\mathrm{K}=\sigma_{\infty} \sqrt{(\pi \mathrm{a})} \mathrm{Y}
\end{gathered}
$$

here

$$
\mathrm{Y}=\frac{2}{\pi} \int_{0}^{1} \frac{\{1-\mathrm{P}(\mathrm{X})\}}{\sqrt{1-\mathrm{X}^{2}}} \mathrm{dX}
$$

To obtain the parameter $\lambda$, equating the energy availability for the continuum and discrete fiber models. For the discrete fiber model, the energy available per unit area for matrix cracking is [2]:

$$
E=\frac{R}{6 \tau} \frac{E_{c}}{\left(1-v^{2}\right)^{2}} \frac{V_{m}^{2} E_{m}^{2}}{V_{f}^{2} E_{f}} \epsilon^{3}
$$

For the continuum model, the energy available per unit area for matrix cracking is [2]: 


$$
\mathrm{E}^{*}=\sigma_{\infty} \Delta \mathrm{u}_{2}^{\infty}-\int_{0}^{\Delta \mathrm{u}_{2}^{\infty}} \mathrm{p}\left(\Delta \mathrm{u}_{2}\right) \mathrm{d}\left(\Delta \mathrm{u}_{2}\right)=\frac{4 \pi}{3 \lambda^{2}}\left(\frac{\mathrm{E}_{\mathrm{c}}}{1-\mathrm{v}^{2}}\right)^{2} \epsilon^{3}
$$

By equating $\mathrm{E}=\mathrm{E}^{*}$, the parameter $\lambda$ is obtained:

$$
\lambda=2 \frac{V_{f}}{V_{m}}\left\{\frac{2 \pi \tau}{R} \frac{E_{f} E_{c}}{E_{m}^{2}}\right\}^{1 / 2}
$$

this is different with the parameter $\bar{\lambda}$ used by Marshall et al. [1].

$$
\bar{\lambda}=2 V_{f}\left\{\frac{2 \pi \tau}{R} \frac{E_{f}}{V_{m} E_{m}}\right\}^{1 / 2}=\left(\frac{V_{m} E_{m}}{E_{c}}\right)^{1 / 2} \lambda
$$

Now let us compare the parameter $\lambda$ with $\bar{\lambda}$. The parameter $\lambda$ is obtained through the energy balance considerations, while the parameter $\bar{\lambda}$ is gotten by doing some mechanical analysis of the discrete fiber model. Therefore, we can know that the parameter $\lambda$ can account for the energy changes like stored energy and frictional energy dissipation.

What's more, it is necessary to choose a more reasonable matrix cracking condition to obtain the final critical matrix cracking stress. Now two matrix cracking conditions will be on the list. It is noted that all the conditions are not on the physics ground. Firstly, it is about Griffith fracture criterion as follows [2]:

$$
\mathrm{K}^{2}=2 \gamma \mathrm{E}_{\mathrm{c}} /\left(1-\mathrm{v}^{2}\right)
$$

According to this, we can derive the cracking condition. Secondly, it is assumed that the matrix and composite stress intensities scale with the stress. So we can derive the relation as follows [2]:

$$
\mathrm{K}^{\mathrm{L}}=\mathrm{K}_{\mathrm{c}}^{\mathrm{L}}=\mathrm{K}_{\mathrm{c}}^{\mathrm{M}} \mathrm{E}_{\mathrm{c}} / \mathrm{E}_{\mathrm{m}}
$$

And this chapter adopts the first kind of condition. Finally, the equations concerned with critical cracking condition in this chapter are derived as follows [2]:

$$
\begin{aligned}
\mathrm{a} / \mathrm{a}_{0} & =\left\{\mu_{\mathrm{c}} / \mathrm{Y}\left(\mu_{\mathrm{c}}\right)\right\}^{\frac{2}{3}} \\
\sigma_{\infty}^{\mathrm{c}} / \sigma_{0} & =\left\{1 / \mu_{\mathrm{c}} \mathrm{Y}^{2}\left(\mu_{\mathrm{c}}\right)\right\}^{\frac{1}{3}}
\end{aligned}
$$

here, $\mathrm{Y}$ is a function only of $\mu$.

To predict the threshold stress and obtain the relation between the cracking stress and the pre-existing defect, we should firstly solve Eq. (5) and obtain the effective traction distribution. Then, we can obtain many values of $\mathrm{Y}(\mu)$ corresponding to a range of values of $\mu$. According to the cracking condition, the curve related to the dependence of critical cracking stress on the pre-existing defect is generated.

\section{Numerical solution to matrix cracking stress}

The main problem is to solve the nonlinear integral Eq. (5). The Simpson's integration formula is used here to derive the discrete form of the nonlinear integral 
equation which makes the substitutions. And finally, we can obtain the following discrete formulation [2]:

$$
\begin{gathered}
\left\{g_{i}^{(N+1)}\right\}^{2}-\left\{2+\mu S_{i}\right\} g_{i}^{(N+1)}+1=\mu \sum_{j=0}^{n}\left\{g_{j}^{(N)}-g_{i}^{(N)}\right\} K_{i j}, i=0, \ldots . n N \geq 0 \\
j \neq i
\end{gathered}
$$

here

$$
\mathrm{g}_{\mathrm{i}}=\mathrm{g}(\mathrm{i} / \mathrm{n}), \mathrm{S}_{\mathrm{i}}=\frac{2(\mathrm{i} / \mathrm{n})^{2}}{1+(\mathrm{i} / \mathrm{n})^{4}}, \mathrm{~g}_{\mathrm{i}}^{(0)}=0, \mathrm{i}=0, \ldots, \mathrm{n},
$$

And,

$$
K_{i j}=\frac{8 \delta_{j}}{\pi n^{4}} \ln \left|\frac{S_{j}+S_{i}}{S_{j}-S_{i}}\right| \frac{j^{3}}{\left(1+(j / n)^{4}\right)^{2}}, j \neq i,
$$

With $\delta_{0}=\delta_{n}=\frac{1}{3}, \delta_{j}=\left\{\begin{array}{ll}\frac{4}{3} & \text { if } \mathrm{j} \text { is odd } \\ \frac{2}{3} & \text { if } \mathrm{j} \text { is even }\end{array}, \mathrm{j}=1, \ldots, \mathrm{n}-1\right.$.

And the corresponding discrete form of Eq. (6) for Y [2] is given by

$$
Y=\frac{8}{\pi n^{2}} \sum_{j=0}^{n} \frac{j \delta_{j} g_{j}}{1+(j / n)^{4}}
$$

When solving Eq. (15), the parameter $\mu$ can be valued like 0.1, 1, 10, 100 and so on. Then we can get the value of $\mathrm{g}_{\mathrm{i}}^{\mathrm{N}+1}$ by solving a quadratic equation and using the starting value. What's more, $0 \leq \mathrm{g} \leq 1$. After getting values of all $\mathrm{g}_{\mathrm{i}}^{\mathrm{N}+1}$, by comparing the two adjacent iterations until a group of solution meets the condition [2]:

$$
\sqrt{\left\{\frac{1}{n+1} \sum_{i=0}^{n}\left(g_{i}^{(N+1)}-g_{i}^{(N)}\right)^{2}\right\}}<\delta
$$

where $\delta$ represents the accuracy and can be valued like $10^{-6}, 10^{-8}$.

In this chapter, the value of $\delta$ is $10^{-6}$, and the values of $\mu$ are $0.1,1,100$.

This is the flow chart of the solution:

\section{Results and discussion}

By solving Eq. (15), we can get the curve of the distribution of effective tractions acting on the crack surfaces as in Figure 1. The horizontal axis represents the location in the crack surface, and the vertical axis represents the continuous effective traction. And it is simple that both the horizontal and vertical axes are in percentage terms. So this figure shows the closing traction distribution in a range of parameter $\mu$. The distributions corresponding to different values of $\mu$ are different. And larger the value $\mu$ is, more load will the fiber support at the same position. 


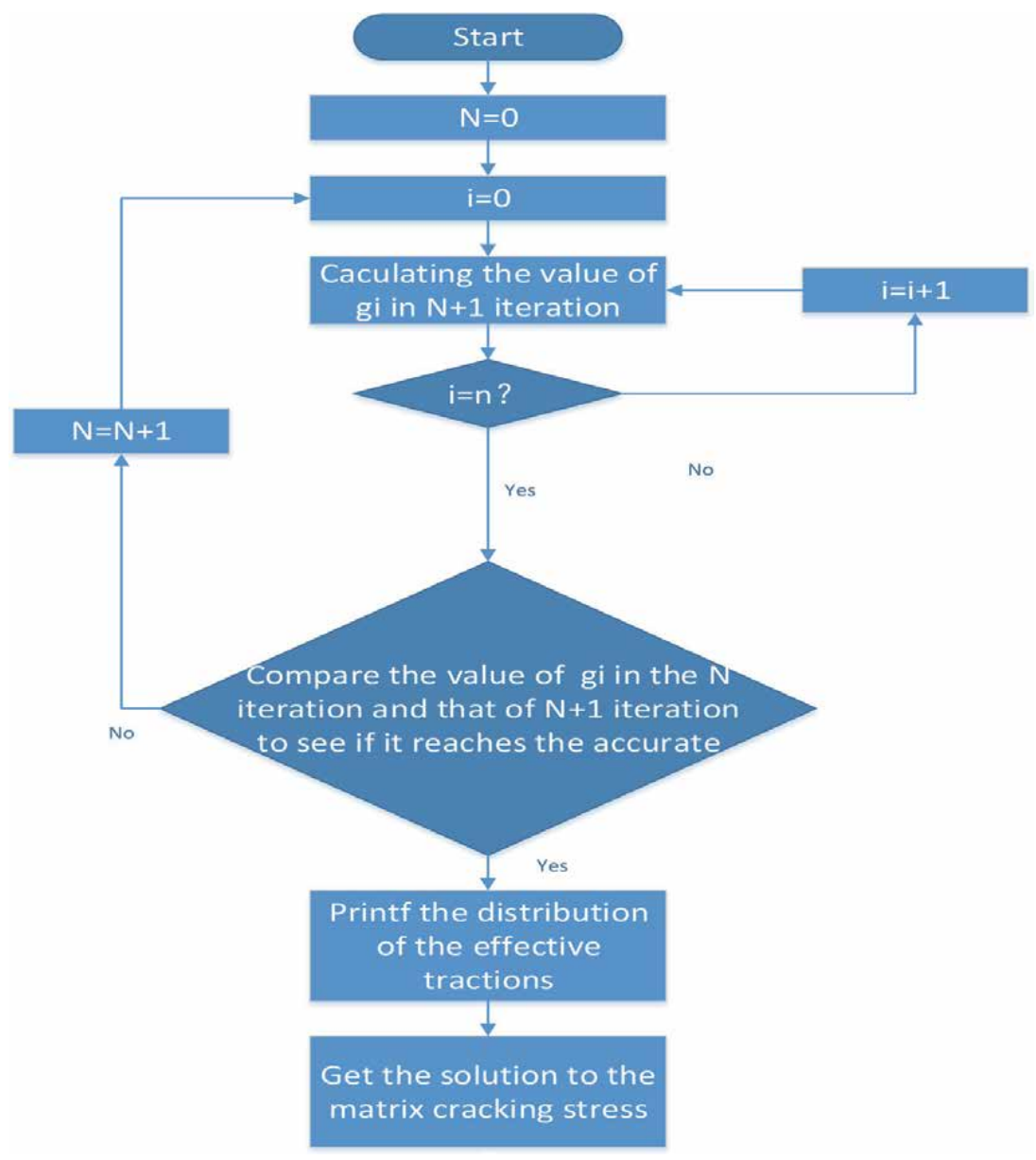

Figure 1.

The flow chart of the solution to the effective fiber tractions.

When $\mu$ comes to 100 , the fiber supports the applied load for most of the crack length. As is mentioned above, this figure gives the accurate result for Eq. (1). And according to this result, we can get the critical matrix cracking stress.

And the corresponding curve which shows the relation between the critical cracking stress and the pre-existing defect is gotten with the cracking condition in Figure 2. And the value of $\delta$ is $10^{-6}$, and the values of $n$ is 60 . The result can be obtained by choosing different values of $\mathrm{a} / \mathrm{a} 0$ and getting the corresponding value of $\mu$. And the values $\sigma_{\infty}^{c} / \sigma_{0}$ varies with $\mathrm{a} / \mathrm{a}_{0} . \mathrm{a} / \mathrm{a}_{0}$ represents the length of preexisting defect, and $\sigma_{\infty}^{c} / \sigma_{0}$ represents the corresponding matrix cracking stress. Both $\mathrm{a} / \mathrm{a}_{0}$ and $\sigma_{\infty}^{\mathrm{c}} / \sigma_{0}$ are standard forms. In this curve, it is noted that the critical stress decreases with the length of pre-existing defect increasing when the length of pre-existing defect is short. And the stress tends to be constant with the length rising when the length is over a value. When the length of pre-existing defect is below a value, the corresponding critical stress is decided by the length of crack, while the critical stress will be independent of the total pre-existing crack length when the length of the defect is over the characteristic distance (Figure 3).

To obtain the threshold matrix cracking stress by choosing $\mathrm{a} / \mathrm{a}_{0} \rightarrow \infty$, we choose the parameter $\mu$ like in the following table. It is shown that $\sigma_{\infty}^{\mathrm{c}} / \sigma_{0} \rightarrow 1.331$ when $\mathrm{a} / \mathrm{a}_{0} \rightarrow \infty$. We can know that it is close to the theoretical value by calculation (Table 1). 
Safety and Risk Assessment of Civil Aircraft during Operation

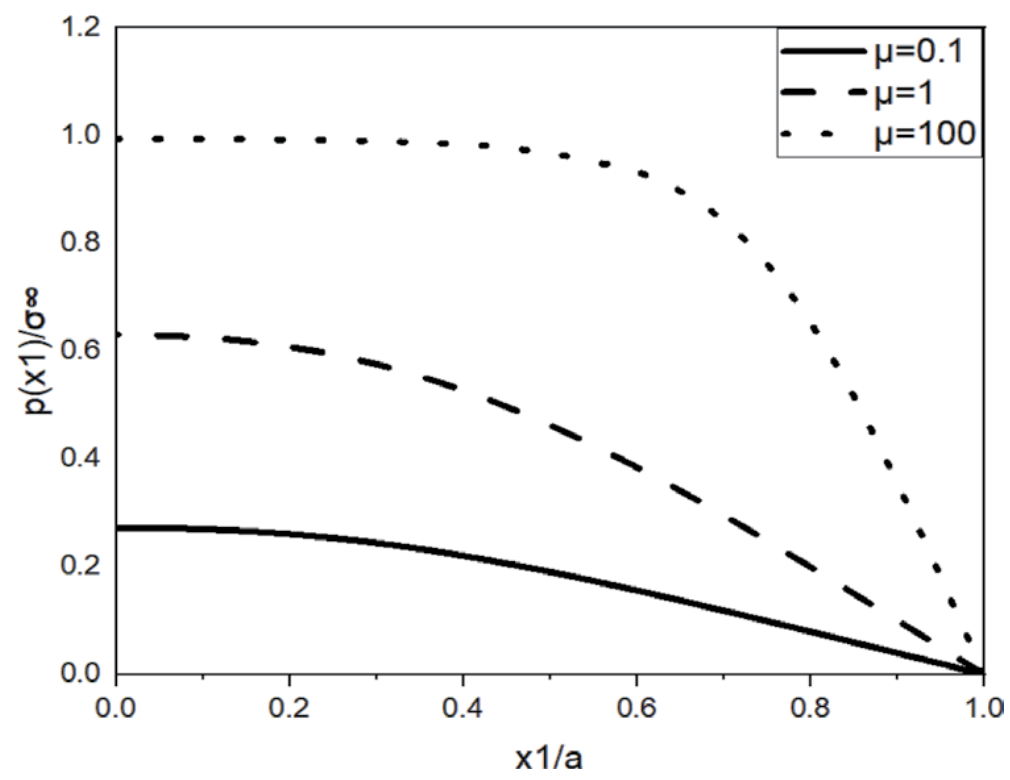

Figure 2.

The distribution of effective traction acting on the crack surface.

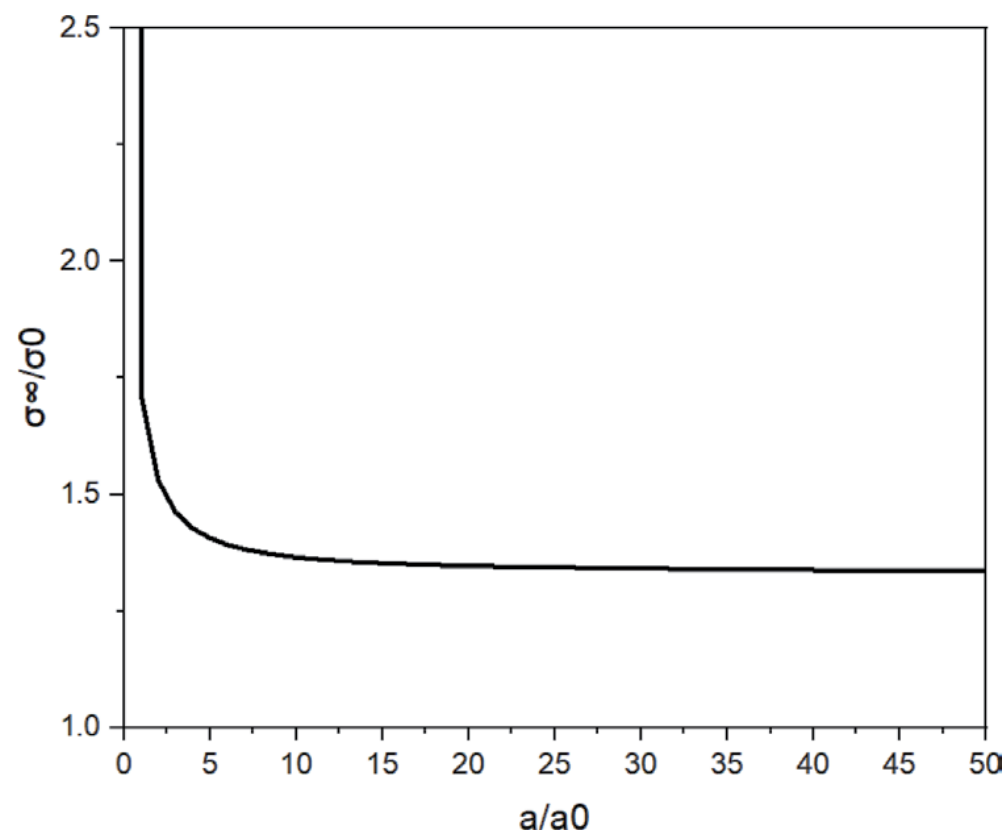

Figure 3 .

The critical stress for matrix cracking on the length of the pre-existing matrix crack.

\begin{tabular}{lccccccc}
\hline $\mathbf{u}$ & $\mathbf{0 . 1}$ & $\mathbf{1}$ & $\mathbf{1 0}$ & $\mathbf{1 0 0}$ & $\mathbf{1 0 0 0}$ & $\mathbf{1 5 0 0}$ & $\mathbf{2 0 0 0}$ \\
\hline$\sigma_{\infty}^{\mathrm{c}} / \sigma_{0}$ & 2.52038 & 1.582594 & 1.355636 & 1.332882 & 1.331029 & 1.331012 & 1.331025 \\
\hline
\end{tabular}

Table 1.

Values of the critical cracking stress for various values of $\mu[2]$. 
Non-Steady First Matrix Cracking of Fiber-Reinforced Ceramics DOI: $h t t p: / / d x$.doi.org/10.5772/intechopen.93060

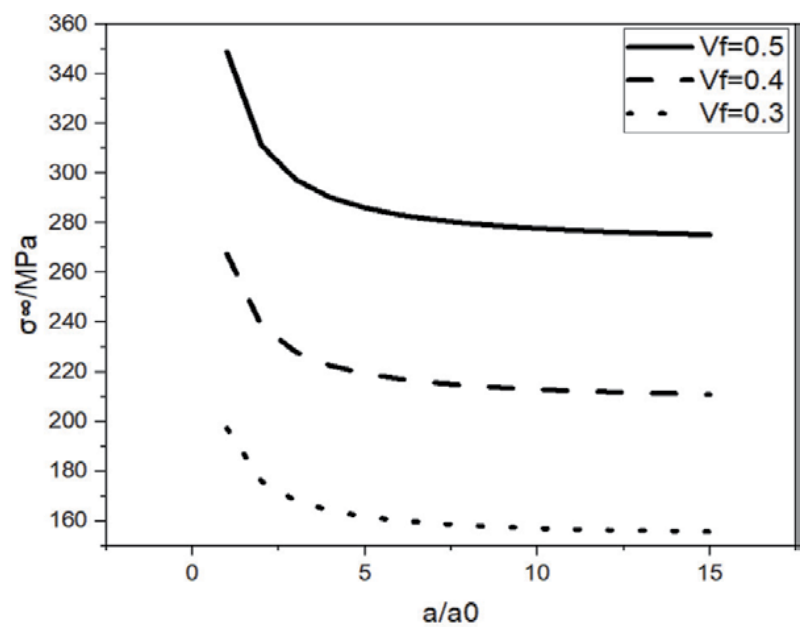

(a) SiC-glass ceramic

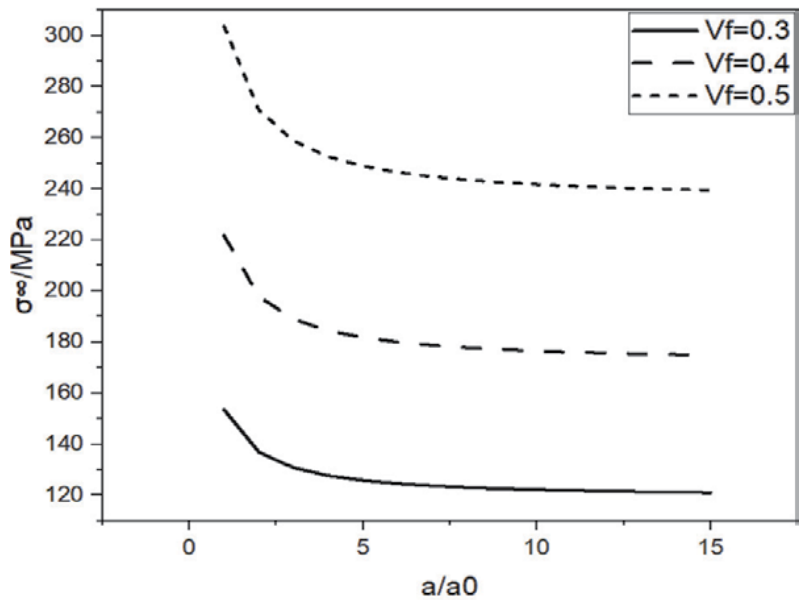

(b) $\mathrm{SiC} /$ borosilicata

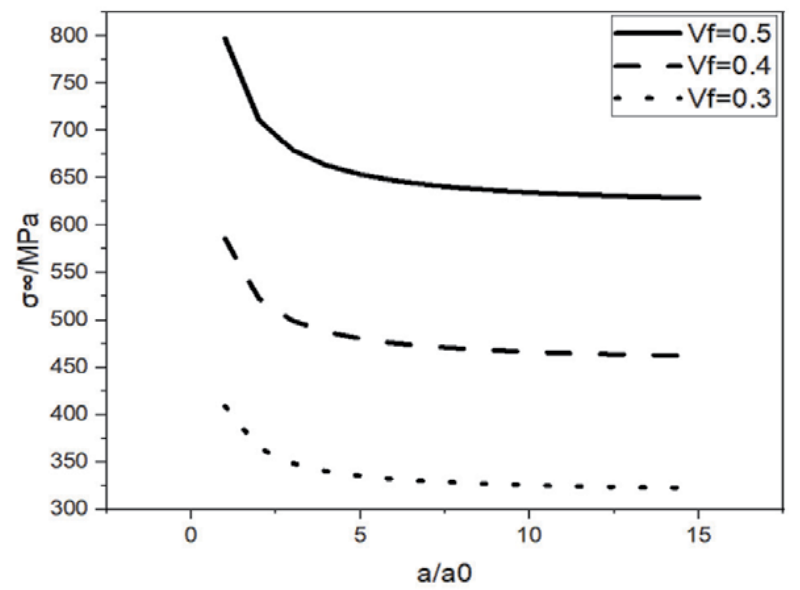

(c) C/borosilicata

Figure 4.

The distribution of effective tractions with different values of parameter $\mathrm{V}_{\mathrm{f}}$ in three kinds of material. (a) SiCglass ceramic. (b) SiC/borosilicata. (c) C/borosilicata. 
a. The condition that the fiber is strong enough to keep intact and it does not take into account the shear deformation in the matrix above the slipping region is considered. But obviously the fiber failure and the deformation above the slipping region influences the matrix cracking stress. This chapter gives the numerical solution. MCE model gives the approximate analytical solution [1] for short crack. And we can see that the two methods show the same trends, and the numerical solution is lower than the analytical solution. It is noted that the MCE model assumed the cracking condition instead of deriving the condition. And the result of MCE model do not establish the threshold matrix cracking stress below which is impossible to make the matrix crack. The model will be valid when the ratio $a / R$ is large enough, as the fiber radius $\mathrm{R}$ was not quoted. It is not possible to determine that part of the curve in Figure 5 satisfying the validity condition $a / R>10$. So it is of vital importance to derive numerical results. As Figure 1 shows, the distribution of effective tractions $\mathrm{p}\left(\mathrm{x}_{1}\right) / \sigma_{\infty}$ increases with the parameter $\mu$ rising at the same position. By changing the value of $\mathrm{V}_{\mathrm{f}}$, we can finally change the standard value $\sigma_{0}$. As a result, the value of matrix cracking stress changes. And the relation between the matrix cracking stress and $V_{f}$ is shown in Figure 4. The parameters of three kinds of material are listed in Tables 2-4. They are SiCglass ceramic, $\mathrm{SiC} /$ borosilicate, and $\mathrm{C} /$ borosilicate. And the formula can be derived according to Eqs. (6) and (11):

$$
\mu=\frac{8 \tau a V_{f}^{2} E_{f}\left(E_{f} V_{f}+E_{m} V_{m}\right)}{R_{m}^{2} E_{m}^{2} \sigma_{\infty}}
$$

The relation that the parameter $\mu$ increases with the $V_{f}$ rising can be gotten by taking the derivative of the equation to determine its monotonicity. As a result, the distribution of effective tractions $\mathrm{p}\left(\mathrm{x}_{1}\right) / \sigma_{\infty}$ acting on the crack surface rises with parameter $\mathrm{V}_{\mathrm{f}}$ increasing. The parameter a represents the matrix cracking length, and $\sigma_{\infty}$ represents the applied stress. And as we all know, the distribution of

\begin{tabular}{lccccc}
\hline Parameter & $\mathbf{E}_{\mathbf{f}} / \mathrm{GPa}$ & $\mathbf{E}_{\mathbf{m}} / \mathrm{GP}_{\mathbf{a}}$ & $\mathbf{K}_{\mathrm{IC}}^{\mathbf{m}}(\mathbf{M P a}-\sqrt{\mathbf{m}})$ & $\mathbf{R} / \boldsymbol{\mu m}$ & $\boldsymbol{\tau} / \mathbf{M P a}$ \\
\hline Value & 200 & 85 & 2 & 8 & 2 \\
\hline
\end{tabular}

Table 2.

The parameters of SiC-glass ceramic.

\begin{tabular}{lccccc}
\hline Parameter & $\mathbf{E}_{\mathbf{f}} / \mathrm{GPa}$ & $\mathbf{E}_{\mathbf{m}} / \mathrm{GP}_{\mathbf{a}}$ & $\mathbf{K}_{\mathrm{IC}}^{\mathbf{m}}(\mathbf{M P a}-\sqrt{\mathbf{m}})$ & $\mathbf{R} / \boldsymbol{\mu m}$ & $\boldsymbol{\tau} / \mathbf{M P a}$ \\
\hline value & 400 & 63 & 0.77 & 70 & $6-8$ \\
\hline
\end{tabular}

Table 3.

The parameters of SiC/borosilicata.

\begin{tabular}{lccccc}
\hline Parameter & $\mathbf{E}_{\mathbf{f}} / \mathbf{G P a}$ & $\mathbf{E}_{\mathbf{m}} / \mathbf{G P}_{\mathbf{a}}$ & $\mathbf{K}_{\mathrm{IC}}^{\mathbf{m}}(\mathbf{M P a}-\sqrt{\mathbf{m}})$ & $\mathbf{R} / \mathbf{\mu m}$ & $\boldsymbol{\tau} / \mathbf{M P a}$ \\
\hline value & 380 & 70 & 0.75 & 4 & 10 \\
\hline
\end{tabular}

Table 4 .

The parameters of C/borosilicata. 
Non-Steady First Matrix Cracking of Fiber-Reinforced Ceramics DOI: $h t t p: / / d x$.doi.org/10.5772/intechopen.93060

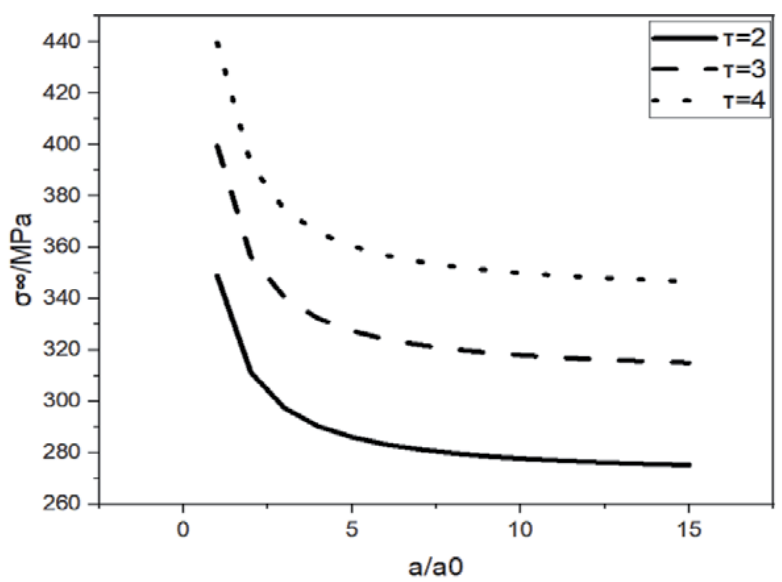

(a) SiC-glass ceramic

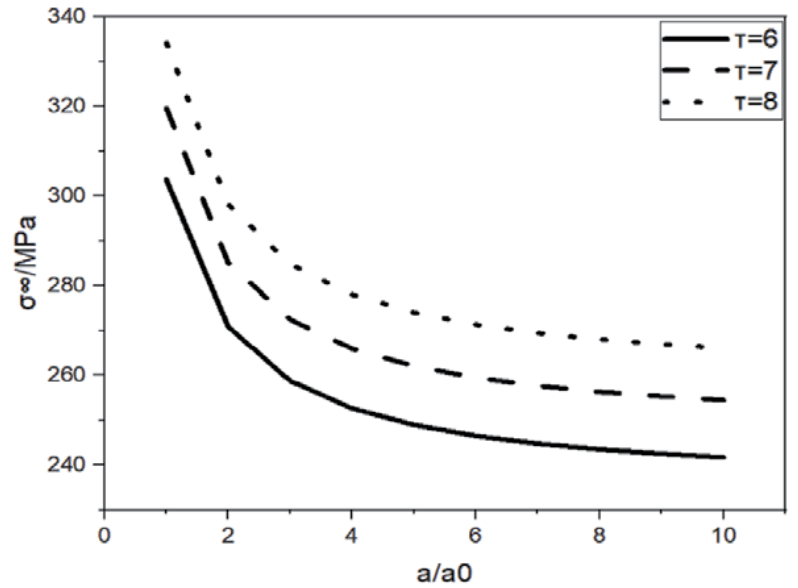

(b) $\mathrm{SiC} /$ borosilicata

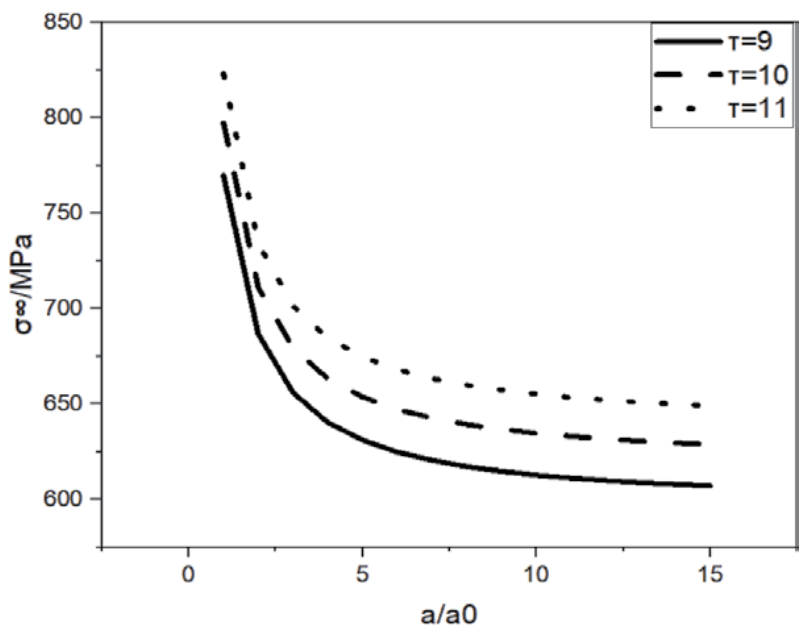

(c) $\mathrm{C} /$ borosilicata

Figure 5.

The distribution of effective tractions with different values of parameter $\tau$ in three kinds of material. (a) SiCglass ceramic. (b) SiC/borosilicata. (c) C/borosilicata. 
effective traction which is equivalent to the effect of fiber traction can make the fiber ends displace to be rejoined. So the greater value of $\mathrm{p}\left(\mathrm{x}_{1}\right) / \sigma_{\infty}$, the harder the matrix to crack which means the value of the matrix cracking stress is bigger. And the parameter $\tau$ is in positive correlation with the parameter $\mu$. In the same way, the matrix cracking stress will increase with the parameter $\tau$ rising. The curve can be seen in Figure 5 with three kinds of material which show the same tendency.

\section{Conclusion}

McCartney model gives a more reasonable parameter $\lambda$ which is gotten by equating the available energy of fiber discrete model and continuum model, while the MCE model do some stress analysis of fiber discrete model to get this parameter. So the McCartney model can explain the energy changes. McCartney model derived rather than assuming the matrix cracking condition. The cracking condition is gotten through the Griffith fracture criterion in McCartney model. MCE model assumed that the matrix and composite stress intensities scale with the stresses. And McCartney gives the threshold stress to verify the theoretical value.

\section{Author details}

Huan Wang

Nanjing University of Aeronautic and Astronautic, Nanjing, P.R. China

*Address all correspondence to: 3058723100@qq.com

\section{IntechOpen}

(C) 2020 The Author(s). Licensee IntechOpen. Distributed under the terms of the Creative Commons Attribution - NonCommercial 4.0 License (https://creativecommons.org/ licenses/by-nc/4.0/), which permits use, distribution and reproduction for non-commercial purposes, provided the original is properly cited. (cc) BY-NC 


\section{References}

[1] Marshall DB, Cox BN, Evans AG. The mechanics of matrix cracking in brittlematrix fiber composites. Acta Metallurgica. 1985;33(11):2013-2021

[2] McCartney LN. Mechanics of matrix cracking in brittle-matrix fiberreinforced composites. Proceedings of the Royal Society A. 1987;409:329-350

[3] Chiang YC, Wang ASD, Chou TW. On matrix cracking in fiber reinforced ceramics. Journal of the Mechanics and Physics of Solids. 1993;41(7):1137-1154

[4] Chiang YC. Tensile failure in fiber reinforced ceramic matrix composites. Journal of Materials Science. 2000; 35(21):5449-5455

[5] Sneddon IN, Lowengrub M. Crack Problems in the Classical Theory of Elasticity. New York: Wiley; 1969

[6] Lawn BR, Wilshaw TR. Fracture of Brittle Solids. Press: Cambridge Univ; 1975 



\title{
The Effect of Random Load on Life Prediction of High-Temperature Ceramic Matrix Composites
}

\author{
En-Zhong Zhang
}

\begin{abstract}
High-temperature ceramic matrix composites (CMCs) are widely used in hot section components of aeroengine, and random loads have an important effect on their safety and reliability during aircraft operation. The current fatigue life prediction model of CMC is divided into macrophenomenon model and microdamage mechanism model. In this chapter, the fatigue life of fiber-reinforced ceramic matrix composites is investigated. The fatigue life of the fiber-reinforced ceramic matrix composites is predicted by micromechanical methods. The effect of random loading on fatigue life is analyzed and compared with constant peak stress fatigue life. The influence of composite constitutive properties on fatigue fracture is also discussed.
\end{abstract}

Keywords: high-temperature ceramic matrix composites, fatigue life, random load, fiber failure

\section{Introduction}

In the rapid progress and development of science and technology, the requirements of the use environment of the required materials are also increasing. For example, with the development of high-performance aero-turbine engine, the inlet temperature of the turbine increases gradually, and the temperature of the hot-end parts can reach more than $1600^{\circ} \mathrm{C}$, which has far exceeded the working limit of superalloy [1]. The main materials of aeroengine combustion chamber, turbine, and other high-temperature structures are still superalloys, although cooling and thermal barrier coating technology is developing, but still cannot fully meet the requirements of engine hot-end components, so high-temperature ceramic-based composites are born. Ceramic matrix composites (CMCs) have a great potential as high-temperature structural materials, especially as materials used in aerospace vehicles with special parts which need to bear a very high temperature.

Compared with traditional materials, ceramic matrix composites have the advantages of wear resistance, high temperature resistance, chemical corrosion resistance, good vibration absorption, high specific strength, high specific modulus, and low cost. The density is only $1 / 4-1 / 3$ of the nickel-base alloy, and the strength will not decrease with the increase of temperature, even higher than at room 
temperature. The application of ceramic matrix composite material structure to civil engine can reduce the amount of cooling air, increase the temperature and efficiency before turbine, and reduce the fuel consumption rate, so it can improve the economy of the engine. If the ceramic matrix composite structure is applied to the military engine, the starting weight can be obviously reduced, the temperature in front of the turbine can be increased, and the pushing weight ratio of the engine can be improved.

The most successful engine company for $\mathrm{SiC}_{\mathrm{f}} / \mathrm{SiC}$ composite is the GE Aviation Group. The GE Aviation Group, supported by the US Department of Energy project, in 1992 developed innovative prepreg-melt infiltration processes that allow high-performance, rapid, and low-cost preparation of $\mathrm{SiC}_{\mathrm{f}} / \mathrm{SiC}$ composites becomes a reality. Developed by the GE Aviation Group, the $\mathrm{SiC}_{\mathrm{f}} / \mathrm{SiC}$ composite lowpressure guide vane was verified on the F136 engine in 2009, and the first flight was completed in 2010. In 2016, $\mathrm{SiC}_{\mathrm{f}} / \mathrm{SiC}$ composite is applied on the turbine outer ring of Leading Edge Aviation Propulsion (LEAP) engines and produced in batches. The $\mathrm{SiC}_{\mathrm{f}} / \mathrm{SiC}$ composite is used in combustor, guide vane, and turbine outer ring of GE9X commercial engine, which reduces fuel consumption by $10 \%$ compared with GE90-115B engine. The new generation of military turboshaft GE3000 engine uses a ceramic matrix composite material, which reduces fuel consumption by $25 \%$ compared with T700 engine, reduces life cycle cost by $35 \%$, prolongs life by $20 \%$, and increases work-weight ratio by $65 \%$. The Safran Group is one of the leading practitioners of $\mathrm{SiC}_{\mathrm{f}} / \mathrm{SiC}$ ceramic matrix composites; the company has mastered the chemical vapor infiltration process and has taken the lead in applying it on engine tail nozzle.

There are two kinds of fatigue life prediction models for ceramic matrix composites, i.e., macroscopic phenomenological model [2] and micromechanical damage mechanism model [3]. Due to the complex microstructure, high anisotropy, and various damage mechanisms of ceramic matrix composites, the macroscopic phenomenological model needs a lot of experimental data to modify the life model. The influence of structure fatigue life of high-temperature ceramic matrix composites is closely related to the reliability and safety of aircraft; it is necessary to investigate the influence of random load on structure fatigue life of high-temperature ceramic matrix composites.

In this chapter, the damage process and mechanism of ceramic matrix composites are studied by means of the micromechanical method. The influence of random load on fatigue life prediction of high-temperature ceramic matrix composites is studied. According to the fatigue fracture mechanism of composite under cyclic load, the life prediction model of composite is established, and an external load is applied to study the influence of random load on fatigue life prediction of hightemperature ceramic matrix composites.

\section{Prediction method of fatigue life of composite materials}

Fatigue damage occurs in composites subjected to repeated loading. Fatigue damage at the initial stage of material application is not easily detected in external observation. With the increasing number of cycles, the matrix began to appear cracks, interfacial debonding, delamination, and irreversible fatigue damage. Results show that the interfacial shear stress and fiber strength will decrease with the increasing number of cycles. The decrease of interfacial shear stress causes the material to be unable to deliver the load effectively, and the fiber strength is reduced, resulting in the material being difficult to resist deformation. With their 
combined action, the fiber volume failure percentage increases with the increasing number of cycles. When the fiber volume failure percentage increases to a critical value, the composite will be damaged. Under critical conditions, with the increase of fatigue peak stress, it will lead to the decrease of cycle times, the decrease of lifetime, and the decrease of safety and reliability.

Li [4] developed a micromechanical fatigue life prediction model considering interface wear and fiber failure. In the process of cyclic loading to fatigue peak load, some fibers first break failure, but also can bear a certain load through interfacial shear stress. The load distribution between an intact fiber and a broken fiber is as follows:

$$
\frac{\sigma_{\max }}{V_{f}}=T[1-P(T)]+<T_{b}>P(T)
$$

where $\sigma_{\max }$ is the fatigue peak stress, $\mathrm{V}_{\mathrm{f}}$ is the fiber volume content, $\left\langle\mathrm{T}_{\mathrm{b}}>\right.$ is the load carried by the broken fiber, and $\mathrm{P}(\mathrm{T})$ is the fiber failure probability:

$$
P(T)=1-\exp \left\{-\left(\frac{T}{\sigma_{c}}\right)^{m+1}\left(\frac{\sigma_{0}}{\sigma_{0}(N)}\right)^{m}\left(\frac{\tau_{i}}{\tau_{i}(N)}\right)\right\}
$$

where $\sigma_{c}$ is the characteristic strength of the reinforced fiber and $\mathrm{m}$ is the fiber Weibull modulus.

Lee [5] investigated the tension-tension fatigue behavior of CMCs at room temperature; the degradation of the fiber strength is

$$
\sigma_{0}(N)=\sigma_{0}\left[1-p_{1}(\log N)^{p_{2}}\right]
$$

where $\mathrm{p}_{1}$ and $\mathrm{p}_{2}$ are the empirical parameters.

Evans et al. [6] investigated the fatigue behavior of SiC/CAS composite at room temperature. The degradation of the interfacial shear stress is

$$
\tau_{i}(N)=\tau_{i 0}+\left[1-\exp \left(-\varpi N^{\lambda}\right)\right]\left(\tau_{i \min }-\tau_{i 0}\right)
$$

where $\tau_{\mathrm{i} 0}$ is the initial value of the interfacial shear stress, $\tau_{\mathrm{i} \text { min }}$ is the steadystate value of interfacial shear stress, and $\omega$ and $\lambda$ are the empirical parameters.

Substituting the stress carried by broken fiber into Eq. (1), it leads to

$$
\frac{\sigma_{\max }}{V_{f}}=T\left(\frac{\sigma_{0}(N)}{\sigma_{0}}\right)^{m}\left(\frac{\sigma_{c}}{T}\right)^{m+1} \frac{\tau_{i}(N)}{\tau_{i}}\left\{1-\exp \left[-\left(\frac{T}{\sigma_{c}}\right)^{m+1}\left(\frac{\sigma_{0}}{\sigma_{0}(N)}\right)^{m} \frac{\tau_{i}}{\tau_{i}(N)}\right]\right\}
$$

Using Eqs. (3), (4), and (5), the intact fiber stress $\mathrm{T}$ can be obtained $\mathrm{N}$ the change of cycle number

$$
\begin{aligned}
& \frac{\sigma_{\max }}{V_{f}}=T\left\{\left[1-P_{1}(\log N)^{P_{2}}\right]\right\}\left(\frac{\sigma_{c}}{T}\right)^{m+1} \frac{\tau_{i 0}+\left[1-\exp \left(-\varpi N^{\lambda}\right)\right]\left(\tau_{i \min }-\tau_{i 0}\right)}{\tau_{i}} \\
& \cdot\left\{1-\exp \left[-\left(\frac{T}{\sigma_{c}}\right)^{m+1}\left(\frac{1}{1-P_{1}(\log N)^{P_{2}}}\right)^{m} \frac{\tau_{i}}{\tau_{i 0}+\left[1-\exp \left(-\varpi N^{\lambda}\right)\right]\left(\tau_{i \min }-\tau_{i 0}\right)}\right]\right\}
\end{aligned}
$$


Using Eq. (2), Eq. (6) changes to

$\frac{\sigma_{\max }}{V_{1}}=T^{\prime}\left\{\left[1-P_{1}(\log N)^{I_{2}}\right]\right\}\left(\frac{\sigma_{\sigma}}{T}\right)^{r y+1} \frac{\tau_{i 0}+\left[1-\exp \left(-\tau N^{i}\right)\right]\left(\tau_{i \min }-\tau_{i 0}\right)}{\tau_{i}} P\left(T^{\prime}\right)$

When the failure fiber volume fraction $\mathrm{P}(\mathrm{T})$ reaches the critical value $\mathrm{q}^{*}$, the composite fatigue fails. The flowchart for the life prediction of CMCs is given by the following (Figure 1):

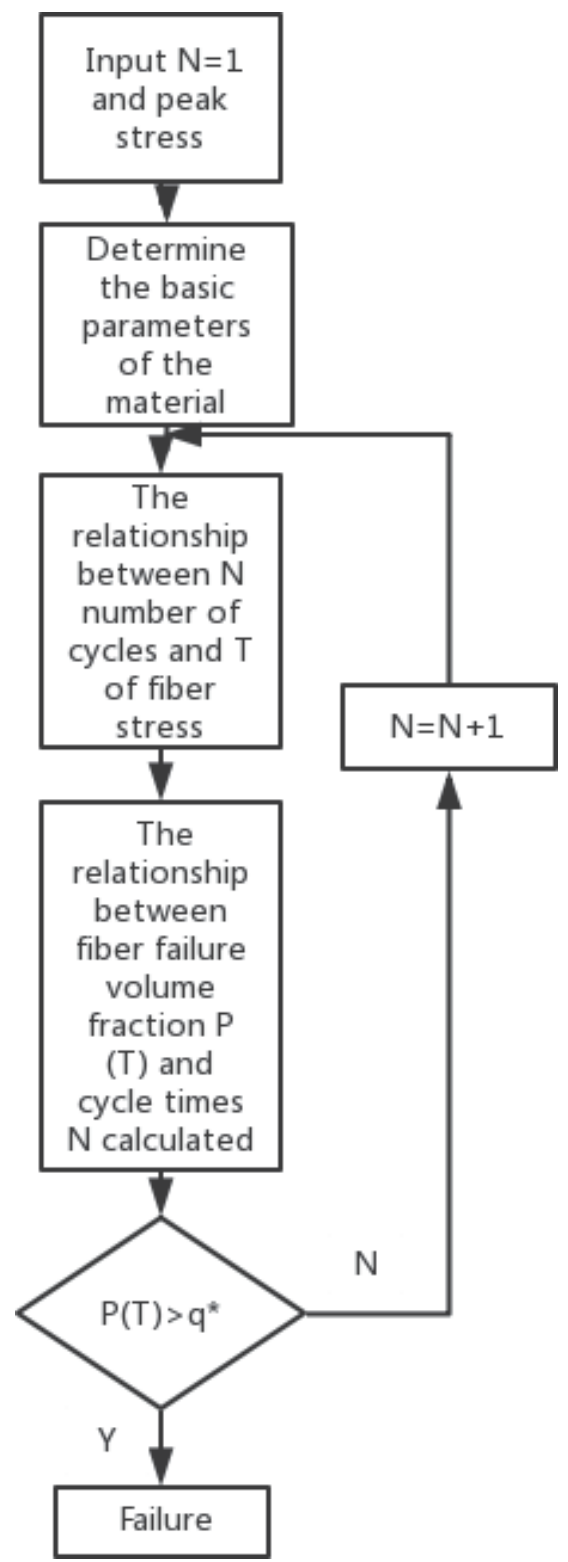

Figure 1.

The flowchart for life prediction of CMCs. 
1. Determine the basic parameters of the material.

2. The relationship between the fiber strength and interfacial shear stress and cycle times $\mathrm{N}$ was calculated by Eqs. (3) and (4), respectively. Then, the relationship between an intact fiber stress $\mathrm{T}$ and cycle number $\mathrm{N}$ under a certain peak stress was calculated by Eq. (5).

3. The relationship between cycle number $\mathrm{N}$ and intact fiber stress $\mathrm{T}$ is obtained from Eq. (2), and the relationship between fiber failure fraction $\mathrm{P}$ (T) and cycle number is calculated by combining Eq. (7). When $P(T)>q^{*}$, the composite fails and the minimum cycle number is output $\mathrm{N}$, which is fatigue life.

\subsection{Theoretical prediction of ceramic matrix composites without random loading}

For $\mathrm{C} / \mathrm{SiC}$ composite, the model parameters are given by $p_{1}=0.01$ and $p_{2}=1.0$; the interfacial shear stress parameters are $\omega=0.04, \lambda=1.5, \tau_{10}=8 \mathrm{MPa}$, and $\tau_{\text {imin }}=0.3 \mathrm{MPa}$; and the other parameters are $\mathrm{V}_{\mathrm{f}}=0.42, \sigma_{\mathrm{c}}=2 \mathrm{GPa}, \mathrm{m}=5$, and $\tau_{\mathrm{i}}=10 \mathrm{MPa}$.

Figure 2 is derived from Eq. (3). It can be concluded that the fiber strength shows a linear decline with the increasing number of cycles and decreases from the original $100 \%$ to about $94 \%$ of the original value when the number of cycles reaches $\mathrm{N}=1,000,000$.

Figure 3 is calculated from Eq. (4). The interfacial shear stress decreases rapidly in the first 20 cycles and decreases very slowly and almost negligible in the 20$1,000,000$ cycles, which is approximately a straight line. It can be speculated that the interface shear stress almost does not change with the increase of cycle times after $1,000,000$ cycles.

Figures 4-6 are obtained by combining Eqs. (6) and (7) under a peak stress of $\sigma_{\max }=355,365$, and $375 \mathrm{MPa}$, respectively. The fiber failure fraction of CMCs changes most slowly with the increase of cycle number in cycles from $\mathrm{N}=1$ to $\mathrm{N}=100$. In the 100-3000 cycles, the fiber failure fraction changes most sharply

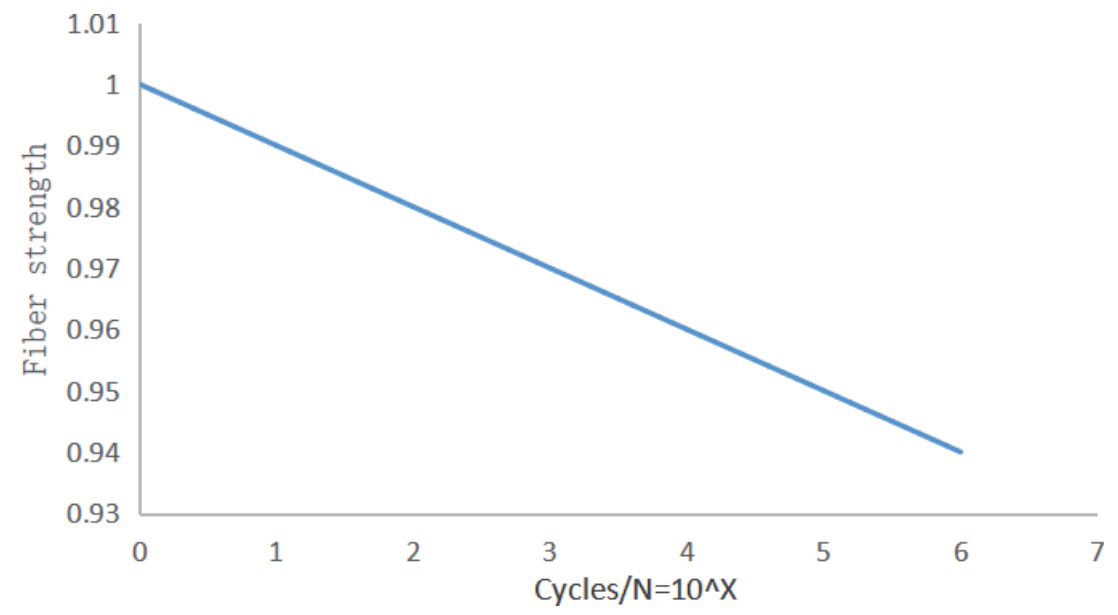

Figure 2.

Fiber strength versus cycle number curve. 


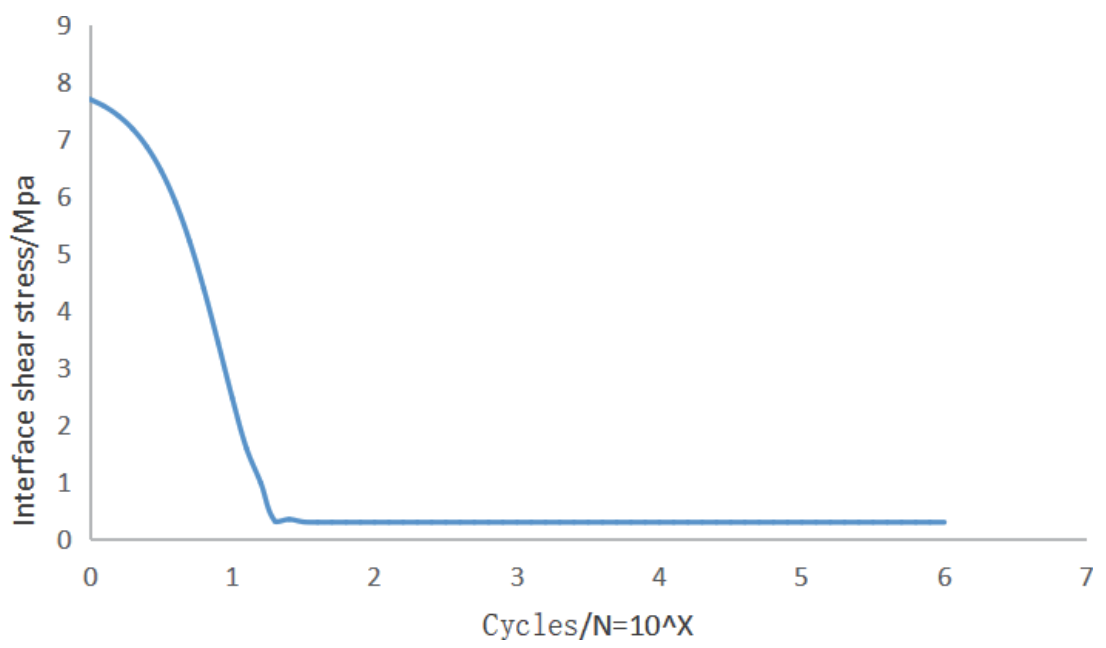

Figure 3.

Interfacial shear stress versus cyclic number curve.

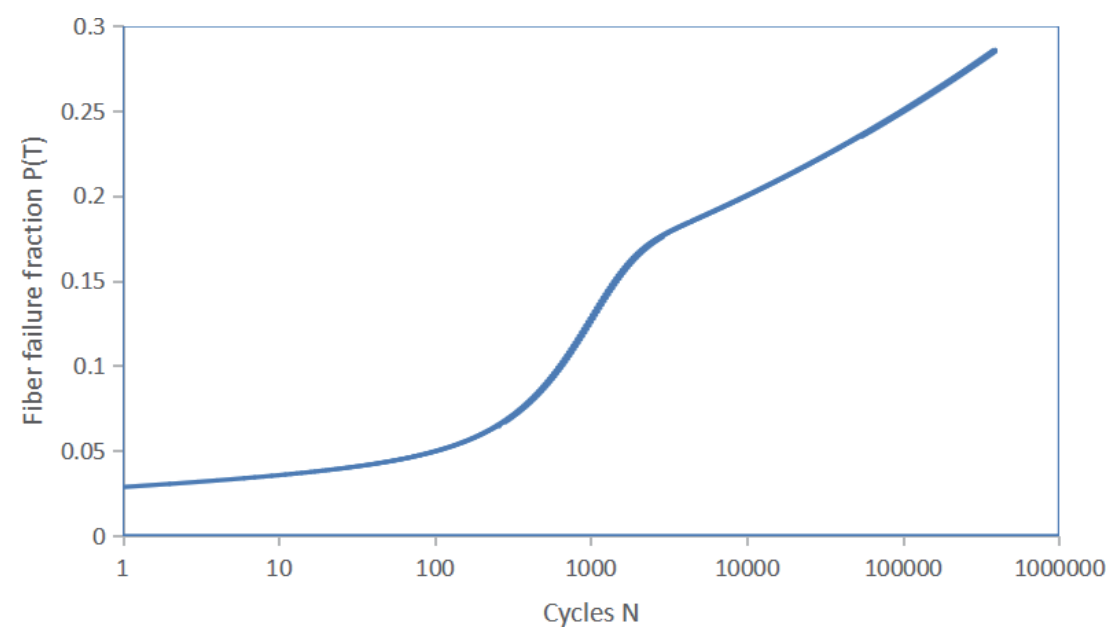

Figure 4.

Fiber failure fraction versus cycle number under $\sigma_{\max }=355 \mathrm{MPa}$.

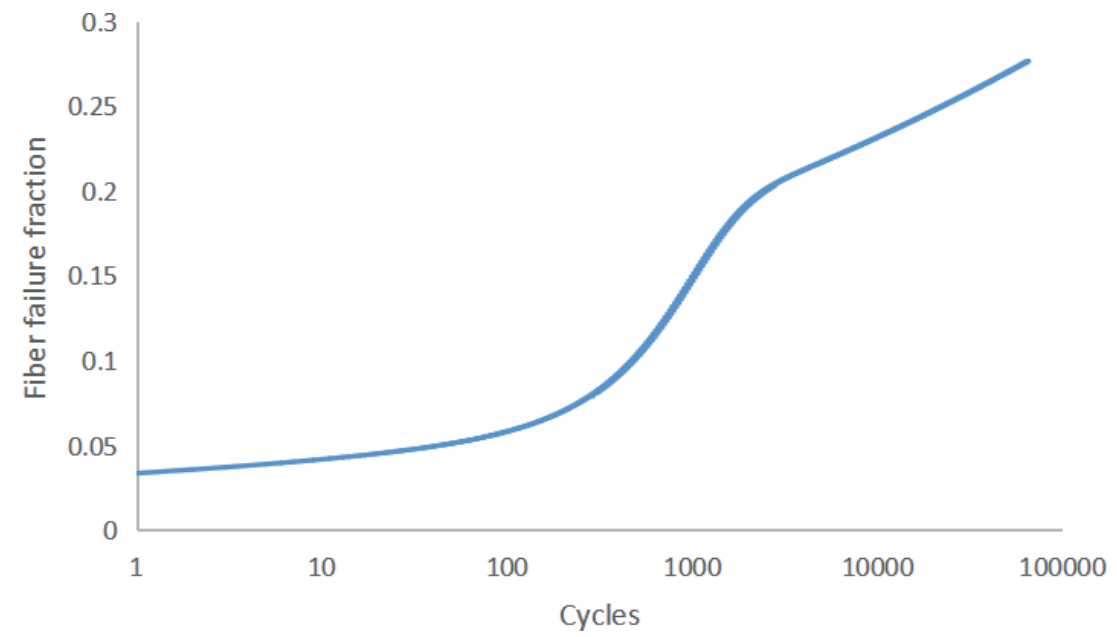

Figure 5 .

Fiber failure fraction versus cycle number under $\sigma_{\max }=365 \mathrm{MPa}$. 


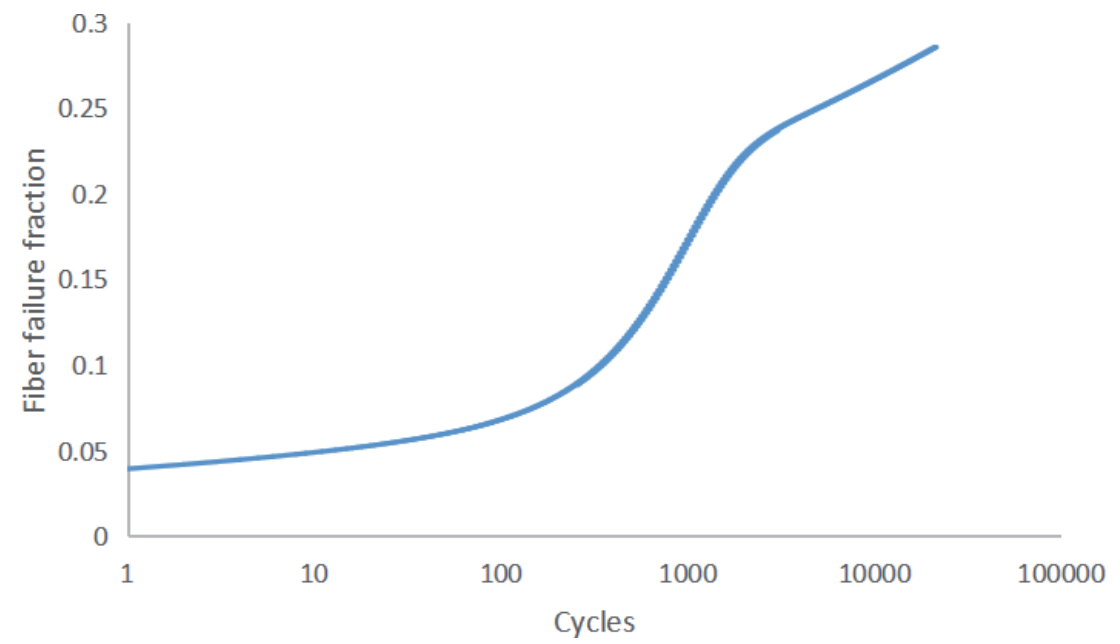

Figure 6.

Fiber failure fraction versus cycle number under $\sigma_{\max }=375 \mathrm{MPa}$.

with the increase of cycle number. The fiber failure fraction in the cycles of $3000-1,000,000$ is similar to the linear growth with the increase of the cycle number.

A calculation process of Figure 7 can be obtained from the steps above. The S-N diagram of the composite is divided into segments. In the first cycle of 1-1000, the peak stress in the cycle changes very slowly in the increase of cycle number, which approximates a horizontal line. In the second stage, during the 1000-2000 cycles, the peak stress changes rapidly in the cycle number. In the third stage, in 2000$1,000,000$, the peak stress in this cycle presents a linear decrease with the increase of the number of cycles.

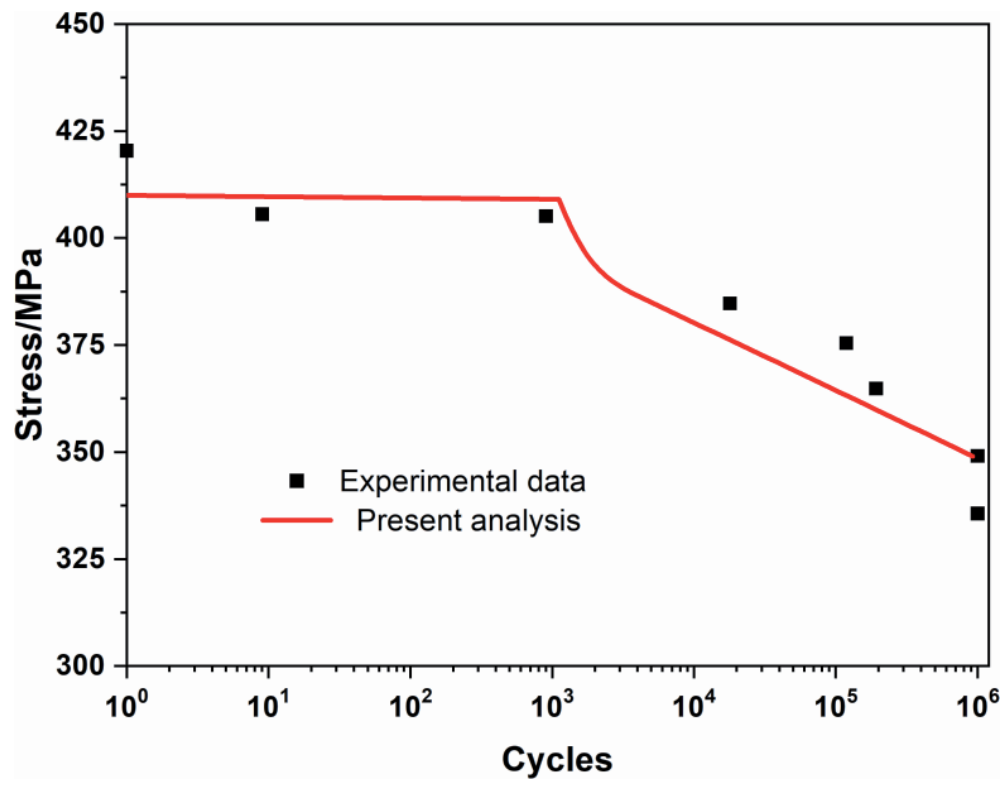

Figure 7.

The experimental and predicted $S-N$ curve. 


\section{Effect of random load on fatigue life of ceramic matrix composites}

The fiber characteristic strength and interfacial shear stress of CMCs are cyclic dependent. The addition of a random load at the Nth cycle can be considered to be the addition of a new peak stress higher than the original peak stress at the Nth cycle, which is approximately equivalent to cycling the random load as the constant peak stress, calculating the difference between its increased fiber failure probability at the Nth cycle relative to the fiber failure probability increased by the original peak stress at the Nth cycle $k$, and adding the $k$ to the fiber failure rate after the first cycle.

\subsection{Effect of random load cycle number on fatigue life}

The parameters of $\mathrm{C} / \mathrm{SiC}$ composite are given as follows: $p_{1}=0.01$ and $p_{2}=1.0$; the interfacial shear stress parameter is given by $\omega=0.04, \lambda=1.5, \tau_{10}=8 \mathrm{MPa}$, and $\tau_{\text {imin }}=0.3 \mathrm{MPa}$; the other related parameters are given by $\mathrm{V}_{\mathrm{f}}=0.42, \sigma_{\mathrm{c}}=2 \mathrm{GPa}$, $\mathrm{m}=5$, and $\tau_{\mathrm{i}}=10 \mathrm{MPa}$.

The fiber failure curves under a constant peak stress of $\sigma_{\max }=355 \mathrm{MPa}$ and random load of $\sigma_{\mathrm{s}}=360 \mathrm{MPa}$ at $\mathrm{N}=100$ are shown in Figure 8. At the 100th cycle, due to the random load of $\sigma_{\mathrm{s}}=360 \mathrm{MPa}$, the fiber failure probability increases 0.004207 than the original value under $\sigma_{\max }=355 \mathrm{MPa}$, the difference of fiber failure probability continues after 100 cycles, and the life is reduced from the original $\mathrm{N}=389,642$ cycles under $\sigma_{\max }=355 \mathrm{MPa}$ to $\mathrm{N}=335,176$ cycles, and the life difference is 54,466 cycles. The occurrence of random load reduces the fatigue life and decreases the fatigue life by $14.0 \%$ relative to the original value.

The fiber failure curves under a constant peak stress of $\sigma_{\max }=355 \mathrm{MPa}$ and random load of $\sigma_{\mathrm{s}}=360 \mathrm{MPa}$ at $\mathrm{N}=1000$ are shown in Figure 9. At the 100th cycle, due to the random load of $\sigma_{\mathrm{s}}=360 \mathrm{MPa}$, the fiber failure probability increases 0.010321 than the original value under $\sigma_{\max }=355 \mathrm{MPa}$, the difference of fiber failure probability continues after 1000 cycles, and the life is reduced from the original $\mathrm{N}=389,642$ cycles under $\sigma_{\max }=355 \mathrm{MPa}$ to $\mathrm{N}=268,176$ cycles, and the life difference is 121,466 cycles. The occurrence of random load reduces the fatigue life and decreases the fatigue life by $31.1 \%$ relative to the original value.

The fiber failure curves under a constant peak stress of $\sigma_{\max }=355 \mathrm{MPa}$ and random load of $\sigma_{\mathrm{s}}=360 \mathrm{MPa}$ at $\mathrm{N}=10,000$ are shown in Figure 10. At the 100th

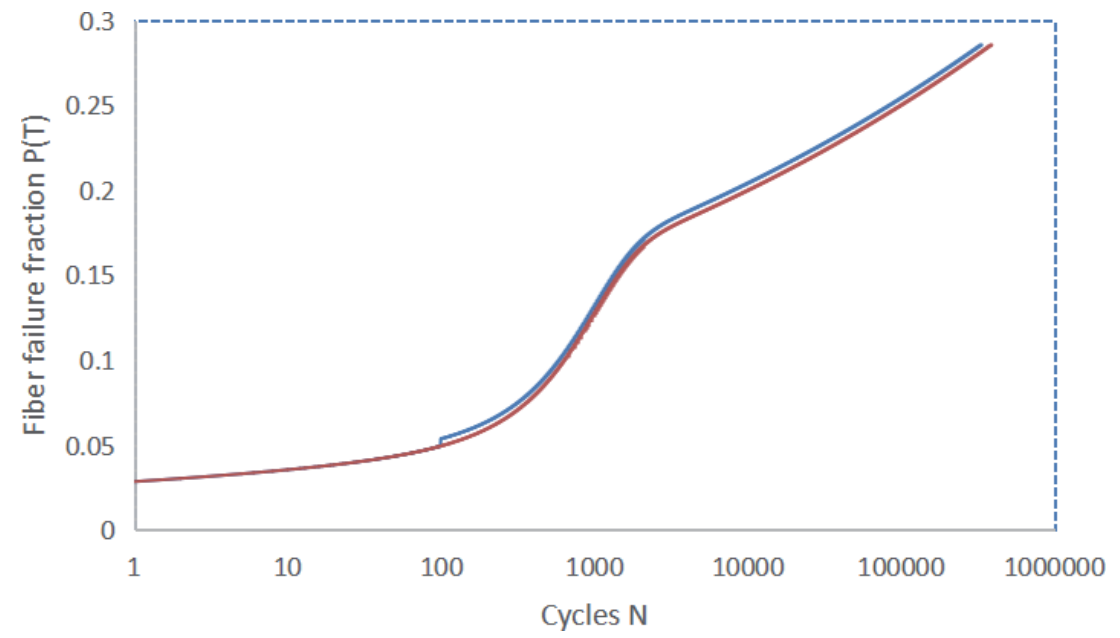

Figure 8.

The fiber failure probability versus cycle number under $\sigma_{\max }=355 \mathrm{MPa}$ and random load of $\sigma_{s}=360 \mathrm{MPa}$ at $N=100$. 
The Effect of Random Load on Life Prediction of High-Temperature Ceramic Matrix Composites DOI: http://dx.doi.org/10.5772/intechopen.93059

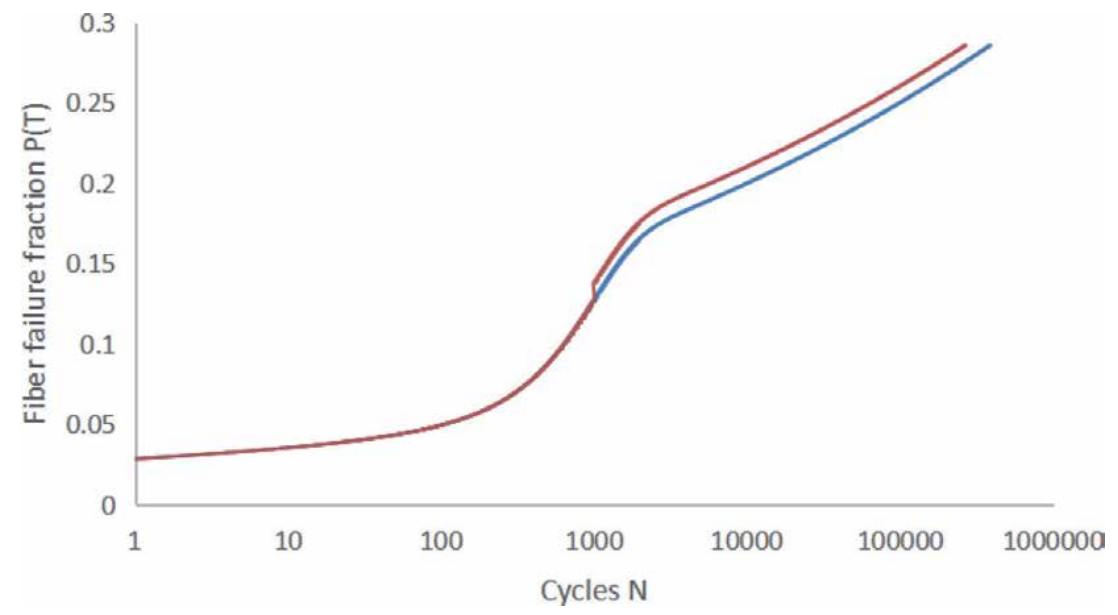

Figure 9.

The fiber failure probability versus cycle number under $\sigma_{\max }=355 \mathrm{MPa}$ and random load of $\sigma_{s}=360 \mathrm{MPa}$ at $N=1000$.

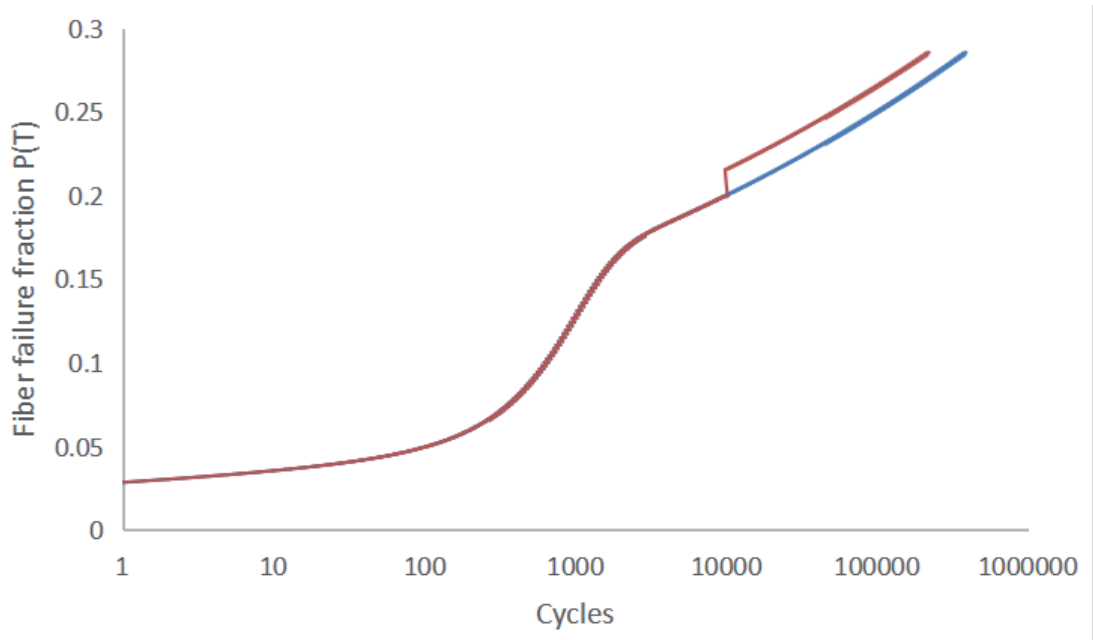

Figure 10.

The fiber failure probability versus cycle number under $\sigma_{\max }=355 \mathrm{MPa}$ and random load of $\sigma_{s}=360 \mathrm{MPa}$ at $N=10,000$.

\begin{tabular}{lccccccc}
\hline $\begin{array}{l}\text { Number } \\
\text { of cycles }\end{array}$ & $\begin{array}{c}\text { Fiber failure } \\
\text { fraction } \\
\text { under the } \\
\text { original load }\end{array}$ & $\begin{array}{c}\text { Fiber } \\
\text { failure } \\
\text { fraction } \\
\text { after } \\
\text { random } \\
\text { load }\end{array}$ & $\begin{array}{c}\text { Difference } \\
\text { of fiber } \\
\text { failure } \\
\text { fraction }\end{array}$ & $\begin{array}{c}\text { Fatigue } \\
\text { life } \\
\text { under } \\
\text { original } \\
\text { load }\end{array}$ & $\begin{array}{c}\text { Fatigue } \\
\text { life after } \\
\text { random } \\
\text { load }\end{array}$ & $\begin{array}{c}\text { Difference } \\
\text { of fatigue } \\
\text { life }\end{array}$ & $\begin{array}{c}\text { Fatigue life } \\
\text { decreasing } \\
\text { rate }\end{array}$ \\
\hline 100 & 0.049407 & 0.053614 & 0.004207 & 389,642 & 335,176 & 54,466 & $14.0 \%$ \\
\hline 1000 & 0.12704 & 0.137361 & 0.010321 & 389,642 & 268,176 & 121,466 & $31.1 \%$ \\
\hline 10,000 & 0.199833 & 0.215297 & 0.015464 & 389,642 & 221,415 & 168,227 & $43.2 \%$ \\
\hline
\end{tabular}

Table 1.

Fatigue life and fiber failure fraction under $\sigma_{\max }=355 \mathrm{MPa}$ and random load of $\sigma_{s}=360 \mathrm{MPa}$ at different cycle number. 


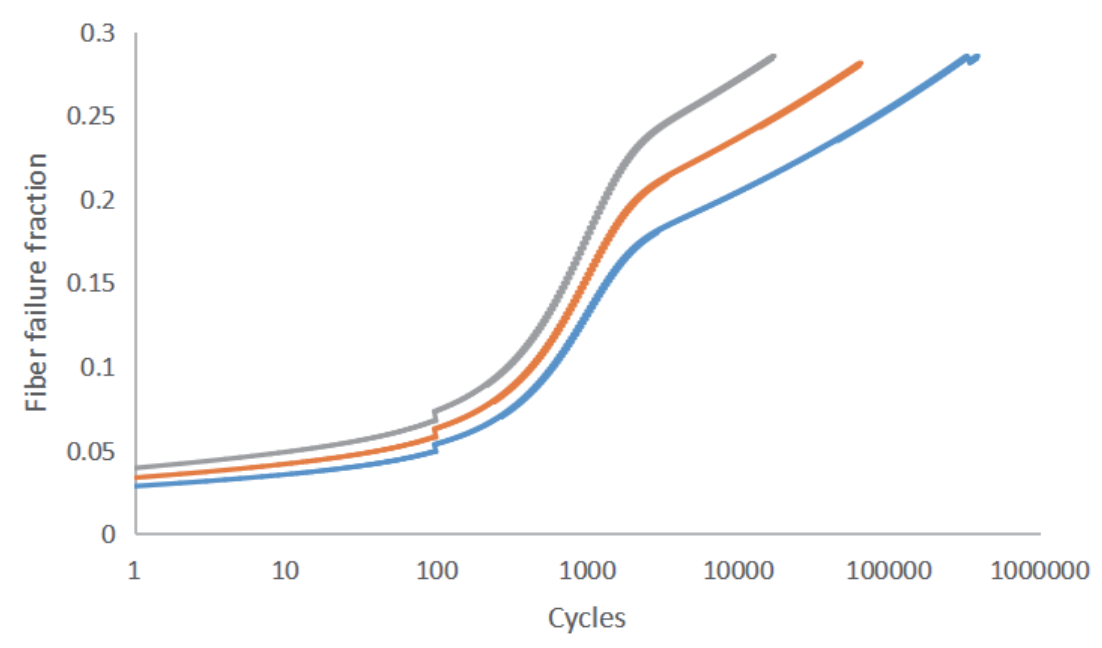

Figure 11.

The fiber failure fraction versus cycle number curves under different random stresses at $N=100$.

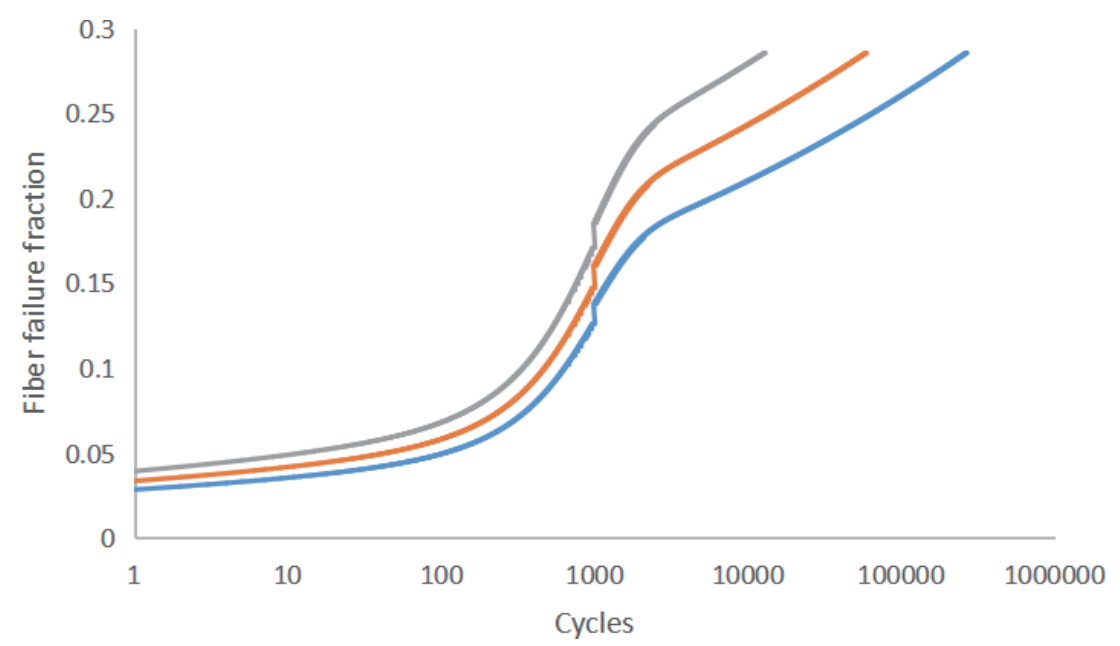

Figure 12.

The fiber failure fraction versus cycle number curves under different random stresses at $N=1000$.

cycle, due to the random load of $\sigma_{\mathrm{s}}=360 \mathrm{MPa}$, the fiber failure probability increases 0.015464 than the original value under $\sigma_{\max }=355 \mathrm{MPa}$, the difference of fiber failure probability continues after 10,000 cycles, and the life is reduced from the original $\mathrm{N}=389,642$ cycles under $\sigma_{\max }=355 \mathrm{MPa}$ to $\mathrm{N}=221,415$ cycles, and the life difference is 168,227 cycles. The occurrence of random load reduces the fatigue life and decreases the fatigue life by $43.2 \%$ relative to the original value.

Table 1 shows the fatigue life and fiber failure fraction under $\sigma_{\max }=355 \mathrm{MPa}$ and random load of $\sigma_{\mathrm{s}}=360 \mathrm{MPa}$ at different cycle number. The difference of fiber failure probability under random load increases with the increase of cycle number. The long-term use of ceramic matrix composites with multiple cyclic loads has weak resistance to random loads and low safety and reliability, but on the contrary, the initial use of ceramic matrix composites has a strong ability to resist random loads and high safety and reliability. 
The Effect of Random Load on Life Prediction of High-Temperature Ceramic Matrix Composites DOI: http://dx.doi.org/10.5772/intechopen.93059

\subsection{Effect of random load peak stress on fatigue life}

The parameters of $\mathrm{C} / \mathrm{SiC}$ composite are as follows: $p_{1}=0.01$ and $p_{2}=1.0$; the interfacial shear stress parameters are $\omega=0.04, \lambda=1.5, \tau_{10}=8 \mathrm{MPa}$, and $\tau_{\text {imin }}=0.3 \mathrm{MPa}$; and the other parameters are given by $\mathrm{V}_{\mathrm{f}}=0.42, \sigma_{\mathrm{c}}=2 \mathrm{GPa}, \mathrm{m}=5$, and $\tau_{\mathrm{i}}=10 \mathrm{MPa}$. As shown in Figures 11-13, the random loads of $\sigma_{\mathrm{s}}=360,370$, and 380 occur at the applied cycles of $\mathrm{N}=100,1000$, and 10,000, and the percentage of fiber failure increases with peak stress and random stress. As shown in Table 2, the difference between the fiber failure fraction under constant peak stress and the fiber failure fraction under random load stress increases with the random stress level. As shown in Table 3, the difference of the cycle life decreases with the

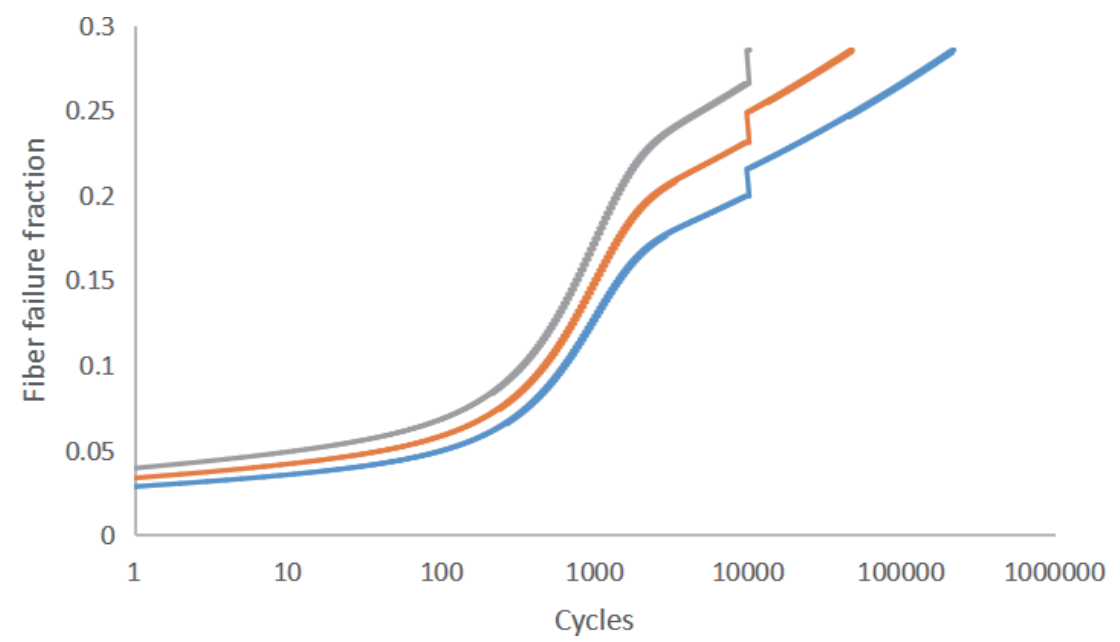

Figure 13.

The fiber failure fraction versus cycle number curves under different random stresses at $N=10,000$.

\begin{tabular}{lcccccc}
\hline $\begin{array}{l}\text { Peak } \\
\text { stress } \\
(\mathbf{M P a})\end{array}$ & $\begin{array}{c}\text { Fiber failure } \\
\text { fraction } \\
\text { difference at } \\
\mathbf{1 0 0} \text { cycles }\end{array}$ & $\begin{array}{c}\text { Fiber failure } \\
\text { fraction } \\
\text { difference at } \\
\mathbf{1 0 0 0} \text { cycles }\end{array}$ & $\begin{array}{c}\text { Fiber failure } \\
\text { fraction } \\
\text { difference at } \\
\mathbf{1 0 0 0 0} \text { cycles }\end{array}$ & $\begin{array}{c}\text { Fatigue life } \\
\text { difference } \\
\text { at } \\
\mathbf{1 0 0} \text { cycles }\end{array}$ & $\begin{array}{c}\text { Fatigue life } \\
\text { difference } \\
\text { at }\end{array}$ & $\begin{array}{c}\text { Fatigue life } \\
\text { difference at } \\
\mathbf{1 0 0 0 0} \text { cycles }\end{array}$ \\
\hline 355 & 0.004207 & 0.010321 & 0.015464 & 54,466 & 121,466 & 168,227 \\
\hline 365 & 0.004784 & 0.011549 & 0.017028 & 14,888 & 32,234 & 43,591 \\
\hline 375 & 0.005412 & 0.012827 & 0.012828 & 4008 & 8399 & 11,076 \\
\hline
\end{tabular}

Table 2.

Comparison of fatigue life under different random stresses.

\begin{tabular}{lccc}
\hline $\begin{array}{l}\text { Peak stress } \\
\text { (Mpa) }\end{array}$ & $\begin{array}{c}\text { Decay rate of loading } \\
\text { cycle in 100 cycles }\end{array}$ & $\begin{array}{c}\text { Decay rate of loading } \\
\text { cycle in 1000 cycles }\end{array}$ & $\begin{array}{c}\text { Decay rate of loading cycle } \\
\text { in 10,000 cycles }\end{array}$ \\
\hline 355 & $14.0 \%$ & $31.1 \%$ & $43.2 \%$ \\
\hline 365 & $16.2 \%$ & $35.2 \%$ & $47.5 \%$ \\
\hline 375 & $18.7 \%$ & $39.7 \%$ & $51.7 \%$ \\
\hline
\end{tabular}

Table 3.

Comparison of cyclic decay rates under different random stresses. 


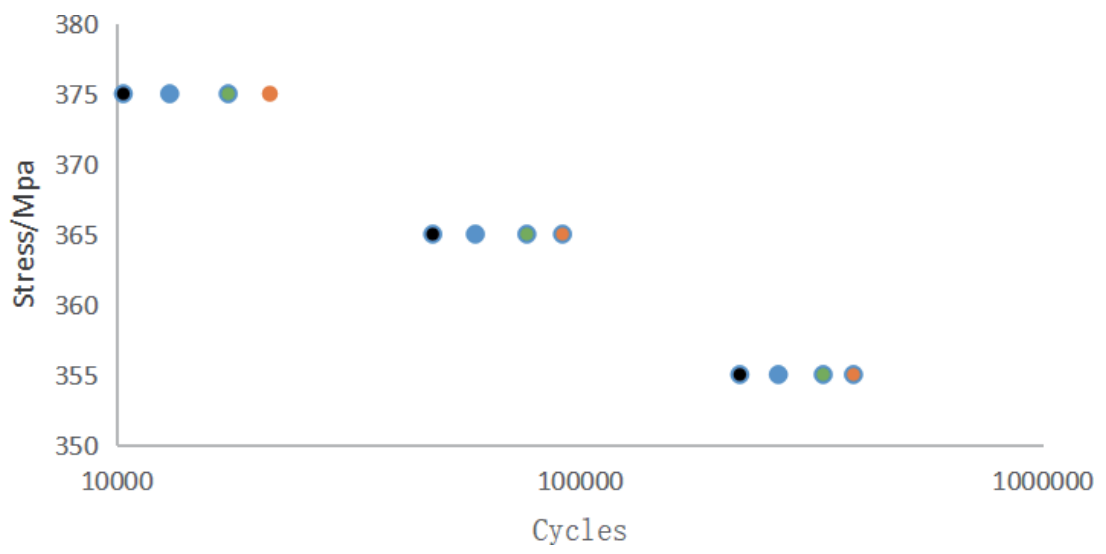

Figure 14.

The fatigue life S-N curve under different random stresses.

increase of the peak stress, the proportion of the reduced cycle to the total cycle increases, so the effect of the random load on the higher peak stress is greater. As shown in Figure 14, the fatigue life decreases at higher random stress.

\section{Conclusion}

The influence of random load on fatigue life of high-temperature ceramic matrix composites is investigated. A curve of fiber failure rate with cycle number and an $\mathrm{S}-\mathrm{N}$ curve of fatigue life of $\mathrm{C} / \mathrm{SiC}$ composites are presented in this paper. The random loads are loaded under different peak stresses, and the variation law of fiber failure rate and cycle life is analyzed. It can be concluded that when the same random load is added under the same peak stress, the difference of fiber failure rate increases with the increase of cycle number at which the random load occurs, and when the same random load is added at the same cycle number, the difference of fiber failure rate increases with the increase of peak stress. If the added random load is too high and exceeds the material's bearing limit, the fiber will break directly.

\section{Author details}

En-Zhong Zhang

College of Civil Aviation, Nanjing University of Aeronautics and Astronautics, China

*Address all correspondence to: 1913054374@qq.com

\section{IntechOpen}

(C) 2020 The Author(s). Licensee IntechOpen. Distributed under the terms of the Creative Commons Attribution - NonCommercial 4.0 License (https://creativecommons.org/ licenses/by-nc/4.0/), which permits use, distribution and reproduction for non-commercial purposes, provided the original is properly cited. (cc) BY-NC 
The Effect of Random Load on Life Prediction of High-Temperature Ceramic Matrix Composites DOI: http://dx.doi.org/10.5772/intechopen.93059

\section{References}

[1] Ma QG, Liu HT, Pan Y. Research progress on the application of $\mathrm{C} / \mathrm{Si} \mathrm{C}$ composites in scram jet. Journal of Inorganic Materials. 2013;28(3):247-255

[2] Sabelkin V, Mall S, Cook TS. Fatigue and creep behaviors of a $\mathrm{SiC} / \mathrm{SiC}$ composite under combustion and laboratory environments. Journal of Composite Materials. 2016;50(16): 2145-2153

[3] Min JB, Xue D, Shi Y. Micromechanics modeling for fatigue damage analysis designed for fabric reinforced ceramic matrix composites. Composite Structures. 2014;111(1): 213-223

[4] Longbiao L. Damage monitor and life prediction of carbon fiber-reinforced ceramic-matrix composites at room and elevated temperatures using hysteresis dissipated energy-based damage parameter. Composite Interfaces. 2018; 25(4):335-356

[5] Lee SS. Damage Analysis and Mechanical Response of as Received and Heat Treated Nicalon/CAS-2 Glass Ceramic Matrix Composites. Blacksburg, VA (United States): Virginia Polytechnic Inst. and State Univ.; 1993

[6] Evans AG, Zok FW, Mcmeeking RM. Fatigue of ceramic matrix composites. Acta Metallurgica et Materialia. 1995; 43(3):859-875 



\title{
Multiple Matrix Cracking of Fiber-Reinforced Ceramic-Matrix Composites during Operation
}

\author{
Chengzheng Zhu
}

\begin{abstract}
In the field of civil aviation, the most important factor is safety quality. Improving aircraft performance can increase flight safety factor in some degree. To improve the thrust-to-weight ratio of aircraft engines and reduce fuel consumption, the fundamental measure is to increase the turbine inlet temperature of engines, while hot-section components is directly related to the maximum allowable operating temperature. Ceramic-matrix composite (CMC) material is one of the important candidate materials for aeroengine. To improve CMCs in aircraft engine application, it is necessary to investigate the failure mechanism of CMCs and also failure models. However, during operation, matrix multiple cracking occurs with fiber debonding and fracture, which affects the flight safety and failure risk. In this chapter, the multiple matrix cracking of fiber-reinforced CMCs is investigated using energy balance approach.
\end{abstract}

Keywords: ceramic-matrix composites (CMCs), failure mechanism, matrix cracking, evolution, energy balance approach

\section{Introduction}

Ceramic matrix composites (CMCs) have high specific stiffness, specific strength, high temperature resistance, corrosion resistance and other excellent properties [1-6]. However, CMCs also have inherent weaknesses. Due to the low failure strain of the matrix, cracking of the matrix occurs before the failure of the fiber. Matrix multiple cracking affects the reliability and safety of CMCs during operation. In this chapter, based on the failure model of CMCs, the matrix cracking problem CMCs is investigated.

\section{The matrix cracking of unidirectional CMCs}

A partial fiber/matrix interface debonding model is used in this chapter. The problem of multiple cracking of unidirectional brittle composites was first analyzed by Aveston [7]. The fiber and matrix are simulated as concentric cylinders with radius $r_{o}$ and $R$ respectively. The composite material consists of a series of repeating units connected by the fiber, as shown in Figure 1. When matrix cracking occurs, the interfacial shear stress tends to concentrate near the matrix crack, which may lead to fiber/matrix debonding in these areas. Crack spacing is denoted by $\mathrm{L}$ and 


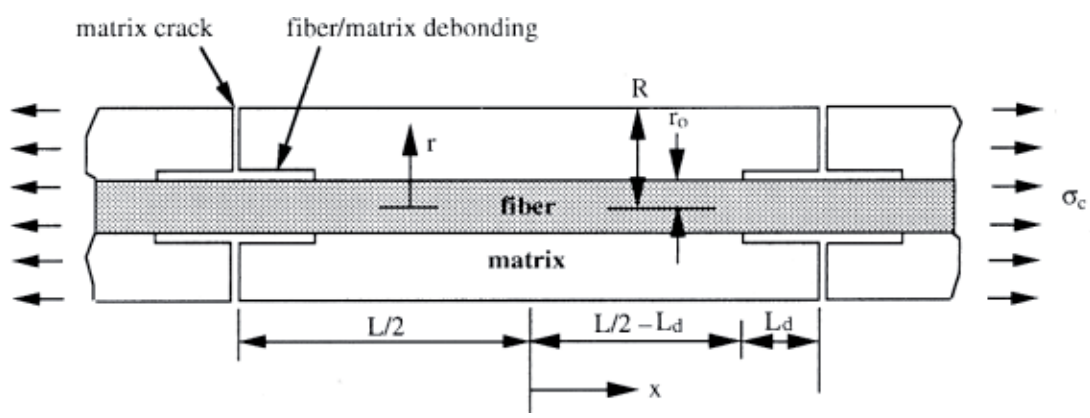

Figure 1.

Partial interfacial debonding model for unidirectional composites.

stripping length by $\mathrm{L}_{\mathrm{d}}$. X represents the displacement of the center of the composite. By changing $L$ and $L_{d}$, the model can include: (1) complete bonding, (2) partial debonding/sliding, and (3) complete debonding/sliding. Because the fiber failure strain in most ceramic matrix composites is much higher than that in matrix, it is assumed that the fiber is intact during matrix cracking.

By using the energy method, the critical stress of matrix cracking is determined considering the energy balance between the undamaged state and the cracked state. The energy terms involved in the generation of matrix crack include matrix surface energy, fiber/matrix debonding energy, energy consumed by friction fiber sliding, strain energy change and work done by external load. According to the shear-lag model, the stress distribution of the fiber, the matrix and the interface before and after crack propagation was obtained, and the initial cracking stress of the matrix was obtained by combining with the energy balance equation. When matrix cracking and interface debonding occur, the composite strain is,

$$
\varepsilon_{\mathrm{c}}=\left\{\begin{array}{l}
\frac{\sigma}{V_{\mathrm{f}} E_{\mathrm{f}}} \eta-\frac{\tau_{\mathrm{i}}}{E_{\mathrm{f}}} \frac{l_{\mathrm{d}}}{r_{\mathrm{f}}} \eta+\frac{\sigma_{f o}}{E_{\mathrm{f}}}(1-\eta)-\frac{2}{\rho E_{\mathrm{f}}}\left(\frac{V_{\mathrm{m}}}{V_{\mathrm{f}}} \frac{r_{\mathrm{f}}}{l_{\mathrm{c}}} \sigma_{m o}-\eta \tau_{\mathrm{i}}\right) \\
\times\left[\exp \left(-\frac{\rho}{2} \frac{l_{\mathrm{c}}}{r_{\mathrm{f}}}(1-\eta)\right)-1\right]-\left(\alpha_{\mathrm{c}}-\alpha_{\mathrm{f}}\right) \Delta \mathrm{T}, \eta<1 \\
\frac{\sigma}{V_{\mathrm{f}} E_{\mathrm{f}}}-\frac{1}{2} \frac{\tau_{\mathrm{i}}}{E_{\mathrm{f}}} \frac{l_{\mathrm{c}}}{r_{\mathrm{f}}}-\left(\alpha_{\mathrm{c}}-\alpha_{\mathrm{f}}\right) \Delta \mathrm{T}, \eta=1
\end{array}\right.
$$

where $V_{\mathrm{f}}$ is the fiber volume, $V_{\mathrm{m}}$ is the matrix volume, $E_{\mathrm{f}}$ is the fiber elastic modulus, $\eta$ is the interface debonding ratio, $\tau_{\mathrm{i}}$ is the interface shear stress, $r_{\mathrm{f}}$ is the fiber radius, $l_{\mathrm{c}}$ is the matrix crack spacing.

The composite tangent modulus is defined as:

$$
E_{\mathrm{p}}=\frac{d \sigma}{d \varepsilon}
$$

Figure 2 shows the evolution of the composite tangent modulus versus the composite strain for different matrix crack spacing. The initial composite tangent modulus is about $310 \mathrm{GPa}$, with increasing composite strain, the tangent modulus decreases rapidly during the stage of matrix cracking and interface debonding, and slowly at the stage of the fiber failure.

Figure 3 shows the evolution of the composite tangent modulus versus the composite strain for different fiber volume. When the fiber volume increases, the composite tangent modulus increases. 
Multiple Matrix Cracking of Fiber-Reinforced Ceramic-Matrix Composites during Operation DOI: http://dx.doi.org/10.5772/intechopen.93074

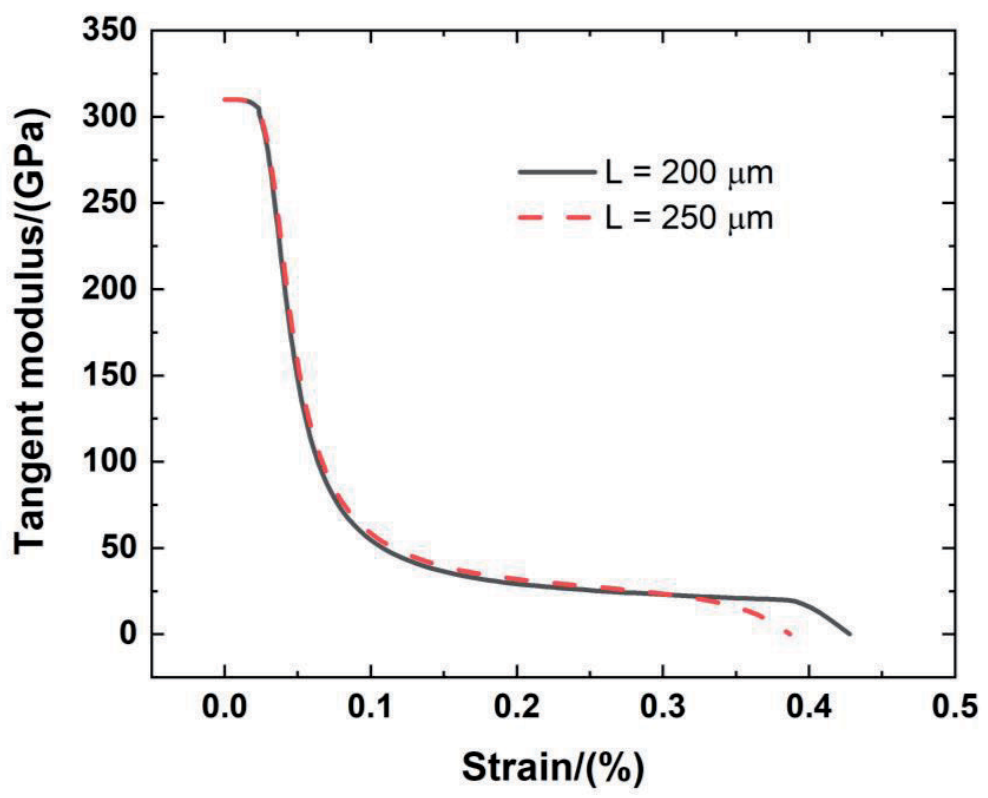

Figure 2.

The tangent modulus versus composite strain of C/SiC composite for different matrix crack spacing.

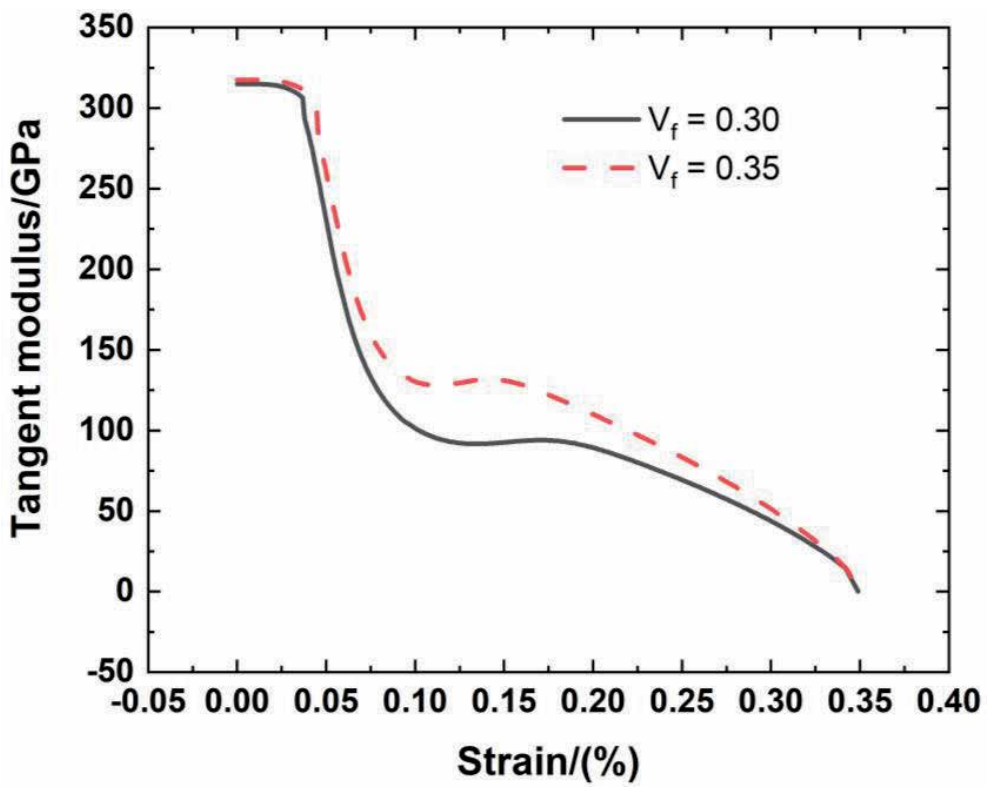

Figure 3.

The tangent modulus versus composite strain of $\mathrm{C} / \mathrm{SiC}$ composite for different fiber volume.

\section{Results and discussion}

In this section, the effect of interface shear stress and interface debonding energy on the evolution of the matrix cracking is analyzed. Figure $\mathbf{4}$ shows the effect of interface shear stress on the matrix cracking evolution of CMCs with the interface shear stress of $\tau_{\mathrm{i}}=25,30 \mathrm{MPa}$. When the interface shear stress increases, the first matrix cracking stress increases, and the saturation matrix cracking stress also increases, however, the saturation matrix cracking density may decrease. Figure 5 


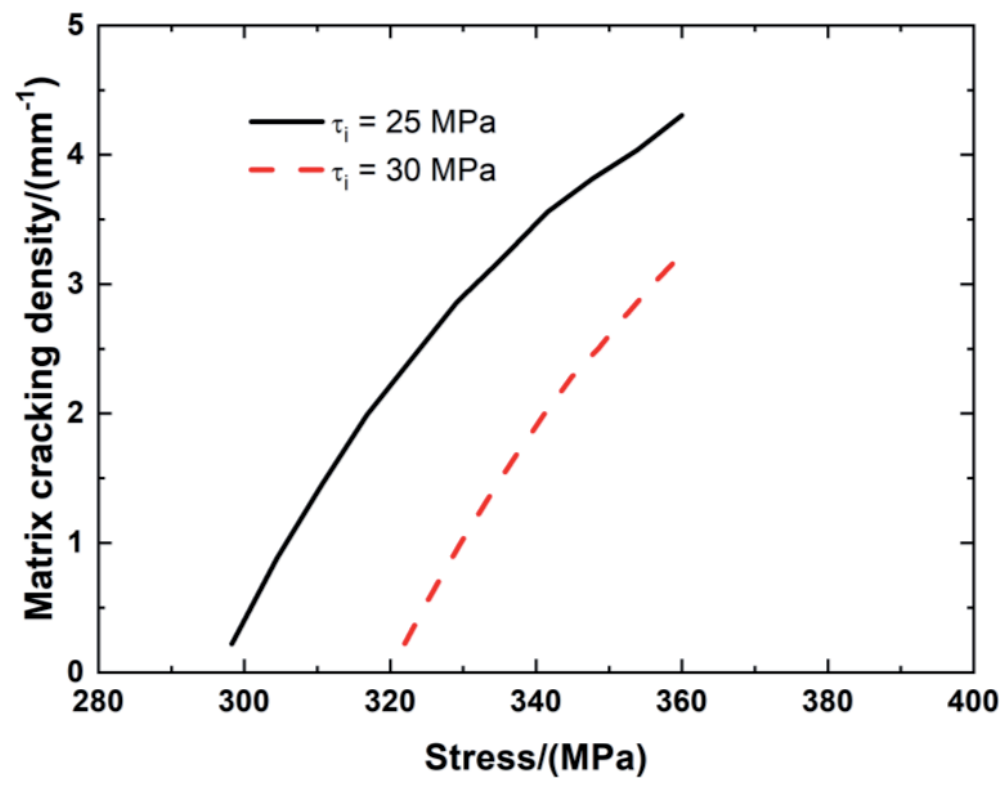

Figure 4.

The matrix cracking evolution of CMCs with different interface shear stress.

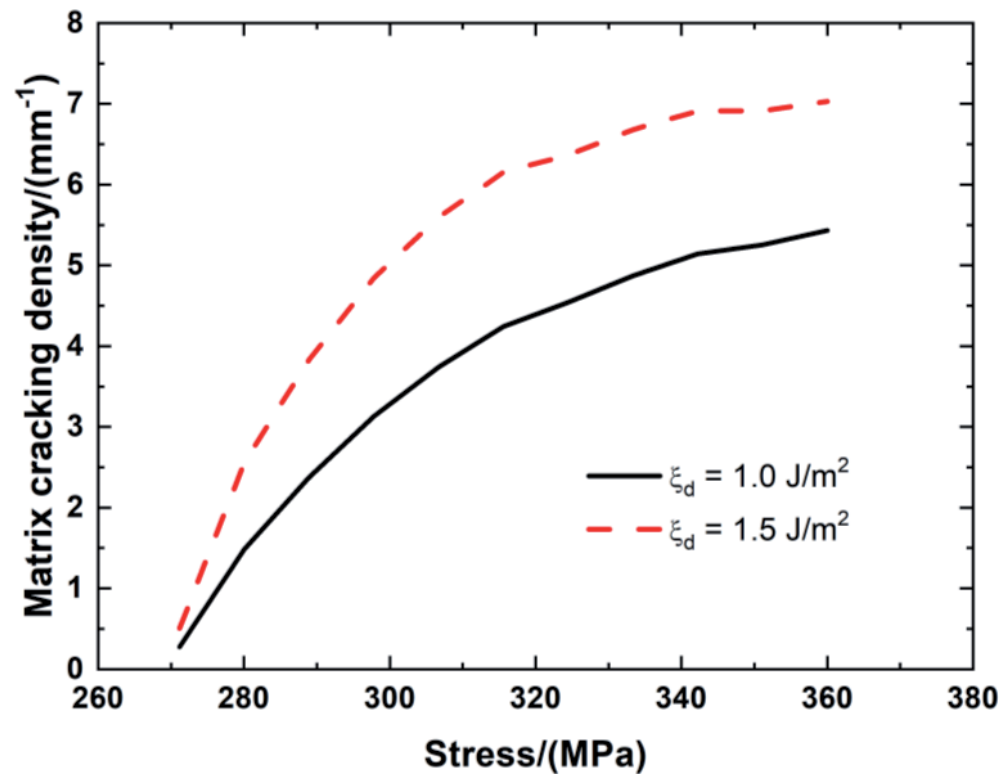

Figure 5.

The matrix cracking evolution of CMCs with different interface debonding energy.

shows the effect of interface debonding energy on the matrix cracking evolution of CMCs with the interface debonding energy of 1.0 and $1.5 \mathrm{~J} / \mathrm{m}^{2}$. When the interface debonding energy increases, the saturation matrix cracking density increases.

\section{Experimental comparisons}

Based on the energy balance approach, the experimental and predicted matrix cracking density of $\mathrm{SiC} / \mathrm{SiC}$ composite is shown in Figure 6. When the applied 


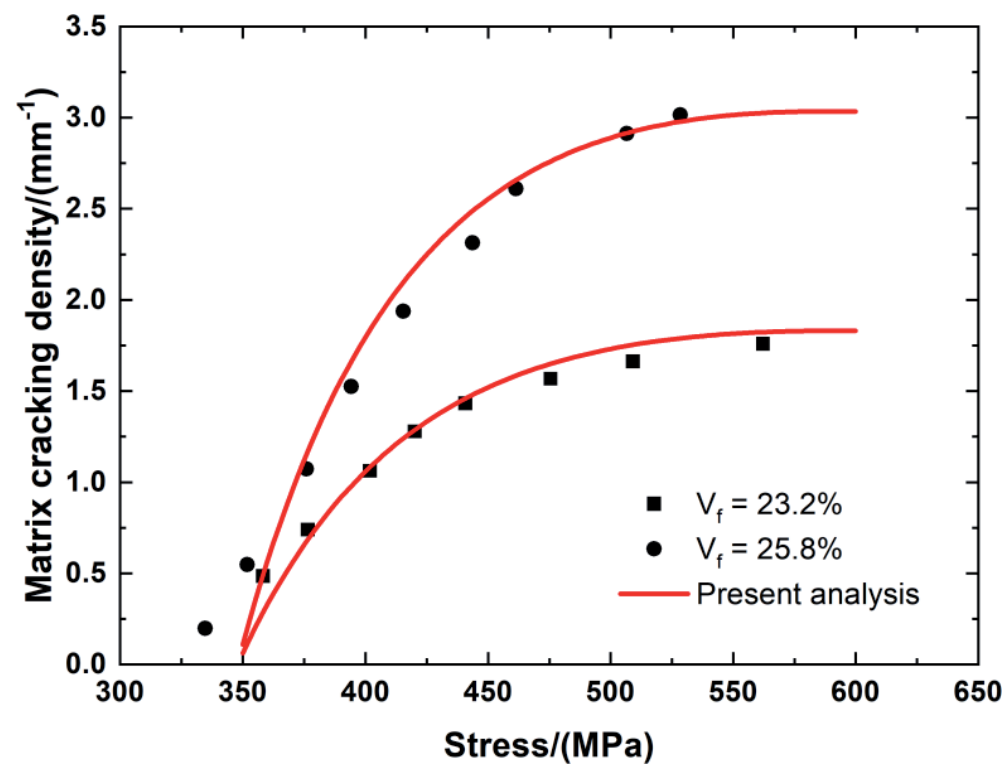

Figure 6.

Experimental and predicted matrix cracking density versus the applied stress curves of SiC/SiC composite.

stress increases, the matrix cracking density increases and approaches saturation. When the fiber volume is $\mathrm{V}_{\mathrm{f}}=23.2 \%$, the matrix cracking starts at the applied stress of $350 \mathrm{MPa}$, and approaches saturation at $590 \mathrm{MPa}$ with the saturation matrix cracking density of $1.83 / \mathrm{mm}$; and when the fiber volume is $\mathrm{V}_{\mathrm{f}}=25.8 \%$, the matrix cracking starts at the applied stress of $334 \mathrm{MPa}$, and approaches saturation at $550 \mathrm{MPa}$ with the saturation matrix cracking density of $3.03 / \mathrm{mm}$. When the fiber volume increases, the stress transfer between the fiber and the matrix increases, leading to the increase of the saturation matrix cracking density and saturation matrix cracking stress.

\section{Conclusions}

In this chapter, the multiple matrix cracking of CMCs is investigated. During multiple matrix cracking, the composite tangent modulus decreases with increasing stress, and the evolution of the tangent modulus with composite strain can be divided into several stages, due to the damage mechanisms of the matrix cracking, interface debonding and fiber failure. The effects of the fiber volume and the matrix crack spacing on the evolution of the composite tangent modulus are analyzed. The effects of the interface shear stress and interface debonding energy on the multiple matrix cracking evolution of CMCs are also analyzed. The experimental matrix cracking density versus the applied stress of $\mathrm{SiC} / \mathrm{SiC}$ composite is predicted using the present analysis. 


\section{Author details}

Chengzheng Zhu

College of Civil Aviation, Nanjing University of Aeronautics and Astronautics, Nanjing, P.R. China

*Address all correspondence to: zhuchengzheng@hotmail.com

\section{IntechOpen}

(c) 2020 The Author(s). Licensee IntechOpen. Distributed under the terms of the Creative Commons Attribution - NonCommercial 4.0 License (https://creativecommons.org/ licenses/by-nc/4.0/), which permits use, distribution and reproduction for non-commercial purposes, provided the original is properly cited. ((c) B BY-NC 


\section{References}

[1] Aveston J, Kelly A. Thor of multiple fracture of fibrous composites. Journal of Materials Science. 1973;8:352-362

[2] Parvizi A, Garrett KW, Bailey JE. Constrained cracking in glass fibrereinforced epoxy cross-ply laminates. Journal of Materials Science. 1978;13:195-201

[3] Wang ASD, Crossman FW. Initiation and growth of transverse cracks and edge delamination in composite laminates. Part 1: An energy method. Journal of Composite Materials. 1980;14:71-87

[4] Fukunaga H, Chou TW, Peters PWM, Schulte K. Probabilistic failure strength analyses of graphite-epoxy cross-ply laminates. Journal of Composite Materials. 1984;18:339-356

[5] Laws N, Dvorak GJ. Progressive transverse cracking in composite laminates. Journal of Composite Materials. 1988;22:900-916

[6] Ogin SL, Smith PA, Beaumont PA. Matrix cracking and stiffness reduction during the fatigue of a (0/90)s GFRP laminate. Composites Science and Technology. 1985;22:23-31

[7] Aveston J, Cooper GA, Kelly A. Single and multiple fracture. In: The Properties of Fibre Composites, Conference Proceedings, National Physical Laboratory; Guildford, UK. Teddington, UK: IPC Science and Technology Press; 1971. pp. $15-26$ 



\title{
Finite Element Analysis of Fiber Pull-Out of Ceramic Matrix Composites
}

\author{
Wang Hong
}

\begin{abstract}
Ceramic matrix composites (CMCs) are widely used in aerospace, defense industry, and other fields because of their high strength, high toughness, and high temperature resistance. The interface phase with matching performance and structural coordination is the key element to improve the brittleness of CMCs and improve their strength and toughness. In this chapter, based on the fiber pull-out experiment, using the cohesive zone model as the interface element model, a two-dimensional axisymmetric fiber pull-out finite element model was established and simulated. The results show that within a certain range, higher interface bonding strength and interface fracture energy increase the maximum debonding load during fiber pull-out and enhance the material bearing capacity.
\end{abstract}

Keywords: ceramic matrix composites (CMCs), interface mechanics, fiber pull-out, finite element method (FEM), cohesive zone model

\section{Introduction}

Ceramic matrix composite (CMC) is a third-generation composite material composed of ceramic as the matrix and various reinforcing phase fibers [1]. It has excellent properties such as high strength, high toughness, high temperature resistance, and oxidation resistance, which overcome traditional ceramic materials that have large brittle performance defects and are widely used in components such as nose cones and wing leading edges of space vehicles, rocket engine nozzles, rocket head radar radomes, etc. [2,3]. The interfacial phase is the medium and transition zone between the matrix and the reinforced phase material of the ceramic matrix composite material [4], which mainly plays the role of transferring load and blocking crack propagation. Its structure and composition play a vital role in the performance of the interface, in turn, affects the mechanical properties of ceramic matrix composites. There are methods for studying interface problems such as fiber pull-out and fiber push-out. The most typical one is the fiber pull-out experiment. This method was introduced several decades ago [5] and has now become the basic experimental method for related research. However, the experimental investigation can only reflect a certain phenomenon intuitively. It is difficult to prepare the specimen for the fiber pull-out experiment. At the same time, the debonding process between the fiber and the matrix is also affected by factors such as interface strength and interface fracture energy. 
The numerical simulation method can obtain data that is difficult to obtain in the experiment, which provides a powerful tool for studying interface problems.

In this chapter, the cohesive zone model $[6,7]$ is used to simulate the interface of ceramic matrix composites, the maximum nominal stress damage criterion is used to determine the initial damage of the interface element, and the energy-based linear attenuation damage evolution criterion is used to determine the damage evolution law of the interface element. At the same time, considering the influence of interface bonding strength and interface fracture energy, the debonding process of fiber pull-out of ceramic matrix composites are analyzed.

\section{Fiber pull-out model}

In this chapter, the commercial software ABAQUS is used to perform finite element simulation analysis on the fiber-out process of ceramic matrix composites. In the calculation process of the finite element method, it is necessary to first establish a geometric model for single fiber extraction. According to the geometric and mechanical characteristics of the single fiber extraction experiment, a two-dimensional axisymmetric cylindrical model is used to simulate and analyze it. The geometric model of the fiber pull-out is shown in Figure 1. Its structure contains fiber, interface layer, and matrix. The fiber has a certain embedding depth in the matrix.

In the fiber pull-out model, the fiber and the matrix are its main structures. Considering the calculation efficiency, the CAX4R element is selected for the fiber and the matrix. The interface layer is the most deformed part of the fiber pull-out model, which requires higher accuracy. The COHAX4 element is selected for the interface. The meshing result of the fiber pull-out model is shown in Figure 2.

The cohesive element $[8,9]$ is a special element constructed based on the cohesive zone model. In the two-dimensional model, the debonding of the interface is divided into two directions, tangential and normal. The stress $\sigma$ in the crack area is a function of the crack opening displacement $\boldsymbol{\delta}$.

$$
\boldsymbol{\sigma}=f(\boldsymbol{\delta})
$$

As the crack opening displacement $\boldsymbol{\delta}$ increases, the stress $\boldsymbol{\sigma}$ increases. When the stress reaches the initial damage criterion, the initial damage of the cohesive element in the interface occurs. The initial damage criterion uses the maximum nominal stress criterion.

$$
\max \left\{\frac{\sigma}{\sigma_{s}}, \frac{\tau}{\sigma_{t}}\right\}=1
$$

where $\sigma$ and $\tau$ represent the tangential and normal stress at the interface and $\sigma_{s}$ and $\sigma_{t}$ represent the bonding strength of the interface.

The energy released during cracking is called fracture energy or energy release rate $G$, and its calculation formula is

$$
G=\int \boldsymbol{\sigma} d \boldsymbol{\delta}=\int f(\boldsymbol{\delta}) d \boldsymbol{\delta}
$$

In order to characterize the damage evolution law after the initial damage of the cohesive element at the interface, the damage factor $d$ needs to be defined. When the cohesive element just occurred at the initial damage, the damage factor $d=0$, and no damage evolution of the cohesive element occurred at this time. When the stress of the cohesive element in the interface continues to increase and the damage evolution conditions are met, the damage factor will increase according to its evolution 


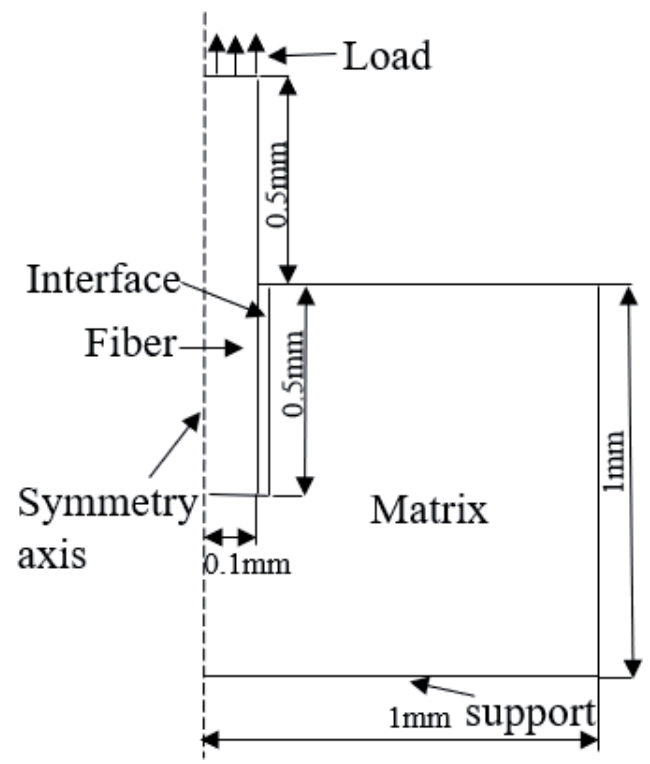

Figure 1.

Geometric model of fiber pull-out.

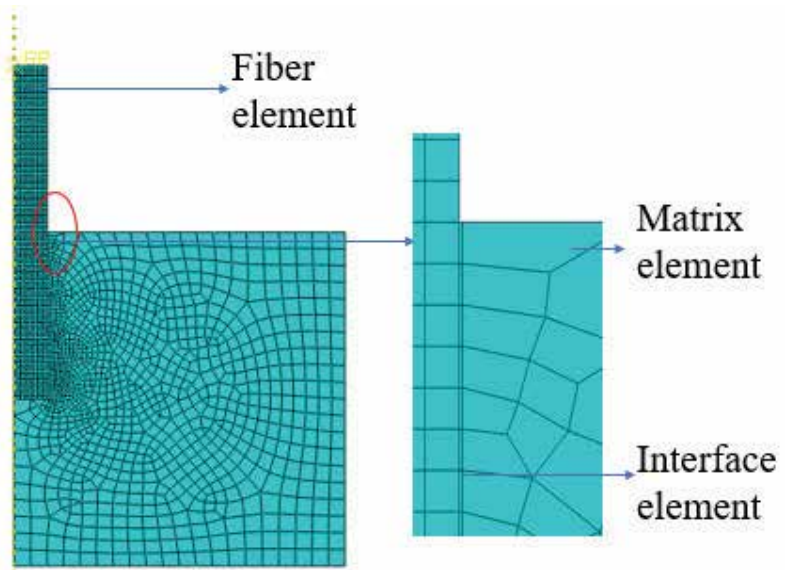

Figure 2.

Finite element meshing results.

rule until the damage factor $d=1$, and at this time the cohesive element fails and is deleted. Damage evolution criterion adopts energy-based damage evolution form.

$$
d=\int_{\delta_{m}^{\prime g l i l}}^{\delta_{m i t}^{\text {init }}} \frac{\boldsymbol{\sigma}_{m}}{G-G_{i n i t}} d \boldsymbol{\delta}
$$

where $\boldsymbol{\delta}_{m}$ represents the equivalent displacement, $\boldsymbol{\delta}_{m}^{\text {init }}$ represents the equivalent displacement when the cohesive element is initially damaged, and $\boldsymbol{\delta}_{m}^{\text {fail }}$ represents the equivalent displacement when the cohesive element fails completely. $G$ is the fracture energy and $G_{\text {init }}$ is the energy at the initial damage of the cohesive element.

In the following research, $\mathrm{T} 300$ fiber, $\mathrm{SiC}$ matrix, and $\mathrm{PyC}$ interface layers are taken as the research objects, and the material properties are shown in Tables $\mathbf{1}$ and 2. 


\begin{tabular}{lccc}
\hline Material & $\begin{array}{c}\text { Transverse Young's } \\
\text { modulus (GPa) }\end{array}$ & $\begin{array}{c}\text { Axial Young's modulus } \\
(\mathrm{GPa})\end{array}$ & $\begin{array}{c}\text { Transverse shear } \\
\text { modulus (GPa) }\end{array}$ \\
\hline $\begin{array}{l}\text { Fiber } \\
\text { (T300) }\end{array}$ & 15 & 230 & 7 \\
\hline Material & Axial shear modulus (GPa) & Transverse Poisson's ratio & Axial Poisson's ratio \\
\hline $\begin{array}{l}\text { Fiber } \\
\text { (T300) }\end{array}$ & 27 & 0.3 & 0.013 \\
\hline
\end{tabular}

Table 1.

Material properties for T300 fiber.

\begin{tabular}{lccc}
\hline Material & Modulus (GPa) & Poisson's ratio (GPa) & Fracture energy $\left(\mathrm{J} / \mathbf{m}^{2}\right)$ \\
\hline Matrix $(\mathrm{SiC})$ & 450 & 0.17 & - \\
\hline Interface $(\mathrm{T} 300)$ & 35 & - & $4-10$ \\
\hline
\end{tabular}

Table 2.

Material properties for SiC matrix and PyC interface.

\section{Results and discussion}

Figure 3 shows the load-displacement curve of the simulation results of fiber pull-out. The fiber pull-out process is mainly divided into four stages: elastic deformation, partial debonding, complete debonding, and fiber friction slip. It can be seen from the figure that during the stage of elastic deformation $(\mathrm{O}-\mathrm{A})$, there is a linear relationship between load and displacement, and no damage occurs at the interface. During the stage of partial debonding (A-B), the load-displacement curve exhibits nonlinearity, at which time some interface elements are damaged and enter the damage evolution phase. During the stage of complete debonding $(B-C)$, the load drops suddenly, and all interface elements are damaged. When the damage factor $d$ of all units is zero, the interface is completely debonded. During the stage of fiber friction slip (C-D), the load is kept at a low level to resist friction.

The load-displacement curve of fiber pull-out under different interface bonding strength is shown in Figure 4. With the increase of the interface bonding strength,

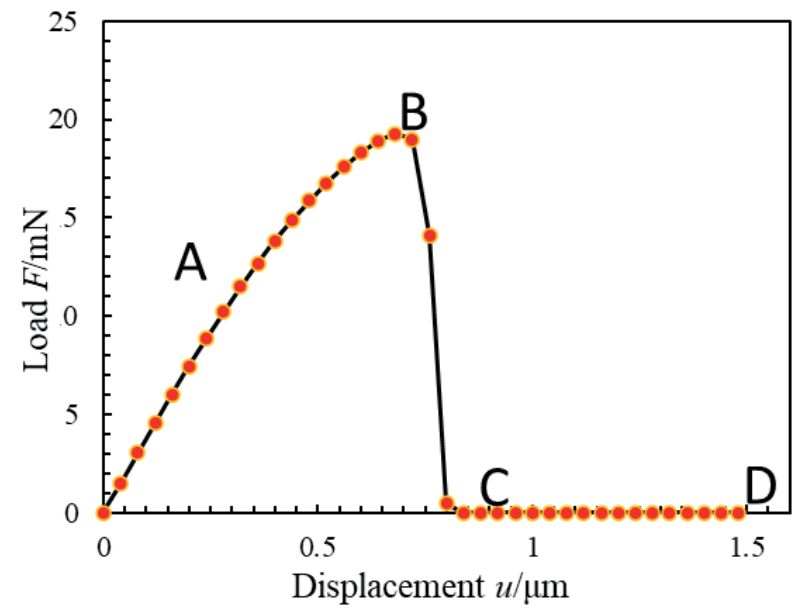

Figure 3.

Load vs. displacement curve of fiber pull-out. 
the initial damage of the interface unit needs to be carried out under a higher load, thereby increasing the maximum debonding load and improving the bearing capacity of the material. The maximum debonding load at the interface bonding strength of $\sigma_{s}=\sigma_{t}=30 \mathrm{MPa}$ is increased by nearly $28.34 \%$ compared to the interface strength of $\sigma_{s}=\sigma_{t}=15 \mathrm{MPa}$. At the same time, the stiffness of the load-displacement curve also increases as the interface bonding strength increases.

The load-displacement curve of fiber pull-out under different interface fracture energy is shown in Figure 5. Due to the increase of the interface fracture energy, more energy need to be released during the damage evolution of the interface element to completely damage the interface, thereby increasing the maximum debonding load, expanding the debonding area of the interface, and improving the bearing capacity of the material. At the same time, at a higher interface fracture energy level, its influence on the fiber pull-out process becomes smaller, possibly because the failure of the cohesive element at this time is mainly controlled by the interface bonding strength.

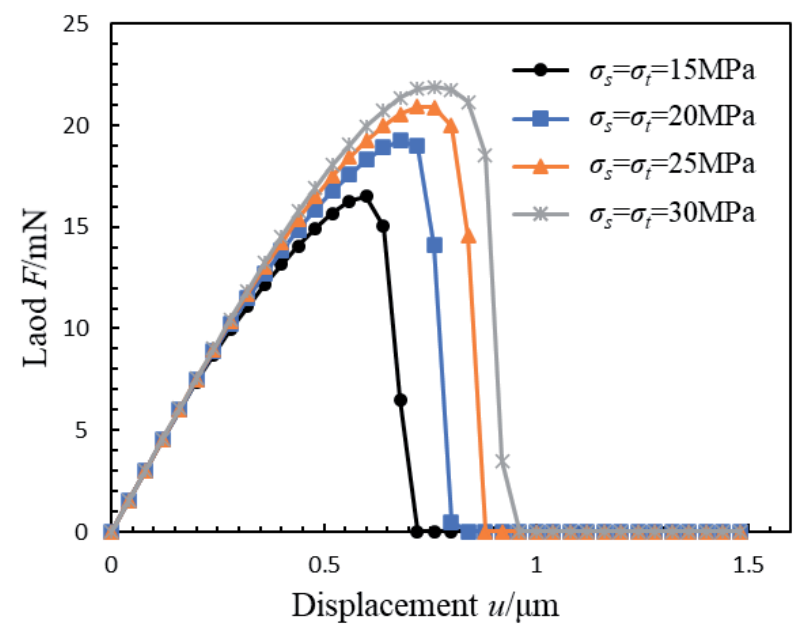

Figure 4 .

Load vs. displacement curve of fiber pull-out under different interface bonding strength.

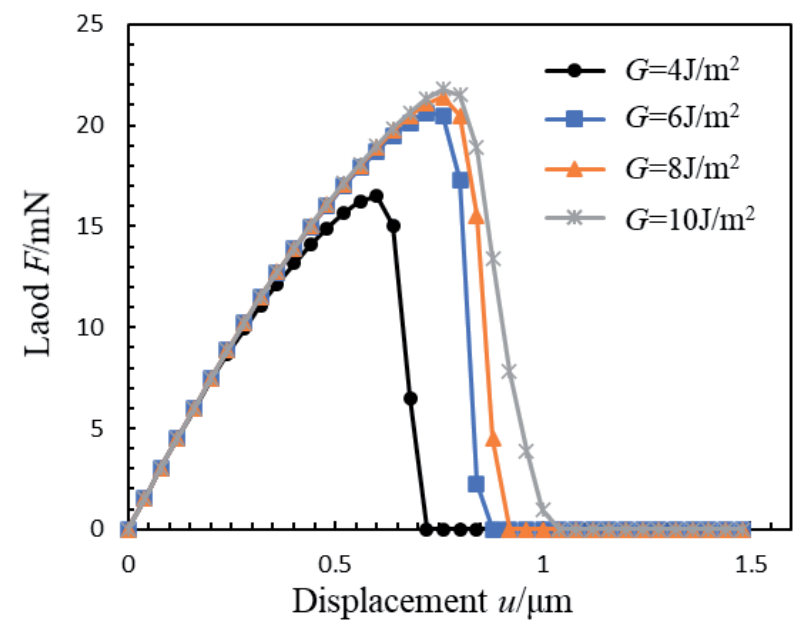

Figure 5.

Load vs. displacement curve of fiber pull-out under different interface fracture energy. 


\section{Conclusion}

Fiber pull-out has experienced four stages, elastic deformation, partial debonding, complete debonding, and fiber friction slip. The maximum debonding load and the bearing capacity of the material increase with the increase of the interface bonding strength and interface fracture energy. However, when the interface bonding strength is too large, the fibers will first undergo brittle fracture, and its impact on the load-bearing capacity of ceramic matrix composites needs further study.

\section{Author details}

Wang Hong

Southwest Jiaotong University, Chengdu, China

*Address all correspondence to: hongwang369@163.com

\section{IntechOpen}

(C) 2020 The Author(s). Licensee IntechOpen. Distributed under the terms of the Creative Commons Attribution - NonCommercial 4.0 License (https://creativecommons.org/ licenses/by-nc/4.0/), which permits use, distribution and reproduction for non-commercial purposes, provided the original is properly cited. (cc) BY-NC 


\section{References}

[1] Jia C. Introduction to Ceramic Matrix Composites. Beijing: Metallurgical

Industry Press; 1998

[2] Zhang L. Fiber-Toughened Silicon

Carbide Ceramic Composites:

Simulation, Characterization and

Design. Beijing: Chemical Industry

Press; 2009

[3] Kaya H. The application of ceramicmatrix composites to the automotive ceramic gas turbine. Composites Science and Technology. 1999;59(6):861-872

[4] Yang X. Composite Material Interface. Beijing: Chemical Industry Press; 2010

[5] Favre JP, Merienne MC.

Characterization of fibre/resin bonding in composites using a pull-out test. International Journal of Adhesion and Adhesives. 1981;1(6):311-316

[6] Jinquan X. Interface Mechanics Model. Beijing: Science Press; 2006

[7] Barenblatt GI. The formation of equilibrium cracks during brittle fracture: General ideals and hypotheses, axially symmetric cracks. Applied Mathematics and Mechanics. 1959;23(3):622-636

[8] Needleman A. Micromechanical modelling of interfacial decohesion. Ultramicroscopy. 1992;40(3):203-214

[9] Zhang J. Application of Interface Stress and Cohesion Model in Interface Mechanics. Zhengzhou: Zhengzhou University Press; 2011 



\title{
Modeling of Damage Evolution of Fiber-Reinforced Composite Structure
}

\author{
Muhammad Bilal Afzal
}

\begin{abstract}
This chapter is the result of a study of many special disciplines, such as damage of matrix, cracking, interface, debonding, and fiber failure. A damage mechanics model is presented to characterize brittle failure in elastic fiber-reinforced composite materials. During the life of the aircraft, cracks and damage can occur in aviation structures that should be analyzed to determine the decrease in stiffness and resistance due to the presence of the cracks. Theoretical and numerical problems related to intralaminar and interlaminar failure modeling are very well discussed. The formulations of the constitutive models presented in this chapter support the Continuum Damage Mechanics (CDM) approach and enable the control of energy dissipation in relation to each failure mode, regardless of the refinement of the network and the orientation of the fracture plane. In context to CDM, internal thermodynamic irreversible damage variables are defined to quantify the damage concentration in relation to each possible failure mode and to predict the gradual reduction in stiffness for each bond layer. Numerical examples are provided to possibly explain the capabilities of the model.
\end{abstract}

Keywords: cracking, debonding, damage mechanics, fiber-reinforced, modeling of damage

\section{Introduction}

Composite materials - the history of their use dates back to the ancient times. Already the early South American and African civilizations used to build from mud and straw bricks. This is not, however, an example of a composite material as we know it, but its purpose was the same as it is today-a complex material which takes the benefits of all its constituents.

Today composite material is most common and mostly used in every field of industries, from Aircraft to naval craft automotive industries to sport industries. They also can find in medical industries hospital application. Since the 1980s, the scope of their usage has increased thanks to the significant progress in material science and technology continuously, and mainly the computer equipment. While the initial driving force yielded mostly from the need for weight savings, other factors play important roles today when inclining to composites, such as cost competitiveness, lifetime, durability, chemical resistance. 
We say that composite is a combination of two different components. Presently days in industry composites are materials made by two different more material. One is natural one and other is artificial material components. That are both stronger as a team than work alone player. They join and contribute their generally stunning amazing properties to improve the desirer final outcome product, commonly in view of utilization.

For example, if you are want to add more quality, more effectiveness, and more toughness and more strength, more durability. Composite, likewise know as fiberReinforced polymer (FRP) composites are made as a polymer matrix that is joined with reinforced with the help of engineered. Human-made, or some regular fibers (like glass, carbon) or other reinforced material. The matrix protects the fiber from any kind of environment cold hot any kind and each sort of outside damage transfers the external and internal load between the fiber. Fiber provides strength to the reinforced matrix, which resisting cracking and fracture (Figure 1).

In huge numbers of our industry's items, for example, the polyester material resin is such a matrix and glass fiber is reinforcement. However, we realize that mixing of resin and reinforcement composite are utilized in composite and each, also, every material adds to the most astonishing and interesting properties of the last item. Fiber, amazing yet we realize it is a week, gives quality and firmness, and strength and more important stiffness.

And keeping in mind that it is progressively adaptable and flexible resin, give shape, and protect the fiber of the composite final product. (FRP) composite may likewise contain fillers, additive substances, material and surface finishes designed to improve the final product the whole manufacturing and the assembling procedure, appearance and more important is the performance of the final product of composite. In the aerospace sector, development of high-performance aircraft cannot be counted without the use of composite technology. Composite material has reached $50 \%$, while the usage of composite has reached $24 \%$ in the production has reached $25 \%$ on the AirbusA380.

In military aircraft, composite amount reached $24 \%$, in the production of (F35) and for the making (F22) fighter composite usage is reached $30 \%$. Figure 2 below gives a brief account of composite material used till now in the aerospace industry. Composite material has played a fundamental role in weight decrease, and we can utilize composite for both internal and external structure basic application and segments of air plane and rocket and more important in a space vehicle. Furthermore, air planes from lightweight planes and tourist balloons to numerous air plane whatever such aircraft is used for military or civil purposes, space transport, and air crafts.

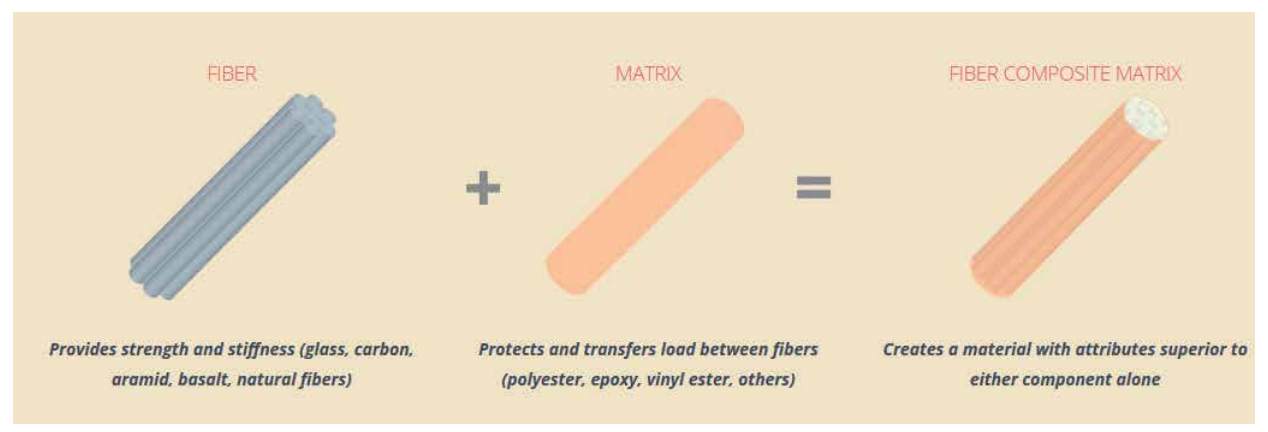

Figure 1.

How to make fiber-composite matrix. 
When we talk about advanced composite, manufacturing costs are relatively high in the aviation Markets. The very high coast of fabrication is the leading cause of the slow development of Advanced Composite in the civilian and military sectors. However, due to the development of advanced composite manufacturing technologies and economic globalization has made it easy for the industry to use them. Developing interest for better execution of final product items and material has developed every year on prompted consistent improvement in the field of composites must more advanced separate composite fiber.

Resins and cores and new manufacturing fabricating techniques were created and used to build different materials or items that have stunning and remarkable mechanical properties thought to be exotic a few years ago. Those next-level generation composites are utilized in numerous businesses like aviation and spacecraft. Are also given so much importance in other industries such as automotive, energy, significant sport, and just every everywhere low weight give the composite so much importance in all industries.

\subsection{Fiber-reinforced composites (FRC)}

Fiber composites material are also known as fiber-reinforced composites (FRC) having continuous fibers that are of particular relevance. And the first composite used in the modern era, in the marine and automotive industries due to the less weight and strength.

Their mechanical properties as we know strength and stiffness and strongly direction which allows the engineering and designer to get his desired final product in many attractive and high-tech applications, for example, replacing the metals of water boats with the composite and now the water boats are more fuel-efficient and lightweight and spend more time in the water than before.

It is, therefore, so important to know or seek essential and necessary tools for the description of the behavior of such a dynamic composite since these substituents must undergo the same production procedures as their metal. The impact of the analytical and numerical method, together with the corresponding computer

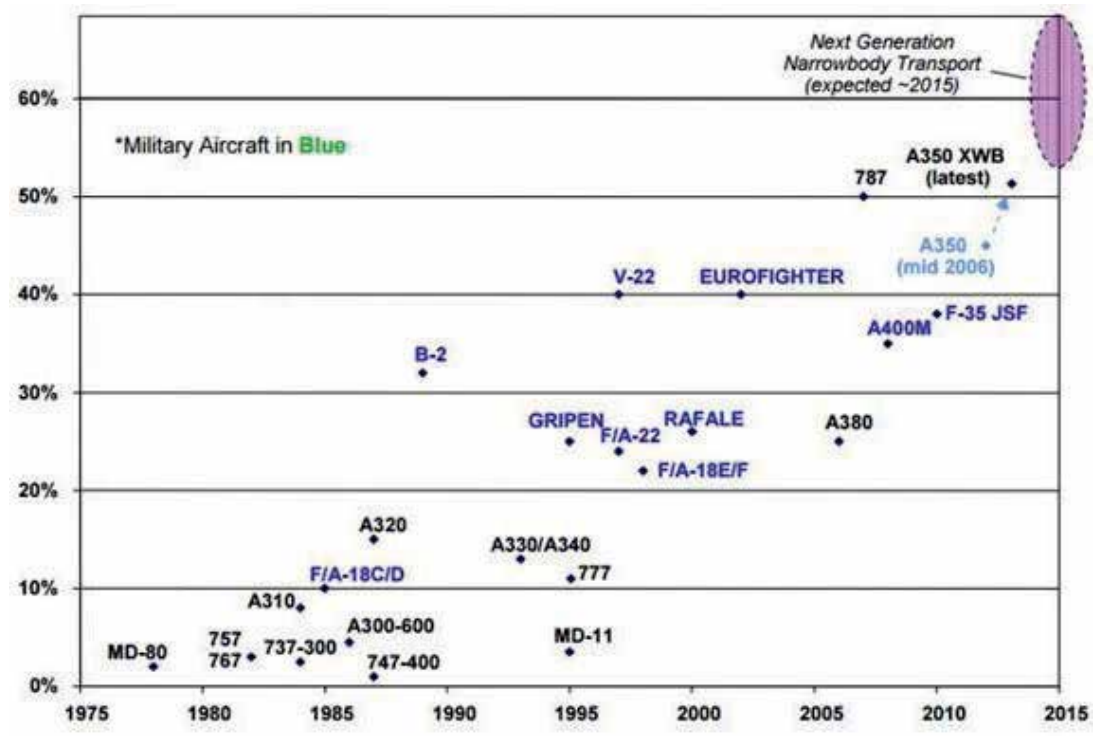

Figure 2.

Usage of the composite in the aerospace industry. 
hardware equipment, is more important. The thesis should be focused mainly on the theoretical field of research. The individual goals of this thesis were stated as follows:

1. To perform a survey of literature focusing on proposed topic

2. To study the behavior of Fiber-reinforced composite

3. To seek appropriate local failure criteria for FRC

4. To seek appropriate material damage model of FRC

5. To seek appropriate damage analysis methods of FRC

Advantages of composites usage in aerospace:

1. Weight decrease up to $20-60 \%$.

2. Single-shell formed structure gives higher quality at the lower weight.

3. The amazing ability of the impact, for instance, like we also know Kevlar reinforcement armor, let planes have less accidental harm and damage to main frame engine which carry most of important fuel lines and engines control systems.

4. Higher thermal stability ability.

5. Structural important components made of composite material are very important for the aircraft.

\section{NDE tools and method}

Non-destructive evaluation (NDE/NDI) is a tool that most of the time used interchangeably with non-destructive tools. So far, non-destructive evaluation is used to describe measurement that is quantitative in nature. We can use the nondestructive method not only defect, but we can use for measurement something about defects such as more important its size shape and orientation. We used non-destructive evaluation to find material important properties; one of them is fracture of the product and toughness, formability, and other physical properties characteristics. (NDE) is essential and a necessity for both the manufacturing quality of the final product of the composite material and in-service performance monitoring for the maintenance purpose. With every day, new composite materials and advance composite materials are coming in industries and their broader application in the aerospace industry. An increasing need and fast and robust and reliable and economical (NDE) techniques to inspect composite components that have uniquely new and complex damage failure modes and responses are evident.

We can say that one of the designs of modern aircraft. The structure consists of higher fatigue life damage tolerance capability and corrosion resistance to fewer maintenance costs and also comply with operator requirement and full fill the airworthiness requirement.(NDE) is essential, although time-consuming and much expansive, to fulfill all requirements and for the assessment of widespread damage 
and repairs. The existing major non-destructive inspection/evaluation methods include the following techniques:

\subsection{Tapping technique}

- Thermography

- X-ray Radiography

- Eddy Current

\subsection{Tapping TechniqueTab}

Testing is an old and extremely dimple Non-destructive technique. and that we also are referred to as coin Testing, which involves the knocking of an one which one you want testing object surface with a little or big hammer or coin and judging its incorruptibility and damage by the sound that come from the thing because of the result when someone knocking on the object. A duller sound come from the object would indicate that such a sway has been dampened possible due to the presence of a defect in the object within the final product.

However, when we used this method is applied manually it does't provide too much data and record of such response and it naturally start begs to question of the object reliability of the evaluation.so the main thing is that it highly dependent on such operators' perception. Real time, a permanent record of the method in such identifying the presence of the flaw and defect and establishing its size and placement of the object (Figure 3).

\subsection{Thermography}

Infrared thermography from (NDE) tools aims at the detection and finding of subsurface features of an object, which incorporates subsurface defects and cracks, and more important anomalies. Attributable to the important is temperature difference observed, the final product surface during monitoring of object by the infrared camera. As we know that at temperatures above temperature all bodies emit non-particulate radiation within the spectrum usually in such region from 2 to $5.6 \mathrm{~mm}$ to $8-14 \mathrm{~mm}$. These two important spectral bands are commonly mostly used

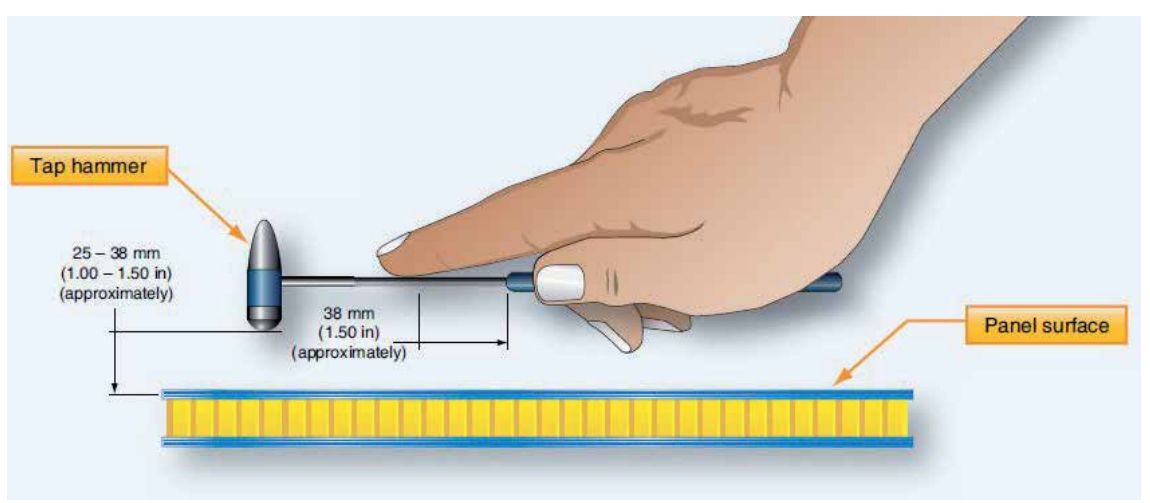

Figure 3.

Use the method of TabTechnique. 
due to their atmosphere absorption. It is very useful to detect in-service damage such we know as impact, and lightning damage whose superficial visual appearance often belies the full extent of their underlying damage.

As we know recently, a new thermography method called Lock-in Thermography has been found. So this method is a combination of infrared thermo-graphy and thermal wave method and thus is more sensitive and higher detection capability compared to conventional reflection and through transmission methods (Figure 4).

\subsection{X-ray radiography}

Radiographic Testing is additionally one in every of the (NDT) methods, which uses either one method is $\mathrm{x}$-ray and gamma rays to look at and therefore the internal and external structure of the manufacturing of components identifying every kind of crack, damage or some flaws or defect as we all know that in radiography. Testing the object test-part of the final product is placed between the radiation sources and the film.

The fabric density and therefore the thickness difference of the test part will attenuate to the object and the going through radiation through the interaction process involves scattering and absorption. In industries radiography, there are many types of imaging methods available, such as film radiography, real-time radiography, computed axial tomography, digital radiography, or computed radiography. There are two different but important radioactive sources used for industrial use; X-ray or Gamma-ray. If we are used these two methods the radiation origin mostly use higher energy levels, as an example, shorter wavelength and different forms of electromagnetic waves due to the radioactivity involved in radiography examination or testing (Figure 5).

\subsection{Eddy current}

The eddy current array is also one of all NDT test methods that offer the flexibility and flexibility to operate multiple electronic eddy current coils that are

\section{Pulsed thermography images}
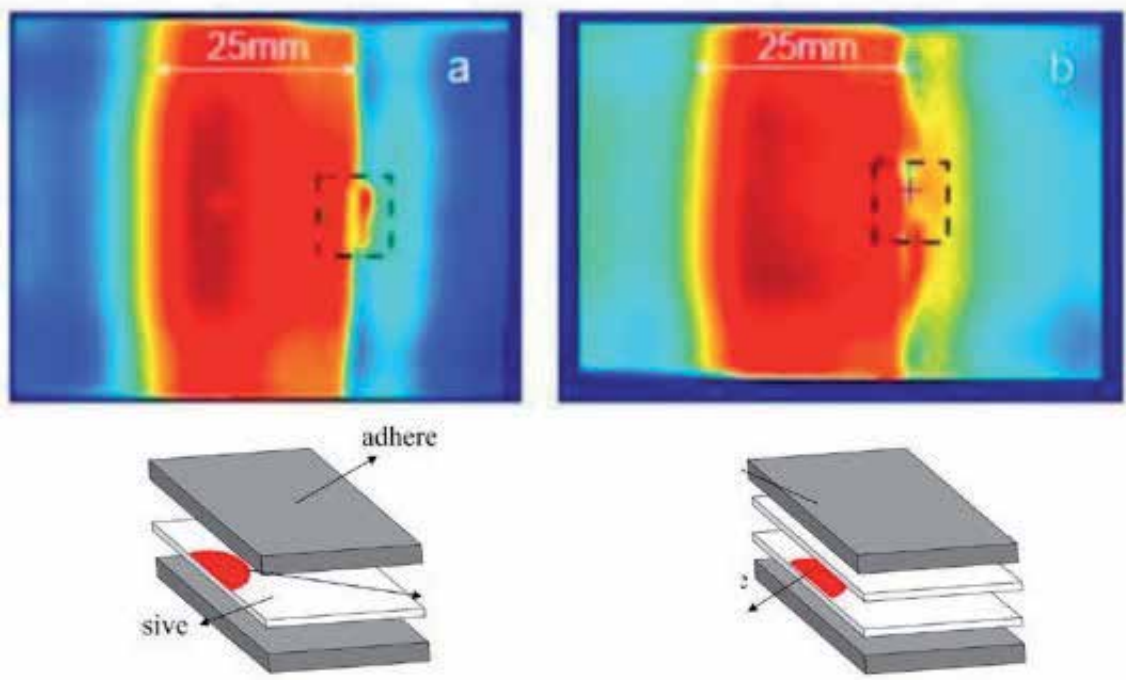

Figure 4.

Show the image of thermography how it work. 


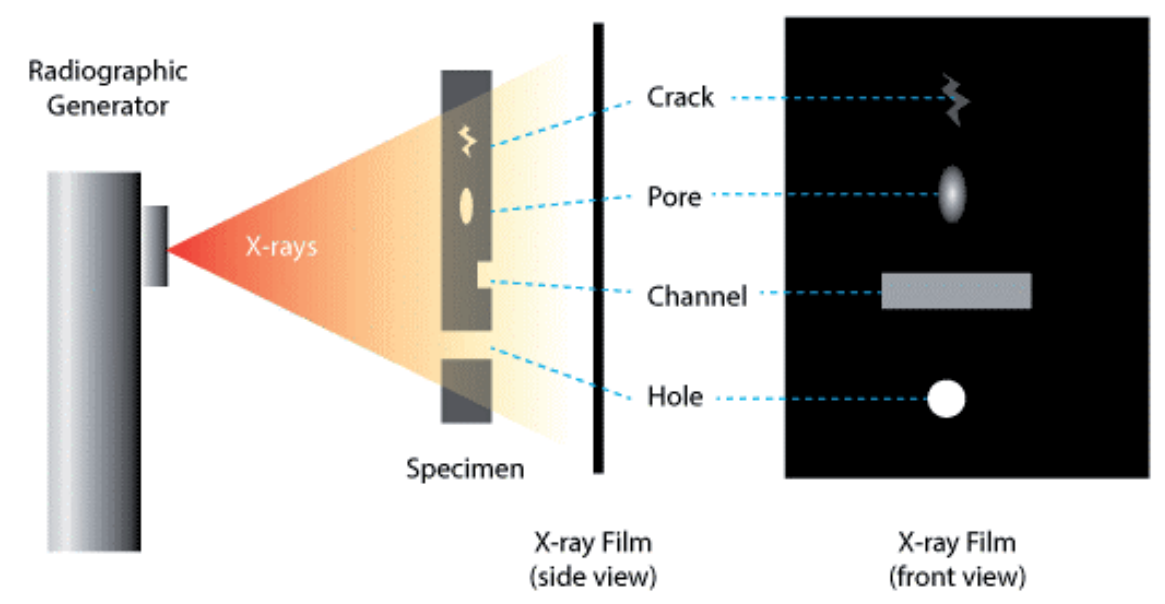

Figure 5.

Show how $X$ - ray radiography find crack.

juxtaposed in a single collection of queries and each eddy current coil within the probe result signal is discussed for the shape and spread of its downstream design. These data are assigned to the encryption positive and thus to the time and is described graphically as a $\mathrm{C}$ scene image. As we investigate, the eddy current fault detection or discovery method is created with the ECA inspection.

Nevertheless, the amazing advantage of the ECA method or technology enables better detection and inspection. The eddy current array is additionally one in each NDT test method and technology, which offers the flexibility to drive multiple electronic eddy current coils currently used in the identical probe arrangement of these methods, and each eddy current coil within the request generates a sign proportional to the phase and Amplitude of the frame and structure below. These data relate to a coded positive and a coded time and are shown schematically as a $\mathrm{C}$-Sean image. As we know, the eddy current error check and detection method are reproduced with the ECA check. However, the great advantage of the ECA method and application enables improved detection and investigation.

The eddy current is a very high test speed and no need a black surface is no longer required and there is no longer any danger to our environment. Colored surfaces have no influence, no temperature influence, and no calculation of the crack height of an object. And with the assistance of the eddy current, many materials such as steel, stainless -steel, duplex, alloy, and other conductive material can be checked (Figure 6).

\subsection{Evolution of multiple matrix cracking}

Composite laminates are those composites that provide the intended stiffness. If you see laminated, the properties have a linear or longitudinal direction and a direction outside the axis due to the combination of laminates axis and axis positions. As soon as we have carried out the quasi-static loading, the matrix suddenly fails first, which leads to the formation of micro-cracks. Such a product is inherently sensitive. These micro-cracks increase quickly.

Cover the thickness and build up the width of the layers transversely to the direction of loading. If we put more stress on such a product of an object, more new cracks appear in the transverse piles, which form an almost parallel arrangement that is even the same size and the same distance from the surface. There they are considered fully grown for damage mechanics. The expansion of a personal layer tear is not very important in our final product, which is important for the object, or the increase in its 


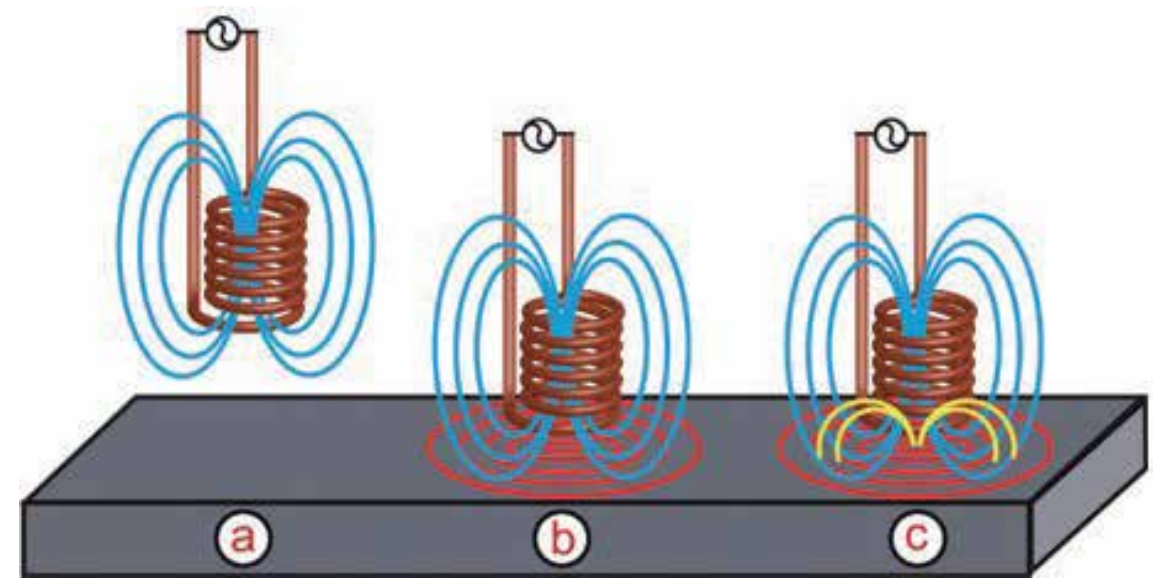

Figure 6.

Show how the eddy current work.

density if further loads are exerted on the composite laminate material is of concern as all of such cracks decrease the stiffness of such a composite structure. Because we have equal size and reliable spacing, such ply cracks we will find by the analyzed through many methods like edge- replication, acoustic- emission or, X-ray radiography, and ultrasonic C-scan, or Raman spectroscopy is used worldwide.

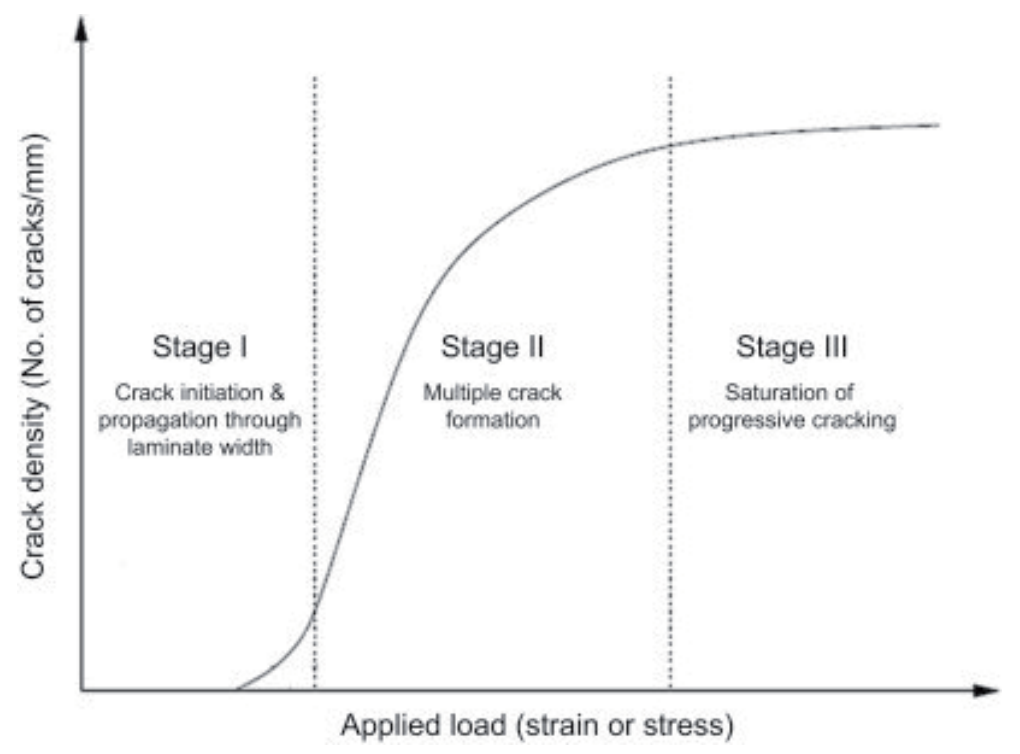

\subsection{Analytical models for evolution of multiple matrix cracking in cross ply laminates}

This technique to seek out or predict damage evolution because of multiple matrices cracking maybe we classify into a two-group (1) strength-based and (2) energy-based. And once we are talking about strength-based concept used some extent failure criterion for the crack initiation and increase, and once we speak about the energy-based techniques consider the balance of energy while the cracking process or formation and are conceptualize same because of the to the energy discharge rate concept in linear-elastic fracture or crack mechanics. 
Most models developed so far have $90 \%$ cross-ply laminates for ply cracks. Many studies have shown that great progress has been made in dealing with off-axis layer cracks in multi-directional laminates. First we looked at analytical models for the detection and prediction of cross breaks in cross-layer laminates.

Assuming the self-similarity of fully developed layer cracks, we can define the boundary value problem as shown in Figure 7, whereby state 1 shows the damaged state with crack spacing, while $s=21$, while state 2 represents the crack density twice $s=1$. The damage process normally involves a tension and stress field in the composite laminate with a presetting of equivalent breaks in the transverse planes.

For this purpose, an increase in the applied far-field pressure or stress $\sigma 0$ is required to create further fractures between the existing fractures. And the energybased approach is therefore expressed in terms of the energy required to make these cracks Multiplication. Self-similarity of stress fields around existing fractures and constant resistance to fractures in material micro-structure and new fractures and new cracks. The existing fractures (points $\mathrm{A}$ and $\mathrm{B}$ ) must be from the middle (point $\mathrm{C}$ ). But, in fact, local fracture toughness varies spatially due to material heterogeneity and manufacturing-type defects and cracks.

\subsection{Fiber failure and debonding in composite materials}

When we talk about fiber-matrix interface de-bonding initiation from random fiber breaks is thought in this idea of the critical losses and loss mechanisms in unidirectional composites subjected to quasi-static and cyclic loading. The rise in fiber-matrix interface de-bonds ends up in a discount of the difference and ultimately to the final word failure of the UD composite.

\subsection{Damage mechanisms in UD composites in quasi-static loading}

As we know that in fiber failure and debonding in composite materials, Damage mechanisms in (UD) composites in quasi-static loading are more critical, so let we talk first about (UD) composite. In polymeric (UD) composite, the fiber strain to failure is so smaller than the matrix strain to failure of fiber, and when they are loaded in quasi-static tension in the fiber direction as the first fiber breaks occur in a somewhat random position.

As we know, because of statistical defect size distribution in fibers, which leads to the famous Weibull strength distribution, which has been used and, which is

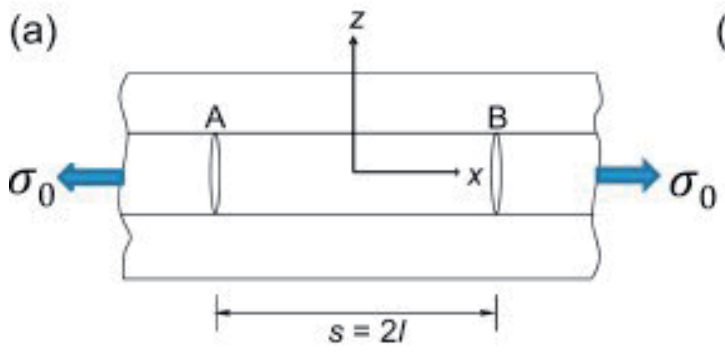

State 1 (b)

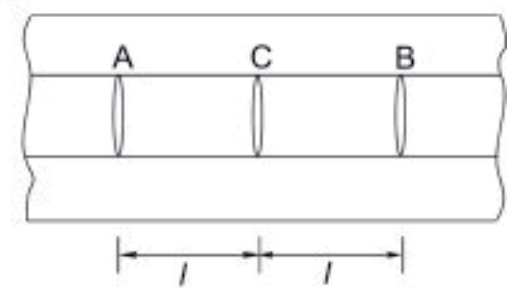

State 2

Figure 7.

Show schematics showing progressive multiplication of transverse ply cracks in a cross-ply laminate. 
employed and that we know that fiber breaks make less and reduced the viscosity and stiffness and viscosity of the UD composite (Figures 8 and 9).

Stress travel or moves through the fiber-matrix interface causes multiple cracks fractures of one fiber. It depends on the main point of the properties of the fibers, matrix, or and fiber-matrix interface. Many of this event may follow formation of each fiber breaks (Figure 10): (a) The fracture or cracks extends from the fiber to the matrix until it's capturer by the neighboring fiber. (b) Fiber break tip, which can occur at the shear yield of the matrix, will slow the fracture or crack. Or (c) the deboned crack increases from the fiber to fiber break.

The latter layout is commonly observed and calculated and we are using the single-fiber fragmentation test. In the mix, this deboned crack increases until another material of deboned crack is met. It's growing together with the identical or

(a)

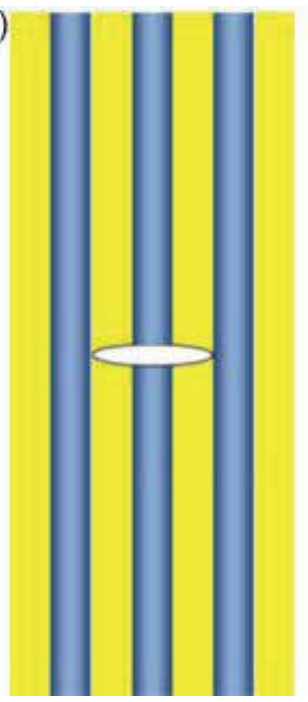

(b)

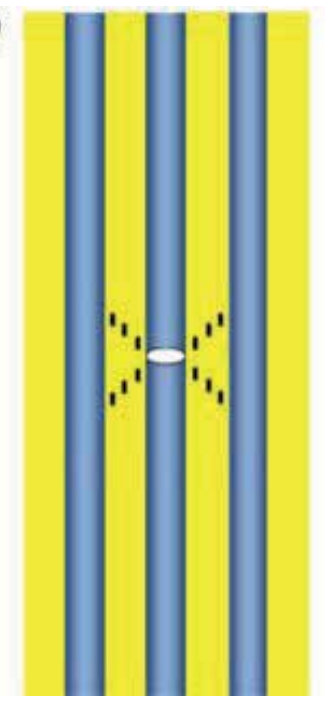

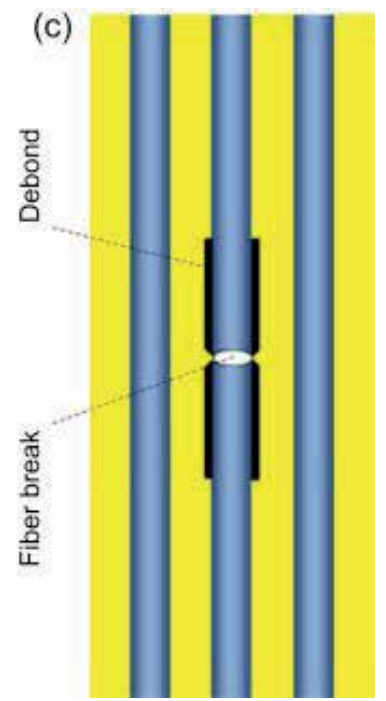

Figure 8.

Damage development scenarios after fiber break formation. (a) Crack propogation in the matrix. (b) Matrix yielding. (c) Debonding of the fiber-matrix interface.
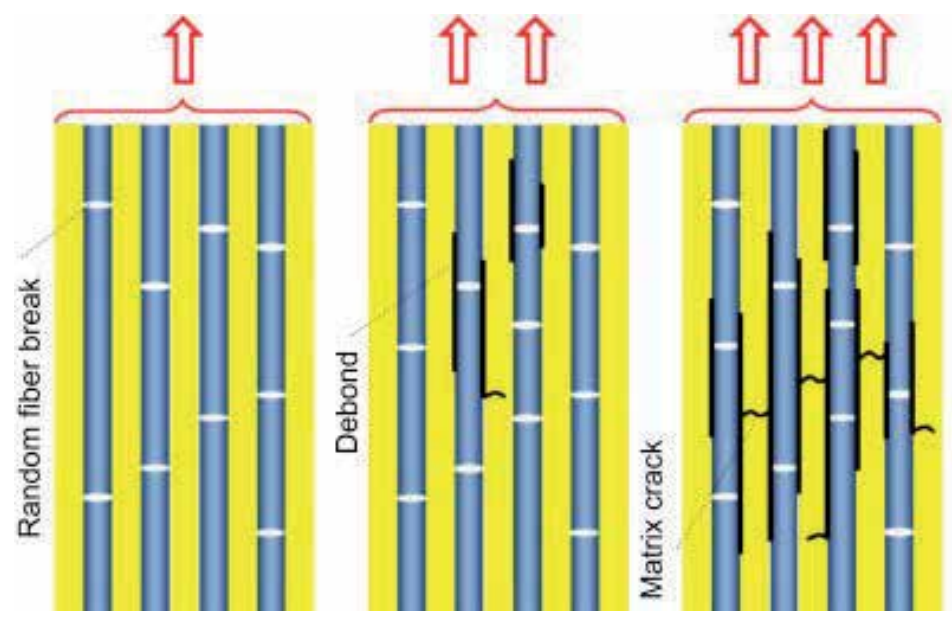

Final failure

Figure 9.

Schematic of damage events leading to the final failure of a UD composite due to increase of the applied tensile load. 


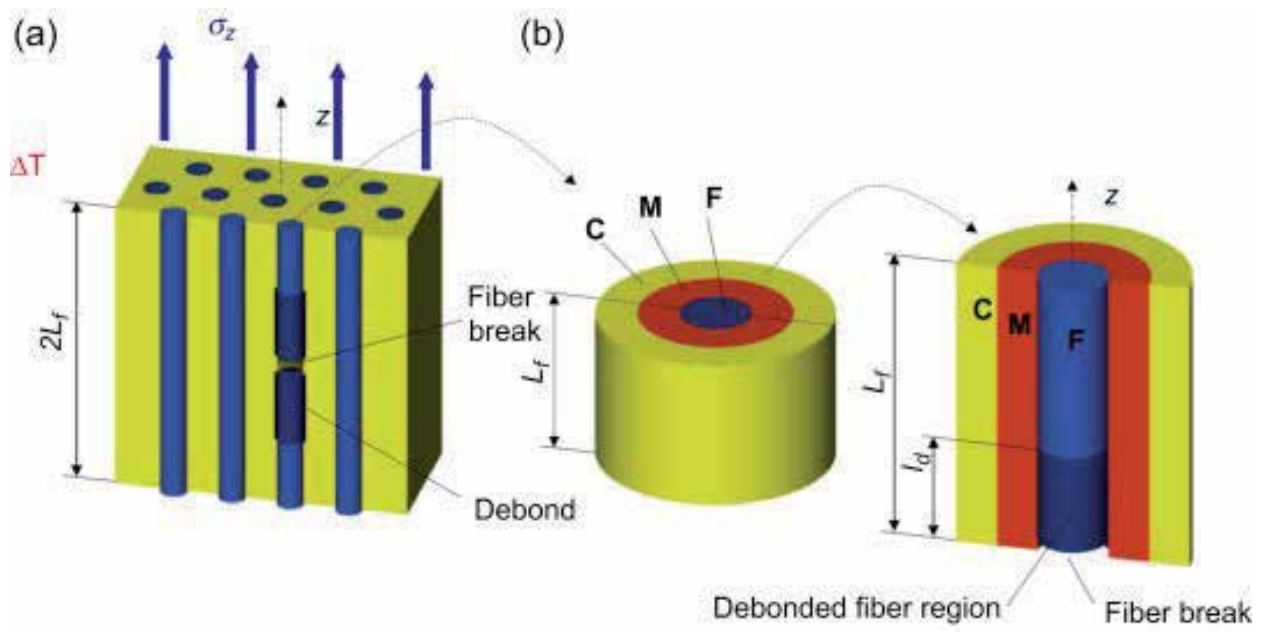

Figure 10.

$U D$ composite with random fiber break and partial interface debonding. (b) Representation of the UD composite by a CCA model. $C$, effective composite; $F$, fiber; $M$, matrix.

other thing is that neighboring fiber. Finally, all fractures and cracks are combined into large fracture or crack, which ends up in complete totally failure of the UD alloy or composite, as shown systematically in Figure 10.

\subsection{Fiber de-bonding in quasi-static loading}

The fiber-matrix de-bond crack propagation usually applies linear-elastic fracture mechanics (LEFM). In LEFM, the analysis first requires calculation of the energy release rate of the (ERR). In the under-static loading, the EER within the initial standard is often compared to the crucial ERR value. EER is that the most ordinarily used single-fiber fragmentation test worldwide and round the industries.

is mostly used around the world analyzed for denond growth in the single-fiber fragmentation test.

The way of the method used to cover a wide spectrum from analytical method to numerical methods such as finite-element method (FEM) or we have other methods called boundary element method (BEM). If we want very accurate numerical local stress state analysis at debonding, the crack tip was only performed using $(\mathrm{BEM})$. But this method is some limitation to isotropic constituents. And one more important thing is that such a method is not used for the carbon fibers (transversally isotropic) or another anisotropic constituent in the model.

The (EER) debond crack propagation in (UD) composite has been previously analyzed. In frictional sliding of debonding, faces were analyzed using a fiber-matrix unit with a free outer surface without including in the analysis the surrounding composite. The (UD) composite may be represented by a model with axial symmetry, a broken and partially debonded fiber surrounded by matrix embedded in an effective composite.

\section{Damage evolution in composites using damage mechanics and micro-mechanics}

When we think about the composite material first thing, come our mind is the specific strength and stiffness are the primary concern about the application of 


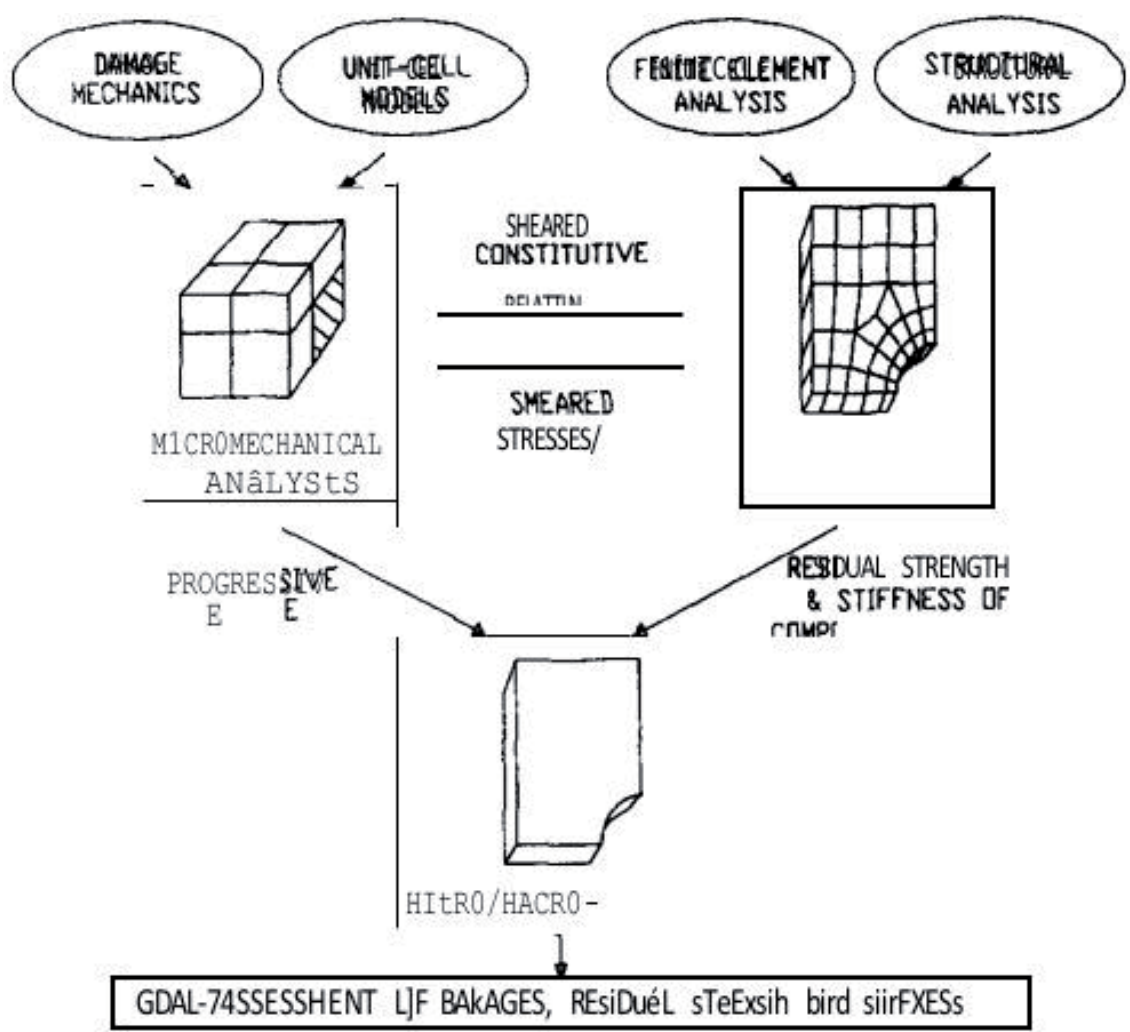

Figure 11.

Micro-/macro-mechanical approach.

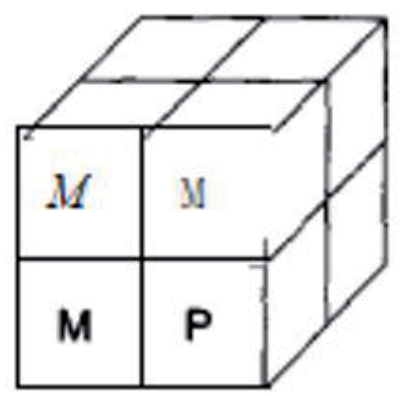

(a)

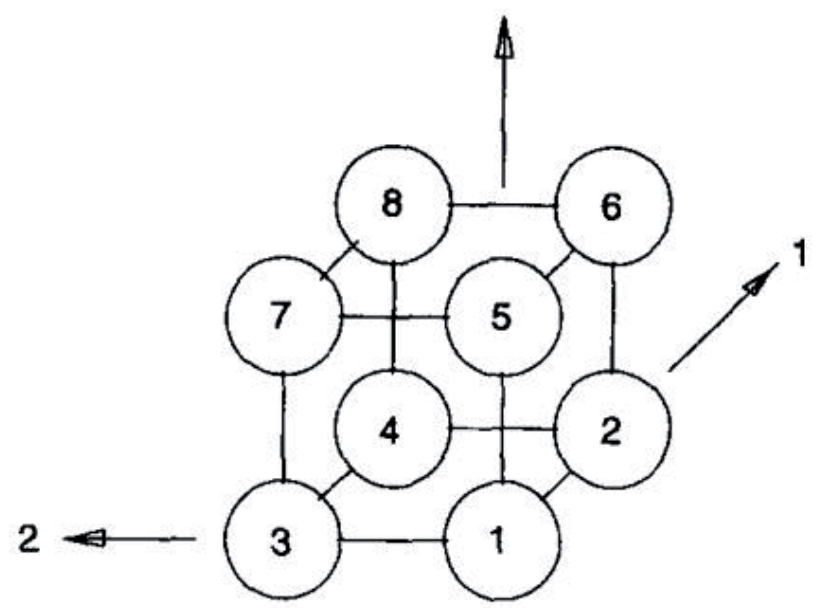

Figure 12.

Simplified, three-dimensional micromechanical model.

composite material is using in the aerospace and military structure aircraft and also in civil aviation. Many more industries used composite material around the world. So, around the world, the engineer has significant challenges about Design and analysis of the composite because of the complex nature of the compositional failure modes and mechanisms of the composite. Predicting and evaluating the 
progressive damage of the composite structure is critical for analysis and style using the advanced composite and property.

Formerly want to model damage or defects in composites generally employing a macro-mechanical approach [1-7], since we all know that there are many various kinds of damage or defect states in composites, looking on their physical properties and their layout or damage. or error criteria depend. In macromechanics we have got assumed for each case [8-16] because we all know that different damage and failure states at the macro-mechanical level can cause the identical damage and failure state within the macro-mechanical model. For instance, once we do matrix damage or failure, we understand the results of fiber splitting, cross-matrix cracking, and de-lamination. So, if we use the damage or failure in terms of the micro-mechanical level, this could be more immediate (Figures 11 and 12).

\section{Micro/macromechanical approach}

The micro/macro mechanical consists of the two levels of detection and analysis. One is called macro-mechanical and micro-mechanical. If you need the input and output data, we have to join it together these methods. Figure 1 shows the schematic diagram of the procedure is illustrated. The finite-element technique [18] is used for the macro-level analysis.so this way, we can analyze the general composite structure, which also includes plates and shells.

Finite-element analysis is very useful and so much effective for the composite material properties if we are used this method in the form of micro-level analysis using a micro-mechanical model. So, can say that the micro level analysis calculates much useful and more effective material properties from the constitutional material properties. If we talk about the mixed tensions from the finite element analysis using the micro-mechanical model, this can be broken down into a constitutional micro-structure. Micro-stress and micro strain are applied for continuous damage. On the other hand, the smeared, mixed-level stresses from the finite-element analysis using the micro-mechanical model can be decomposed into micro-structures (i.e., stresses-fiber, particle and matrix species) at the constitutional level. Then, continuous damage mechanics is applied to microstress-micro strain. Determine loss initiation or increase in the constitutional material. We also do independent analysis for the damaged fiber and matrix failure.

\section{Three-dimensional micromechanical model}

A micro-mechanical model for a fibrous combo- site was developed by Know et al. $[17,19,20]$. Thus, this section presents a micro-mechanical model for a particulate composite. The fibrous.

The micro-mechanical model can be considered as a subset of the particle micromechanical model. A simplified, micro-mechanical, unit-cell model is shown in Figure 13(a). Figure 13(b) shows a clear view of the positions of the eight subunits of the unit-cell as seen in Figure 13(a). Sub-cell 1 is a subset of cells and the rest are binder subunits. 1-2, 2-3 and 3-1 are symmetrical planes. For simplicity, it is assumed that each subunit has uniform stresses and strains. The balance of subcellular pressures at all interfaces must be satisfied as given below

$$
\sigma_{11}^{1}+\sigma_{11}^{2}, \sigma_{1}^{3},-\delta_{11}, \sigma_{11}^{5}=\sigma_{11}^{6}, \sigma_{11}^{7}=\sigma_{1}^{8}
$$




$$
\begin{gathered}
\sigma_{22}^{1}+\sigma_{22}^{3},{ }_{22}^{2} \sigma_{22}^{4},{ }_{22}^{2} \frac{7}{22 s} 22^{\prime} 22 \\
\sigma_{33}^{1}=\sigma_{33}^{5}, \sigma_{33}^{2}=\sigma_{33}^{6}, \sigma_{33}^{3}=\sigma_{33}^{7}, \sigma_{33}^{4}=\sigma_{33}^{8}
\end{gathered}
$$

The subscripts here represent the stress components along the axis shown in Figure 2, and the superscript denotes the subcell number. Only the normal stress components are considered in these equations. Similar equations can be written to cut the stress components. However, each subunit is assumed to be orthotropic or isotropic, so that the normal stress-strain components are not attached to the shear components. Therefore, the current development is limited to normal parts of stress-strains and a similar development can be developed for shear stress-strains. Subcells are thought to satisfy the following strain compatibility.

$$
\begin{gathered}
\begin{aligned}
l_{\mathrm{p}} \varepsilon_{11}^{1}+l_{\mathrm{m}} \varepsilon_{11}^{2} & =l_{\mathrm{p}} \varepsilon_{11}^{3}+l_{\mathrm{m}} \varepsilon_{11}^{4}=l_{\mathrm{p}} \varepsilon_{11}^{5}+l_{\mathrm{m}} \varepsilon_{11}^{6} \\
& =l_{\mathrm{p}} \varepsilon_{11}^{7}+l_{\mathrm{m}} \varepsilon_{11}^{8}
\end{aligned} \\
\begin{aligned}
l_{\mathrm{p}} \varepsilon_{22}^{1}+l_{\mathrm{m}} \varepsilon_{22}^{3} & l_{\mathrm{p}} \varepsilon_{22}^{3}+l_{\mathrm{m}} \varepsilon_{22}^{4}=l_{\mathrm{p}} \varepsilon_{22}^{5}+l_{\mathrm{m}} \varepsilon_{22}^{7} \\
& =l_{\mathrm{p}} \varepsilon_{22}^{6}+l_{\mathrm{m}} \varepsilon_{22}^{8}
\end{aligned} \\
\begin{aligned}
l_{\mathrm{p}} \varepsilon_{33}^{1}+l_{\mathrm{m}} \varepsilon_{33}^{5} & =l_{\mathrm{p}} \varepsilon_{33}^{2}+l_{\mathrm{m}} \varepsilon_{33}^{6}=l_{\mathrm{p}} \varepsilon_{33}^{3}+l_{\mathrm{m}} \varepsilon_{33}^{7} \\
& l_{\mathrm{p}} \varepsilon_{33}^{4}+l_{\mathrm{m}} \varepsilon_{33}^{8}
\end{aligned}
\end{gathered}
$$

In which

$$
l_{\mathrm{m}}=1-l_{\mathrm{p}}
$$

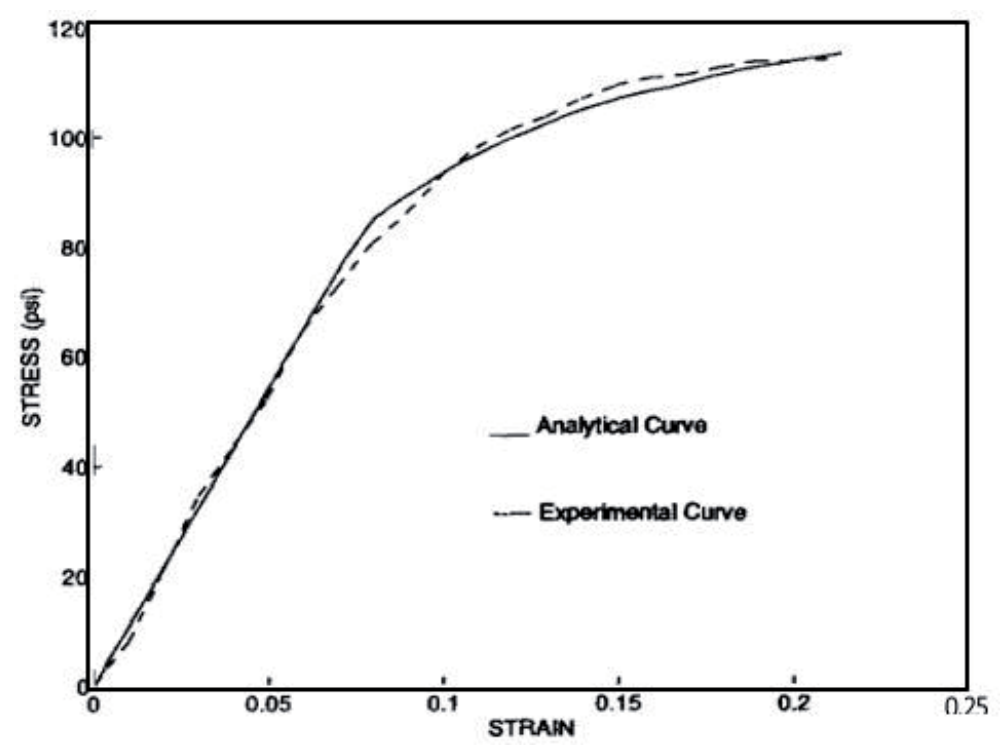

Figure 13.

Stress-strain curves. 
and Up is the particle volume fraction of the composite. The unit-cell stresses and strains are obtained from the volume average of sub-cell stresses and strains. In other words,

$$
\begin{aligned}
& \sigma_{i j}=\sum_{n=1}^{8} V^{n_{\sigma_{i j}}} \\
& \varepsilon_{i j}=\sum_{n=1}^{8} V^{n^{\varepsilon_{i j}^{n}}}
\end{aligned}
$$

In other words, we say Here $V^{n}$ is define the volume fraction in terms of nth sub-cell complete over unit-cell. i represent the subscripts $i$ and $j$ from 1 to 3 and $\sigma_{i j}$ and $\varepsilon_{i j}$, represent in this equation average cell stresses and strain. And the constitutive in the terms of equation between the sub-cell stresses and strains is defined.

$$
\sigma_{i j}=E_{i j k k^{\varepsilon l l}}
$$

If we combine or manipulating these equations result, we get Eqs. (11) and (12)

$$
\begin{gathered}
\sigma_{i j}=E_{i j k l^{\varepsilon l l}} \\
\varepsilon_{i j}^{n}=T_{i j k l^{\varepsilon k l}}
\end{gathered}
$$

References $[17,19,20]$ show that the Eq. (11) define in terms of the structural equation for the unit-cell. And you see in this equation the $E_{i j k l}$ is represented the composite material properties matrix which we get from the physical properties of the cell and the matrix. This Eq. (11) gives us a straight path from the micromechanical method analysis to macro-mechanical analysis. If we see, Eq. (12) shows us more relates to the macro-species and the micro-strain. Substituting micro-strains into Eq. (10) yields subtle stresses. Therefore, these equations cause the macro species to decompose into micro-structures and thus cause micro-stress. For the present analysis, we have the Micro-strain and micro-states are used for the criteria of the damage mechanics or failure criteria. Equation (12) gives relation and relation of the macro-mechanical analytic thinking to micro-mechanical analysis definitely, which is opposite to all process which we get from the last paragraph.

\section{Continuum damage model}

In the continuum damage model, if we talk about the loss and failure in a composite material structure are defined constitutional level. And we have many examples like fiber particle fracture or matrix cracking or the fiber/matrix debonding. The following derivative in this part is continuous loss and the mechanics for the matrix loss. Current policy of It begins to occur when the current species reaches its previous maximum. This phenomenon has been observed in some particle. If we are seeing in the Ref. [22] we find the composite material such as the solid rocket propellant material.

Equation of risk evolution is described as Number D - digit u g [é] (18) Overate refers to a temporary derivative. In Ref. [21], it is clearly shown that the loss loading and unloading condition can be defined and follows the Simo and Xu develop the 
Continuum Damage Mechanics is a race-based isotropic damage model and we can introducing as the quantitative relation variable as the parameter and loss of stress is expressed as:

$$
\sigma_{i j}=\frac{\sigma_{i j}}{(1-d)}
$$

where $\bar{\sigma}_{i j}$ and, $\sigma_{i j}$ denoted the effective and home-agenized stress tensors, respectively is defined as a limited damage variable $d$ between 0 and $d_{c}(<1)$, denoted the damage saturation. And the equation number 15 we get the stress tensor and free energy.

$$
\sigma_{i j}=\frac{\partial^{\varnothing}}{\partial_{\varepsilon_{i j}}}=(1-d) \frac{\partial^{\varnothing 。}}{\partial_{\varepsilon_{i j}}}
$$

where $\Psi^{\circ}$ is defined as $\frac{1}{2} E_{i j k l_{i j} j^{k k l}}^{\circ}$ and $E_{i j k l}^{\circ}$ defined in terms of the tensor of the undamaged material properties. In Eq. (15), we also assumed function for the damage criterion.

$$
F=f\left(\varepsilon_{i j}, \sigma_{i j}\right)-k
$$

Eq. 15, we have, which is continuant for the damage beginning and the quantity, which kept increases with the damage. On another side, we have the $F$, which is less than zero. We know that at zero, damage in this equation does not occur. But we have one condition when damage happens when $F=0=0$. For the existing damage, the model $f$ is assumed.

$$
\begin{gathered}
f\left(\varepsilon_{i j)}=\bar{e}\right. \\
\bar{e}=\sqrt{2 \Psi^{\circ}}
\end{gathered}
$$

In Ref. [21], which is defined by Simo and Ju. This tells us the equivalent strain measure in Eqs. (16) and (17), which shows us count on the previous maximum state of strain. But when we see the damage, the damage starts to happen when the existing state of strains reach the former rate, which we have the maximum state of strain. We observed this concept in some particulate composite material, such as we know that is solid rocket propellant material [22]. In terms of damage evolution is defined in terms of Eq. (18).

$$
d=k g(\bar{e})
$$

where the over-dot defines in the terms of the temporary derivative. We can say that Damage loading and the unloading conditions can be define as in Eqs. (19)-(21).

$$
k \geq 0
$$




$$
\begin{gathered}
F \leq 0 \\
k F=0
\end{gathered}
$$

$F<0$ defines the unloading and $k=0$, then $d=0$ from the Eq. (18), which inform no more damage. If look another side if $k=0$, then $F=0$ and $d>0$ damage is happening. In order to find or find out the damage tangent modulus. And in Eq. (14), the time derivative substituted.

$$
\dot{\sigma}_{i j}=(1-d) E_{i j k l^{s k l}}^{\circ}-\dot{d} \sigma_{i j}^{\circ}
$$

where

$$
\sigma_{i j}^{\circ}=\frac{\partial^{\varnothing^{\circ}}}{\partial_{\varepsilon_{i j}}}
$$

If we are using the previous equation, finally get the outcome in damage tangent modulus.

$$
E_{i j k l}=(1-d) E_{i j k l}^{\circ}-\frac{g}{e} \sigma_{i j k^{\circ} k l}^{\circ}
$$

Present study shows a mixture of particles. Function g we take like the constant. When we see the rate of loss, the rate of loss is definitely proportional to the rate of equal strain measurement. If parametric quantity d damage reaches its critical value at the general zone. Facture is assumed to occur at that location, and the damage is saturated. We have also thought that the direction of crack propagation is discovered from the path of $\mathrm{d}$ in the material.

\section{Results and discussion}

This is all study conduct to find about the crack beginning in a particle composite material while using a micro-mechanical mode, which is what damage mechanics are described in the last section. Uniaxial tensile testing for the material was carried out the exam the micro-mechanical model and other one is damage mechanics model. For the micro-mechanical model study, we need the physical properties of the particle and the matrix. For the studies in which the current mixture we have to need, the elastic modulus of the particles is about the $1.0{ }^{*} 106 \mathrm{psi}$, and the binding matrix is 110 psi. Therefore, the cell is much Stiner than which matrix material we have. And the particle volume fraction is 0.78 as you see in Figure 13, the stressstrain curve shown by the violent stress well with the experimental curve.

The study we have inspect crack start beginning or initiation from a sample made with the above-mentioned material. The models were 3 inches wide by 3 inches long and 0.25 inches thick. We have to make Two circular holes of two modification different sizes are drilled within the center one hole is 0.25 -in. Diameter and therefore the other contain 0.5 -in. Samples were subjected to tension with regular displacement until the fracture began from the outlet. Numerical estimation for crack initiation was also performed. A finite-element mesh is shown 
in Figure 1. Refined round the mesh hole. For a sample containing 0.25-in. The applied load vs. displacement for the experimentally and numerically diameter hole is plotted in Figure 13.

Call outcome of examination until a crack begins. Due to symmetry of the sample displacement reaction is half the displacement reaction between the two grips (Figure 14). The curve is linear until the displacement of 0.11 inches and then becomes linear. Fractures occurred at approximately 0.14 inches of displacement. Damage is initiated from the linearity of the curve before the breaking point. However, the tangent modulus had a very little effect because of the small quantity of damage in the local area around the notch tip of the hole. As the loss increases the loss tangent modulus decreases from the Virgin modulus and the curve deviates from the linearity. Some curve was obtained from both (Figure 15).

Numerical and experimental studies and analyses show an identical result. Also, the size of the crack is cracked more than 0.048 in. But the measured size of the crack is almost between 0.048 and 0.051 . Therefore, estimation rest on we have experimental data if you see Figure 16, which illustrates the circular hole, which is deformed deformation shape of the initially. The circular hole we have in an elliptical shape, and the main circular diameter is about 60 taller than the smaller diameter. Then we have the saturation loss zone, which did not increase for some time even when the pressure to sample was increased.

This all phenomenon and analysis were also exam and study in an experiment. The critical fracture was hesitant for some time before the experimental study was published. If you see in Figure 17 in terms of the normalized species distribution from the distance from the opening come near the load direction as a function. With relation to the opening, the gap is normalized but with relation to the applied strain, but the strain is normalized. With the increase of the applied strain but before the damage occurs and therefore the density of the opening decreases within

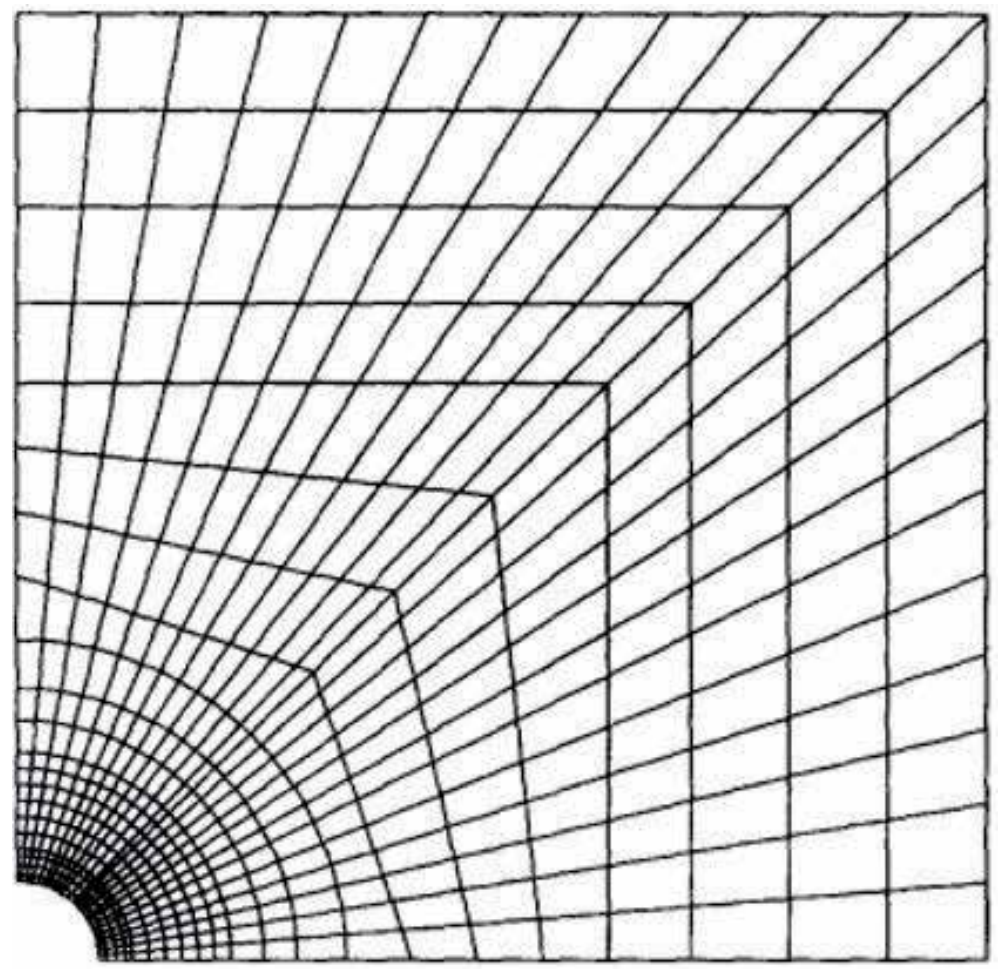

Figure 14.

Finite-element mesh for a specimen with a 0.5-in. Diameter hole. 
Modeling of Damage Evolution of Fiber-Reinforced Composite Structure DOI: http://dx.doi.org/10.5772/intechopen.93323

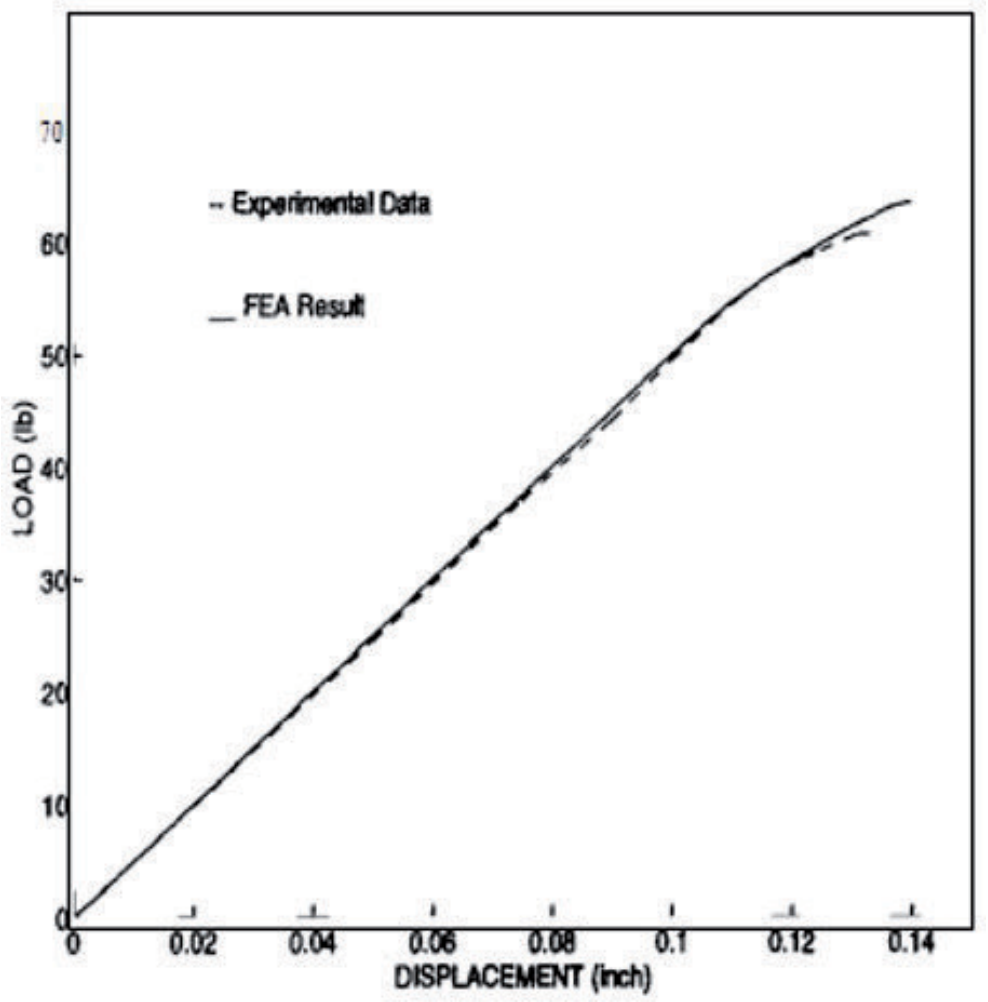

Figure 15.

Deformed shape of a specimen with a 0.25-in. Diameter hole.

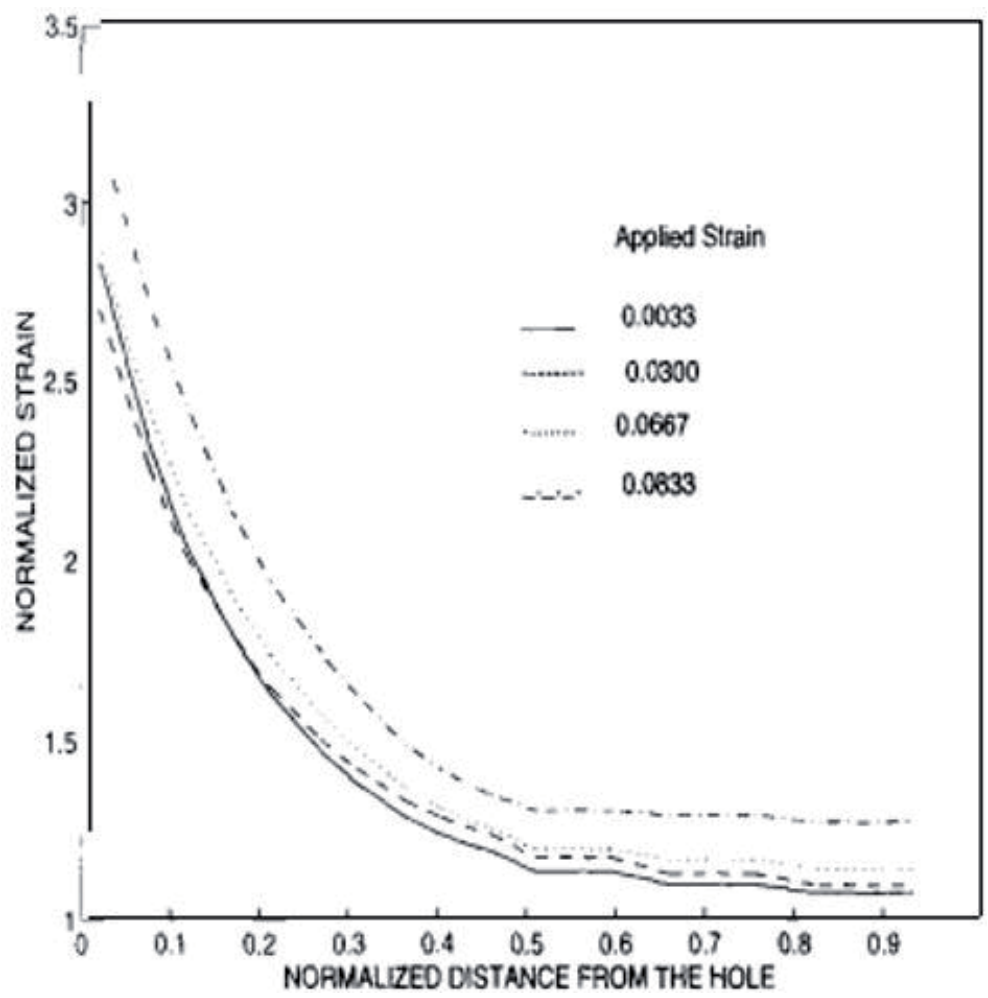

Figure 16.

Strain distribution along the minimum section. 


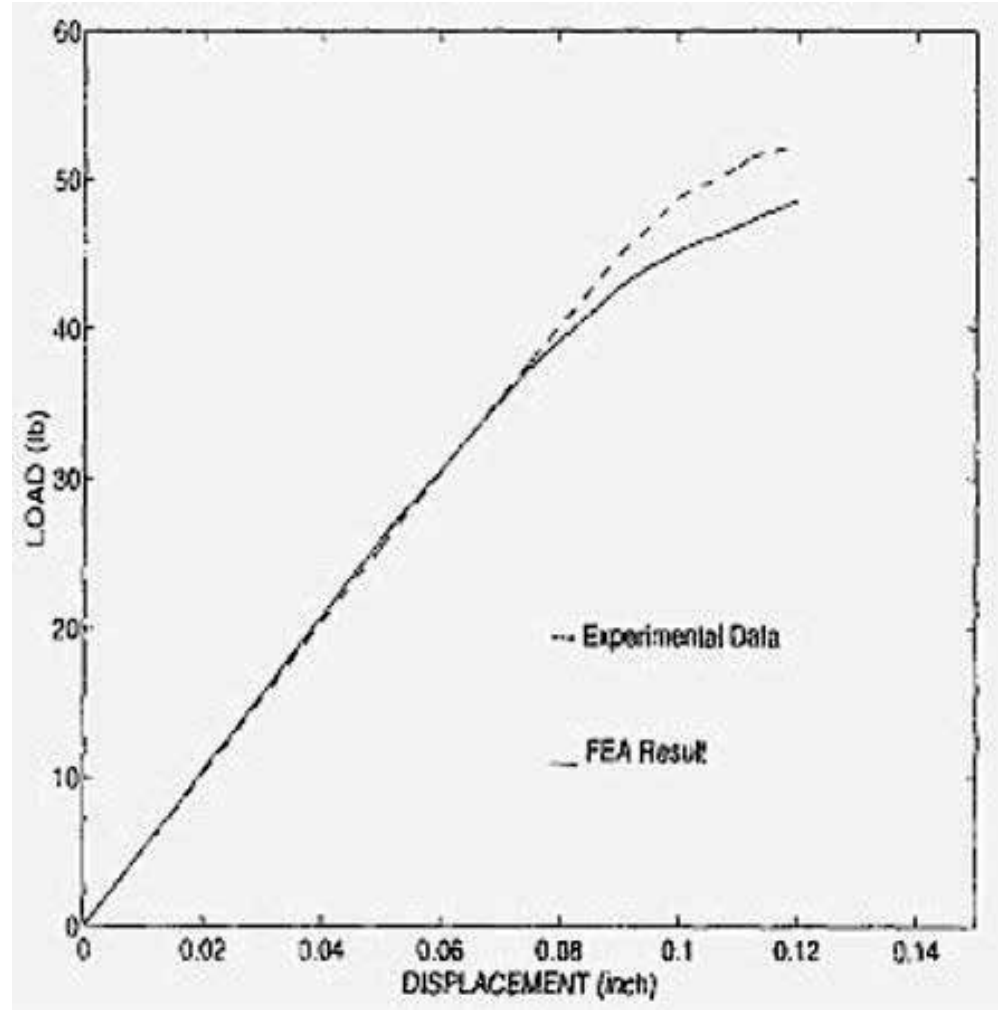

Figure 17.

Load-displacement curve for a specimen with a 0.5-in. Diameter hole.

the vicinity of the resin. This phenomenon is that the reduction caused by deformation of the circular hole into ellipse along the main axis of the loading direction. The concentration factor of the elliptical hole is given by Timoshenko and Goodier [22] $(\mathrm{I}+2 \mathrm{alb})$, where $2 \mathrm{a}$ is the axis of the ellipse.

Axis of loading direction and $2 \mathrm{~b}$ loading direction. So this expression matched the current result. However, as the load increases, the normal size elongation increases far from the opening. (Compare the two curves in Figure $\mathbf{1 6}$ for the species used, 0.0033 and 0.0300 , respectively.) Regarding as the loss begins and spreads, the normalized elongation increases because the loss tangent modulus decreases. In Figure 17, the cases with applied strains of 0.0667 and 0.0833 show a generalized strain increase compared to other curves. Similar comparisons were also made for the 0.5-inch sample. Hole diameter (Figure 17).

gives the load-displacement curve for comparison. The predicted crack size was $0.045 \mathrm{in}$., while the measured crack was between 0.035 and $0.067 \mathrm{in}$. Therefore, the prediction agreed well with the experimental data. The measured crack size for the 0.5 -in. diameter hole had a larger variation than that for the 0.25-in. diameter hole.

\section{Conclusions}

This research presented a general approach in analyzing the modeling of damage evolution of fiber-reinforced composites structure. It is clear that in both major cases modeling of damage evolution method and the damage evolution in composites using damage mechanics and micro-mechanics method obey the basic principle rule 
that in every type of the crack in unidirectional FRC material tends to grow in the matrix and find it in the parallel to the direction of the fiber, for example, we know that and studies shows that the crack grows from one location definitely from the weakest direction which is characterized by the matrix.

This phenomenon is proscribed by the standard of the mesh within the finite element numerical model. The foremost crossroads and significant moment is essentially the purpose of initial failure. That is why we used mesh. The mesh surrounding the entire is intentionally modeled, and therefore the uniform rings of the weather have a decent chance of accurately predicting the constant initiation. The following process of crack growth is then influenced by the interaction point size and therefore the shape of the element.

Therefore the direction of the crack growth deviates slightly from the assumed direction parallel to fiber. And which mesh and therefore the design we have and experimental data. Such a design of the mesh and therefore the values of the unknown material properties should be justified by comparing the results with relevant experimental data.

The FEM method is using only an approach for the micro/macro mechanical model. As simple, we can say that a simplified micromechanical model. And the damage mechanics was created or developed to simulate the growth and initiation in a composite structure. In terms of this model, we can approach a general composite framework made of fibrous or particulate composite material and is computationally efficient. The proposed approach only investigates the crack growth in some particulate composite material specimens with a center hole. The numerical calculation predicted result that we have is agreed well with the experimental data. So in this thesis, all the proposed approach is useful for the design and detection and analysis of composite structure in terms of damage and failure.

We also examine the techniques of NDT to analyze the damage detection in the fiber or material, which is more important for detecting the crack and fracture in fibers. We used visual observation, optical microscopy, X-rays, acoustic emission eddy current, ultrasonic, tapping technique, laser-based technology (LBT). In this thesis, we discuss the principle and hole working of all these NDT tools for the analysis of modeling damage of the evolution of fiber-reinforced composite.

\section{Recommendations for future work}

\subsection{Partially growth and curved cracks}

In the off-axis planes, the fractures do not increase. Furthermore, if we speak about the multi-axial stress state and also the material variability also causes the crack path to bend round the stable regions. we will ignore these styles of complexities in most cases using an approximation, but our main objective is strictly the evolution of crack density, which is not significantly plagued by thesis complexities.

\subsection{Fatigue loading}

The joint response under fatigue loading for structural applications is of primary importance. Therefore, an extension of this work is required within the case of fatigue loading to supply an understanding of the damage initiation, progression and failure mechanisms for this loading case, which might be further evidence of structural durability and reliability assessment. 


\subsection{Wideband transducers}

Narrow band resonance sensors are used for threshold-based acoustic systems and typically have an operating frequency range of $100 \mathrm{kHz}$ to $300 \mathrm{kHz}$, while wideband displacement sensors are used for waveform-based AE systems and their operating frequency reaches $150 \mathrm{MHz}$ or higher. There are two significant difficulties with the narrow band approach. First, it's difficult to differentiate between real, crack-based $\mathrm{AE}$ and extra AEs (for example, because of friction and anger). Second, the accuracy of the source position is poor or nonexistent for narrow band, threshold-based systems. Thanks to these limitations of the resonant transducer, the AE data obtained during this study distort actuality source-wave characteristics.

\subsection{Transient AE analysis}

With data acquired by wideband transducers, it is possible to perform a transient $\mathrm{AE}$ analysis, and a database of signature waveforms for each damage mechanism could be established.

\section{Author details}

Muhammad Bilal Afzal

Nanjing University of Aeronautics and Astronautics, Nanjing, China

*Address all correspondence to: bilalafzal167@gmail.com

\section{IntechOpen}

(C) 2020 The Author(s). Licensee IntechOpen. Distributed under the terms of the Creative Commons Attribution - NonCommercial 4.0 License (https://creativecommons.org/ licenses/by-nc/4.0/), which permits use, distribution and reproduction for non-commercial purposes, provided the original is properly cited. (cc) BY-NC 


\section{References}

[1] Berthelot JM, Le Corre JF. Statistical analysis of the progression of transverse cracking and delamination in cross-ply laminates. Composites Science and Technology. 2000;60(14):2659-2669

[2] Garrett KW, Bailey JA. Multiple transverse fracture in $90^{\circ}$ cross-ply laminates of a glass fibre-reinforced polyester. Journal of Materials Science. 1977;12(1):157-168

[3] Hashin Z. Analysis of cracked laminates: A variational approach. Mechanics of Materials. 1985;4(2):121-136

[4] Hashin Z. Finite thermoelastic fracture criterion with application to laminate cracking analysis. Journal of the Mechanics and Physics of Solids. 1996;44(7):1129-1145

[5] Huang Y, Talreja R. Statistical analysis of oblique crack evolution in composite laminates. Composites Part B: Engineering. 2014;65(65):34-39

[6] Huang Y, Varna J, Talreja R. Statistical methodology for assessing manufacturing quality related to transverse cracking in cross ply laminates. Composites Science and Technology. 2014;95:100-106

[7] Joffe R, Varna J. Damage evolution modeling in multidirectional laminates and the resulting nonlinear response. In: International Conference on Composite Materials 12. 5-9 July, Paris, France; 1999

[8] Joffe R, Krasnikovs A, Varna J. CODbased simulation of transverse cracking and stiffness reduction in [s/90n] $\mathrm{s}$ laminates. Composites Science and Technology. 2001;61(5):637-656

[9] Kaddour AS, Hinton MJ, Li S, et al. The background to part a of the third world-wide failure exercise
(WWFE-III). Journal of Composite Materials. 2013;47(20-21):2417-2426

[10] Kashtalyan M, Soutis C. Stiffness and fracture analysis of laminated composites with off-axis ply matrix cracking. Composites Part A Applied Science and Manufacturing. 2007;38(4):1262-1269

[11] Laws N, Dvorak GJ. Progressive transverse cracking in composite laminates. Journal of Composite Materials. 1988;22(10):900-916

[12] Liu SL, Nairn JA. The formation and propagation of matrix microcracks in cross-ply laminates during static loading. Journal of Reinforced Plastics and Composites. 1992;11(2):158-178

[13] Manders PW, Chou TW, Jones FR, Rock JW. Statistical analysis of multiple fracture in [0/90/0] glass fiber/epoxy resin laminates. Journal of Materials Science. 1983;19:2876-2889

[14] Montesano J, Singh CV. A synergistic damage mechanics based multiscale model for composite laminates subjected to multiaxial strains. Mechanics of Materials. 2015;83:72-89

[15] Montesano J, Singh CV. Predicting evolution of ply cracks in composite laminates subjected to biaxial loading. Composites: Part B. 2015;75:264-273

[16] Nairn JA. Chapter 13: Matrix microcracking in composites a. In: Kelly CZ, Talreja R, Manson JA, editors. Polymer Matrix Composites. Comprehensive Composite Materials. Vol. 2. Woodhead publishing; 2000. pp. 403-432

[17] Kwon YW, Berner J. Analysis of matrix damage evolution in laminated composite plates. Engineerig Fracture Mechanics. 1994;48:811-817 
[18] Kwon YW, Berner JM.

Micromechanics model for damage and failure analyses of laminated fibrous composites. Engineering Fracture Mechancis. 1995;52:231-242

[19] Simo JC, Ju JW. Strain- and stressbased continuum damage models-I. Formulation. International Journal of Solids and Structures. 1987;23:821-840

[20] Gurtin ME, Francis EC. Simple rate independent model for damage. Journal of Spacecraft and Rockets. 1981;18:285-286

[21] Yen SCM, Liu CT. Investigating the local behaviors near the crack tip of a particular composite containing a circular hole. In: Hui D, editor. Third International Conference on Composites Engineering. New Orleans, Louisiana; 1996. pp. 953-954

[22] Timoshenko P, Goodier JN. Theory of Elasticity. 3rd ed. New York: McGrawHill; 1970 

